\title{
POINTS OF DIFFERENCE IN AFFILIATIONS WITHIN WIRELESS INDUSTRY CONSORTIA
}

by

Sorin Sorlescu

A thesis submitted to the Faculty of Graduate Studies and Postdoctoral Affairs in partial fulfillment of the requirements for the degree of Master of Applied Science in Technology Innovation Management

Department of Systems and Computer Engineering

Carleton University

Ottawa, Ontario, Canada, K1S 5B6

December 2010

(C) Copyright 2010, Sorin Sorlescu 
Library and Archives

Canada

Published Heritage Branch

395 Wellington Street Ottawa ON K1A ON4 Canada
Bibliotheque et

Archives Canada

Direction du

Patrimoine de l'édition

395 , rue Wellington

Ottawa ON K1A ON4

Canada
Your file Votre référence

ISBN: 978-0-494-79555-2

Our file Notre référence

ISBN: 978-0-494-79555-2
NOTICE:

The author has granted a nonexclusive license allowing Library and Archives Canada to reproduce, publish, archive, preserve, conserve, communicate to the public by telecommunication or on the Internet, loan, distribute and sell theses worldwide, for commercial or noncommercial purposes, in microform, paper, electronic and/or any other formats.

The author retains copyright ownership and moral rights in this thesis. Neither the thesis nor substantial extracts from it may be printed or otherwise reproduced without the author's permission.
AVIS:

L'auteur a accordé une licence non exclusive permettant à la Bibliothèque et Archives Canada de reproduire, publier, archiver, sauvegarder, conserver, transmettre au public par télécommunication ou par l'Internet, prêter, distribuer et vendre des thèses partout dans le monde, à des fins commerciales ou autres, sur support microforme, papier, électronique et/ou autres formats.

L'auteur conserve la propriété du droit d'auteur et des droits moraux qui protège cette thèse. $\mathrm{Ni}$ la thèse ni des extraits substantiels de celle-ci ne doivent être imprimés ou autrement reproduits sans son autorisation.
In compliance with the Canadian Privacy Act some supporting forms may have been removed from this thesis.

While these forms may be included in the document page count, their removal does not represent any loss of content from the thesis.
Conformément à la loi canadienne sur la protection de la vie privée, quelques formulaires secondaires ont été enlevés de cette thèse.

Bien que ces formulaires aient inclus dans la pagination, il n'y aura aucun contenu manquant.

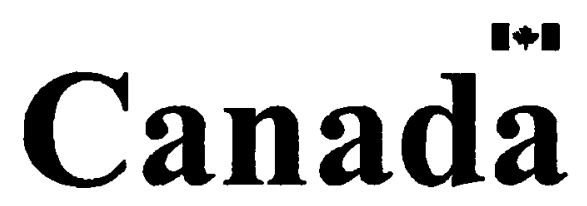




\section{ABSTRACT}

Salient constructs of 736 organizations affiliated with 9 associations, forums and alliances in the wireless industry are used to determine consortia points of difference. The comparison of consortia indicates that: (i) support for legacy technologies is focused on optimization, services, and cost reduction, (ii) support for newer technologies is focused on standards, research, hardware, and testing, (iii) two standards are paths of technological adoption, the third standard suggests new market entrants, (iv) motivation for membership to consortia is based on product certification and interoperability. Comparing consortia's identified points of difference to consortia's declared objectives three types of relationships are observed: (i) strong support, with a good mapping between the constructs and the objectives for two consortia, (ii) a definitional role, where the constructs provide suggestions for what six consortia's objectives mean, and (iii) weak support, with a poor mapping between the identified constructs and the objectives for one consortium. 


\section{ACKNOWLEDGEMENTS}

My deepest gratitude and thanks are extended to my thesis supervisor, Professor Antonio Bailetti. Without his support, direction and continued dedication this research would not have possible. I would like to thank Professor Stoyan Tanev and Professor Michael Weiss for their expert knowledge and feedback which contributed greatly to the completion of this research. 


\section{Table of Contents}

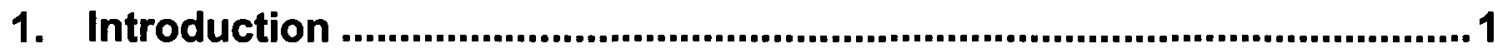

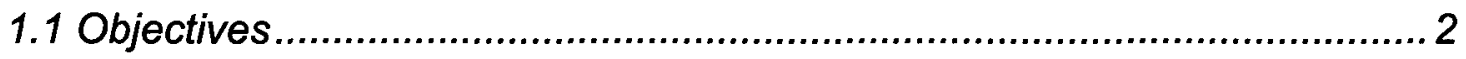

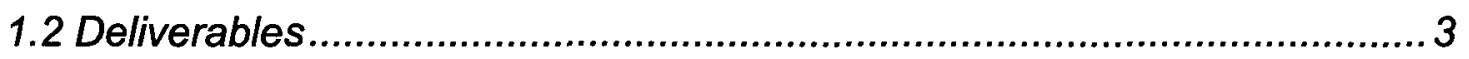

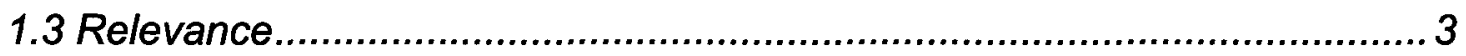

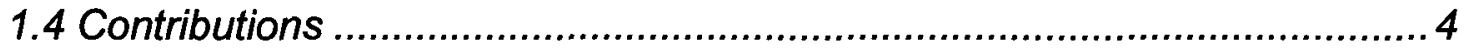

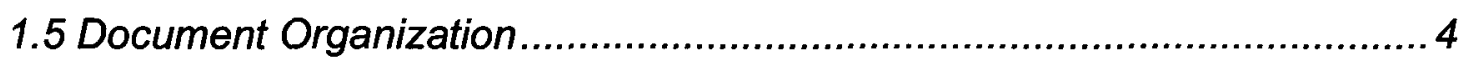

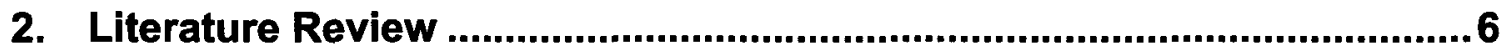

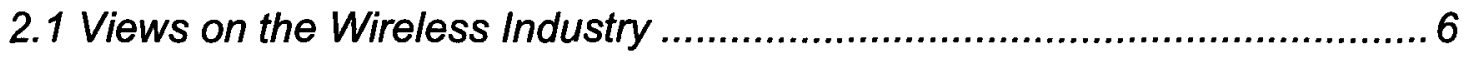

2.1.1 Standards: competing through cooperation ..................................... 6

2.1.2 The evolution of the value chain in the mobile industry ..................... 9

2.1.3 The layered model.......................................................................... 13

2.1.4 The business ecosystem model and key players............................. 14

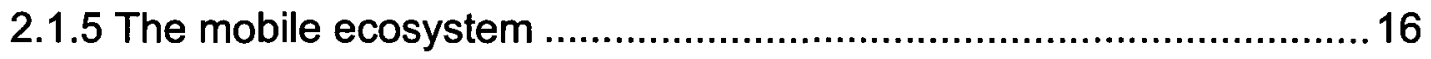

2.1.6 The Double Helix model ................................................................. 17

2.1.7 The dynamic ecosystem model................................................... 18

2.1.8 Real options approach in the wireless industry evolution ..................19

2.1.9 Strategic value assessment model ............................................... 19

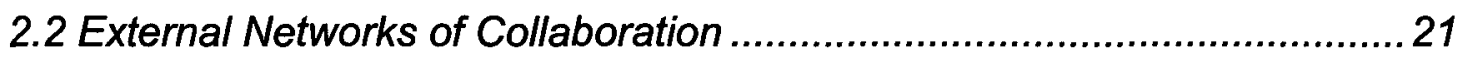

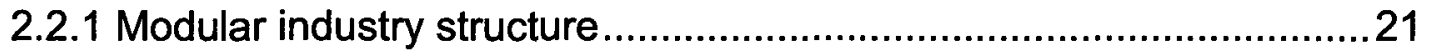

2.2.2 Evolution of a firm's networks of collaboration ................................23

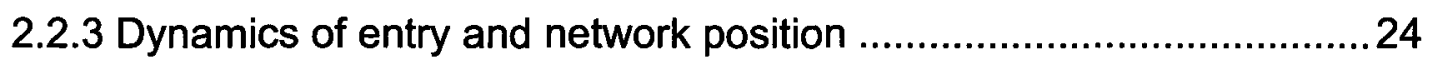

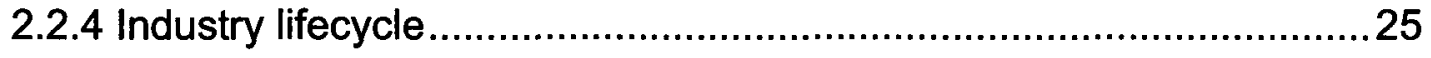

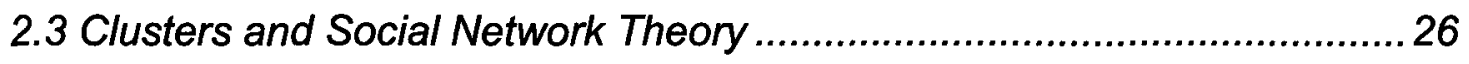

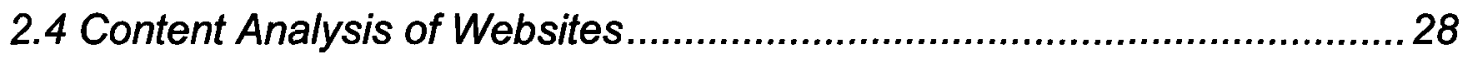

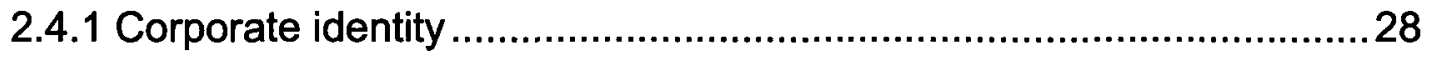

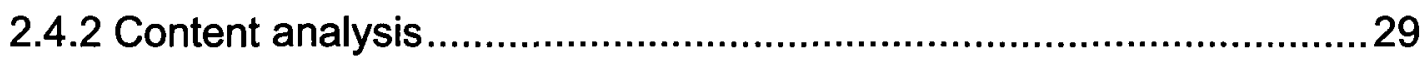


2.5 Lessons Learned from the Literature. 31

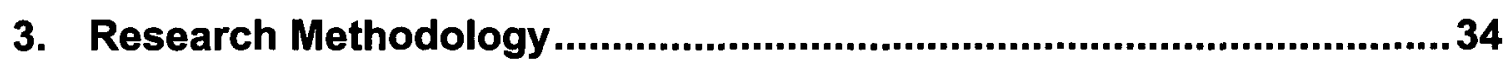

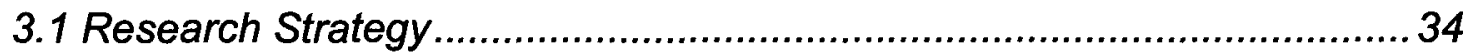

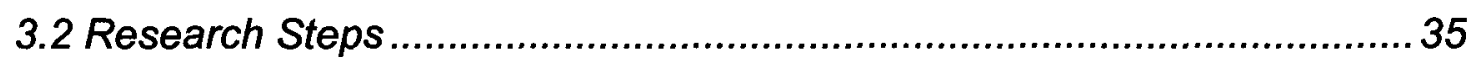

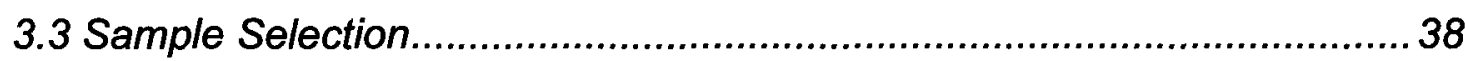

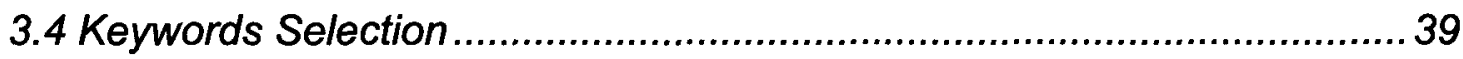

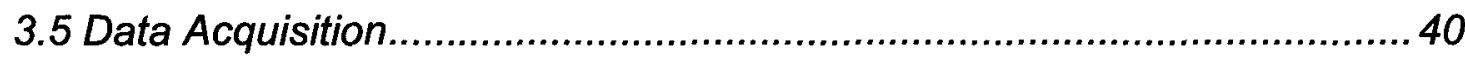

3.6 Factor Analysis Method ........................................................................ 40

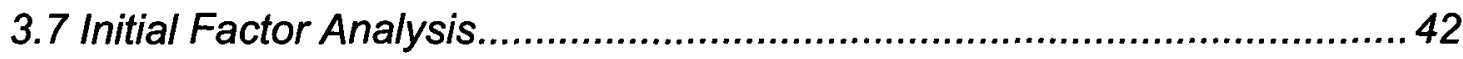

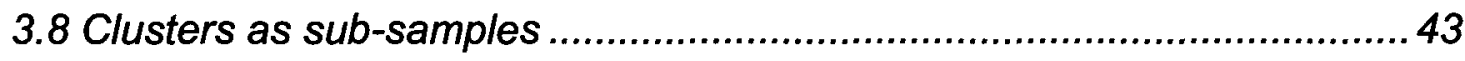

3.9 Multiple Factor Analysis................................................................ 43

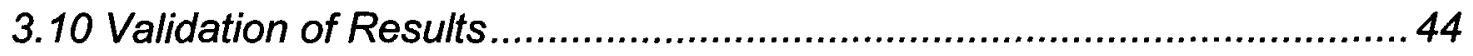

3.11 Points of difference as measure of alternatives...................................45

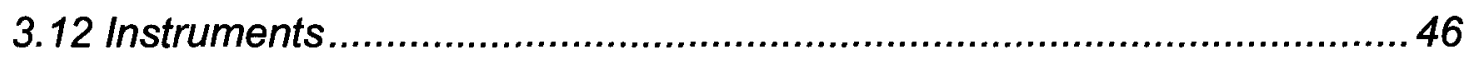

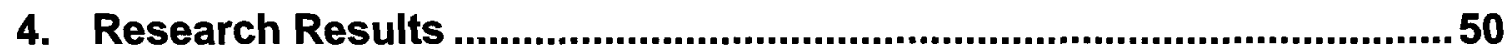

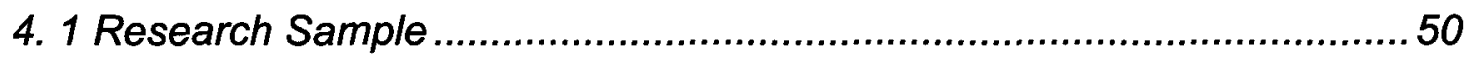

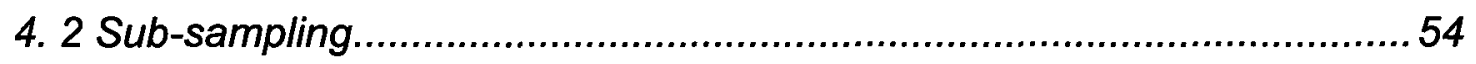

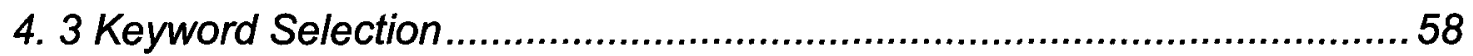

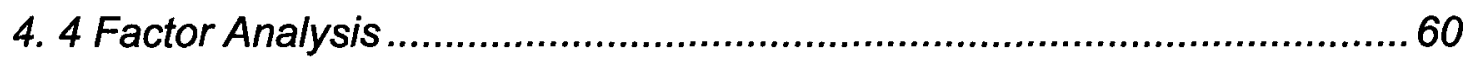

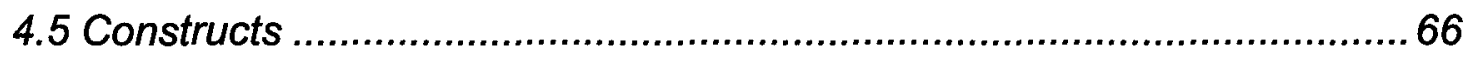

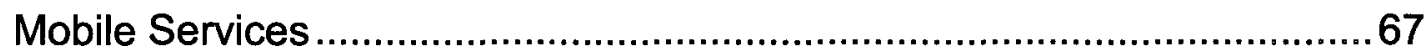

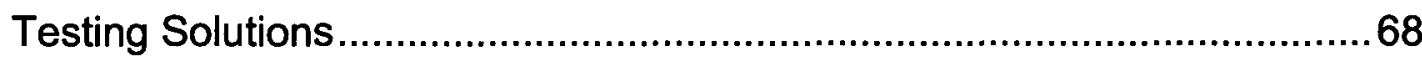

Fee Based Business Solutions...............................................................69

WiMAX Technology and Standard ...................................................... 71

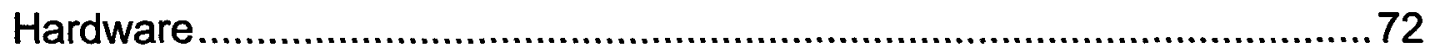




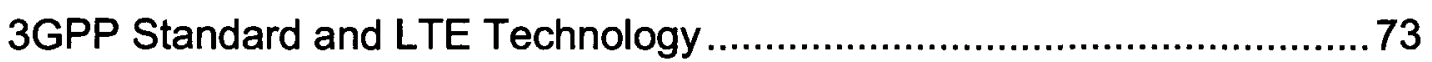

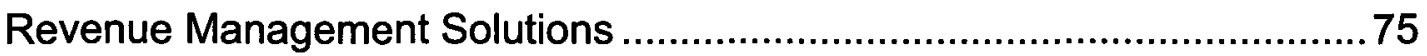

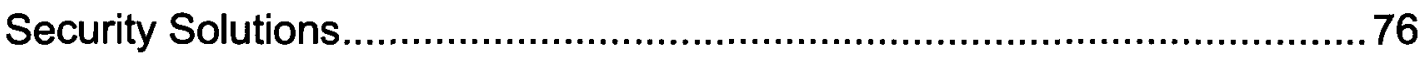

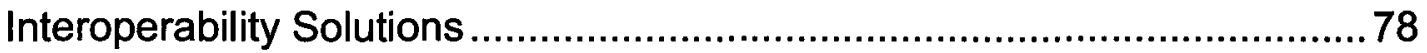

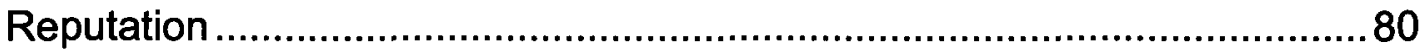

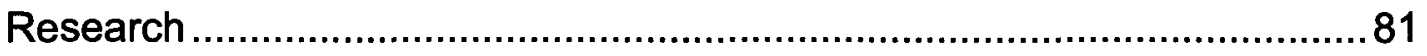

3GPP Standard and 3G Technologies Evolution ....................................82

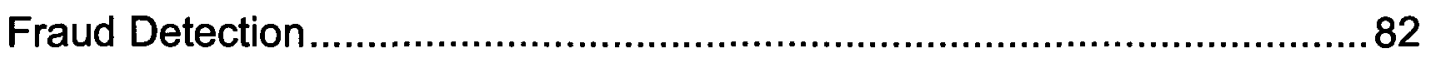

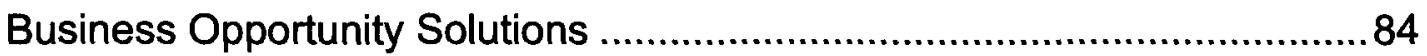

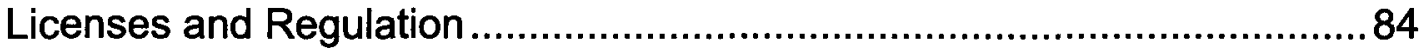

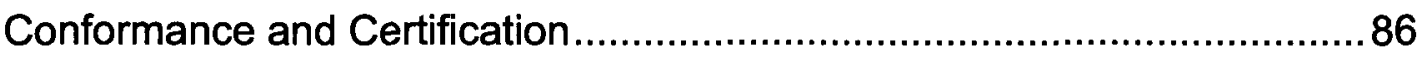

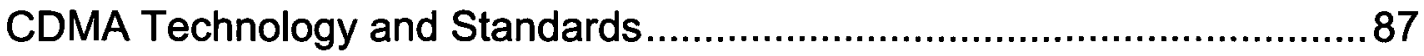

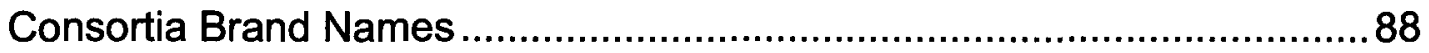

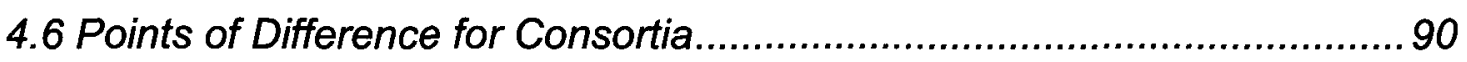

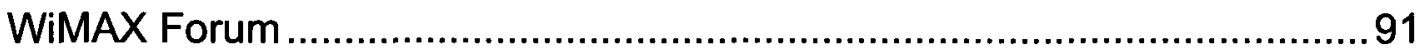

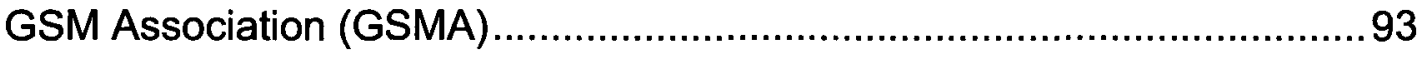

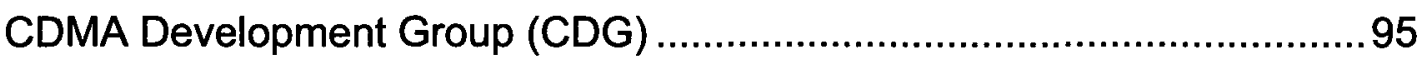

Next Generation Mobile Networks Alliance (NGMN)................................97

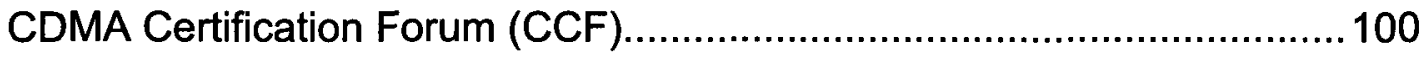

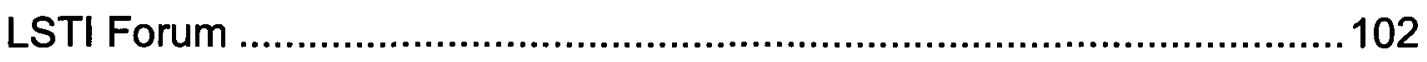

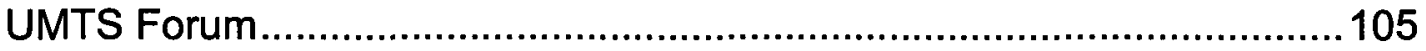

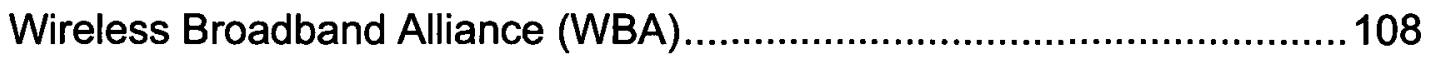

Open Patent Alliance (OPA) ............................................................. 111

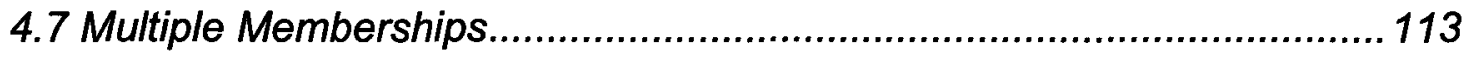

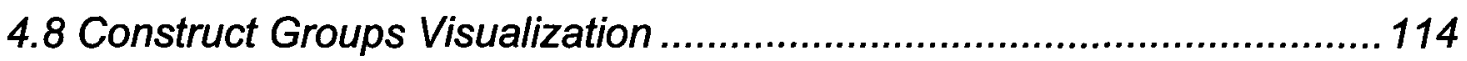

5. Discussion of Results ..........................................................................118

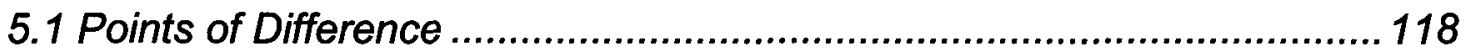

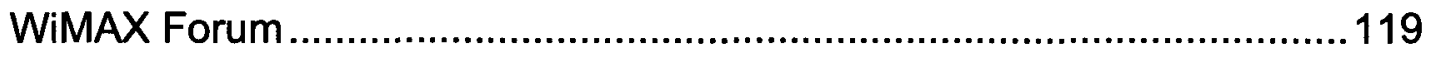

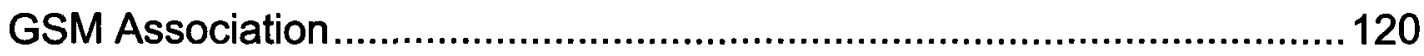




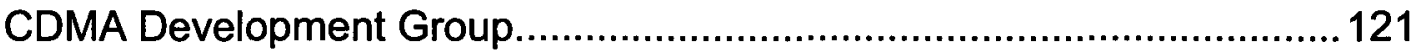

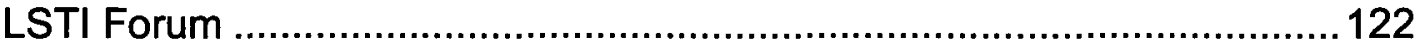

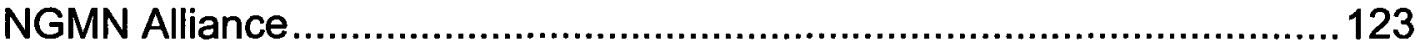

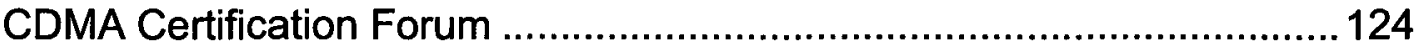

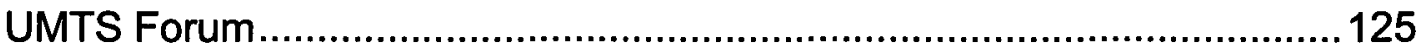

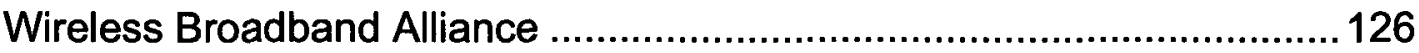

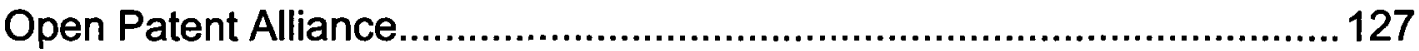

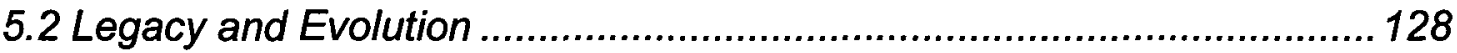

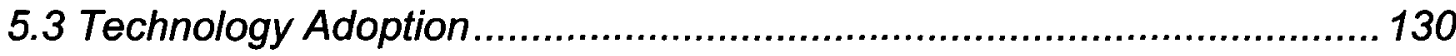

5.4 The Emerging Role of Backend Systems....................................... 132

5.5 Members Motivation for Participation .............................................. 133

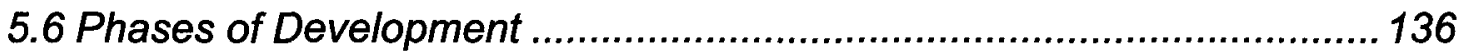

5.7 Insights Gained From Research ................................................. 138

5.8 Recommendations for Keystone Organizations ............................... 142

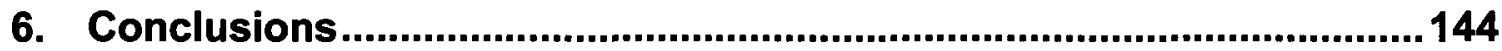

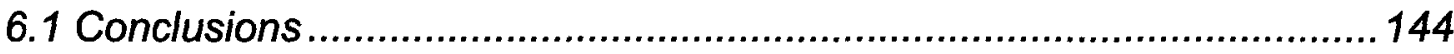

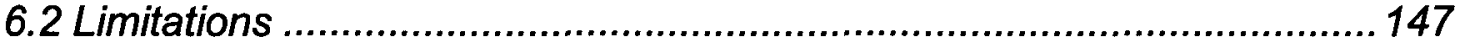

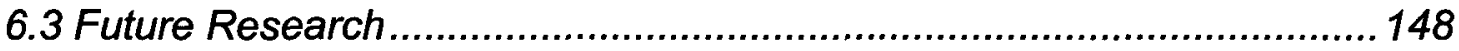

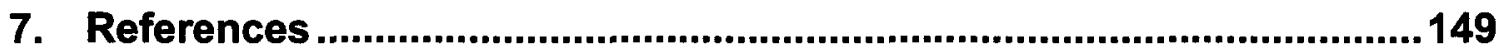

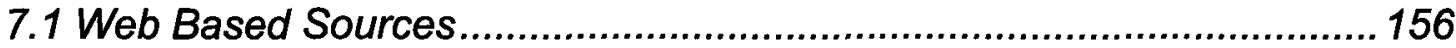

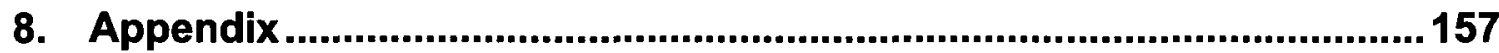

Appendix A: URLs, Samples and Membership ...................................157

Appendix B: Hierarchical Decomposition ...............................................165

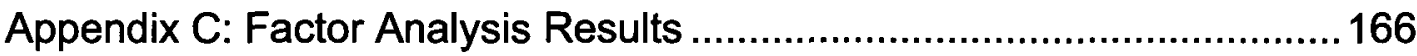

Appendix D: Membership Distribution ....................................................179 


\section{List of Tables}

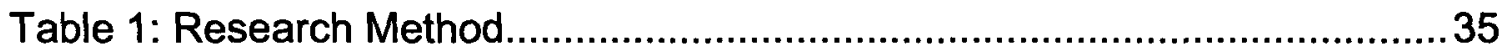

Table 2: Multiple Factor Analysis Solutions .............................................. 44

Table 3: Factor Analysis Data Validity Test Criteria.......................................45

Table 4: Instruments of Analysis and Interpretation ......................................46

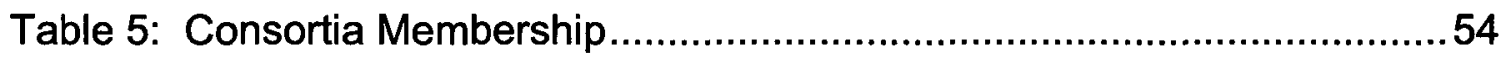

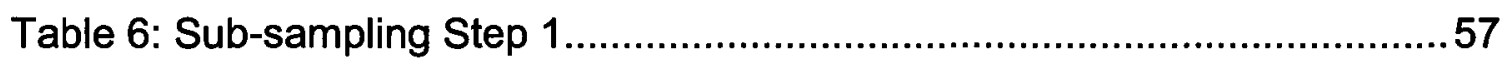

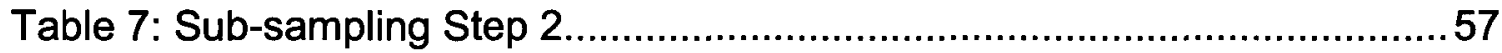

Table 8: Number of keyword sets in each sample ........................................59

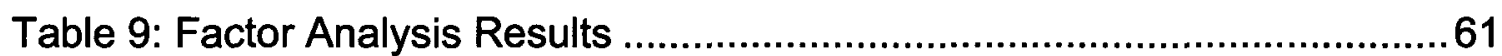

Table 10: Group E Factor Analysis Solutions ..............................................64

Table 11: Group F Factor Analysis Solutions ..............................................65

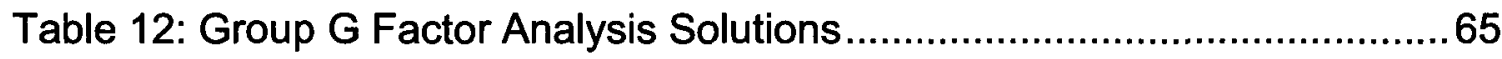

Table 13: Group H Factor Analysis Solutions ...............................................65

Table 14: Group I Factor Analysis Solutions ................................................66

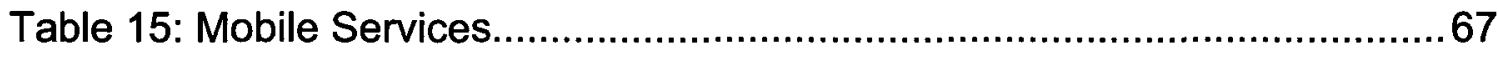

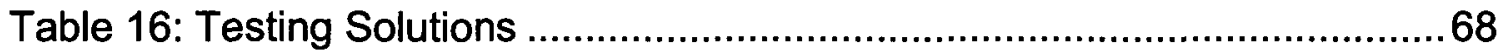

Table 17: Fee Based Business Solutions ................................................... 70

Table 18: WiMAX Technology and Standard ................................................

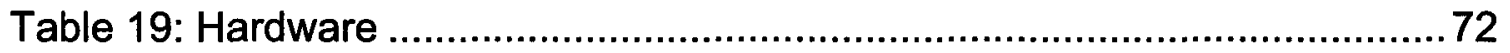

Table 20: 3GPP Standard and LTE Technology ......................................... 74

Table 21: Revenue Management Solutions..................................................75

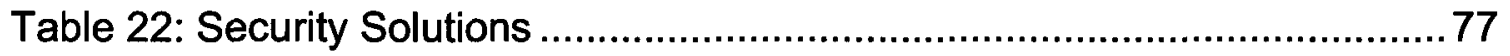

Table 23: Interoperability Solutions …................................................... 78

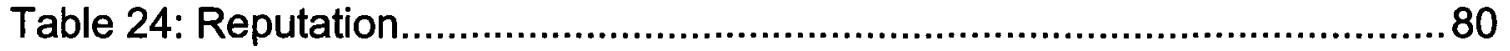

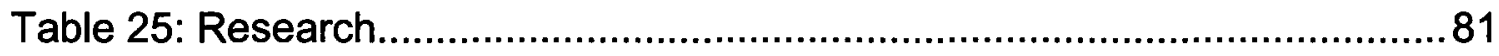

Table 26: 3GPP Standard and 3G Technologies Evolution............................ 82

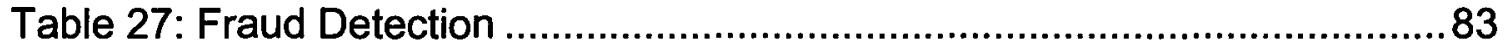

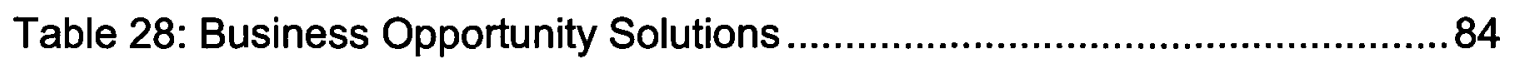

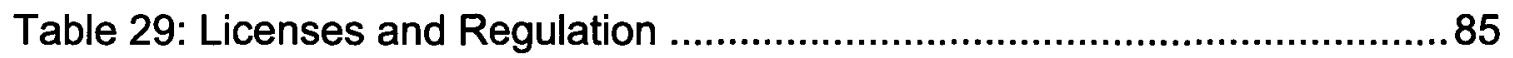

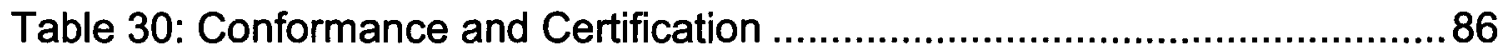




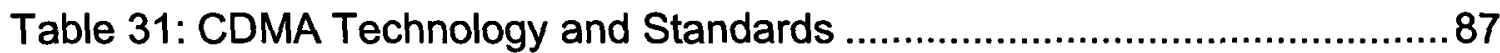

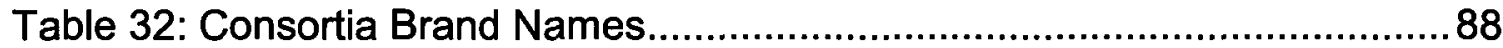

Table 33: WiMAX Forum Salient Constructs .................................................92

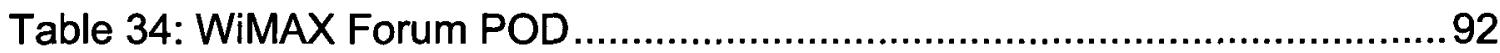

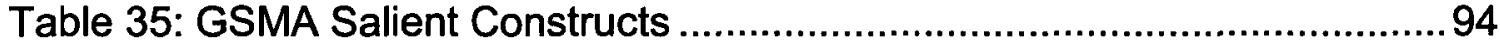

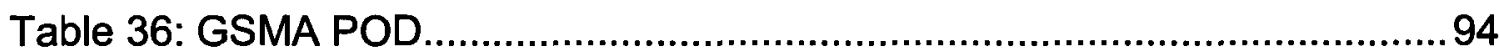

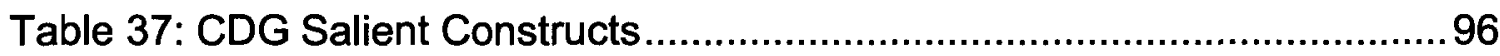

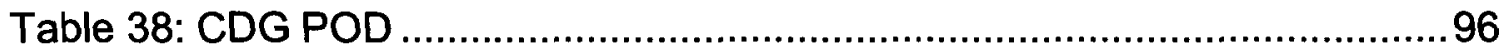

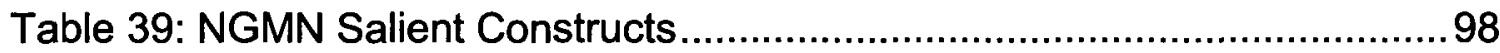

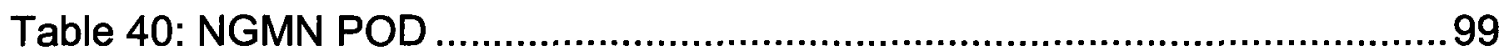

Table 41: CCF Salient Constructs .............................................................101

Table 42: CCF POD

Table 43: LSTI Forum Salient Constructs......................................................103

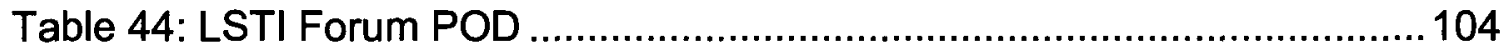

Table 45: UMTS Forum Salient Constructs ...............................................106

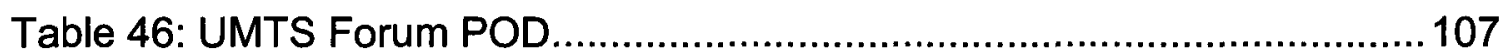

Table 47: WBA Salient Construct .................................................................. 109

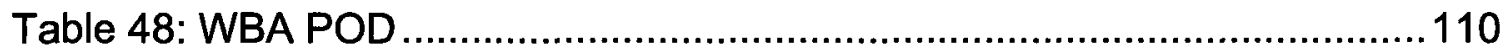

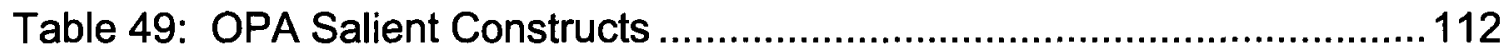

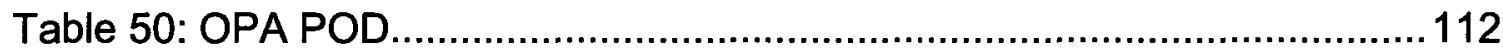

Table 51: Mapped Objectives for WiMAX Forum .......................................119

Table 52: Mapped Objectives for GSMA ..................................................120

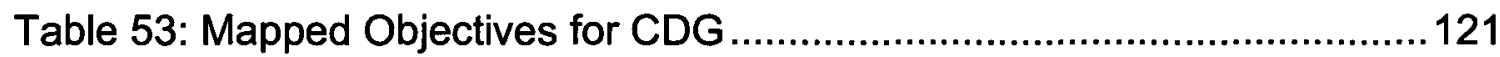

Table 54: Mapped Objectives for LSTI Forum .......................................... 122

Table 55: Mapped Objectives for NGMN Alliance ......................................123

Table 56: Mapped Objectives for CCF.......................................................124

Table 57: Mapped Objectives for UMTS .................................................125

Table 58: Mapped Objectives for WBA …..................................................126

Table 59: Mapped Objectives for OPA ….................................................127

Table 60: Legacy and Evolution Constructs ..............................................128

Table 61: Members Motivation for Participation .........................................134 
Table 62: Consortia Phases of Development ............................................136

Table 63: Recommendations for Keystone Organizations ............................142 


\section{List of Figures}

Figure 1: Hemphill's Wireless Standards Development Model .......................... 8

Figure 2: Value Chain in the Wireless Industry............................................. 10

Figure 3: Players in the Wireless Industry Value Chain ................................... 13

Figure 4: Basole's Converging Mobile Ecosystem..........................................17

Figure 5: Fine's Double Helix Model ............................................................18

Figure 6: Construct and Consortium PODI Lists...........................................49

Figure 7: Networks Based on Keyword Scores ............................................55

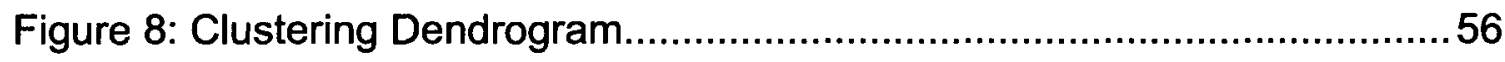

Figure 9: Sample I and sub-samples E, F, G, H ........................................58

Figure 10: WiMAX Forum POD Index Chart .................................................91

Figure 11: GSM Association POD Index Chart.............................................93

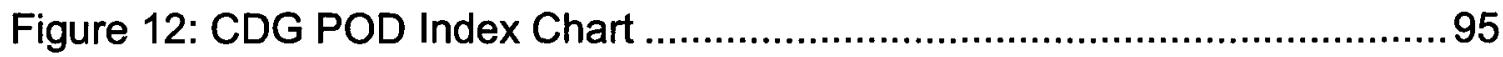

Figure 13: NGMN Alliance POD Index Chart...............................................97

Figure 14: CCF POD Index Chart.............................................................. 100

Figure 15: LSTI Forum POD Index Chart ..................................................102

Figure 16: UMTS Forum POD Index Chart................................................105

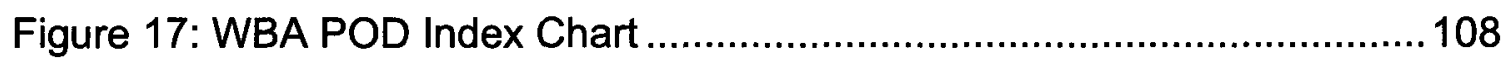

Figure 18: OPA POD Index Chart...............................................................111

Figure 19: Distribution of CDMA Technology and Standards .......................113

Figure 20: Distribution of WiMAX Technology and Standards.......................114

Figure 21: Distribution of LTE Technology and Standards ...........................114

Figure 22: Sample Group E: Construct Groups Visualization .........................115

Figure 23: Sample Group F: Construct Groups Visualization .........................116

Figure 24: Sample Group G: Construct Groups Visualization ......................116

Figure 25: Sample Group H: Construct Groups Visualization .......................117

Figure 26: Sample Group I: Construct Groups Visualization ..........................117

Figure 27: Legacy and Evolution ...........................................................129

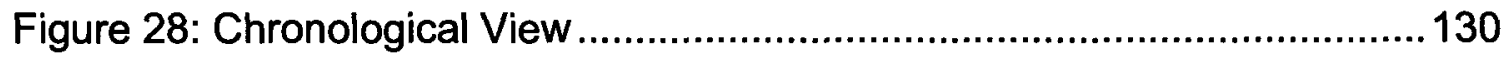

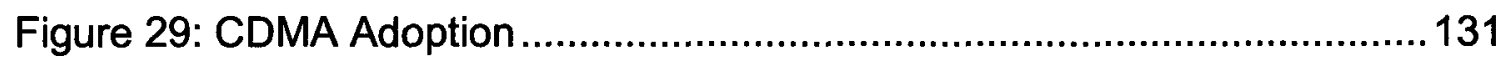

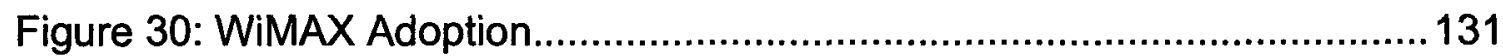




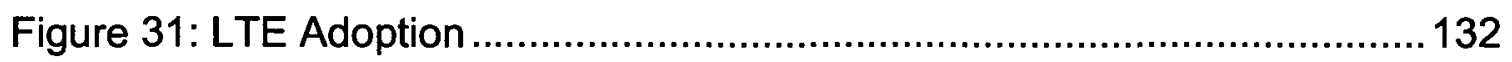

Figure 32: Consortia Evolution Cycle .....................................................137 


\section{Introduction}

Information and communication technology firms affiliate to industry associations, forums and alliances as well as standards development organizations that design or promote technical standards. Standard setting has become such a central technology-strategic activity that many of these firms make substantial financial investments in cooperative standard-setting organizations (Leiponen and Bar, 2008). Standards are increasingly recognised as a core alignment mechanism, in which the interests of various types of stakeholders are being negotiated. This process has major economic and political consequences, and covers not only technical but also many social, economic and legal aspects (Bekkers and Martinelli, 2010). Participation in associations, forums and alliances is very important for being able to contribute to new specifications and work items (Leiponen, 2008).

In this study the term consortia is used to identify industry associations, forums and alliances. Based on the definition suggested by Leiponen (2008), the affiliation is defined by the links firms have with consortia and not directly with one another. The indication of the links that firms have with consortia - or firms' affiliation with consortia - is based on consortia membership. The term construct is based on the definition provided by Carlile and Christensen (2005) and represents an abstraction that help us rise above the details to understand the essence of what the observed phenomena are and how they operate. 
Anderson et al. (2006) identifies the points-of-difference as a building block of a successful customer value proposition and defines it as elements that make a supplier's offering either superior or inferior to the next best alternative. In this study the points-of-difference term refers to the relative importance of the salient constructs identified for each association, forum or alliance. For example, the Points of Difference Index (POD) for the "Hardware" construct, for the WiMAX Forum, provides a numerical value indicating the strength of the "Hardware" construct for members versus non-members of the WiMAX Forum in the sample analysed.

Although the literature has addressed the relationship between consortia and standard setting, and how standards affect - or are affected by - technological change, relatively little attention has been paid to what differentiate the associations, forums and alliances that support standards.

\subsection{Objectives}

The first objective of the research is to analyze the constructs that can be used to distinguish the members of 9 consortia: GSM Association (GSMA), CDMA Development Group (CDG), UMTS Forum, WiMAX Forum, LTE/STI Trial Initiative, Next Generation Mobile Networks (NGMN), Wireless Broadband Alliance (WBA), CDMA Certification Forum (CCF) and Open Patent Alliance (OPA). These organizations were created at various points over the last two 
decades $^{1}$, in order to support the wireless standards and technologies of the day.

The second objective of this research is to provide a methodology for identifying the predominant constructs that characterize wireless industry organizations.

\subsection{Deliverables}

The research produced the following deliverables:

- A list of salient constructs for organizations that are members of associations, forums or alliances in the wireless industry

- The points of difference for each association, forum and alliance

- Interpretations of the points of difference to identify: (i) constructs of organizations involved in legacy or evolution technologies, (ii) trajectories for technological adoption, and (iii) the membership motivation

- Recommendations for designing non-profit keystone organizations

\subsection{Relevance}

This research is relevant to:

- Management teams and entrepreneurs who will be able to examine the salient constructs that define the focus areas, business models and collaborations of organizations at various stages of technology and standards development.

\footnotetext{
${ }^{1} 1987-2008$
} 
- Academic researchers who will be interested in the methodology used for searching for constructs; they will be interested in methods to automate the process of classifying organizations.

\subsection{Contributions}

The research makes at least three contributions:

- Constructs and points-of-difference identification can help improve member value proposition of associations, forums and alliances. The consortia can add value to their members by anticipating the changes in the standards and technologies they support, and the business models of their members.

- It improves the terminology used to describe the mobile communication industry attributes. The keywords identified from the organizations web sites could assist in subsequent automated searches that can improve the understanding of the evolution of standards, technologies and how keystone organizations adapt. The terminology and the method could provide a faster analysis of an industry and its evolution over time.

- The new approach for identifying the constructs improves the data mining methodologies used for mapping companies' attributes and industry trends.

\subsection{Document Organization}

This thesis is organized into six chapters. The first chapter includes the introduction and an overview of the research. The second chapter contains a 
review of the literature pertaining to the mobile communication industry, web content analysis using keywords, hierarchical decomposition in relationship networks and factor analysis. The research strategy and method are described in chapter three. Chapter four provides the results of the data acquisition and analysis. Chapter five contains a discussion of the results. Finally, chapter six presents the conclusions, limitations and recommendation for future research. 


\section{Literature Review}

This chapter provides the review of the literature. It is organized into five sections. Section 2.1 reviews the literature on wireless industry. Section 2.2 reviews the literature on networks of collaboration. Section 2.3 reviews the cluster and social network theory. Section 2.4 reviews the content analysis of websites. Finally, section 2.5 provides lessons learned.

\subsection{Views on the Wireless Industry}

\subsubsection{Standards: competing through cooperation}

The impact of standards can be articulated both in terms of the technologies and processes to which they are applied and in terms of economic issues that they may resolve in the market (Blind et al, 2010). Open system standards are defined by formal standard bodies and vendor consortia. The vendor consortia are organizations primarily composed of companies from industry that have a vested interest in defining standards for their own commercial products and who work together to achieve consensus on standard services and interfaces (Dargan, 2005). A standards strategy is a plan to achieve consistency between product development and public standards evolution. The focus of the plan is the alignment of the purpose of the firm's participation in standards development, the identification of the activities to be undertaken, and the structure required to implement these activities (Bailetti and Callahan, 1995). Organizations are motivated to come together to reach common objectives in order to create and develop new markets whose evolution depends on the 
interoperability of the systems produced by different vendors and the interconnection of the networks of different operators. It is the drive of this common goal to move technology forward and create demand for the products or services in the market (Kazi, 2006).

Blind et al. (2010) study on the impact of the information and communication technology standards at firm and industry level, found that the most significant impact of standards were seen to occur in the product development and in the coordinating the structure of industries and markets. The study notes that "somewhat counter-intuitively", formal standards were seen to actually increase product variety by facilitating a greater number of value-added combinations. Formal standards appear to have their greatest impacts at downstream application levels; major positive impacts were also seen on the globalization of markets and on market entry, but no overall impact in terms of changing market structure. Contrary to claims that standards level the competitive playing field, stakeholders perceived that formal standards may even increase the market share of dominant firms. Regarding the impact of different standardisation bodies, the same study shows that there is no particular variance according to the primary institutional affiliation of the respondent. The overall conclusion of the study is that the strategic impacts of the standards are more positive than the traditionally assumed cost and price impacts based on the exploitation of the economies of scale.

In a study of three generations of wireless standards development, Hemphill (2009) provides three standards development models, for TDMA (generation 
2.0), CDMA (generation 2.5) and WCDMA (generation 3.0). The three conceptual models are shown to be generally similar in their designs and are shown in Figure 1.

Regulatory Environment

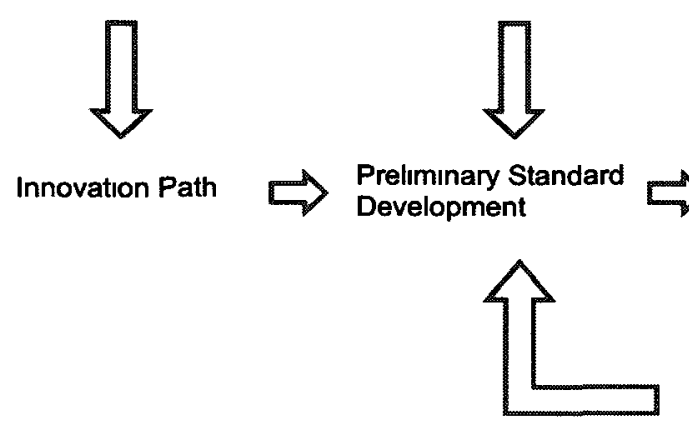

Legal Environment

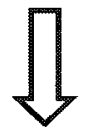

Formal Standard

Development

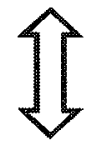

External Liaisons

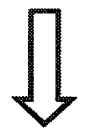

$\Longrightarrow$ Commercialization

Figure 1: Hemphill's Wireless Standards Development Model

The study findings are relevant to the competitive strategy chosen by wireless telecommunications firms. Manufacturing firms tend to have a greater stake in the development of standards than the network operators since they profit from the licensing fees on patents related to manufacturing to the standard. In the case of competing technologies, as was the case for CDMA adoption, the owner of the patents entered in joint testing arrangements with a number of network operators and cooperative working relationships with other manufacturers that lead to the move from the preliminary standards phase to the formal standards phase. The competition for the dominant design was won by the firm that made a concerted effort to place itself as de facto leader and establish a preconceived momentum for its technology. The study also highlights that in cases where there are questions about its technology, a competing firm must actively participate in public industry forums to address the technical concerns raised by 
members of the industry. The strategic technology alliances, among manufacturers and manufactures and carriers, must be entered before the formal standards development phase begins, as these strategic alliances will provide concerted support for agenda-setting in the standards organizations, protecting the technology "champion" (Hemphill, 2010).

Keil (2002) argues that standards are increasingly created through alliances. The standardization through alliances combines elements of pure market-based and committee-based standardization. Its largest strength lies in enabling rapid standardization while decreasing the uncertainty that is caused by a large number of competing technologies. Standardization alliances are often semiopen in that the standard is developed by a limited number of firms while a larger number of companies support the standard as adopters.

Leiponen (2008) argues that affiliations with consortia, alliances, or committees are relevant in standardization due to the knowledge accumulation through joint research and development arrangements. The connections that firms form directly to one another are more important in the work item committee network. In the empirical study of the Third Generation Partnership Program (3GPP) Leiponen (2008) suggests that participating in consortia significantly enhances a firm contribution to the development of specifications in committees.

\subsubsection{The evolution of the value chain in the mobile industry}

The value chain analysis was introduced by Porter (1985) as an assessment tool for businesses that wanted to understand how they should position 
themselves strategically amongst their suppliers, buyers and competitors. Porter argued that competitive advantage stemmed from many discreet activities a firm performs in designing, producing, marketing, delivering, and supporting its product. Porter's traditional value chain model proposed a sequential model for value creation at the firm level. The value chain concept has been broadened later to describe an entire industry

In applying this model to the wireless industry Maitland et al (2002) indicates that in this case the value chain is shaped by the underlying technology and does not fully determine firm and industry structure. As the industry evolves firms will re-position themselves, carving out specific roles and position themselves differently in the industry value chain. The wireless industry value chain maps the wireless industry in stages, showing how each stage feeds and supports the next. The value chains from Maitland et al. (2002) and Constance and Gower (2001) were modified and are presented in Figure 2.

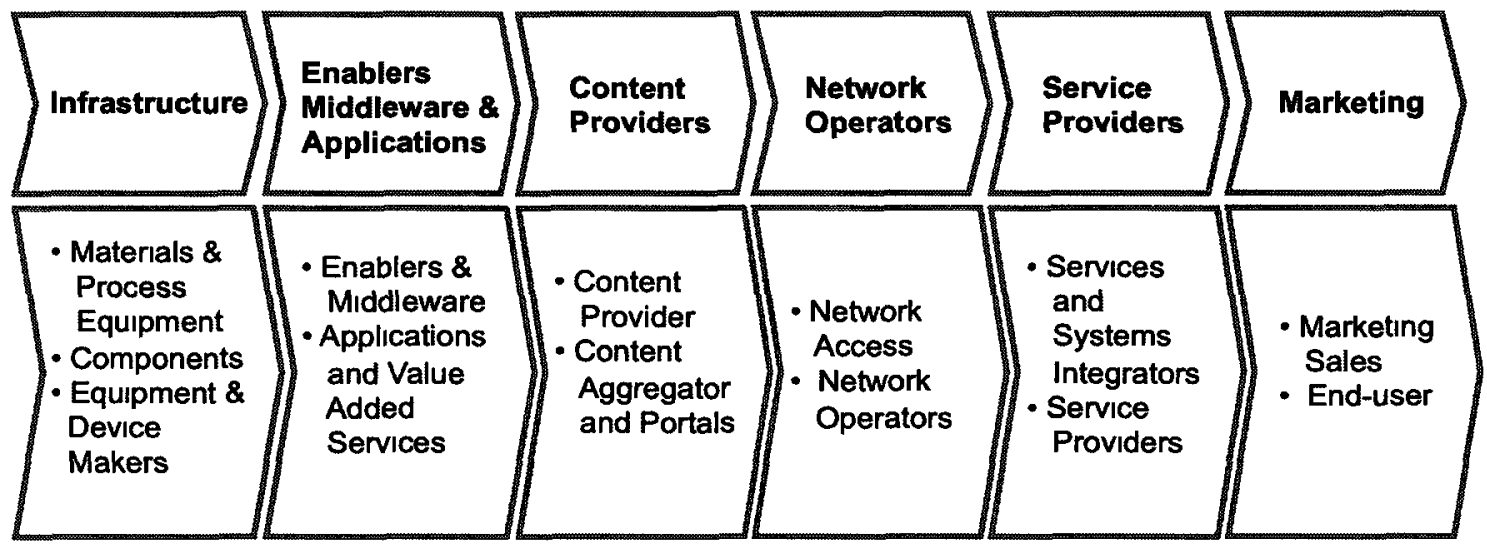

Figure 2: Value Chain in the Wireless Industry 
Maitland et al. (2002) value chain model for the third generation (3G) in the wireless industry was based on the second generation $(2 G)$ value chain with the addition of components from the Internet access value chain. This evolution in mobility is described through the addition of 'enablers' into the value chain firms that bridge the gap between equipment, application and services.

Infrastructure providers design and manufacture the physical infrastructure needed for wireless communication to take place. In migrating to the next generation, one of the challenges for the infrastructure providers lied in replacing the proprietary service platforms with open network protocols and high capacity base stations. Their typical business models include hardware, software and service sales to the network operators. With the majority of the network equipment revenue coming from the base stations, the wireless equipment started to move into partnerships with application developers and at times come in conflict with network operators who did not want to see their roles degraded (Maitland et al, 2002). The network operator is the link between the infrastructure provider and the end-user. A wireless network operator licenses spectrum from the government and makes use of the infrastructure to provide mobile series to the end-user. With the introduction of fourth generation (4G) networks the traditional network carriers face increased competition from new entrants in the industry ${ }^{2}$ - the new service providers. The typical business models for the operators are based on monthly fees, which are determined by the speed of connection and the volume of data flowing through.

\footnotetext{
${ }^{2}$ http://www mobiledia.com/news/72122.html, last accessed August 5, 2010
} 
The analysis of the mobile industry through the evolution of the value chain provides a framework for the assessment of the technical and competitive landscape, and for value propositions of the industry. Sabat (2002) used this model to show that over time the traditional players in the industry are repositioning themselves from their old slots into newer niches even as new entrants are rushing to grab their slots. Competitive threats lead to forming synergistic partnerships in the value chain as the technological challenges and costs of the $4 G$ have forced device manufacturers to seek alliances to better compete. Sabat (2002) indicates that customer demands for mobile business value has led to the convergence of functionality in products, which in turn necessitated the convergence of technology and standards and divergence of products coupled with differentiation of services along the value chain. Understanding the value chain and network economics will help the mobile wireless companies 'unleash the potential of the value chain and to sustain profitability levels' (Sabat, 2002).

The model for the wireless industry value chain proposed by Constance and Gower (2001) is shown in Figure 3, in a map of the largest players in the industry. A dotted line indicates an information exchange, while a solid line indicates both information and a monetary exchange. 


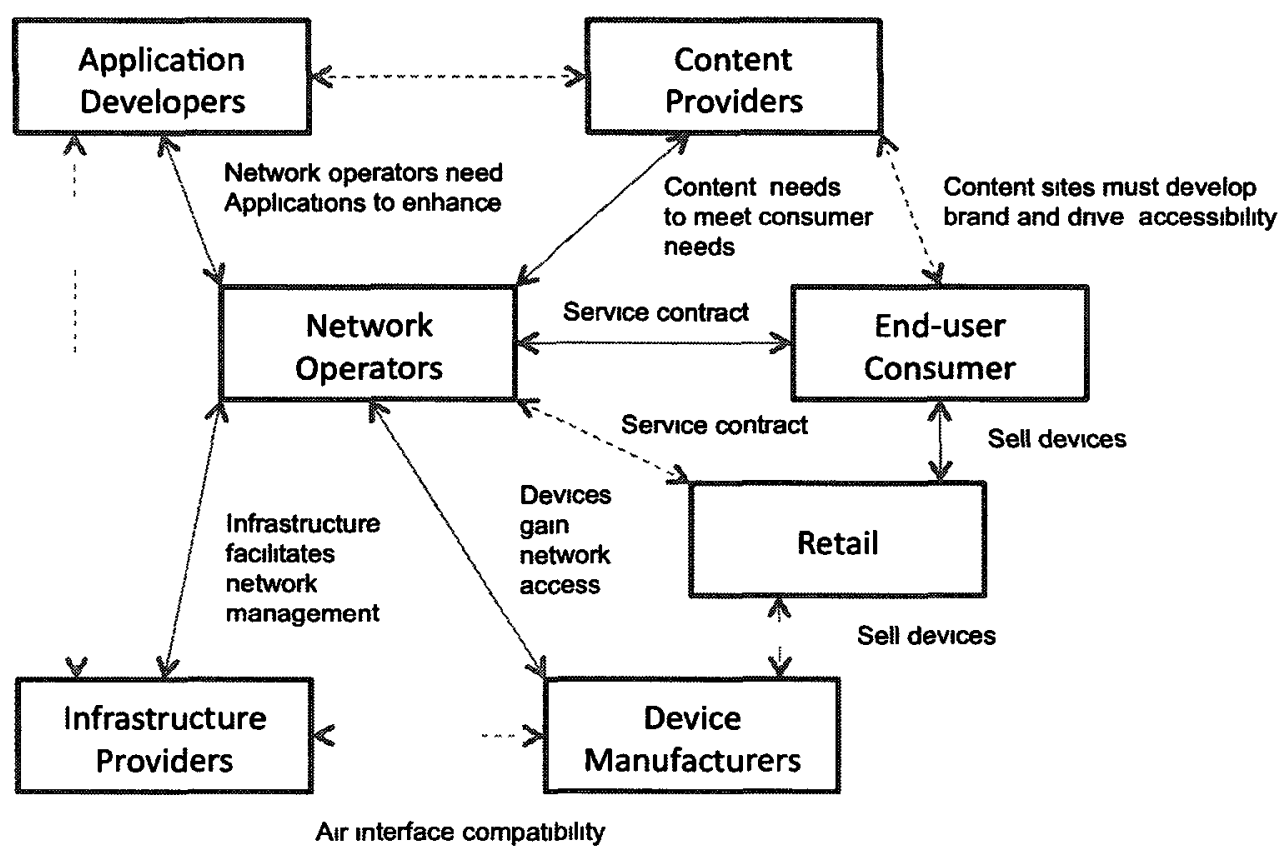

Figure 3: Players in the Wireless Industry Value Chain

\subsubsection{The layered model}

In an attempt to characterize the evolution of the telecommunication industry Fransman (2002) proposes a layered model as a framework similar to the model used by telecom engineers and software developers. In this model, Layer 1 is defined by the Equipment and Software Layer (with solutions from infrastructure providers), Layer 2 is defined by the Network Layer (represented mainly by network operators), Layer 3 is the Connectivity Layer (Internet access, Web hosting), Layer 4 is the Navigation and Middleware Layer (browsers, portals), Layer 5 is the Application Layer (online information services) and finally Layer 6 is represented by the consumers. This approach allowed for identification of opportunities for new entrants when the new TCP/IP became a platform on 
which new services were built. The model also allows the visualization of the industry modularization that facilitates entries of companies into all the layers by allowing them to focus on their activities and ignoring the complementary ones. The coordination of activities between layers and within layers, the comparison and contrast between industries are also cited advantages of the model. Fransman (2002) also highlights some of the shortcoming of the model: it is static by not including the processes of change, it does not explain the coordination among the players and it neglects the differences within layers. The model leaves out the role of regulatory and standards organization.

A similar layered model presented by Maitland et al (2002) shows the position of the mobile virtual network operators against a layered network architecture composed of: physical, radio access, network, call control, and service platform layers. The market orientation and business model of the network operator is explained by the number of layers encompassed in its operations.

\subsubsection{The business ecosystem model and key players}

It has been argued that networks studied in biology and other natural sciences provide an appropriate frame of reference and useful terminology for understanding business networks (Moore, 1996; Peltoniemi, 2006). The business ecosystem is "an economic community supported by a foundation of interacting organizations and individuals - the organisms of the business world" (Moore, 1993). A company should not be viewed as a member of a single industry but "as part of a business ecosystem that crosses a variety of 
industries". In business ecosystems, firms compete and cooperate at the same time as they have a mutual interest in defending, developing, and growing an ecosystem (Moore, 2006).

Similar to biological ecosystems, participants in a business ecosystem are not all created equal and do not necessarily pursue the same strategies. lansiti and Levien (2004a) identified three types of behaviours among actors, namely keystone players, dominators, and niche players, which are useful in understanding the strategies and positioning of participants in business ecosystems. Keystone players are active leaders in the ecosystem and tend to improve the overall health of the ecosystem. Keystones tend to assume roles of hubs in the network; they often lie at the core's network as the most connected. However, any firm occupying a hub in a business ecosystem, often faces temptations to exploit their position - characteristic of a dominator, or hub landlord, strategy. Dominators are firms that control a large part of their networks. They take most of the value for themselves and leave little for other companies in the ecosystem. In mature industries, where little innovation takes place and change is slow, dominators can have a beneficial effect. In emerging industries, this behaviour can be highly destructive as it limits innovation. Niche players constitute the largest group in any ecosystem. They are non-dominant, large, and small, companies that specialize in specific capabilities to differentiate themselves from others in the ecosystem. Niche players collectively create much of the value in a niche and generally capture the value they create. 
Their growth depends on their ability to leverage keystone platforms and to maintain a level of differentiation.

\subsubsection{The mobile ecosystem}

As early as 1980 s, telecommunications industry was compared to an ecosystem (Young, 1980), where the "ecological enquiry evaluates the adaptability of the system". There are several recent studies that have adopted the ecosystem perspective in the mobile industry context (Maitland et al., 2002; Tilson and Lyytinen, 2005; 2006). There are studies on the role of specific players in the industry, such as network operators (Peppard and Rylander, 2006) and device manufacturers (Dittrich and Duysters, 2007). Some have focused on mobile marketing (Becker, 2005), mobile multimedia (Balaji et al., 2005), mobile content (Peppard and Rylander, 2006), mobile business (Coursaris et al., 2006) and globalization of the mobile industry (Steinbock, 2003).

Basole (2009) presents a picture of the mobile ecosystem which consists a variety of firms from numerous enabling and supporting segments of products and services. The incumbent (currently existing) segments are depicted by darker spheres and the emerging segments by lighter spheres as indicated in Figure 4. 


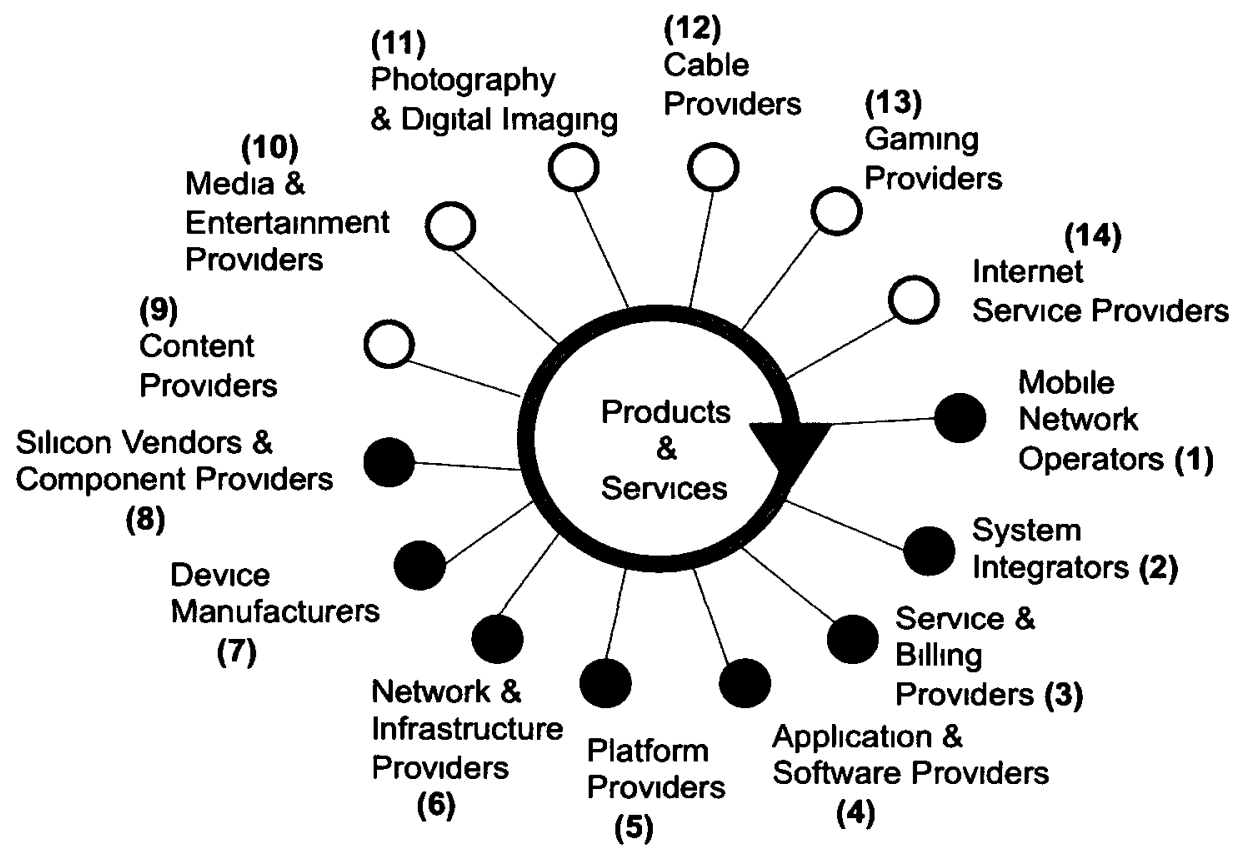

Figure 4: Basole's Converging Mobile Ecosystem

\subsubsection{The Double Helix model}

The Double Helix model illustrates the evolution of industry structure over time. According to Fine (1998), a given industry oscillates between vertical/integral and horizontal/modular structure. Fine's model helps participants prepare for shifts in industry structure by emphasizing the notion of temporary advantage participants must realize that current critical capabilities may become commodity capabilities in the future. 


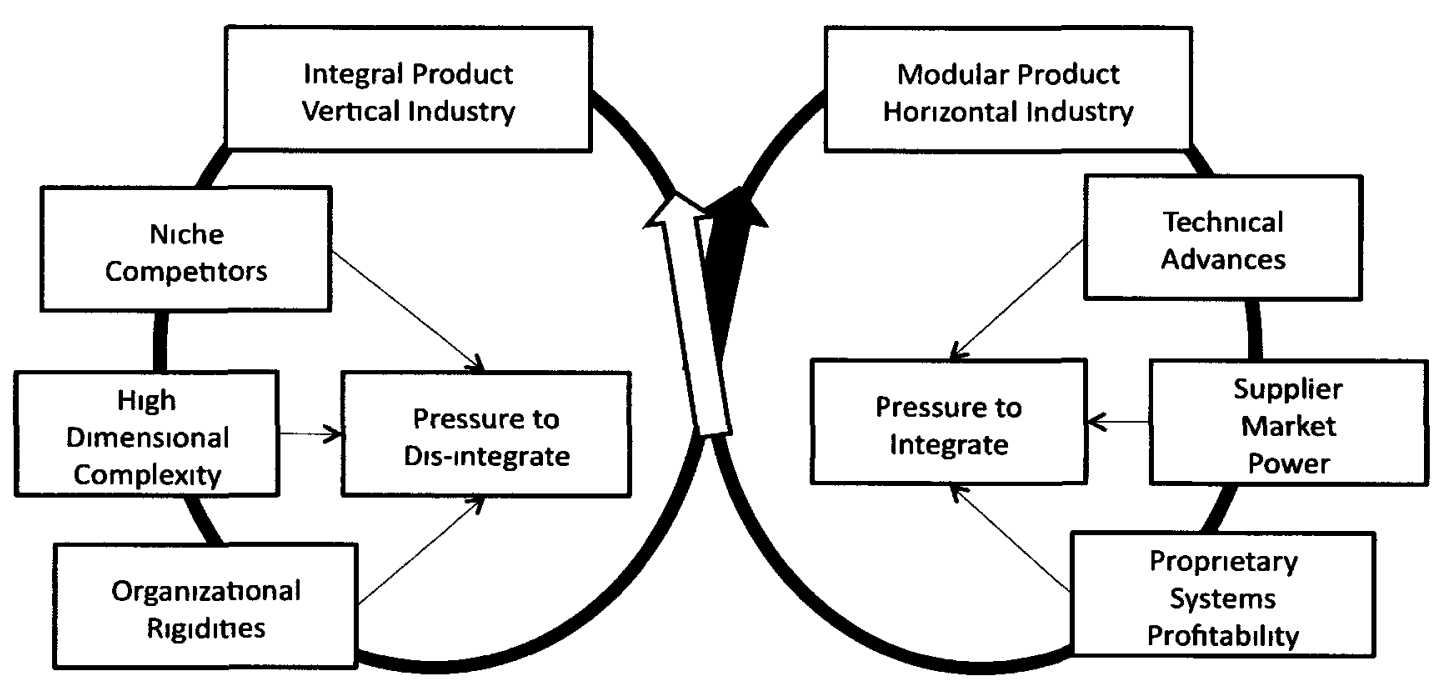

Figure 5: Fine's Double Helix Model

In this model the two drivers are the competitive intensity and technological innovation. When the industry structure is vertical and products architectures integral, the competitive intensity is low. Eventually the entry of competitors will force the vertical firms to disintegrate. The previously vertical firms become dependent on its new suppliers. These dynamics result in complete modularity, as participants specialize in the production of horizontally applicable components. The double helix model suggests an eventual reintegration of the horizontally oriented industry. Constance and Gower (2001) applied this model to the wireless industry in the 1990s to explain the device and infrastructure value chain dynamics.

\subsubsection{The dynamic ecosystem model}

The dynamic ecosystem model (DEM) proposed by Vesa (2003) is an analytical framework built on the business ecosystem concept and the Double Helix model. It combines the evolutionary ideas of the business ecosystem and the 
cyclic nature of the development of product architecture and organizational structure. The DEM model is used to carry out a "macro-level" analysis of the fast moving wireless industry and is able to manage the complexity of the adaptive and dynamic nature of the industry and provides a network perspective.

\subsubsection{Real options approach in the wireless industry evolution}

The real options approach (ROA) is a strategic tool to evaluate business projects investment used by Kim et al (2009) to analyze the technology policy issues in wireless networks, network service provisioning, and network regulation and policy. Their study looked at the wireless industry migration path options to $3 G$ by exploring two typical network migration alternatives: architectural innovation (infrastructure replacement) and modular innovation (upgrades to existing equipment). The two alternatives involved evolution to two different technologies (GSM-based or CDMA-based), and described by two different sets of standards (3GPP or 3GPP2). The approach is a blend of a comparative study and a "what if" study (or contingency study). Reaching relevant data for technology development was considered challenging and as a result the data used in the study was based on the market shares of competing technologies.

\subsubsection{Strategic value assessment model}

Pagani and Fine (2008) developed a map to analyze the dynamic forces that influence the structure and evolution of $3 G$ wireless industry motivated by the 
fact that this is an industry where competition is intense, growth is rapid, innovation is abundant, and technological options are increasingly complex. The dynamic of the industry creates great opportunities for the participants in the global value network but poses enormous challenges for participating organization and their business models. The resulting map focuses on the dynamic complexity of the value network and on the interdependencies among the wireless network providers, service providers, and the customers. The study proposes a range of behaviours and plausible scenarios that resulted from the discussions with several panels of experts and interviews. The $3 G$ communication value network scenarios were: (1) cycles of entry and bankruptcy, where the combination of competition in infrastructure and service provision and the creation of global markets for $3 G$ infrastructure and terminals may prove challenging for sustainable business models but good for customers, (2) stable oligopoly, where powerful incumbents can discourage market entry by new service providers, especially in the case of a breakdown in collaboration on telecoms and software standards worldwide, (3) free for all, where governments allow more unlicensed spectrum which could encourage market entry by service providers and the development of global standards that could help to reduce service and terminal prices, (4) appearance of a new dominant force, an innovator entrant becoming a dominant force which might increase the barriers to entry of other potential entrants while global standards help reduce service and terminal prices, and (5) piracy development, which could be characterized by slowing growth in profits for content providers, but could help to attract new 
adopters and help network providers prosper from service to the customers. The use of such a theoretical map for the industry is tentative until further data collection could shed more light onto the likelihood of each scenario.

\subsection{External Networks of Collaboration}

Research into inter-firm networks has become prominent (Freeman, 1991; Langlois, 1992; Baldwin, 2007) as a firm is no longer seen as a closed entity that produces and markets products independently. The boundaries of the firm are expanding to include their external interactions and relationships with suppliers, customers, distributors, strategic partners and research organizations, each who provide a source of innovation and have opportunities to shape the final product. It has been found that product and industry structure have an impact on the shape of these external networks as well as its evolution among the firms within that industry (Hite and Hestley, 2001; Langlois, 1992; Langlois, 2002).

\subsubsection{Modular industry structure}

Modular product architectures can be an important source of strategic flexibility when they enable a firm to respond faster to changing markets and technologies by rapidly creating product variations based on new combinations of new or existing modular components. They also enable the coordination of a global network of component developers and suppliers (Sanchez and Mahoney, 1996). One important implication of product modularity is that it leads to more modular industry structure, with increased division of labour across companies, 
specializing in different components within a given architecture. This demands tight cross-company interaction and coordination that can be performed by "system integrators" at the organizational and knowledge levels (Brusoni and Prencipe, 2001). Greater heterogeneity in the production process for an industry leads to a greater use of modular organization forms such as contract manufacturing, alternative work arrangements, and strategic alliances. The extent to which industries respond to heterogeneity partly depends on industry standards, the rate of technological change, and the degree of competitive intensity, which all facilitate the use of modular organizational forms (Schilling \& Steensman, 2001). The effect of modularity on external networks is one of enablement (Baldwin, 2007). Transactions that previously were too expensive or not possible now can take place. Modularization creates new boundaries transaction-free zones - where new entry can take place. For areas in the network where transactions are dense and complex, their costs can be minimized by moving them to transaction-free zones, thereby reducing the burden on the system. These new boundaries form breakpoints where firms (and industries) may split apart. The "modularity theory of the firm" (Langlois, 2002) suggests new roles for firms to facilitate the communication of rich information for purposes of qualitative coordination, innovation, and remodularization. Hybrid forms like joint ventures and collaborative arrangements arise for similar reasons. Modularity can help inter-firm networks engage in knowledge exchanges, becoming brokers that specialize in the particular type of 
knowledge exchanges within an industry - and extracting value from those exchanges by becoming the entities that can execute them most optimally.

\subsubsection{Evolution of a firm's networks of collaboration}

The evolution of firm's networks is based on the firm's requirement to adapt to the firm's resource needs and challenges (Hite and Hesterly, 2001). The main driver is the resource availability, access and uncertainty. The identity-based networks characterize the emergence phase. In this phase the networks are egocentric, the ties are personal or socially related and who the ties are matter more than the economic functions or resources that the tie provides to the firm, because these ties are more likely to provide the resources. The ties are few and strong. The identity-based networks do not possess the breath of resources needed to meet the information and knowledge requirements and are more path-dependent. By comparison, the calculative networks characterize the later, early growth phase of a firm. The calculative networks provide greater resources, the functions of the networks are more important than the identity of the ties, which are motivated by economic benefits. They have a greater density, the majority are week ties and more likely to be less redundant and better able to bridge structural holes. The evolution of the firm networks "will be

dominated by path-dependent processes during emergence but will become intentionally managed as the firm moves into early growth". An organization needs to map the ecosystem in terms of inter-firm interconnections and adapt to it as it evolves in order to have access to the complementary assets through relationships (lyer, 2006). 
In the evolution of firms' strategic alliances, the alliance-based learning is vital in the initial phase, when learning is associated with exploration. This learning becomes more internalized, intra-firm and exploitative in the later phases (Oliver, 2001). It has been proven that a lack of a strategic alliance can be associated with organizational death. But participating in a network exposes organizations to risks of being exploited by unpredictable and opportunistic partners. There are liabilities associated with alliances. At the early stages, a lack of alliances suggests inability to attract partners and thus inability to learn, leading to organizational failure. The benefits from an increased number of learning opportunities outweigh the risks and firms in this explorative phase follow a path of increasing the number of alliances. In the later phases of the lifecycle the alliances become more exploitative, it is a period of alliance rationalization, as firms realize that the new alliances are too demanding in terms of the communication energy they require, while they get too little in return. Another view of this exploitative phase is that organizations already raised enough funds so the alliances are not needed anymore. The organization has already acquired the external knowledge from the new technologies and enters a period of more internalized learning.

\subsubsection{Dynamics of entry and network position}

Orsenigo et al (2001) indicates that firms have found serious difficulties in modifying their structural position within a network. Specialized firms have tended to remain specialists, while early entrants have enjoyed significant firstmover advantages, precisely because they have been able to embody 
knowledge at a high level of generality. Thus, a major asymmetry seems to have characterized the evolution of the network: while in many cases "generalist" firms have been able to gradually absorb increasingly specific knowledge, specialist firms found it much harder to move in the opposite direction. As the locus of innovation moves from the firm to the network, the firm position in the network becomes a competitive advantage (lyer, 2006). The network path length, clustering coefficient, and degree can be used to understand an individual firm's position and relationships in the network compared to competitors.

\subsubsection{Industry lifecycle}

The waves of diffusion and concentration in the networks evolution have been observed since the late nineteen century (Freeman, 1991). The initial upsurge in the inter-firm linkages is a transitory phenomenon of adaptation to the diffusion of new generic technologies. Once firms have become familiar with these technologies they will wish to shift the strategically sensitive areas under their control and internalize some of the networks. According to this view, this phase will be followed by a new wave of "rationalization and industrial reconcentration". In the early formative period of any major new technology system, almost by definition there are no dominant designs or standards and a state of organizational flux. As technology becomes more mature the economies of scale become more important and standardization takes place (Freeman, 1991). The patterns of inter-firm linkages are linked to industry's development lifecycle (Gloor et al, 2007). The need to innovate places pressures on the 
evolution of the network structures in the lifecycle of an industry. When firms in the pharmaceutical industry entered a more mature era, the industry witnessed a series of defensive mergers with direct rivals and takeovers of small biotechnology firms, but the 'bureaucratic solidity' of the pharmaceutical firms reduced the innovativeness of the biotechnology firms significantly. Pharmaceutical firms were forced to change their strategy towards establishing more loosely coupled linkages (Gloor et al, 2007).

Chesbrough and Prencipe (2008) propose a model for the innovation lifecycle, which suggests that the evolutionary dynamics of modularity is reflected in the innovation network evolution. In particular, they argue that firms should align their innovation networks with phases of technology modularity, and focus their openness in specific directions at specific stages of technology development. In order to cope with changes in the information and knowledge requirements that characterize the modularization process of technologies, firms must change their innovation networks in terms of their search approach (explorative vs. exploitative), intensity of relationships (weak vs. strong ties), number and type of partners (research centers, startups, complementary asset holders) (Chesbrough and Prencipe, 2008).

\subsection{Clusters and Social Network Theory}

The analysis of organizations through multidimensional constructs has a long history, but it created a conceptual challenge in that a vast array of combinations could be developed along multiple dimensions (Ketchen and 
Shook, 1996). The response to the challenge was to identify the organizational configurations: sets of firms that share a common profile along conceptually distinct variables (Miller and Mintzberg, 1983). For example, an "entrepreneurial" configuration is one that consists of firms that are small, young, informal, and have centralized decision making; similar organizational configurations are the organizational typologies and taxonomies.

One of the particularities of exploratory factor analysis is that the results cannot be inferred from the sample to the population (Field, 2005). The use of factor analysis in literature (Opoku, 2005; Hicks, 2006; Lombardi, 2008; Allen, 2009) indicates that the sample is defined based on well-defined criteria rather than selecting random cases from a population. The cluster analysis approach takes a sample of elements (e.g. organizations) and groups them together such that the statistical variance among the elements grouped together is minimized while between-group variance is maximized (Ketchen and Shook, 1996). The cases from the literature where databases with large sets of cases were available (Hicks, 2005; Costello and Osborne, 2005) the variables for selecting the clusters as samples for further factory analysis were clearly defined. In other studies, the cluster selection was based on the researcher experience with the subject matter and was based on a manual selection process (Allen, 2009).

Social and collaborative network theory provides us with a number of tools and models for analyzing the relationships among actors in a network and for creating clusters of actors with shared characteristics. Social network theory models persons as nodes of a graph and their relationships as edges of the 
graph (de Nooy, 2005; Caldarelli, 2007). Thus two actors are connected directly if they have a relationship with each other, in which case they are one link away from one another. More distant relationships are modeled as paths through the graph. Collaborative networks are variations of social networks, where the relationships are collaborations, e.g., open source software development (Madey et al., 2002), or co-authors on research papers (Newman, 2001). Often entire populations are connected into one large cluster with characteristic cluster coefficients (Watts, 1999). Highly prolific actors or authors are linchpins in collaborative networks. Linchpin actors or researchers play key roles in bridging disparate groups into one large cluster by being the only joint participant in two different projects.

\subsection{Content Analysis of Websites}

\subsubsection{Corporate identity}

The vast majority of companies use their corporate websites to reach a diverse group of target audiences including investors, customers, employees, researchers and the media (Insch, 2008). Companies use websites to advertise their corporate identity and their aspirations, and to describe their products, actions in the marketplace, and organizational credentials. This has led to a wealth of research focusing on the content companies place on their website and on why and how it is reflective of the company's position in the marketplace. Almost every organization's website has an "About Us" page stating company description, values and history. Heldal et al. (2004) discussed the usability, 
human computer interaction and branding to demonstrate how each field alone is insufficient but taken together they can offer optimal communication through the Internet to maintain and build sustainable customer relationships.

Hicks et al. (2006) found that most websites are not used to interact with potential customers. Most firms go beyond describing their current identity; they describe their potential and their aspirations. Pollach (2005) found that even large and well established companies use their about page to make themselves look better than other firms in the industry. For example, many organizations claimed dominance of the same market. Positive attributes were written in a passive voice to insinuate a general acceptance of them. Hicks et al. (2006) show that in defining their corporate identity, companies relate their current situation as well as their aspirations. "A successful web site satisfies the goals of both the users and the provider of the website" (Pollach, 2005).

\subsubsection{Content analysis}

The corporate website can be used as a valuable tool by researchers for collecting information. Data is much more readily available than using interviews or questionnaires and can be gathered quickly and efficiently using harvesting tools. A number of tools that can scour a website searching for relevant information can be used to find lists of sites based on a particular topic, can search for specific content within a predefined set of websites or choose search results based on any number of factors. Perry and Bodkin (2000) examined self promotion by Fortune 100 companies on their websites. McMillan (2000) 
surveyed 19 different studies using web content analysis. Pollach (2005) examined how companies present themselves on their websites. Porter et al. (2007) described a method for collecting technical intelligence and Opoku (2005) investigated the most innovative business schools. A number of researchers have recently used keyword based search techniques to build theory and/or test hypotheses in the field of management science (Ferrier, 2001; Hicks et al, 2006; Opoku, 2005; Lombardi, 2008; McGinnis, 2008).

Ferrier (2001) conducted an exhaustive manual search of keywords in thousands of press releases of sixteen firms over seven years to study the aspects and performance of different classes of competitive attacks within a population of high tech firms. Hicks et al. (2006) used web mining techniques to gather data on the commercialization strategies of innovative small high tech firms. Opoku (2005) studied brand personality of US business schools using a dictionary of terms representative of the dimensions of brand personality. The frequencies of the words on the schools' websites were obtained and the pattern of occurrence assessed to classify the schools. Lombardi (2009) used web content analysis of keywords to assess and classify the interactions between Eclipse Foundation Members and Eclipse Projects. McGinnis (2008) used the same methodology to assess and classify the competitive actions of companies reliant on open source software for revenue. Allen (2009) used the content analysis of keywords to assess and classify the activities that organizations employ to enable value co-creation with customers and end users. 
Various tools are available to support the web searches required to gather the data for these analyses. Of the many commonly available search engines, those with the most readily available and adaptable Application Programming Interfaces (API) includes Google's Ajax API, Microsoft Live Search API, Yahoo! Search API and $\mathrm{KSAT}^{3}$.

Exploratory Factor Analysis (EFA) has a long history in the social sciences. While it has been used most often for research on human psychology, recently it has been shown to be an effective tool to reduce the large volumes of data gathered through internet mining by extracting the base constructs underlying how small and medium firms do business (Hicks et al, 2006; Lombardi, 2009; McGinnis, 2008; Allen 2009). In simple terms, factor analysis is used to discover patterns in the relationships among a number of variables. It specifically seeks to explain these relationships using a much smaller set of variables called factors. A number of recent texts and papers provide excellent treatments of how to perform exploratory factor analysis using SPSS (Darlington, 2010; Field, 2005; Costello \& Osborne, 2005; Reinard, 2006; Stevens, 2009).

\subsection{Lessons Learned from the Literature}

The following are the major insights from the literature review.

Social network theory, content analysis and factor analysis can be used to analyze the relationships among actors in a network.

\footnotetext{
${ }^{3}$ http //github com/mwnorman/KSAT
} 
The participants in business ecosystems and networks of collaboration are identified by various roles and behaviours. The keystones or the hubs assume leadership role while niche players focus on specific capabilities.

Data on the wireless industry from public sources is scarce. The theoretical studies use panels of experts and the ones from public data sources are most often one-sided. The more detailed and complete studies of the wireless industry use data from private sources.

Web sites are used to communicate the identity and aspirations of organizations; the industry associations, forums and alliances are created to promote the interests of their members, but there is little evidence on how this information can be verified or validated; this creates an opportunity to confirm this information by analyzing member's web pages.

Standards are increasingly created and influenced by consortia. This type of standardization combines elements of pure market-based and committee-based standardization. Its largest strength lies in enabling rapid standardization while decreasing the uncertainty that is caused by a large number of competing technologies. Standardization alliances are often semi-open in that the standard is developed by a limited number of firms while a larger number of companies support the standard as adopters.

A firm is no longer seen as a closed entity that produces and markets products independently. The boundaries of the firm are expanding to include their external interactions and relationships with industry stakeholders that contribute 
to the development and commercialization of the firm's products. An organization's identity is shaped by its external networks of collaboration.

As technology evolves and new standards emerge a firm's relationships in its networks of collaboration are changing. By understanding the evolution cycles in the industry a firm can shape its entry points and strategic alliances. 


\section{Research Methodology}

This chapter describes the research design and method. It is organized into eleven sections. Section 3.1 provides an overview of the research strategy. Section 3.2 describes the steps carried out in this research. Section 3.3 describes the sample selection. Section 3.4 discusses the keyword selection process. Section 3.5 describes how the data used in this research was collected. Section 3.6 includes a description of the factor analysis method used in this research. Section 3.7 describes the results from the initial analysis. The methodology for creating the clusters is presented in Section 3.8. Section 3.9 discusses the use of multiple factor analyses. Section 3.10 covers the criteria for results validation, and finally Section 3.11 presents the instruments for data analysis and interpretation.

\subsection{Research Strategy}

This research uses data mining techniques and website content analysis to identify the main characteristics of consortia in the wireless industry. The approach is based on grounded theory and follows the recommendations of Carlile and Christensen (2005).

A dataset comprised of information on members of several consortia in the wireless industry was developed using search engines and keywords associated with wireless technologies, standards and business models. Factor analysis was used to reduce the dimensions of the information in the dataset. As the goal of this research is to uncover the diversity of constructs, a multiple 
non-probability sample approach was used to gain a better understanding of the diversity of organizations' constructs.

This approach builds on the research of Hicks et al. (2006) and Opoku (2005) for web search and analysis methods and on social network theory (de Nooy et al, 2005) and Caldarelli (2007) for clustering methods.

The factor analysis results were grouped together, based on their similarity, to form constructs. The relative importance of the constructs is used to present two point-of-difference views: (i) how consortia ranks based on a construct, and (ii) how the constructs rank for a consortium. The identified salient constructs represent the points-of-difference for consortia.

\subsection{Research Steps}

Table 1 identifies the steps carried out to complete this research:

Table 1: Research Method

\begin{tabular}{|c|c|c|}
\hline \multicolumn{2}{|c|}{$\begin{array}{l}\text { Research Method } \\
\text { Step }\end{array}$} & Activity \\
\hline 1 & $\begin{array}{l}\text { Literature } \\
\text { review }\end{array}$ & $\begin{array}{l}\text { - Select and review literature on: } \\
\text { - business models, technologies and standards in the } \\
\text { - wireless industry } \\
\text { - clustering and similarity } \\
\text { - statistical techniques for dimension reduction } \\
\text { - develop lessons learned from the literature review }\end{array}$ \\
\hline 2 & $\begin{array}{l}\text { Select } \\
\text { sample of }\end{array}$ & $\begin{array}{l}\text { - Select a non-probability sample of consortia from the } \\
\text { wireless industry: GSM Association, CDMA }\end{array}$ \\
\hline
\end{tabular}




\begin{tabular}{|c|c|c|}
\hline \multicolumn{2}{|c|}{$\begin{array}{l}\text { Research Method } \\
\text { Step }\end{array}$} & Activity \\
\hline & $\begin{array}{l}\text { industry } \\
\text { consortia }\end{array}$ & $\begin{array}{l}\text { Development Group, UMTS Forum, WiMAX Forum, } \\
\text { LSTI Forum, NGMN Alliance, Wireless Broadband } \\
\text { Alliance, CDMA Certification Group, Open Patent } \\
\text { Alliance } \\
\text { - Criteria: } \\
\circ \text { From wireless industry news, websites, } \\
\text { conferences } \\
\circ \text { Consortia from the major wireless technologies } \\
\circ \text { Consortia with diverse members: network } \\
\text { operators, infrastructure providers, equipment } \\
\text { and device manufacturers, service and } \\
\text { application providers, etc. }\end{array}$ \\
\hline 3 & $\begin{array}{l}\text { Select } \\
\text { sample of } \\
\text { organizations }\end{array}$ & $\begin{array}{l}\text { - Sample: } \\
\quad \circ \text { Websites with at least } 10 \text { pages in English }\end{array}$ \\
\hline 4 & $\begin{array}{l}\text { Select } \\
\text { keywords }\end{array}$ & $\begin{array}{l}\text { Keyword sets selected based on: } \\
\circ \text { Concepts from literature } \\
\circ \text { Concepts from } 30 \% \text { of sample websites } \\
\circ \text { Create keyword sets using AND/OR for stronger } \\
\text { meaning }\end{array}$ \\
\hline 5 & $\begin{array}{l}\text { Data } \\
\text { acquisition }\end{array}$ & $\begin{array}{l}\text { Search websites using Keyword Search and Analysis } \\
\text { Tool } \\
\circ \text { Capture keyword set scores }=\text { count } / \text { website } \\
\text { number of pages }\end{array}$ \\
\hline 6 & $\begin{array}{l}\text { Design factor } \\
\text { analysis } \\
\text { method }\end{array}$ & $\begin{array}{l}\text { SPSS factor analysis selections: } \\
\text { o Principal component analysis } \\
\circ \text { Varimax rotation method } \\
\circ \text { Retain keywords with loadings }>0.4 \\
\circ \text { Minimum } 3 \text { variables with loadings }>0.5\end{array}$ \\
\hline
\end{tabular}




\begin{tabular}{|c|c|c|}
\hline \multicolumn{2}{|c|}{$\begin{array}{c}\text { Research Method } \\
\text { Step }\end{array}$} & Activity \\
\hline & & $\begin{array}{l}\text { Select number of factors: Kaiser criterion and } \\
\text { Scree plot }\end{array}$ \\
\hline 7 & $\begin{array}{l}\text { Initial factor } \\
\text { analysis }\end{array}$ & $\begin{array}{l}\text { - Initial factor analysis } \\
\circ \text { Assess the degree of homogeneity of the sample } \\
\circ \text { Determine the number of factors that can be } \\
\text { extracted and the level of diversity of the factors }\end{array}$ \\
\hline 8 & Clus & $\begin{array}{l}\text { - Introduce dissimilarity as control variable } \\
\text { - Create networks of organizations that are linked if they } \\
\text { share similar scores for the same keywords } \\
\circ \text { Similar to four-point Likert scale } \\
04 \text { networks: organizations are linked if they share } \\
\text { keywords in the } 1^{\text {st }}, 2^{\text {nd }}, 3^{\text {rd }} \text { and } 4^{\text {th }} \text { quartile of the } \\
\text { keyword range } \\
\text { - Use hierarchical decomposition on each of the } 4 \\
\text { networks } \\
\text { - Create clusters of organizations in each network } \\
\text { - Each cluster is defined by a dissimilarity index } \\
\text { Retain all clusters with more than } 200 \text { organizations: } \\
\text { O Clusters A, B, C, D, E, F, G, H }\end{array}$ \\
\hline 9 & $\begin{array}{l}\text { Multiple } \\
\text { factor } \\
\text { analyses in } \\
\text { all sample } \\
\text { groups }\end{array}$ & $\begin{array}{l}\text { - Run multiple factor analyses in each cluster } \\
\text { - Analyze the factors in each cluster } \\
\text { - As some clusters overlap retain only the clusters with } \\
\text { diverse and relevant factors }\end{array}$ \\
\hline 10 & $\begin{array}{l}\text { Validate } \\
\text { factor } \\
\text { analysis }\end{array}$ & $\begin{array}{l}\text { - Select factor analysis solution only if: } \\
\circ \text { Keywords associated in one factor make sense } \\
\text { to the experienced researcher } \\
\circ \text { Correlation table determinant }>1.0 \times 10^{-5} \\
\circ \text { KMO sampling adequacy test }>0.5\end{array}$ \\
\hline
\end{tabular}




\begin{tabular}{|c|c|c|}
\hline \multicolumn{2}{|c|}{$\begin{array}{c}\text { Research Method } \\
\text { Step }\end{array}$} & \multirow[t]{2}{*}{ Activity } \\
\hline & & \\
\hline 11 & $\begin{array}{l}\text { Validate } \\
\text { results }\end{array}$ & $\begin{array}{l}\text { - Repeat the factor analysis for the solutions retained for } \\
\text { interpretation with a sample or organizations not } \\
\text { involved in the wireless industry }\end{array}$ \\
\hline 12 & $\begin{array}{l}\text { Rank } \\
\text { consortia }\end{array}$ & $\begin{array}{l}\text { In each sample create a ranked list of consortia based } \\
\text { on the relative importance of each construct using the } \\
\text { POD Index as defined in Section } 3.11\end{array}$ \\
\hline 13 & $\begin{array}{l}\text { Rank } \\
\text { constructs }\end{array}$ & $\begin{array}{l}\text { In each sample create a ranked list of constructs based } \\
\text { on their relative importance in each consortium, using } \\
\text { the POD Index as defined in Section } 3.11\end{array}$ \\
\hline 14 & $\begin{array}{l}\text { Validate } \\
\text { factor groups }\end{array}$ & $\begin{array}{l}\text { - Check that factor analysis identified factors are part of } \\
\text { the same factor analysis solution }\end{array}$ \\
\hline 15 & $\begin{array}{l}\text { Draw } \\
\text { conclusions }\end{array}$ & - Synthesize conclusions and insights \\
\hline
\end{tabular}

\subsection{Sample Selection}

The unit of analysis is the website of an organization which is a member of one of the wireless industry consortia included in this research. Neuman (2003) identified two types of sampling: probability and non-probability sampling.

Eisenhardt $(1989,2007)$ and Patton $(1990)$ highlight the inappropriateness of random sampling when searching for diversity of phenomena. This type of sampling is used in similar research (Hicks et al., 2006) where factor analysis methods are exploratory in nature and their results are not expanded to the population from which the sample was selected. 
In this study, the primary purpose of sampling is to collect a diverse enough group of organizations that could help understand as many characteristics as possible of the organizations in the wireless industry consortia. Random (probability) sampling could carry the risk of samples too homogenous to allow for meaningful cluster analysis and also of disproportionate representation of organization types.

Regarding the size of the sample of consortia to include, this study followed the recommendations made by Eisenhardt $(1989,2007)$ to include between four and ten cases. Patton (1990) indicates that the validity and the insights generated from qualitative research have to do more with the information richness of the cases selected and the analytical capabilities of the researcher than with the sample size.

\subsection{Keywords Selection}

The keywords are intended to represent as many of the characteristics of the wireless industry consortia as possible. Keywords were collected through an exhaustive search of the literature and supplemented with additional words found through a theoretically informed contextual search of the 9 consortia' web pages and from $30 \%$ of the selected organizations' web pages. The initial set of keywords was rationalized to eliminate words that either produced negligible successful searches or were found to be ubiquitous (Hicks et al, 2006).

Since the Keyword Search and Analysis Tool (KSAT) supports logical "OR" and "AND" operations it was possible to combine many keywords to form sets of 
keywords that allow a stronger and more focused meaning. In this study the factor analysis is used with a large number of keywords aiming to uncover the diversity of features in our samples.

\subsection{Data Acquisition}

Data was collected following a web data mining approach similar to Hicks et al. (2006) and Opoku (2005). The Keyword Search and Analysis Tool (KSAT) is an open source tool used to perform web searches and is based on the Google Ajax search API. The tool uses text files containing lists of keywords and website URLs to automate the search of applicable web-pages for the presence of the desired keywords (Hicks et al., 2006). The output is an Excel comma separated variable file containing counts of "hits" for each search term at each website normalized by the total number of web pages present at the website. The tool was configured to allow for English pages only. This change was considered necessary because many of the firms searched maintain a global presence and since the search terms were comprised of only English language words, web pages in other languages artificially lowered the keyword frequencies reported for those global firms.

\subsection{Factor Analysis Method}

The factor analysis is an exploratory research method used to identify the main dimensions underlying the variation of a large number of variables. In our research we are studying the patterns of relationships among the keywords used on the web sites of organizations involved in the wireless industry. 
The factor analysis was performed with IBM SPSS Statistics 18 software by selecting the dimension reduction option with factor analysis.

As the factor analysis technique is complex in nature, with many options, this research used the recommendations of Costello and Osborne (2005). There are two statistical techniques used by researchers conducting exploratory factor analysis, Common Factor Analysis (CFA) and Principal Component Analysis (PCA). Recent publications generally recommend the use of CFA over PCA but most acknowledge that usually both PCA and CFA produce equally valid results and suggest that researches try multiple approaches and select the one that produces the best fit of results with theory (Stevens, 2009). For this research PCA was selected as it produced the best fit of the results with the knowledge on the mobile communication industry.

While the literature differs on the strengths of the various extraction methods, it indicates that a large sample size (300) results in similar results regardless of extraction technique. In this sense researchers should choose the method providing the clearest structure and the best fit with theory (Reinard, 2006). SPSS allows the researcher to specify the number of factors to extract and provides a scree plot as an aid tool. Kaiser's criterion and examination of the scree plot are the two main approaches suggested in the literature for determining the number of factors to extract. Kaiser's criterion assumes that all factors with Eigenvalues $>1.0$ represent a significant contribution to the overall variation in the data. The scree plot can be used to identify a threshold for factor selection because only factors that contribute a relatively high degree of 
variation are above the knee. Like selecting the optimal extraction method, many recent authors recommend that researchers examine the results of extraction with a range of factors and select the set that provides the best structure (Darlington, 2010).

Rotation is used to "find the best distribution of factor loadings in terms of the meanings of the factors" (Reinard, 2006, p. 417). SPSS supports the five distinct factor rotation methods: Varimax, Quartimax, Equamax, Promax and Direct Oblimin. Orthogonal rotation such as Varimax is generally used for factors which are expected to be uncorrelated (Field, 2005).

\subsection{Initial Factor Analysis}

An initial factor analysis was run on the results from the KSAT which contained the scores of all keywords from the initial sample of websites. The use of a large number of keywords is necessary with this type of exploratory research but impedes significantly the selection of all the relevant factors. In this sample group several factor analyses solutions were identified. The factors identified are relevant but they do not reflect completely the diversity of the sample, due to the heterogeneity of the sample and the strict criteria for acceptance as indicated in Section 3.10 Validation of Results. The reduction in the number of keywords provided factor analysis solutions at the expense of losing meaningful information.

As the purpose of this study is to uncover as many constructs as possible, the results from the initial factor analysis suggested a focus on more similar groups 
of organizations in a sample. The literature on factor analysis indicates that the methodology is used primarily for dimension reduction. In this study the content analysis using factor analysis is meant to uncover as many factors as possible and therefore the use of multiple sub-samples is warranted. The process for identifying the sample groups is described in Section 3.8 Clusters as subsamples.

\subsection{Clusters as sub-samples}

The literature on sampling for factor analysis indicates that in the cases studied, the criteria for sample selection were based on 'organizational configuration': sets of firms that share a common profile along conceptually distinct variables (Meyer et al., 1993). Studies which have identified "entrepreneurial" organizations (Miller and Mintzberg, 1983) or "highly innovative" firms (Hicks et al., 2006) are examples of creating clusters used as samples for further content analysis with factor reduction. This is an accepted technique since the results from exploratory factor analysis cannot be generalized outside the sample. This study proposes a clustering methodology that is more suitable for large sets of keywords which is meant primarily to map the characteristics of the cases in the sample.

\subsection{Multiple Factor Analysis}

The literature on factor analysis indicates that the methodology is used primarily as a factor reduction for understanding a few dimensions for the cases under study. In this study the methodology is used for identifying and mapping the 
main characteristics in an industry. In an attempt to find as many factors as possible multiple solutions are searched for. This approach needs to meet two conditions: (1) once a factor is identified any subsequent solutions that use this factor must find it as a factor too and the factor's keywords must not be shared, and (2) any final interpretation of results that use multiple factors must have all the factors from the same solution, in other words, it needs to prove that the factors are independent from each other or that they are not correlated. As exemplified in Table 2, the second solution is valid only if by removing factor F2 and adding a new factor, F5, the factor analysis solution finds the rest of the factors intact and there is no sharing of keywords among any of the factors. In this example factors F2 and F5 should never be used together as they were not validated for correlation.

Table 2: Multiple Factor Analysis Solutions

\begin{tabular}{|l|l|l|l|l|l|}
\hline Factor Analysis Solution 1 & F1 & F2 & F3 & F4 & \\
\hline Factor Analysis Solution 2 & F1 & & F3 & F4 & F5 \\
\hline
\end{tabular}

\subsection{Validation of Results}

Successful exploratory factor analysis demands that the data set meet specific criteria for correlation, sampling adequacy and statistical significance (Field, 2005). The statistical analysis tool SPSS was used to perform these validity tests on the data. Every solution in the multiple factor analyses that was retained met the criteria indicated in Table 3. 
Table 3: Factor Analysis Data Validity Test Criteria

\begin{tabular}{|c|c|}
\hline Metric & Limit \\
\hline Correlation table determinant & $>1.0 \times 10-5$ \\
\hline Kaiser-Meyer-Olkin (KMO) Measure of Sampling Adequacy. & $>0.5$ \\
\hline Bartlett's test of Sphericity Significance test & $<0.05$ \\
\hline
\end{tabular}

Hicks et al (2006) suggest that the results from factor analysis should be validated against a control sample. There is no readily available database of firms which are not members of the studied consortia in the wireless industry. A control sample was constructed from the first 250 firms from the 2009 Fortune 1000 companies that were not members of the 9 consortia studied. The factor analysis was run with the keywords from the solutions used in the final interpretation and the results and assessed for correlation, sampling validity and statistical significance.

\subsection{Points of difference as measure of alternatives}

Anderson et al. (2006) indicates that there are three building blocks of a successful customer value proposition: points of parity, points of difference and points of contention.

- Points of difference are elements that make a supplier's offering either superior or inferior to the next best offer

This type of value proposition explicitly recognizes that the customer has an alternative. To make customer value propositions persuasive, suppliers must be 
able to demonstrate and document them. Anderson et al. (2006) recommends the use of value word equations to express in words and simple mathematical operators how to assess the differences in functionality of performance.

Following the model suggested by Anderson et al. (2006), this study defined the points of difference as a numerical value for the relative strength or importance of a construct.

\subsection{Instruments}

The following instruments are used in the analysis and interpretation of the results:

Table 4: Instruments of Analysis and Interpretation

\begin{tabular}{|l|l|}
\hline Instrument & \multicolumn{1}{|c|}{ Description } \\
\hline $\begin{array}{l}\text { Keyword } \\
\text { Score }\end{array}$ & $\begin{array}{l}\text { The number of instances the keyword is found on a web site, } \\
\text { normalized to the number of web pages. The value is provided by } \\
\text { the Keyword Search and Analysis Tool (KSAT). }\end{array}$ \\
\hline Factor & The keywords grouped by factor analysis in one sample. \\
\hline $\begin{array}{l}\text { Factor } \\
\text { Score }\end{array}$ & $\begin{array}{l}\text { For each website the factor score is calculated as the sum of the } \\
\text { keyword scores of the variables loaded on the factor. This } \\
\text { approach follows the recommendations described in Reinard } \\
(2006)\end{array}$ \\
\hline $\begin{array}{l}\text { Factor } \\
\text { Average } \\
\text { Score }\end{array}$ & $\begin{array}{l}\text { Represents the average of a group of organizations' factor scores } \\
\text { in a sample. }\end{array}$ \\
Construct & $\begin{array}{l}\text { The abstract concept represented by similar factors from all } \\
\text { samples. In a sample the construct is defined by a single factor. }\end{array}$ \\
\hline
\end{tabular}




\begin{tabular}{|c|c|}
\hline Instrum & Des \\
\hline $\begin{array}{l}\text { Points of } \\
\text { Difference } \\
\text { Index } \\
\text { (PODI) }\end{array}$ & $\begin{array}{l}\text { The points-of-difference index (PODI) represents the relative } \\
\text { importance of a factor. } \\
\text { In a sample, the PODI compares a factor's average scores for } \\
\text { members against non-members of a consortium. This provides an } \\
\text { indication of the factor or construct relevance for the consortium. } \\
\text { The numerical value for the points-of-difference is represented by } \\
\text { the POD Index and is defined as: } \\
\qquad \boldsymbol{P O D I}(\boldsymbol{F}, \boldsymbol{Y}, \boldsymbol{G})=\frac{\Sigma_{1}^{m}(\boldsymbol{F a c t o r} \text { Score })}{\sum_{\mathbf{1}}^{n}(\boldsymbol{F} \text { actor Score })} * \frac{\boldsymbol{n}}{\boldsymbol{m}} \\
\qquad \mathrm{F}-\text { Factor } \\
\mathrm{Y}-\text { Consortium } Y \\
\mathrm{G}-\text { Sample group } G \\
\mathrm{~m} \text { - Number of organizations which are members of } Y \\
n-\text { Number of organizations which are not members of } Y\end{array}$ \\
\hline $\begin{array}{l}\text { Salient } \\
\text { Construct }\end{array}$ & $\begin{array}{l}\text { The criterion for a salient construct is defined as follows: } \\
\qquad \text { PODI }>1.5 \\
\text { The criterion is based on the assumption that a consortium's } \\
\text { members with a factor that is } 50 \% \text { larger than the rest of the } \\
\text { sample is sufficiently large to be indicative of a salient construct. }\end{array}$ \\
\hline $\begin{array}{l}\text { Construct } \\
\text { PODI List }\end{array}$ & $\begin{array}{l}\text { It is used to rank consortia based on one construct. } \\
\text { It is defined as a ranked list of POD Indexes for a factor in a } \\
\text { sample group for all consortia: } \\
\text { \{ PODI }\left(\mathbf{F}_{\mathbf{x}}, \mathbf{A}_{\mathbf{1}}, \mathbf{S}\right), \ldots \text {, PODI }\left(\mathbf{F}_{\mathbf{x}}, \mathbf{A}_{9}, \mathbf{S}\right) \text { \} } \\
\qquad \mathbf{F}_{\mathbf{x}} \text { - Factor } \mathrm{X} \text { in sample } \mathrm{S} \\
\text { A - Consortium: } \\
\text { WiMAX, GSMA, UMTS, CDG, CCF, } \\
\text { LSTI, NGMN, WBA, OPA } \\
\text { S - Sample Group: E, F, G, H or I }\end{array}$ \\
\hline Cons & n. \\
\hline
\end{tabular}




\begin{tabular}{|c|c|}
\hline t & Des \\
\hline & $\begin{array}{l}\text { It is defined as a ranked list of POD Indexes for all factors in a } \\
\text { sample group for one consortium: } \\
\left.\text { \{ PODI }\left(F_{1}, A_{x}, \mathbf{S}\right), \ldots, \text { PODI }\left(F_{n}, A_{x}, S\right)\right\} \\
F_{n}-\text { All factors in sample } S \\
A_{x} \text { - One of the: } \\
\text { WiMAX, GSMA, UMTS, CDG, CCF, } \\
\text { LSTI, NGMN, WBA, OPA } \\
\text { S - Sample Group: E, F, G, H or I }\end{array}$ \\
\hline $\begin{array}{l}\text { Salient } \\
\text { Construct } \\
\text { Groups }\end{array}$ & $\begin{array}{l}\text { Several salient constructs can be used together at the same time } \\
\text { only if they do not correlate. } \\
\text { In cases where one consortium has more than one construct that } \\
\text { satisfies the criteria for a salient construct (PODI > 1.5) then } \\
\text { these constructs can be used together only if they are not } \\
\text { correlated. The lack of correlation is indicated by the fact that } \\
\text { there is at least one factor analysis solution that includes these } \\
\text { factors. } \\
\left.\left\{\text { PODI ( } F_{1}, A, S\right), \ldots, \text { PODI }\left(F_{x}, A, S\right)\right\} \\
F_{1}, \ldots, F_{x} \text { are factors in at least one factor analysis solution } \\
\text { in sample group } S \text {, for consortium } A \text {. }\end{array}$ \\
\hline
\end{tabular}

A graphical representation for the PODI Lists is shown in Figure 6: 


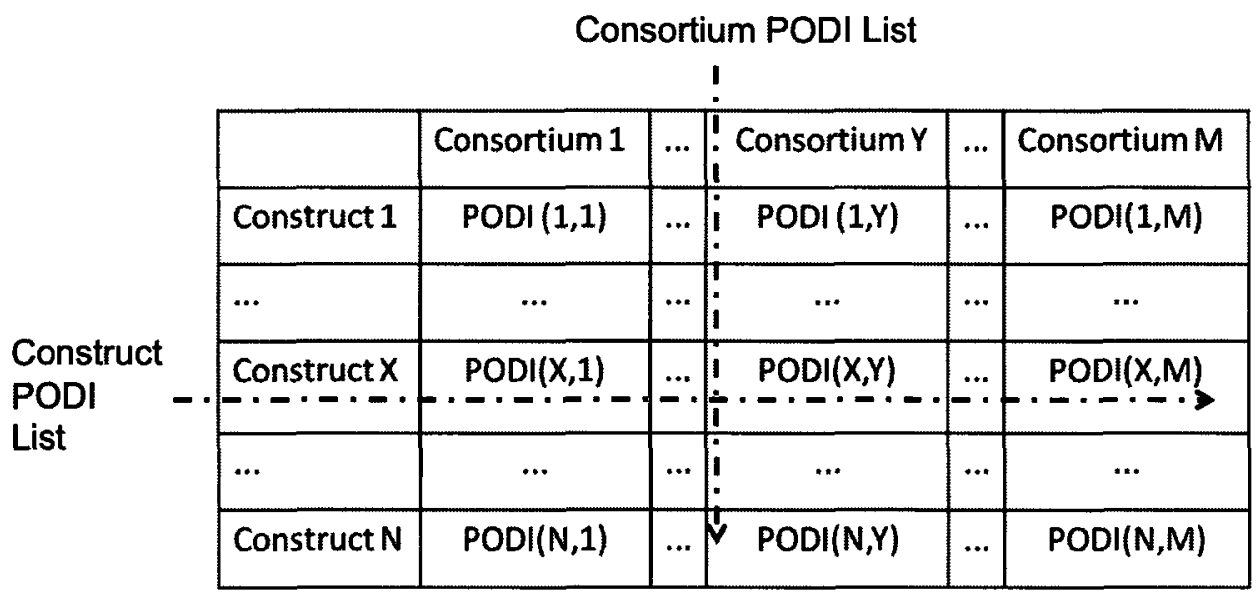

Figure 6: Construct and Consortium PODI Lists

In summary, the points-of-difference term refers to the favourable points of difference (Anderson et al., 2006) and is defined by the groups of salient constructs:

Points of Difference $(P O D)=$ Groups of Salient Constructs 


\section{Research Results}

This chapter is comprised of eight sections. Section 4.1 discusses the research sample. Section 4.2 explains the multiple samples. Section 4.3 presents the keywords and the samples. Section 4.4 presents the constructs identified from the factor analysis. Section 4.5 identifies the constructs. Section 4.6 presents the consortia points of difference. The multiple membership ranking is presented for several factors in Section 4.7. A visualization of the construct groups is presented in Section 4.8.

\section{1 Research Sample}

Focusing on the diversity of the sample the study selected consortia that: (1) represent organizations with interests in the major wireless technologies in the last twenty years: GSM, CDMA, UMTS, WiMAX and LTE, (2) use the main wireless communication standards: 3GPP, 3GPP2 and IEEE 802.16, and (3) have different sizes.

Based on these recommendations, the selected organizations are members of 9 consortia4: GSM Association (GSMA), CDMA Development Group (CDG), UMTS Forum, WiMAX Forum, LTE/STI Trial Initiative, Next Generation Mobile Networks (NGMN), Wireless Broadband Alliance (WBA), CDMA Certification Forum (CCF) and Open Patent Alliance (OPA).

From the complete list of members found on the consortia web sites, the selected organizations have a good description in "About Us", and contained at

\footnotetext{
${ }^{4}$ Based on the membership analyzed in January 2010
} 
least ten pages in English, to avoid spurious results caused by sites with minimal content (i.e. few keyword hits). From this population an initial research sample of 889 organizations was extracted. When compiling the dataset, an organization was identified as a member of one or more of the selected consortia.

The GSM Association ${ }^{5}$ (GSMA) was launched in 1987 and represents the interests of the worldwide mobile communications industry involved in GSM and 3GSM (WCDMA). With members from 219 countries, nearly 800 of the world's mobile operators, and more than 200 companies in the broader mobile ecosystem, including handset makers, software companies, equipment providers, Internet companies, and media and entertainment organisations, the GSMA is "focused on innovating, incubating and creating new opportunities for its membership, all with the end goal of driving the growth of the mobile communications industry"

The CDMA Development Group ${ }^{7}$ (CDG), founded in 1993, is an international consortium of 121 companies who have joined together to lead the adoption and evolution of CDMA wireless systems around the world. The CDG is comprised of CDMA service providers and manufacturers, application developers and content providers, who work together to ensure the interoperability among systems, while expediting the availability of CDMA technology to consumers ${ }^{8}$.

\footnotetext{
${ }^{5} \mathrm{http} / /$ www gsmworld.com, last accessed July 10, 2010

6 http.//www.gsmworld com/about-us/Index.htm, last accessed July 10, 2010

7 http //www.cdg.org, last accessed July 10, 2010

$8 \mathrm{http} / /$ www.cdg.org/about/index.asp, last accessed July 10, 2010
} 
The CDMA Certification Forum ${ }^{9}$ (CCF) is a partnership between CDMA operators and CDMA device vendors to establish and maintain a core global device certification process that helps improve quality through consistent interoperability, conformance and performance testing. Currently it has 58 members ${ }^{10}$.

The UMTS Forum ${ }^{11}$ is a non-profit organization founded in 1996 to help its members "understand and profit from the opportunities of 3G/UMTS networks and their Long Term Evolution (LTE)". The forum supports the interests of its membership with a range of studies and reports on markets trends, mobile broadband services and applications, key growth markets, spectrum and regulation, technology and implementation. Currently the forum has 38 members $^{12}$

The WiMAX Forum ${ }^{13}$ is an industry-led, not-for-profit organization formed to certify and promote the compatibility and interoperability of broadband wireless products based upon the harmonized IEEE 802.16/ETSI HiperMAN standard. The WiMAX Forum's goals are to accelerate the introduction of these systems into the marketplace and to ensure that the products are fully interoperable and support broadband fixed, portable and mobile services. The WiMAX Forum works with service providers and regulators to ensure that its certification programs meet customer and government requirements. The forum was

\footnotetext{
${ }^{9} \mathrm{http} / / /$ www.globalccf.org, last accessed July 10, 2010

${ }^{10} \mathrm{http}: / / \mathrm{www}$.globalccf org/about us.php, last accessed July 10, 2010

${ }_{11} \mathrm{http} / / \mathrm{www}$ umts-forum.org, last accessed July 10, 2010

${ }_{12} \mathrm{http://www.umts-forum.org/content/view/2002/125/,} \mathrm{last} \mathrm{accessed} \mathrm{July} \mathrm{10,} 2010$

${ }^{13}$ http://www.wimaxforum org, last accessed July 10, 2010
} 
launched in 2001 and today has more than 500 members involved in 592 WiMAX network deployments, in 148 countries $^{14}$.

The WBA ${ }^{15}$ (Wireless Broadband Alliance) was founded in 2003 and it currently has 36 members from leading operators offering wireless services across $\mathrm{Wi}-\mathrm{Fi}$, WiMAX and Mobile broadband networks and roaming providers ${ }^{16}$.

The NGMN $^{17}$ (Next Generation Mobile Networks) is an alliance between the major mobile service providers that was formed in 2006 to define the requirements and recommendations for the next-generation broadband wireless networks. Its mandate is to complement and support the work provided by the standardization bodies. Currently the alliance has 58 members $^{18}$

The LSTI Forum ${ }^{19}$ (Long Term Evolution / System Architecture Evolution Trial Initiative) is a global, collaborative technology trial initiative focused on accelerating the availability of commercial and interoperable next generation LTE mobile broadband systems. One of the stated goals of the forum is to "develop an open industry ecosystem by involving all stakeholders (manufacturers, operators, regulators, research community, and application developers) in the process". Launched in 2007, today the forum has 40 members ${ }^{20}$.

\footnotetext{
${ }^{14} \mathrm{http}: / / \mathrm{www}$ wimaxforum.org/about, last accessed July 10, 2010

${ }_{15} \mathrm{http} / / \mathrm{www}$ wballiance.net, last accessed July 10, 2010

${ }_{16} \mathrm{http}: / / \mathrm{www}$.wballiance.net/history.html, last accessed July 10, 2010

${ }_{17} \mathrm{http://www.ngmn.org,} \mathrm{last} \mathrm{accessed} \mathrm{July} \mathrm{10,} 2010$

${ }_{18} \mathrm{http}: / / w w w$ ngmn.org/aboutus.html, last accessed July 10, 2010

${ }_{19}^{19} \mathrm{http}: / /$ www.lstiforum.org, last accessed July 10, 2010

${ }^{20}$ http.//www.Istıforum.org/about//ntro.html, last accessed July 10, 2010
} 
The OPA ${ }^{21}$ (Open Patent Alliance) was formed in 2008 "to foster a global ecosystem that will help ensure the successful and broad adoption of $4 \mathrm{G}$ wireless" by creating a fair, transparent and balanced IPR licensing structure to accelerate the global adoption of WiMAX, which will significantly lower the barriers to entry for those companies wishing to develop innovative technologies using WiMAX. It currently has 12 members ${ }^{22}$.

Organizations with websites with less than 10 web pages were excluded from the sample to avoid spurious results caused by sites with minimal content (i.e. few keyword hits), resulting in the initial research sample, named Group I, consisting of 736 organizations from 9 consortia as indicated in Table 5.

Table 5: Consortia Membership

\begin{tabular}{|l|c|c|c|c|c|c|c|c|c|}
\hline Consortium & WIMAX & GSMA & CDG & NGMN & CCF & LSTI & UMTS & WBA & OPA \\
\hline Members & 346 & 265 & 111 & 54 & 47 & 39 & 36 & 32 & 12 \\
\hline $\begin{array}{l}\text { Percentage } \\
\text { of total [\%] }\end{array}$ & 47.01 & 36.01 & 15.08 & 7.34 & 6.39 & 5.30 & 4.89 & 4.35 & 1.63 \\
\hline
\end{tabular}

Note: some organizations are members of multiple consortia

Multiple sub-samples are used for further analysis as indicated in Section 4.2.

\section{2 Sub-sampling}

Typically, the use of factor analysis is performed on a selected sample that complies with a criterion that is tied later with the results. Our study contains a large number of heterogeneous companies and organizations that were

\footnotetext{
${ }^{21} \mathrm{http}: / /$ openpatentalliance.com, last accessed July 10, 2010

22 http.//openpatentalliance.com/about, last accessed July 10, 2010
} 
selected based solely on the membership in wireless industry consortia. The literature on content analysis of web pages using factor analysis provides little evidence of the effect of samples on the final result. This study uses multiple samples for two reasons: (i) capture as many diverse constructs as possible and (ii) provide a better understanding on the impact of samples on the results.

From the initial research sample (Group I) the sub-samples were obtained in 2 steps. A visual inspection of the table with the score results from the KSAT analysis suggests that there are "pockets" of organizations that share the same keywords with scores values in the same range. Based on this observation, in the first step, the keywords were grouped based on the quartile they belong to. This approach is similar to the four-point Likert scale used in questionnaires processed subsequently by factor analysis. The Q1, Q2, Q3 and Q4 are the four networks created based on the shared keyword in the four quartiles. An example is provided in Figure 7: the score for the keyword $\mathrm{K} 1$ is in the first quartile for the organizations $X 1$ and $X 2$. If $X 1(K 1)=q 1$ and $X 2(K 1)=q 1$ then $X 1$ and $X 2$ share an edge or a link in network $Q 1$.

$$
X 1(K 1)=q 1 \& X 2(K 1)=q 1=>Q 1(X 1, X 2)=1
$$

\begin{tabular}{|c|c|c|c|c|}
\hline & $\mathrm{k1}$ & $\mathrm{k} 2$ & $\mathrm{k3}$ & $\mathrm{k4}$ \\
\hline $\mathrm{x1}$ & $\mathrm{q} 1$ & $\mathrm{q} 3$ & $\mathrm{q} 4$ & $\mathrm{q} 1$ \\
\hline $\mathrm{x} 2$ & $\mathrm{q} 1$ & $\mathrm{q} 2$ & $\mathrm{q}^{4}$ & $\mathrm{q} 1$ \\
\hline $\mathrm{x3}$ & $\mathrm{q} 4$ & $\mathrm{q} 2$ & $\mathrm{q}^{4}$ & $\mathrm{q} 3$ \\
\hline $\mathrm{x4}$ & $\mathrm{q} 2$ & $\mathrm{q} 3$ & $\mathrm{q} 3$ & $\mathrm{q} 3$ \\
\hline
\end{tabular}

\begin{tabular}{|c|c|c|c|}
\hline $\mathbf{q 1}^{\prime}$ & $\mathbf{q}_{2}$ & $\mathbf{a} 3$ & $\mathbf{q 4}$ \\
\hline$\times 1 \times 22$ & $\times 2 \times 31$ & $\times 1 \times 41$ & $\times 1 \times 21$ \\
& & $\times 3 \times 41$ & $\times 1 \times 31$ \\
& & & $\times 2 \times 31$ \\
\hline
\end{tabular}

Figure 7: Networks Based on Keyword Scores 
In each of the four networks, the nodes are organizations with links based on the shared score of the keywords. $Q 1(X 1, X 2)=2$ indicates that $X 1$ and $X 2$ share 2 keywords with similar scores.

The second step in clustering is based on hierarchical decomposition - a concept built on the theory that 2 nodes in a network are similar if they share the same neighbors. This study used Pajek ${ }^{23}$ as the tool for creating the hierarchical decomposition in each of the Q1, Q2, Q3 and Q4 networks. The hierarchical decomposition is characterized by a dissimilarity index which defines the level of dissimilarity among the clusters created. It is up to the researcher to select the number of clusters created. As the generated clusters are used for further factor analysis, this study followed the recommendations of Costello and Osborne (2005) and aimed at obtaining clusters with at least 200 nodes. A dedrogram is the graphical representation of hierarchical decomposition and could help researcher in identifying the number of clusters to retain (de Nooy et al., 2005). As exemplified in Figure 8 , cluster $\mathrm{C} 1(\mathrm{X} 1, \mathrm{X} 2, \mathrm{X} 3, \mathrm{X} 4)$ is characterized by $\mathrm{Dc} 1$ dissimilarity index.

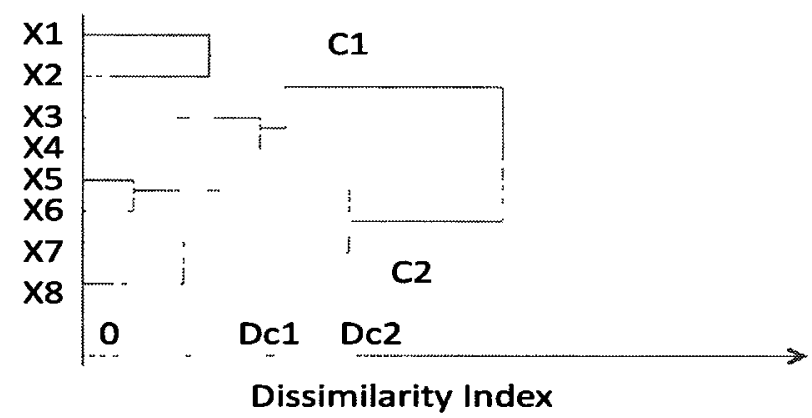

Figure 8: Clustering Dendrogram

${ }^{23}$ http.//pajek Imfm sl/doku.php 
The dissimilarity index is the control variable used in this study for creating the clusters used as sub-samples for further factor analysis. The results are presented in Table 6 and Table 7:

Table 6: Sub-sampling Step 1

\begin{tabular}{|c|c|c|c|}
\hline $\begin{array}{c}\text { Nr. Firms } \\
\text { Sample Group I }\end{array}$ & Group & Nr. Firms & Nr. Keywords \\
\hline \multirow{3}{*}{736} & Q1 & 508 & 46 \\
\cline { 2 - 4 } & Q2 & 729 & 133 \\
\cline { 2 - 4 } & Q3 & 733 & 205 \\
\cline { 2 - 4 } & Q4 & 735 & 255 \\
\hline
\end{tabular}

Table 7: Sub-sampling Step 2

\begin{tabular}{|c|c|c|c|c|}
\hline $\begin{array}{c}\text { Q } \\
\text { Group }\end{array}$ & Partition & $\begin{array}{c}\text { Nr. } \\
\text { Firms }\end{array}$ & HDd1 & $\begin{array}{c}\text { Sub- } \\
\text { sample } \\
\text { Groups }\end{array}$ \\
\hline Q1 & P2 & 295 & 10.33 & A \\
\hline & P1 & 218 & 0.86 & B \\
\cline { 2 - 5 } & P2 & 269 & 0.59 & C \\
\cline { 2 - 5 } Q2 & P1 + P4 & 336 & 2.27 & D \\
\hline \multirow{3}{*}{ Q3 } & P1 & 312 & 0.18 & E \\
\cline { 2 - 5 } & P2 & 202 & 0.28 & F \\
\hline \multirow{3}{*}{ Q4 } & P1 & 305 & 0.36 & G \\
\cline { 2 - 5 } & P2 & 228 & 0.48 & H \\
\hline
\end{tabular}

Node: HDd1 = dissimilarity index for $\mathrm{d} 1$

For the complete results from the hierarchical decomposition see Appendix B: Hierarchical Decomposition.

The factor analysis was run for the initial research sample (Group I) and for every of the sub-sample groups: $A, B, C, D, E, F, G$ and $H$. The $E, F, G$ and $H$ groups produced multiple and meaningful factor analysis results and were 
retained for further study. The groups $E$ and $F$ do not share organizations and have a combined size of 514 . The organizations in Groups $G$ and $H$ are also different with a combined size of 533 . The sub-samples contain a total number of 611 organizations, while the initial sample, Group I, contains 736 organizations. A graphical view of the initial sample, Group I, and the subsamples, Groups $E, F, G$, and $H$ is presented next in Figure 9:

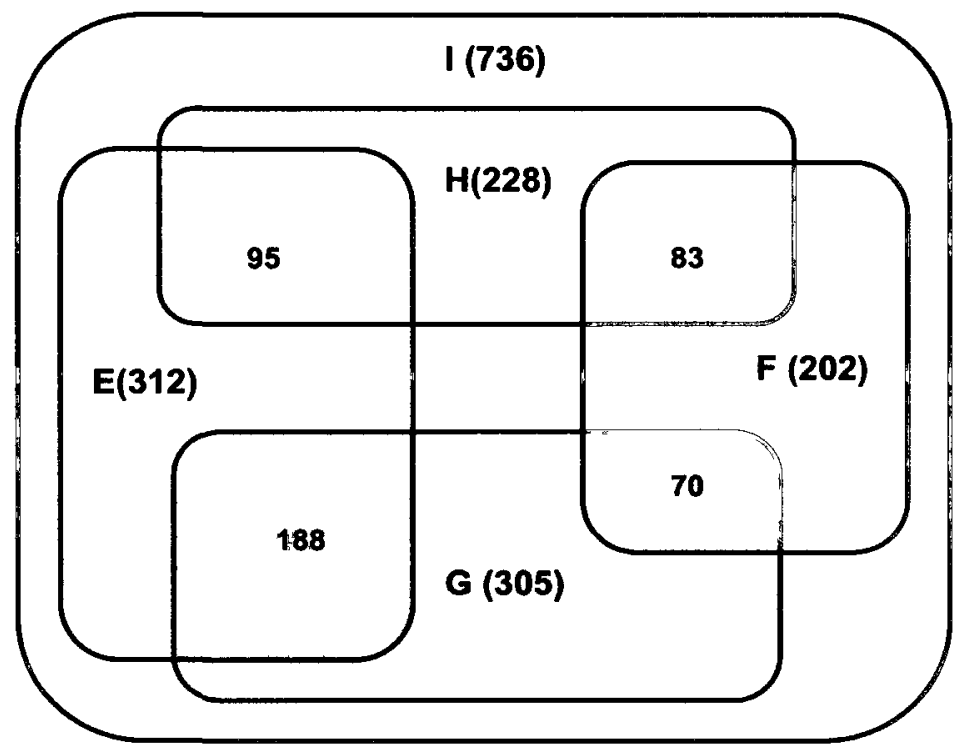

Figure 9: Sample I and sub-samples E, F, G, H

The list of organizations' website URLs, the split samples groups and the consortia they belong to is provided in Appendix A: URLs, Samples and Membership.

\section{3 Keyword Selection}

The initial list of keywords was selected based on the readings of mobile communication literature including published academic works as well as books, and from scanning the websites of the wireless industry consortia and their 
members. About 200 websites were analyzed representing $30 \%$ of the number of organization in the sample. These organizations were selected based on their identification as members of the wireless industry consortia, with proportional representation from each one. Additional criteria included organizations with various business models and diverse number of website pages.

Individual keywords were grouped into sets of synonyms using logical "OR" operations. In cases where a unique phrase was required instead of a single word, the phrase was delimited with quotation marks (")). The logical "AND" operator was used to strengthen the meaning of the individual keywords in cases where keywords were often used together in a context that offers a more meaningful interpretation.

After the preliminary 297 sets of keywords were defined, the list was rationalized by performing multiple factor extractions on groups E, F, G, H and I. The number of the sets of keywords retained from the solutions which complied with the recommended values for the determinant of the correlation matrix and the KMO tests are presented in Table 8 below:

Table 8: Number of keyword sets in each sample

\begin{tabular}{|c|c|c|l|}
\hline Group & Size & Keywords & \multicolumn{1}{c|}{ Nr. Factors (Keywords) } \\
\hline E & 312 & 53 & $\begin{array}{l}5(24), 5(24), 5(25), 5(24), 5(24), 5(23), 5(22), \\
5(23), 5(21), 5(22), 6(26)\end{array}$ \\
\hline & & & $\begin{array}{l}4(17), 4(16), 4(17), 4(17), 4(17), 4(16), 4(16), \\
4(17), 4(17), 5(22)\end{array}$ \\
\hline F & 202 & 48 & $5(22), 4(18), 6(25), 4(17), 4(17), 4(17), 4(16)$ \\
\hline G & 305 & 41 & $4(21), 4(21), 4(23), 3(18), 4(21)$ \\
\hline H & 228 & 38 & $4(30), 7(31), 8(33), 8(32), 8(31)$ \\
\hline I & 736 & 61 & $8(21$ \\
\hline
\end{tabular}


The Keyword Search and Analysis Tool is based on the Google Ajax Application Programming Interface (API) and counts the number of instances that each of the logical combinations of the keywords is found in the web pages at each site specified in the sample list. The tool also returns the total number of pages at each site and the normalized keyword frequency by dividing the keyword counts by the number of web pages found. The tool counts all instances of the keyword sets and can provide normalized keyword frequency in excess of $100 \%$. This is not an issue since the factor extraction is concerned with correlations and not with the specific value of an individual keyword frequency.

\section{4 Factor Analysis}

Both Kaiser's criterion and the Scree plot criteria were used for extracting the number of factors from the multiple factor analysis which were run on groups $E$, F, G, H and I. Group E, with a size of 312 and average commonalities between 0.59 and 0.62 , offers a sample large enough to allow reliance on the Scree plot. For group F, with a size of 202 and average commonalities above 0.7 (except for one analysis out of eight) only the factors with Eigenvalues above 1 were selected. Group G, with a size of 305 and average commonalities between 0.59 and 0.64 has a size large enough to allow reliance on the Scree plot. For the group $\mathrm{H}$, with a size of 228 and average commonalities between 0.58 and 0.61 only the factors with Eigenvalues above 1 were selected. For Group I, with a size of 736, the factors selected based on the Scree plot all have Eigenvalues above 1. 
Table 9: Factor Analysis Results

\begin{tabular}{|c|c|c|c|c|c|c|c|c|}
\hline Group & $\begin{array}{c}\text { Nr. } \\
\text { Firms }\end{array}$ & Solution & DCM & KMO & AVC & $\begin{array}{c}\text { Nr. } \\
\text { Keywords }\end{array}$ & $\begin{array}{c}\text { Nr. } \\
\text { Factors } \\
\end{array}$ & $\begin{array}{c}\text { Total } \\
\text { Variance (\%) }\end{array}$ \\
\hline \multirow{11}{*}{$E$} & \multirow{11}{*}{312} & 1 & $118 \mathrm{E}-05$ & 0772 & 0623 & 24 & 5 & 623 \\
\hline & & 2 & 6 49E-05 & 0756 & 0591 & 24 & 5 & 591 \\
\hline & & 3 & $151 \mathrm{E}-05$ & 0748 & 0599 & 25 & 5 & 599 \\
\hline & & 4 & $226 \mathrm{E}-05$ & 0732 & 0608 & 24 & 5 & 608 \\
\hline & & 5 & $211 \mathrm{E}-05$ & 0758 & 0614 & 24 & 5 & 614 \\
\hline & & 6 & $830 \mathrm{E}-05$ & 0751 & 0601 & 23 & 5 & 601 \\
\hline & & 7 & $820 \mathrm{E}-05$ & 0749 & 0622 & 22 & 5 & 621 \\
\hline & & 8 & $518 \mathrm{E}-05$ & 0761 & 0616 & 23 & 5 & 616 \\
\hline & & 9 & $100 \mathrm{E}-03$ & 0738 & 0585 & 21 & 5 & 585 \\
\hline & & 10 & $220 \mathrm{E}-05$ & 0772 & 0648 & 22 & 5 & 648 \\
\hline & & 11 & $360 \mathrm{E}-05$ & 0757 & 0604 & 26 & 6 & 604 \\
\hline \multirow{10}{*}{$F$} & \multirow{10}{*}{202} & 1 & $138 \mathrm{E}-05$ & 0772 & 0713 & 17 & 4 & 713 \\
\hline & & 2 & $305 \mathrm{E}-05$ & 0729 & 0727 & 16 & 4 & 726 \\
\hline & & 3 & 157 E-05 & 0755 & 0712 & 17 & 4 & 712 \\
\hline & & 4 & 2 29E-05 & 0755 & 0708 & 17 & 4 & 707 \\
\hline & & 5 & $351 \mathrm{E}-05$ & 076 & 0701 & 17 & 4 & 701 \\
\hline & & 6 & $196 \mathrm{E}-05$ & 0737 & 0727 & 16 & 4 & 726 \\
\hline & & 7 & $476 \mathrm{E}-05$ & 0747 & 0716 & 16 & 4 & 715 \\
\hline & & 8 & $484 \mathrm{E}-05$ & 0748 & 0681 & 17 & 4 & 681 \\
\hline & & 9 & 3 37E-05 & 0741 & 0689 & 17 & 4 & 689 \\
\hline & & 10 & $140 \mathrm{E}-05$ & 0797 & 0649 & 22 & 5 & 649 \\
\hline \multirow{7}{*}{ G } & \multirow{7}{*}{305} & 1 & 3 19E-05 & 0775 & 0642 & 22 & 5 & 642 \\
\hline & & 2 & $200 \mathrm{E}-03$ & 0767 & 0593 & 18 & 4 & 593 \\
\hline & & 3 & $711 \mathrm{E}-05$ & 0756 & 0612 & 25 & 6 & 612 \\
\hline & & 4 & $100 \mathrm{E}-03$ & 0792 & 0653 & 17 & 4 & 653 \\
\hline & & 5 & $100 \mathrm{E}-03$ & 0786 & 0644 & 17 & 4 & 643 \\
\hline & & 6 & $200 \mathrm{E}-03$ & 0762 & 0597 & 17 & 4 & 597 \\
\hline & & 7 & $100 \mathrm{E}-03$ & 0802 & 0658 & 16 & 4 & 658 \\
\hline \multirow{5}{*}{$\mathbf{H}$} & \multirow{5}{*}{228} & 1 & $274 \mathrm{E}-05$ & 0767 & 0612 & 21 & 4 & 612 \\
\hline & & 2 & $215 \mathrm{E}-05$ & 0766 & 0613 & 21 & 4 & 613 \\
\hline & & 3 & $127 \mathrm{E}-05$ & 0757 & 0584 & 23 & 4 & 584 \\
\hline & & 4 & $218 \mathrm{E}-05$ & 0795 & 061 & 18 & 3 & 61 \\
\hline & & 5 & $232 \mathrm{E}-05$ & 0791 & 0613 & 21 & 4 & 6132 \\
\hline \multirow{5}{*}{1} & \multirow{5}{*}{736} & 1 & $365 \mathrm{E}-05$ & 0742 & 0599 & 30 & 8 & 599 \\
\hline & & 2 & $398 \mathrm{E}-05$ & 0745 & 0569 & 31 & 7 & 568 \\
\hline & & 3 & 9 43E-05 & 0739 & 0565 & 33 & 8 & 565 \\
\hline & & 4 & $644 \mathrm{E}-05$ & 0761 & 0576 & 32 & 8 & 576 \\
\hline & & 5 & 9 20E-05 & 0696 & 0578 & 31 & 8 & 5775 \\
\hline
\end{tabular}


The factor analysis run in each group provided multiple solutions with unique factors which don't share any keywords across different solutions. This allowed for selecting the most appropriate solutions for final interpretation when the results from the main sample and its sub-samples were analyzed together. The number of factors retained for each factor analysis is presented in Table 9.

The determinant of the correlation table, the results of the Kaiser-Meyer-Olkin (KMO) measure of sampling adequacy and the Bartlett's significance tests are the criteria used for determining the success of the factor extraction. In order to avoid singularities (multicolinearity) in the correlation table the determinant must be greater than $1.0 \times 10^{-5}$ for effective factor extraction (Field, 2005). As shown in Table 9, the determinant of the correlation matrix (DCM) is greater than the minimum required for all solutions, indicating that the correlation data are of adequate quality for good factor extraction.

For the results to be considered statistically valid, the KMO measure of sampling adequacy must be larger than 0.5 (Field, 2005). In our study, the KMO is greater than the minimum required for all solutions, within the range 0.696 0.802. Field (2005) recommends that the values in the range $0.6-0.8$ be considered as "good". The Bartlett's test of sphericity must show a significance of less than 0.5 indicative of an adequate degree of correlation for the factor analysis to converge (Field, 2005). The result of 0.000 for all solutions indicates that data are well within the acceptance range to permit extraction of good factors. 
The amount of variance in each variable that can be explained by the retained factors is represented by the communalities after extraction. Together with the sample size it provides an indication of the reliability of the factor analysis. This research followed Costello and Osborne (2005) recommendation of keeping only the items with commonalities above 0.4 . The average communalities (AVC) for each factor extraction solution are presented in Table 9 and suggest that the analyses are adequate.

Rotation is used to simplify and clarify the data structure, by maximizing the loadings of the variables of all components without affecting the relative loadings of the variables. Most texts recommend the use of Varimax (orthogonal) rotation for uncorrelated components (Field, 2005). The total variance in our factor extraction solutions show that the factors extracted account in all cases for the majority of the variation in the data. Table 9 shows that the total variance in this study is in the range $56.5 \%-72.6 \%$.

Reinard (2006) recommends excluding variables with loadings less than 0.6 and cross-loadings larger than 0.4 from being used when interpreting the meaning of a factor. Costello and Osborne (2005) recommend a minimum loading of 0.32 and suggest that researchers should drop cross-loadings for factors with loaders greater than 0.5 . Stevens (2009) suggest that only variables with loadings larger than 0.4 should be considered for interpretation purposes based on the suggestion that a variable should share at least $15 \%$ of its variance with the factor. In this study only items with loadings greater than 0.5 and with crossloadings below 0.4 were retained. 
Costello and Osborne (2005) indicate that factors with fewer than three items are generally weak and unstable. A solid factor has 5 or more items with loadings greater than 0.5 . Stevens (2009) indicates that when the average of the four largest loadings is larger than 0.6 then the factors are reliable. In this research, the majority of the factors have at least three variables with loadings of 0.5 or greater, which indicates that most of the factors are solid with a few considered adequate.

The factor analysis solutions for Group $\mathrm{E}$ are presented in Table 10.

Table 10: Group E Factor Analysis Solutions

\begin{tabular}{|c|c|c|c|c|c|c|c|c|c|c|c|c|}
\hline Solution & \multicolumn{10}{|c|}{ Factors } \\
\hline 1 & E1 & E2 & E3 & E4 & E5 & & & & & & & \\
\hline 2 & & E2 & E3 & E4 & E5 & E6 & & & & & & \\
\hline 3 & & E2 & E3 & E4 & & E6 & E7 & & & & & \\
\hline 4 & & E2 & E3 & & & E6 & E7 & E8 & & & & \\
\hline 5 & & E2 & E3 & & & E6 & E7 & & E9 & & & \\
\hline 6 & & E2 & E3 & & & & E7 & & E9 & E10 & & \\
\hline 7 & & E2 & E3 & & & & E7 & & E9 & & E11 & \\
\hline 8 & & E2 & E3 & & & & E7 & & E9 & & & E12 \\
\hline 9 & & E2 & & E4 & & & & & E9 & E10 & E11 & \\
\hline 10 & E1 & E2 & & & & E6 & & & E9 & & E11 & \\
\hline 11 & E1 & & & E4 & & E6 & & & & E10 & E11 & E12 \\
\hline
\end{tabular}

The factor analysis solutions for Group F are presented in Table 11. 
Table 11: Group F Factor Analysis Solutions

\begin{tabular}{|c|c|c|c|c|c|c|c|c|c|c|c|}
\hline Solution & \multicolumn{10}{|c|}{ Factors } \\
\hline 1 & F1 & F2 & F3 & F4 & & & & & & & \\
\hline 2 & F1 & & F3 & F4 & F5 & & & & & & \\
\hline 3 & F1 & & F3 & & F5 & F6 & & & & & \\
\hline 4 & F1 & & F3 & & F5 & & F7 & & & & \\
\hline 5 & F1 & & F3 & & & & F7 & F8 & & & \\
\hline 6 & F1 & & F3 & & & & & F8 & F9 & & \\
\hline 7 & F1 & & F3 & & & & & F8 & & F10 & \\
\hline 8 & F1 & & F3 & & & & & & & F10 & F11 \\
\hline 9 & F1 & & F3 & F4 & & & & & & & F11 \\
\hline 10 & & F2 & F3 & & & F6 & & & F9 & F10 & \\
\hline
\end{tabular}

The factor analysis solutions for Group $\mathrm{G}$ are presented in Table 12.

Table 12: Group G Factor Analysis Solutions

\begin{tabular}{|c|c|c|c|c|c|c|c|c|c|c|}
\hline Solution & \multicolumn{10}{|c|}{ Factors } \\
\hline 1 & G1 & G2 & G3 & G4 & G5 & & & & & \\
\hline 2 & & G2 & G3 & G4 & & G6 & & & & \\
\hline 3 & G1 & G2 & G3 & G4 & & & G7 & G8 & & \\
\hline 4 & G1 & G2 & G3 & & & & & & G9 & \\
\hline 5 & G1 & G2 & G3 & & & & & & & G10 \\
\hline 6 & G1 & & & G4 & & & & & G9 & G10 \\
\hline 7 & G1 & & G3 & & G5 & & & & G9 & \\
\hline
\end{tabular}

The factor analysis solutions for Group $\mathrm{H}$ are presented in Table 13.

Table 13: Group H Factor Analysis Solutions

\begin{tabular}{|c|c|c|c|c|c|c|c|}
\hline Solution & \multicolumn{7}{|c|}{ Factors } \\
\hline 1 & $\mathrm{H} 1$ & $\mathrm{H} 2$ & $\mathrm{H} 3$ & $\mathrm{H} 4$ & & & \\
\hline 2 & $\mathrm{H} 1$ & $\mathrm{H} 2$ & & $\mathrm{H} 4$ & $\mathrm{H} 5$ & & \\
\hline 3 & & $\mathrm{H} 2$ & & & $\mathrm{H} 5$ & $\mathrm{H} 6$ & $\mathrm{H} 7$ \\
\hline 4 & $\mathrm{H} 1$ & & & & & $\mathrm{H} 6$ & $\mathrm{H} 7$ \\
\hline 5 & $\mathrm{H} 1$ & $\mathrm{H} 2$ & & $\mathrm{H} 4$ & & & $\mathrm{H} 7$ \\
\hline
\end{tabular}


The factor analysis solutions for Group I are presented in Table 14

Table 14: Group I Factor Analysis Solutions

\begin{tabular}{|c|c|c|c|c|c|c|c|c|c|c|c|c|c|c|c|}
\hline Solution & \multicolumn{10}{|c|}{ Factors } \\
\hline 1 & 11 & 12 & 13 & 14 & 15 & 16 & 17 & 18 & $\mid$ & & & & & & \\
\hline 2 & & & & & & & & & 19 & 110 & 111 & 112 & 113 & 114 & 115 \\
\hline 3 & $I 1$ & 12 & 13 & 14 & & 16 & & 18 & & 110 & & 112 & & & \\
\hline 4 & $I 1$ & 12 & 13 & 14 & & 16 & 17 & 18 & & 110 & & & & & \\
\hline 5 & $I 1$ & 12 & & 14 & 15 & 16 & & 18 & & & & 112 & & & 115 \\
\hline
\end{tabular}

For more details on the factor analysis results see Appendix C: Factor Analysis Results.

\subsection{Constructs}

The solutions retained from factor analysis identified factors corresponding to companies' business models, technologies and standards. Based on the knowledge about the industry and the definition of the keywords derived from the literature each factor was interpreted to produce a descriptive definition for each distinguishing characteristic of the wireless industry consortia.

The $P O D$ Index (factor, consortium, sample) is used to indicate the numerical importance for each factor, consortium and sample as defined in Section 3.11 . The Construct PODI List provides a ranked list of POD Indexes for all the factors comprising the construct. Similar factors from each sample are grouped together to form the following constructs: 


\section{Mobile Services}

Table 15: Mobile Services

\begin{tabular}{|c|c|}
\hline E1: Mobile Services (I) & G1: Mobile Services (II) \\
\hline $\begin{array}{l}\text { a) "mobile AND content AND delivery" } \\
\text { b) "mobıle AND services AND (commerce } \\
\text { OR billing)" } \\
\text { c) "(consulting OR engineering) AND } \\
\text { services" } \\
\text { d) "mobıle AND messaging AND services" } \\
\text { e) "customization OR customize OR } \\
\text { customized OR personalize OR Individualız" }\end{array}$ & $\begin{array}{l}\text { a) "(consulting OR engıneering) AND } \\
\text { services" } \\
\text { b) "mobile AND content AND delivery" } \\
\text { c) "database AND services" } \\
\text { d) "mobile AND services AND (commerce } \\
\text { OR billıng)" }\end{array}$ \\
\hline PODI(E1, All, E) & PODI(G1, All, G) \\
\hline 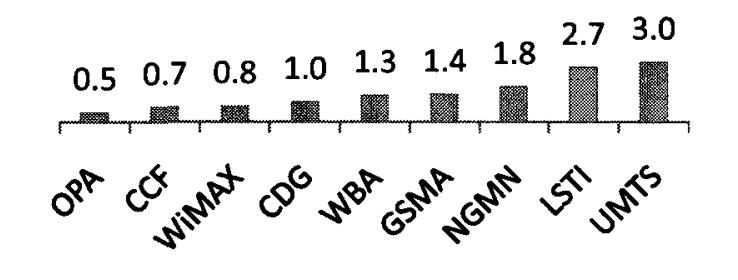 & 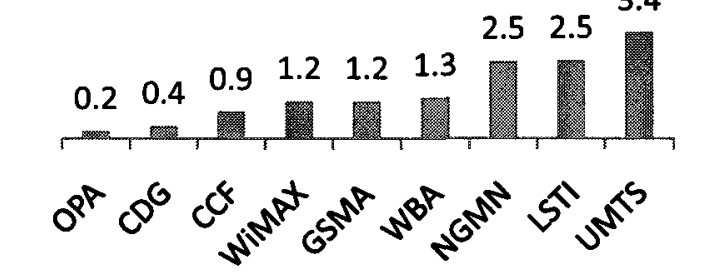 \\
\hline \multicolumn{2}{|c|}{ H6: Mobile Services (II) } \\
\hline $\begin{array}{l}\text { a) "mobile AND applications" } \\
\text { b) "mobile AND messaging AND services" } \\
\text { c) "device AND management" } \\
\text { d) "mobile AND services AND (commerce } \\
\text { OR billing)" } \\
\text { e) "mobile AND (advertising OR marketing)" } \\
\text { f) "(data OR voice) AND plans" } \\
\text { g) "(consulting OR engineering) AND } \\
\text { services" }\end{array}$ & 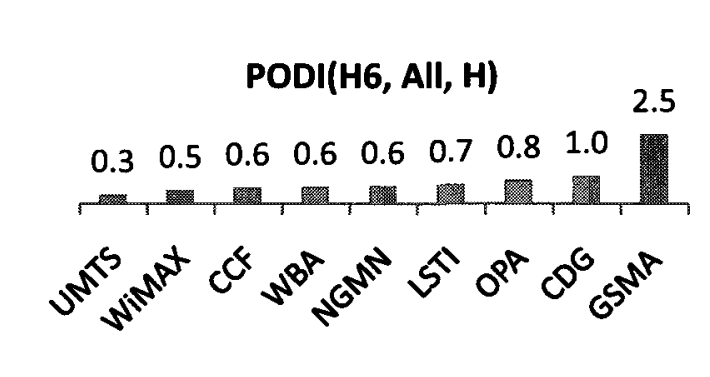 \\
\hline
\end{tabular}

The keywords in Table 15 represent services that enable network operators to efficiently manage and profit from mobile data services, content and commerce. The customized mobile services for messaging, commerce or billing are typically provided by the application or content providers. 
Testing Solutions

Table 16: Testing Solutions

\begin{tabular}{|c|c|}
\hline E2: Testing Solutions (I) & F9: Monitoring Solutions \\
\hline 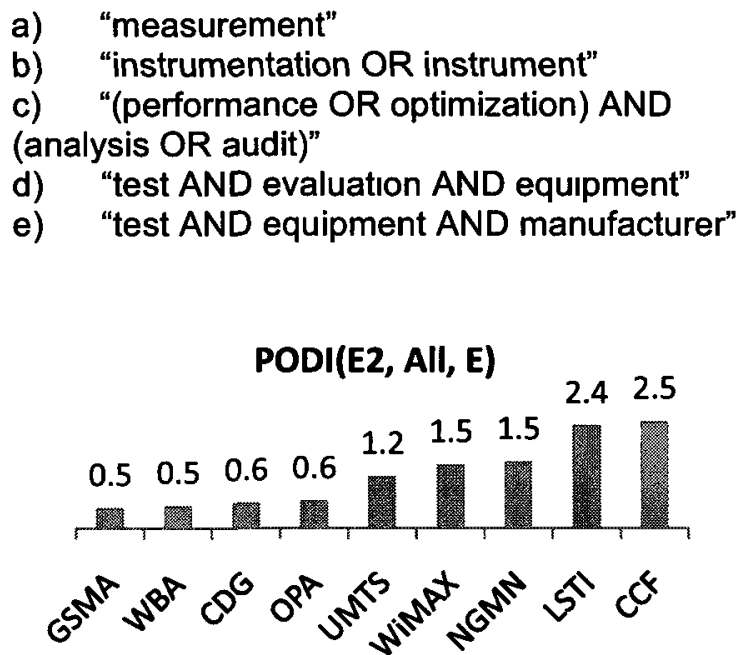 & $\begin{array}{l}\text { a) "solutions AND network AND monitoring } \\
\text { AND analysis" } \\
\text { b) "(performance OR optimization) AND } \\
\text { (analysıs OR audit)" } \\
\text { c) "solutions AND (telematics OR metering } \\
\text { OR tracking OR alarms OR monitoring)" } \\
\text { d) "automation" } \\
\text { PODI(F9, All, F) }\end{array}$ \\
\hline G10: Testing Solutions (II) & ions (III) \\
\hline 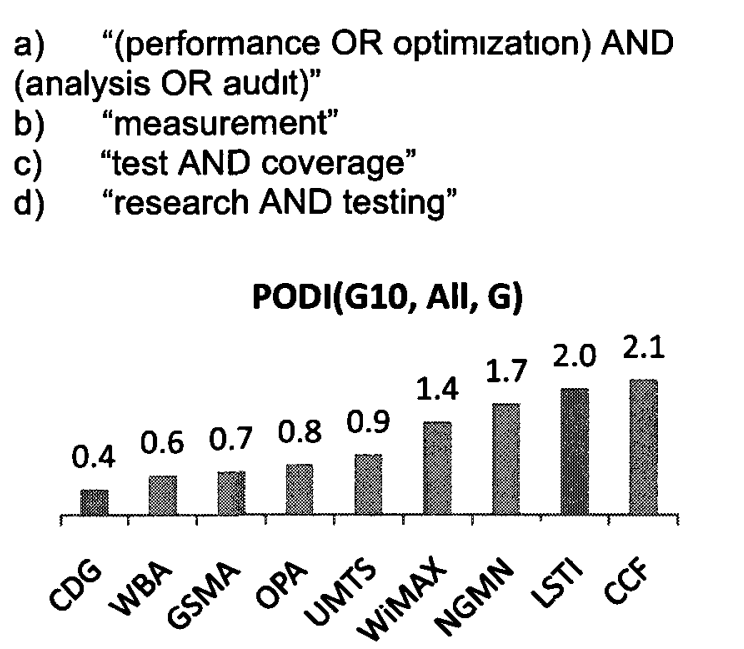 & 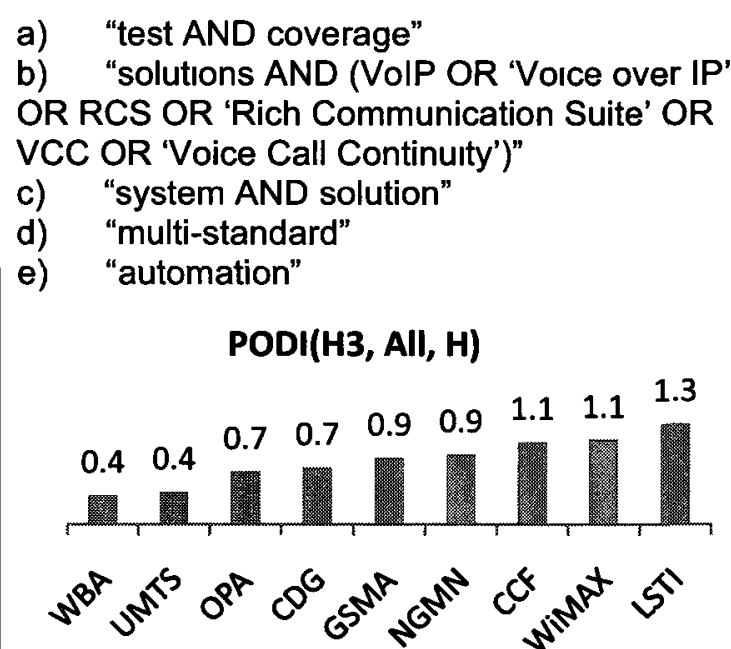 \\
\hline
\end{tabular}


113: Testing Solutions (IV)

a) "measurement"

b) "test AND equipment AND manufacturer"

c) "test AND evaluation AND equipment"

d) "(performance OR optımızation) AND

(analysis OR audit)"

e) "instrumentation OR instrument"

PODI(113, All, I)

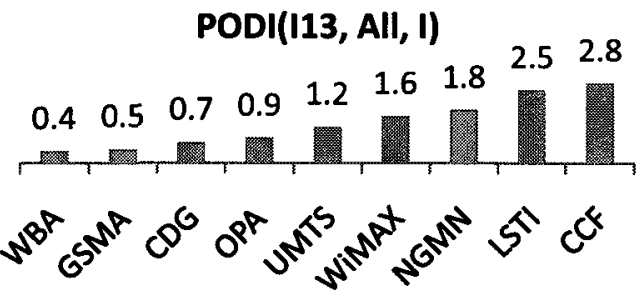

The keywords in Table 16 suggest that the test equipment manufacturers provide instrumentation that allows measurement, performance and optimization analysis for the infrastructure providers and network operators. The infrastructure provider and device manufacturers' equipment needs to be calibrated or certified for compliance before is accepted by the network operators. The service providers provide software systems for monitoring the mobile networks subscribers and customer's traffic flow. These solutions maximize network performance, provide monitoring and analysis tools for services and customer experience. The test coverage and automation for multistandard solutions is aimed at interoperability. This could help network operators expand their coverage for mobile operations.

\section{Fee Based Business Solutions}

The network operator is the link between the infrastructure provider and the end-user. A mobile phone network operator makes use of the infrastructure to provide mobile services to the end-user. The typical business models, identified in Table 17, are based on monthly fees from data and voice plans. 
Table 17: Fee Based Business Solutions

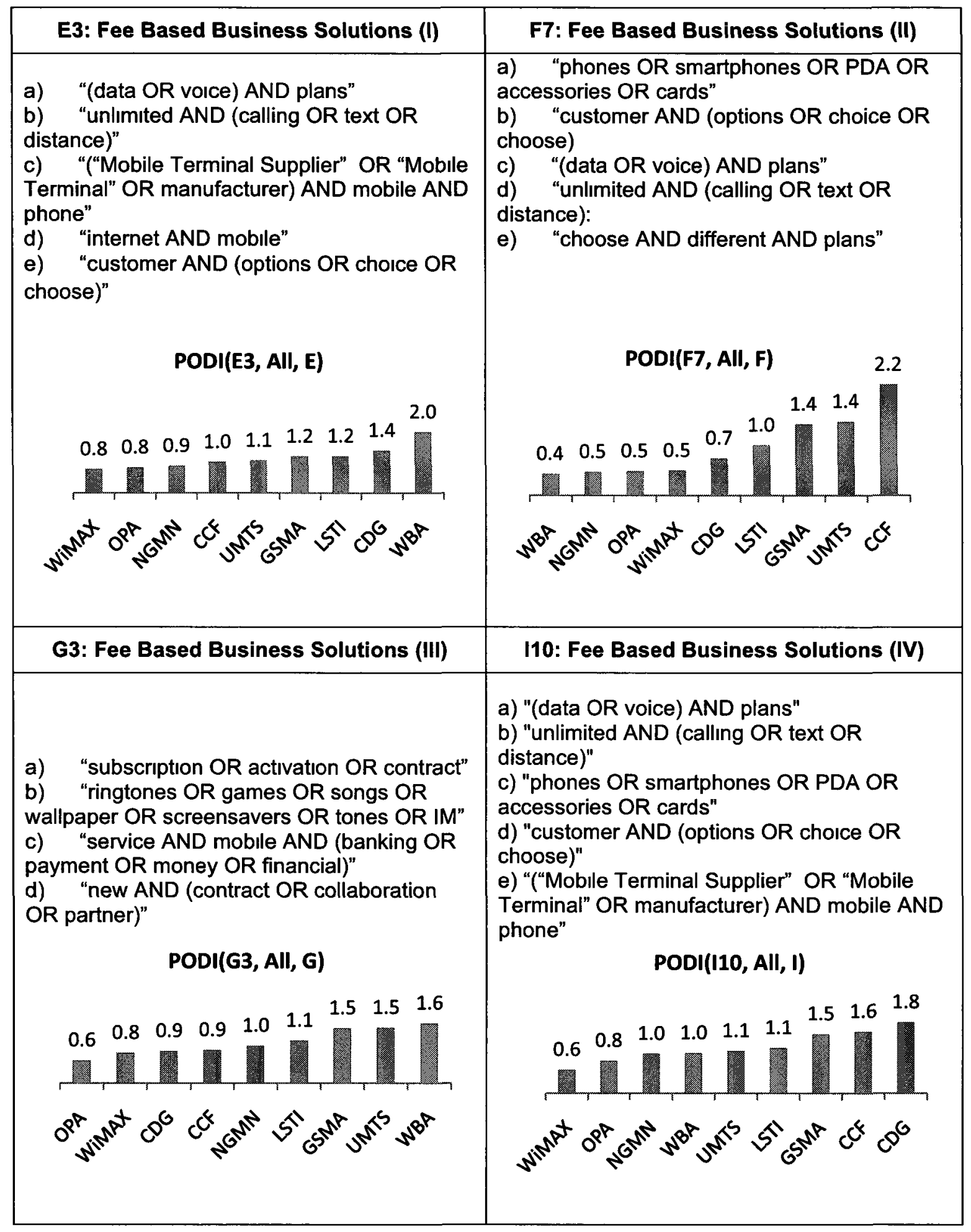




\section{WiMAX Technology and Standard}

Table 18: WiMAX Technology and Standard

\begin{tabular}{|c|c|}
\hline E4: WiMAX Technology and Standard (I) & I1: WiMAX Technology and Standard (II) \\
\hline $\begin{array}{l}\text { a) "WIMAX" } \\
\text { b) "TDD OR FDD" } \\
\text { c) "IEEE AND 802.16" } \\
\text { d) "ecosystem AND mobile AND } \\
\text { broadband" } \\
\text { e) "forum" }\end{array}$ & $\begin{array}{l}\text { a) "OFDMA OR 'Orthogonal Frequency Division } \\
\text { Multiple Access'"' } \\
\text { b) "IEEE AND } 802.16 " \\
\text { c) WiMAX } \\
\text { c) "'base station' OR 'base-station'" } \\
\text { e) "TDD OR FDD" }\end{array}$ \\
\hline 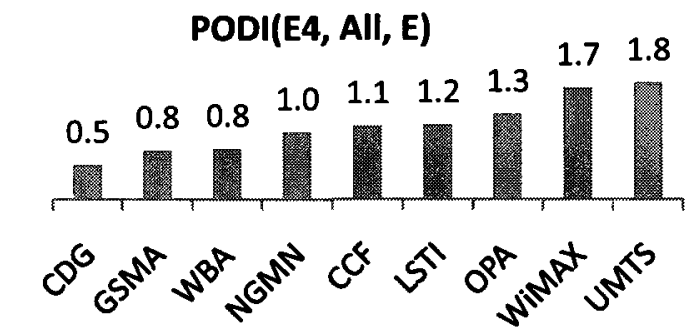 & 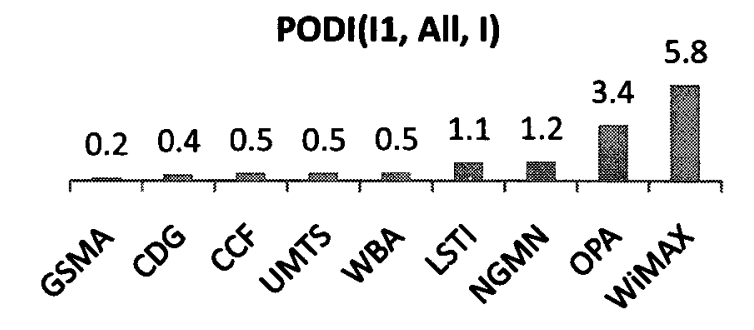 \\
\hline
\end{tabular}

The WiMAX Forum is a non-profit organization that lists about 500 companies with the stated goal of promoting the WiMAX standard, which was developed by the IEEE and also known as 802.16. TDD and FDD are variants of the technology. The WiMAX Forum acts as a keystone. The keywords identified in Table 18 characterize the members' support for the forum, technology and standards. 


\section{Hardware}

Table 19: Hardware

\begin{tabular}{|c|c|}
\hline E5: Hardware (I) & F4: Hardware (II) \\
\hline $\begin{array}{l}\text { a) "microprocessor OR processor OR } \\
\text { microcontroller OR DSP OR 'RF subsystem' } \\
\text { OR 'power management' OR chips OR } \\
\text { chipsets OR sensor" } \\
\text { b) "semiconductor" } \\
\text { c) "design" } \\
\text { d) "packagıng" }\end{array}$ & $\begin{array}{l}\text { a) "signal AND processing" } \\
\text { b) "microprocessor OR processor OR } \\
\text { microcontroller OR DSP OR 'RF subsystem' } \\
\text { OR 'power management' OR chips OR } \\
\text { chipsets OR sensor" } \\
\text { c) "multi-standard" } \\
\text { d) "'base station' OR 'base-station"” }\end{array}$ \\
\hline 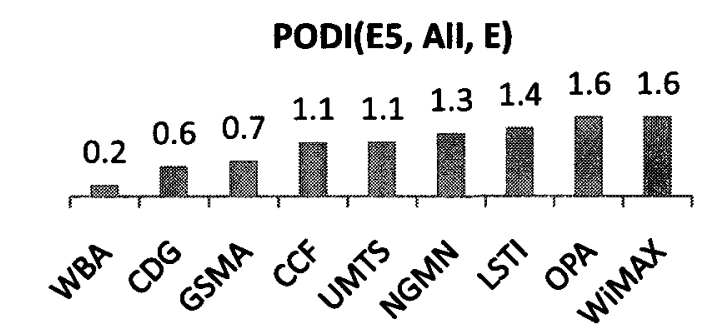 & 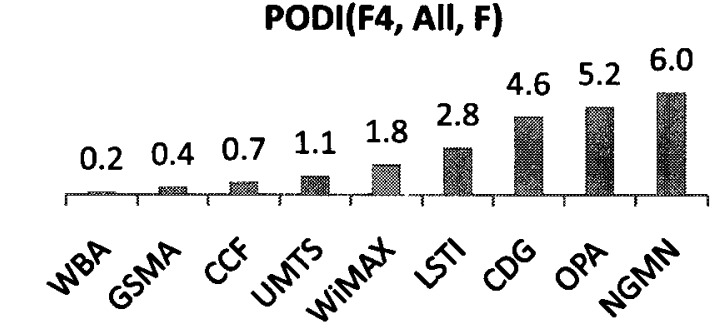 \\
\hline G6: Hardware (III) & I2: Hardware (IV) \\
\hline $\begin{array}{l}\text { a) "microprocessor OR processor OR } \\
\text { microcontroller OR DSP OR 'RF subsystem' } \\
\text { OR 'power management' OR chips OR } \\
\text { chipsets OR sensor" } \\
\text { b) "desıgn" } \\
\text { c) "(product OR process) AND (modularity } \\
\text { OR modular OR module)" } \\
\text { d) "system AND integration" }\end{array}$ & $\begin{array}{l}\text { a) "microprocessor OR processor OR } \\
\text { microcontroller OR DSP OR 'RF subsystem' } \\
\text { OR 'power management' OR chips OR } \\
\text { chipsets OR sensor" } \\
\text { b) "semiconductor" } \\
\text { c) "design" } \\
\text { c) "signal AND processıng" }\end{array}$ \\
\hline 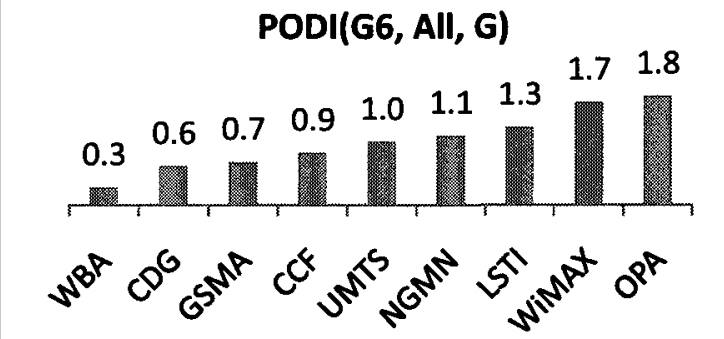 & 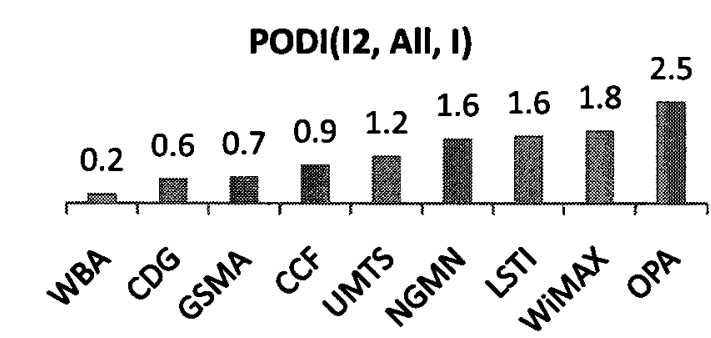 \\
\hline
\end{tabular}

The keywords in Table 19 represent the involvement of the mobile communication industry's infrastructure providers and device manufacturers in 
the design, packaging of semiconductors, integrated circuits, radio frequency (RF) and power management subsystems. The product or the process modularity is one indicator of efficiency and flexibility which are required in satisfying infrastructure provider or device manufacturer's needs for their cost reduction and flexibility. Some of the companies for which these factors are relevant are also involved in hardware for base stations - a term widely used by the wireless industry to denote the portion of the wireless network responsible for the communication over the air with the mobile user equipment.

\section{GPP Standard and LTE Technology}

The Long Term Evolution (LTE) has become the next generation $\left(4^{\text {th }}\right.$ generation or $4 G$ ), the convergence technology to which the current technologies will evolve to eventually, based on the involvement of the infrastructure providers and network operators worldwide. The major changes are at the "radio access" part of the network, which defines the connection over the air between the user equipment (the mobile) and the radio base station. The Multiple In Multiple Out (MIMO) or smart antenna allow for increased data rates between the base station and the mobile unit. The TDD and FDD are variants of the technology for over the air transmissions. The modularity, performance, and the cost effectiveness could be associated with the fact that the network architecture has become simpler, based on open standards, an all IP (Internet Protocol) network. The keywords identified in Table 20 characterize the members' support for the LTE technology and standards. 
Table 20: 3GPP Standard and LTE Technology

\begin{tabular}{|c|c|}
\hline E6: 3GPP Standard and LTE Technology (I) & F8: 3GPP Standard and LTE Technology (II) \\
\hline $\begin{array}{l}\text { a) 'Radio Access' } \\
\text { b) "LTE OR 'Long Term Evolution' OR } \\
\text { eUTRAN" } \\
\text { c) "3GPP" } \\
\text { d) "IMS OR 'IP Multimedia Subsystem"” } \\
\text { e) "(product OR process OR service) AND } \\
\text { (evolution OR evolve) }\end{array}$ & $\begin{array}{l}\text { a) "3GPP" } \\
\text { b) "MIMO OR 'smart antenna"” } \\
\text { c) "LTE OR 'Long Term Evolution' OR } \\
\text { eUTRAN" } \\
\text { d) "TDD OR FDD" }\end{array}$ \\
\hline 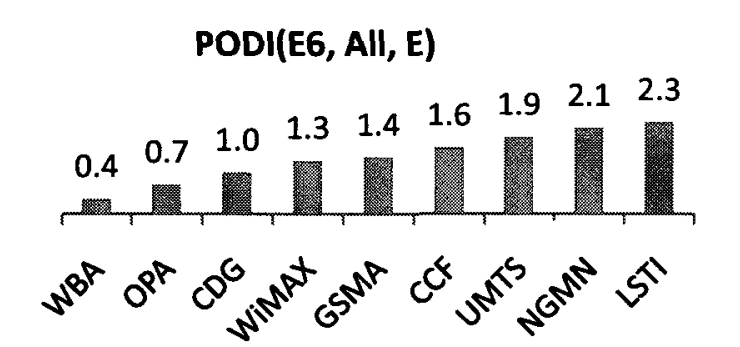 & 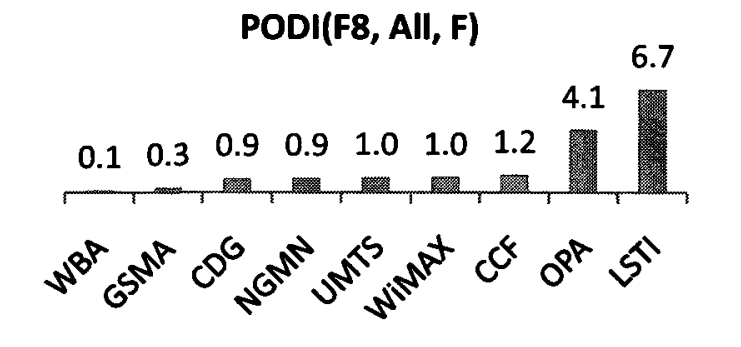 \\
\hline $\begin{array}{l}\text { H2: 3GPP Standard and LTE Technology } \\
\text { (III) }\end{array}$ & 17: 3GPP Standard and LTE Technology (IV) \\
\hline $\begin{array}{l}\text { a) 'Radio Access' } \\
\text { b) "LTE OR 'Long Term Evolution' OR } \\
\text { eUTRAN" } \\
\text { c) "3GPP" } \\
\text { d) "IMS OR ‘IP Multimedia Subsystem'” } \\
\text { e) "(product OR process OR service) AND } \\
\text { (evolution OR evolve)" }\end{array}$ & $\begin{array}{l}\text { a) "LTE OR 'Long Term Evolution' OR } \\
\text { eUTRAN" } \\
\text { b) "3GPP" } \\
\text { c) "MIMO OR 'smart antenna"' }\end{array}$ \\
\hline 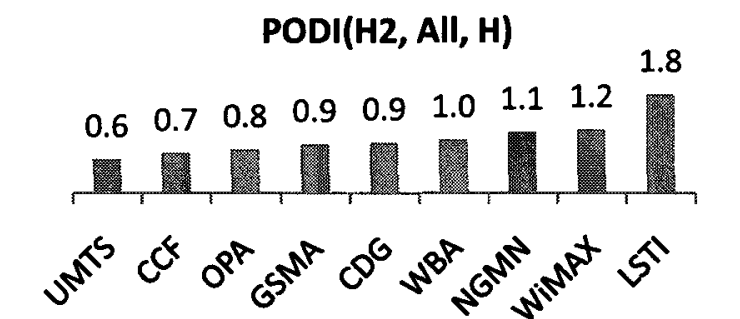 & 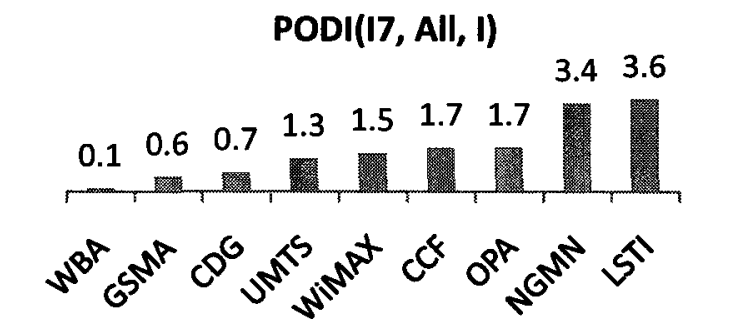 \\
\hline
\end{tabular}




\section{Revenue Management Solutions}

Table 21: Revenue Management Solutions

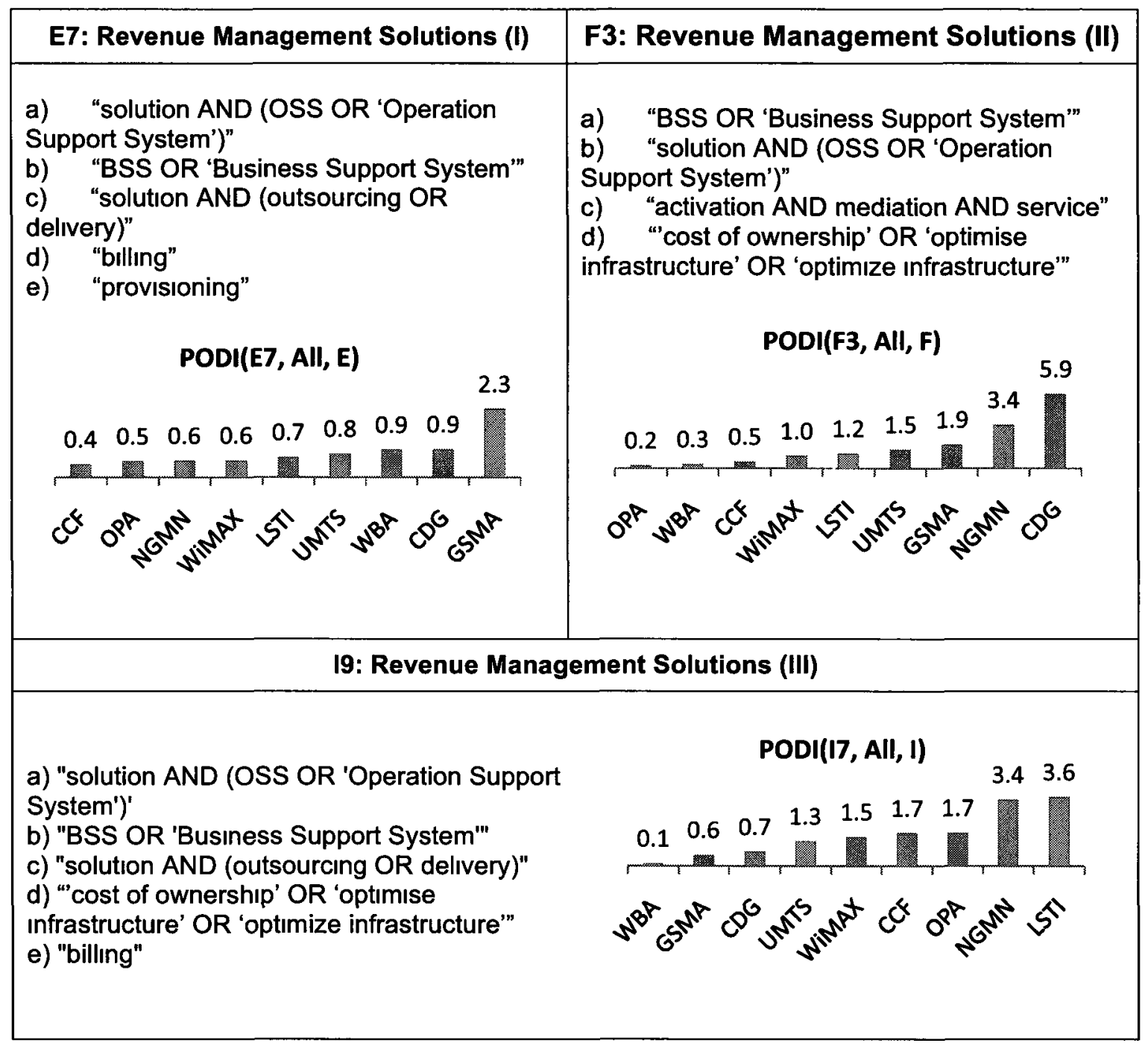

The "Revenue Management Solutions" factors are specific to service and billing providers $^{24}$. Service and billing providers provide software systems necessary for provisioning, billing, and customer service. These backend systems enable the operators to monetize the products and services they offer. These solutions provide provisioning automation, revenue assurance, cost management, billing,

${ }^{24}$ http://www.ossbssworld.com/ 
and subscriber management. These factors indicated that the ability to seamlessly provision and price new, bundled services is important. The providers of Operations and Business Support Systems offer solutions to the network operators to improve the operational efficiency and control. These business models are represented by the keywords indicated in Table 21.

\section{Security Solutions}

The providers of security solutions offer security protection at the corporate and consumer level against the threat of mobile viruses, malware, inappropriate content, unsolicited communications and spam at a corporate and consumer level; the digital signature, authentication and authority are part of the language used in these solutions. These keywords are captured in the factors shown in Table 22. 
Table 22: Security Solutions

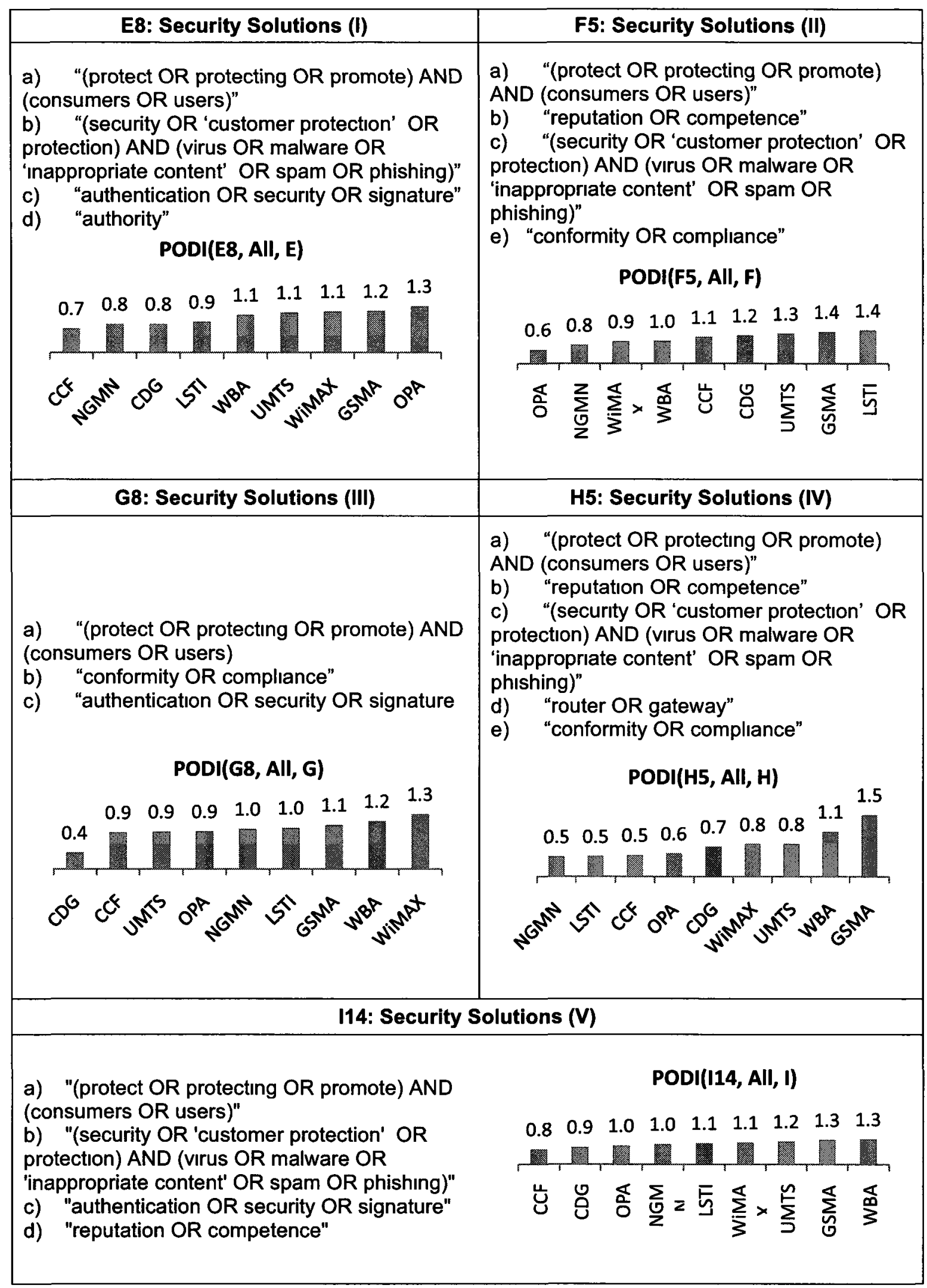




\section{Interoperability Solutions}

Table 23: Interoperability Solutions

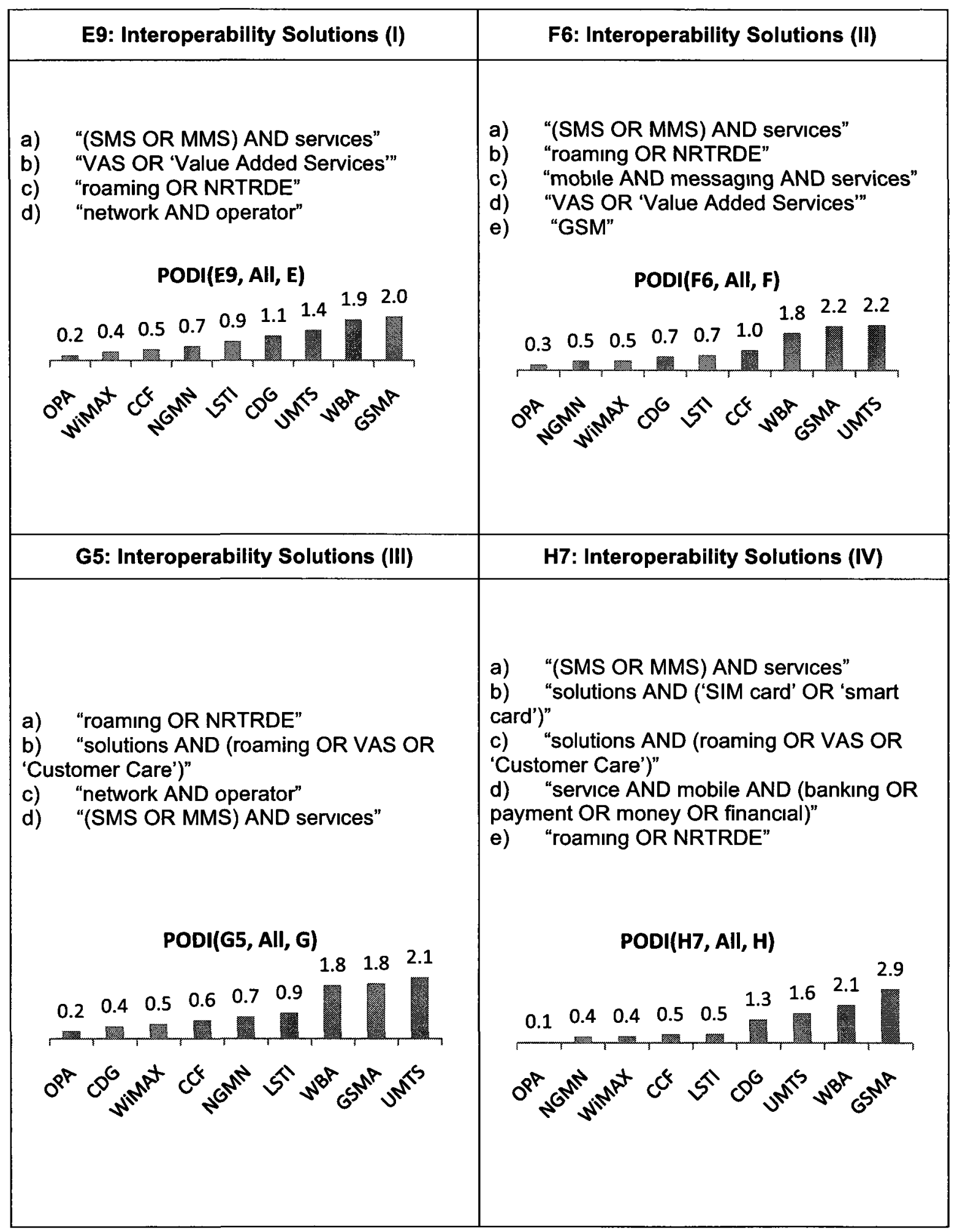


PODI(I12, All, I)

a) "(SMS OR MMS) AND services"

b) "VAS OR 'Value Added Services'"

c) "roaming OR NRTRDE"

d) "solutions AND (roaming OR VAS OR 'Customer Care"'

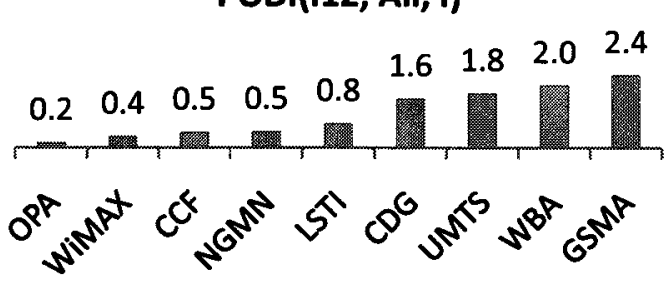

The text messaging (SMS) and multimedia messaging (MMS) services require interoperability solutions when moving from one operator to the other or from one technology to another (e.g. CDMA and GSM). These services also allow the message conversion to and from various formats. These solutions are designed to enable mobile network operators to make more profits out of messaging. For the mobile operators interested to manage large-scale Value Added Services (VAS) applications based on SMS, MMS, WAP and Voice, the providers offer complete solutions. The application providers help mobile operators and service providers to reduce customer care costs and increase revenues from advanced data services such as over the air configuration of terminals, service agreement updates, administration tools, etc. The Near Real Time Roaming Data Exchange (NRTRDE) is a platform for roaming management that provides immediate access to the critical information needed to combat roaming fraud; NRTRDE was introduced by one of the working groups in the GSM Association. These interoperability indicators are captured by the factors shown in Table 23. 


\section{Reputation}

Table 24: Reputation

\begin{tabular}{|c|c|}
\hline E10: Reputation (I) & G7: Reputation (II) \\
\hline $\begin{array}{l}\text { a) "reputation OR competence" } \\
\text { b) "agreement" } \\
\text { c) "governance OR govern" } \\
\text { d) "regulator OR regulate OR supervise OR } \\
\text { regulation OR regulatory" }\end{array}$ & $\begin{array}{l}\text { a) "reputation OR competence" } \\
\text { b) "governance OR govern" } \\
\text { c) "agreement" } \\
\text { d) "regulator OR regulate OR supervise } \\
\text { OR regulation OR regulatory" }\end{array}$ \\
\hline PODI(E10, All, E) & PODI(G7, All, G) \\
\hline 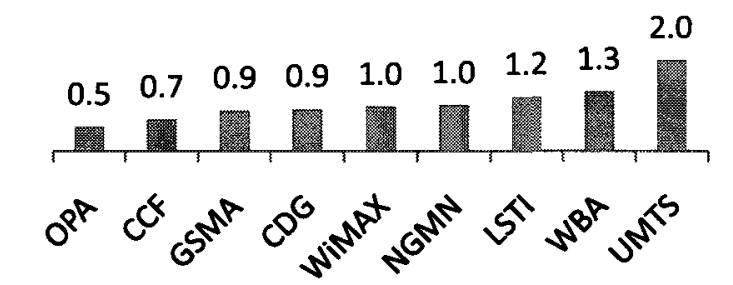 & 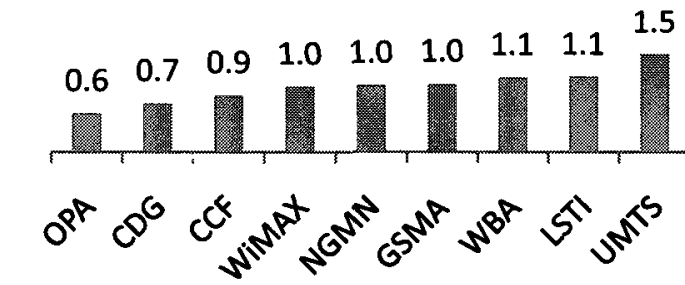 \\
\hline
\end{tabular}

Sociological studies on market competition (Podolny, 2005) indicate that under conditions of market uncertainty the reputation and the status of a firm play an important role in its success. Among the main players in the mobile communication industry the application developers and content providers face the highest levels of rivalry (Teo, 2001). The reputation indicators are captured by the "Reputation" factor as shown in Table 24. 


\section{Research}

Table 25: Research

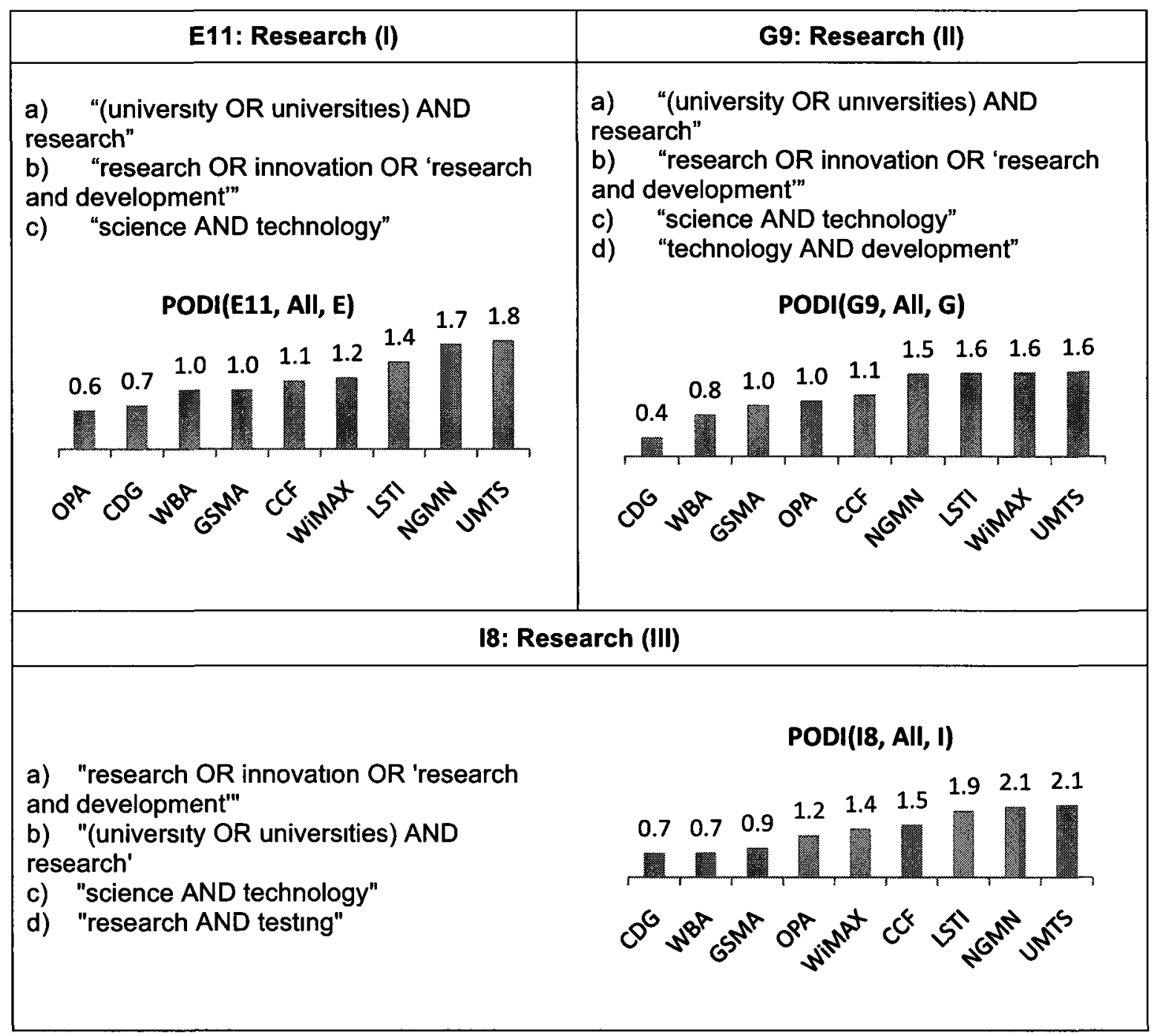

The keywords in Table 25 identify research and innovation as a characteristic of the technology organizations and universities with ties in the mobile communication industry. The factors indicate that organizations are involved in the research and development of the new wireless technologies. 
3GPP Standard and 3G Technologies Evolution

Table 26: 3GPP Standard and 3G Technologies Evolution

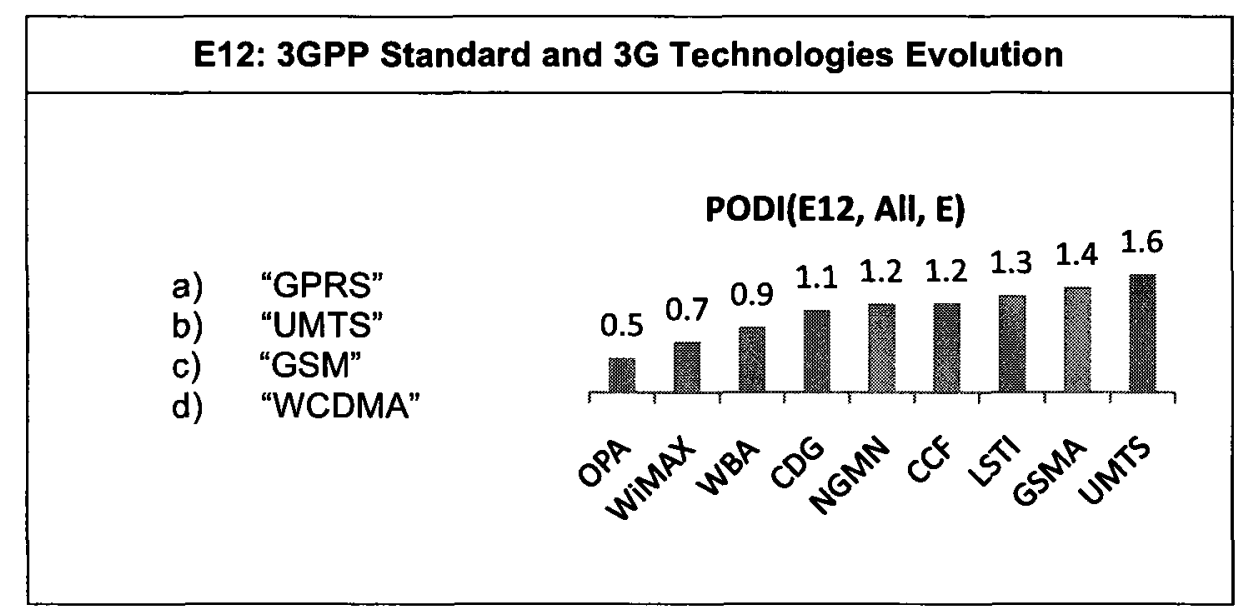

The 3GPP 3G standards cover the technology evolution from GSM, GPRS to UMTS/WCDMA over the last two decades. The organizations for which the component is relevant could indicate continuous involvement with these technologies as indicated in Table 26.

\section{Fraud Detection}

Fraud monitoring and detection are some of the solutions offered by firms involved in the testing and improving of the communication quality. The web pages of the organizations that this study analyzed also indicates that for the companies involved in roaming, the exchange of information related to user's access to other networks require fraud monitoring and analysis. Factor F1 also includes a keyword identifying the GSM Association. This fact confirms that these solutions are provided to the operators to enable the operators monetize 
the services they offer. Table 27 shows the keywords identified for this component.

Table 27: Fraud Detection

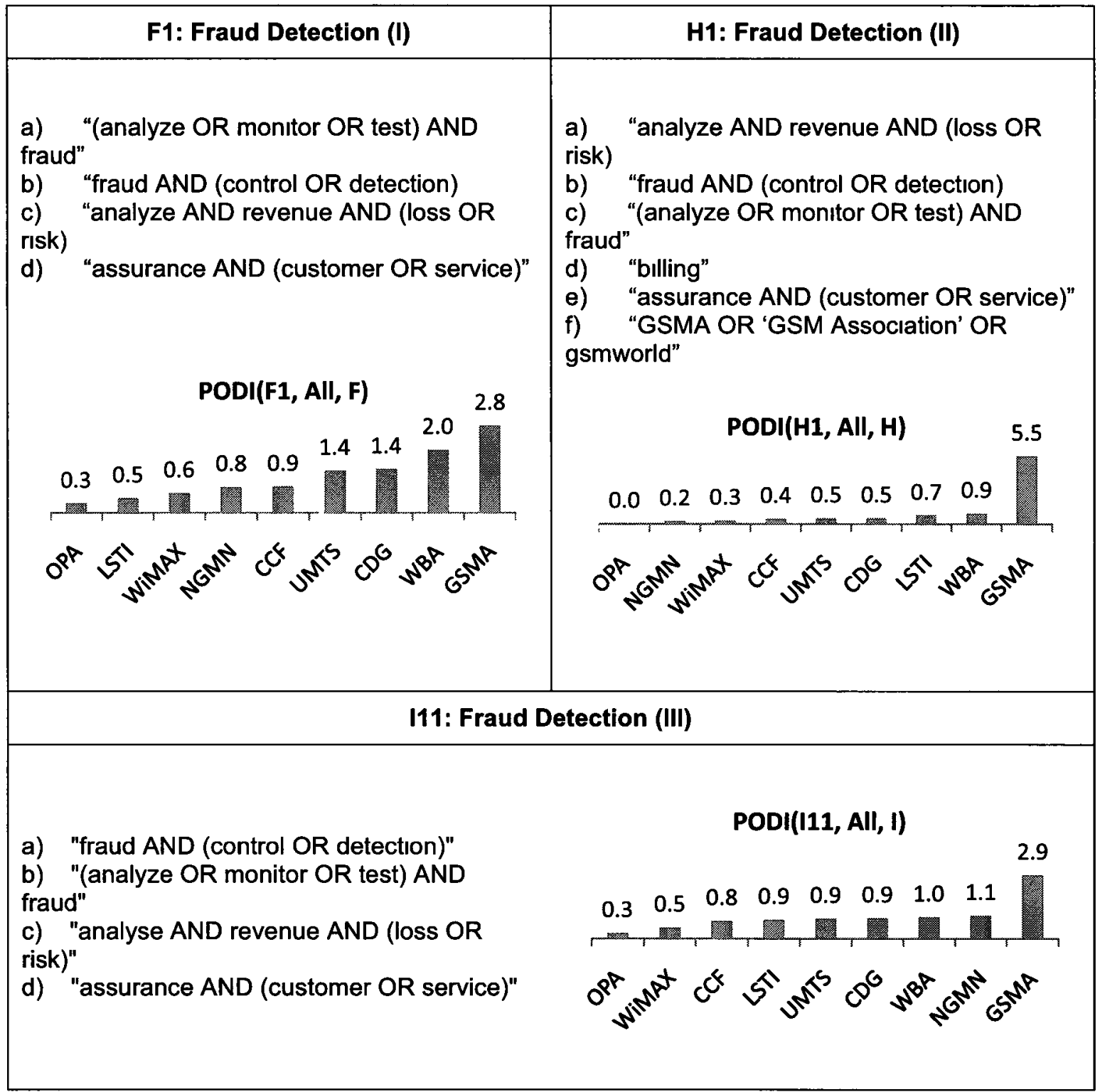




\section{Business Opportunity Solutions}

Table 28: Business Opportunity Solutions

\begin{tabular}{|c|c|}
\hline F2: Business Opportunity Solutions (I) & G2: Business Opportunity Solutions (II) \\
\hline $\begin{array}{l}\text { a) "new AND (market OR industry)" } \\
\text { b) "solution AND (outsourcıng OR } \\
\text { delivery)" } \\
\text { c) "strategy AND development" } \\
\text { d) "network AND operator" } \\
\text { e) "end-to-end AND communication } \\
\text { AND solutions" }\end{array}$ & $\begin{array}{l}\text { a) "solution AND provider" } \\
\text { b) "end-to-end' AND communication AND } \\
\text { solutions" } \\
\text { c) "solution AND (outsourcing OR delivery) } \\
\text { d) "new AND (market OR industry)" } \\
\text { e) "cost AND (reduce OR reduction OR } \\
\text { saving OR effective) }\end{array}$ \\
\hline 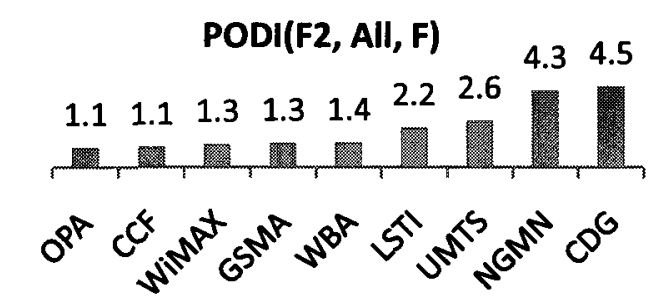 & 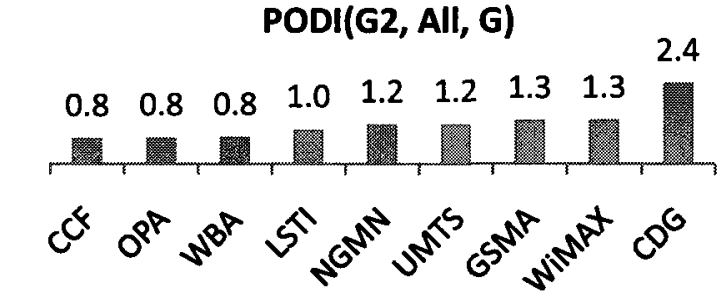 \\
\hline
\end{tabular}

The business oriented solutions are generally providing strategies to the network operators on how to access new markets or industries. The keywords identified in Table 28 suggest that these solutions are aligned with the new market dynamics and business models, and are oriented towards cost effectiveness.

\section{Licenses and Regulation}

Some of the application providers license their software to semiconductor companies, network operators, and mobile terminal manufacturers. Others provide a trading platform for content licensing and distribution. Licensing is also related to network operators for operating telecommunication services in a market that is regulated by an authority which has the power to promote 
competition through its regulations. The keywords shown in Table 29 were analyzed for a number of organizations from the sample and suggest that the mobile communication companies may have just acquired a license for operations and that their new entry in the market promotes competition which ultimately benefits the consumers.

\section{Table 29: Licenses and Regulation}

\begin{tabular}{|c|c|}
\hline F10: Licenses and Regulation (I) & H4: Licenses and Regulation (II) \\
\hline $\begin{array}{l}\text { a) "(issue OR administer) AND (license OR } \\
\text { licensing)" } \\
\text { b) "market AND (regulation OR oversight)" } \\
\text { c) "(enable OR enabling OR promote OR } \\
\text { promoting) AND competition" } \\
\text { d) "authority" }\end{array}$ & $\begin{array}{l}\text { a) "regulator OR regulate OR supervise OR } \\
\text { regulation OR regulatory" } \\
\text { b) "market AND (regulation OR oversight)" } \\
\text { c) "guidelınes OR rules OR regulation" } \\
\text { d) "(Issue OR adminıster) AND (license OR } \\
\text { licensing)" }\end{array}$ \\
\hline \begin{tabular}{ccccccccc}
\multicolumn{8}{c}{ PODI(F10, All, F) } \\
& & & & & & 3.2 \\
0.2 & 0.6 & 0.9 & 0.9 & 0.9 & 1.4 & 1.4 & 1.7 & \\
\end{tabular} & 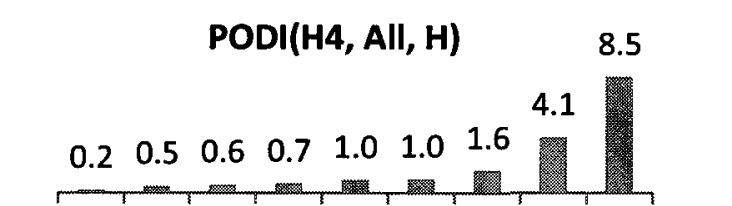 \\
\hline \multicolumn{2}{|c|}{ I15: Licenses and Regulation (III) } \\
\hline $\begin{array}{l}\text { a) "guidelines OR rules OR regulation" } \\
\text { b) "regulator OR regulate OR supervise OR } \\
\text { regulation OR regulatory" } \\
\text { c) "(issue OR administer) AND (IIcence OR } \\
\text { licensing)" } \\
\text { d) "authority" }\end{array}$ & 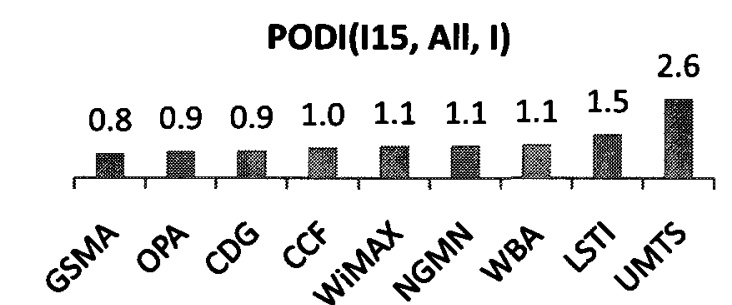 \\
\hline
\end{tabular}




\section{Conformance and Certification}

Table 30: Conformance and Certification

\begin{tabular}{|c|c|}
\hline F11: Conformance and Certification (I) & G4: WiMAX Certification \\
\hline 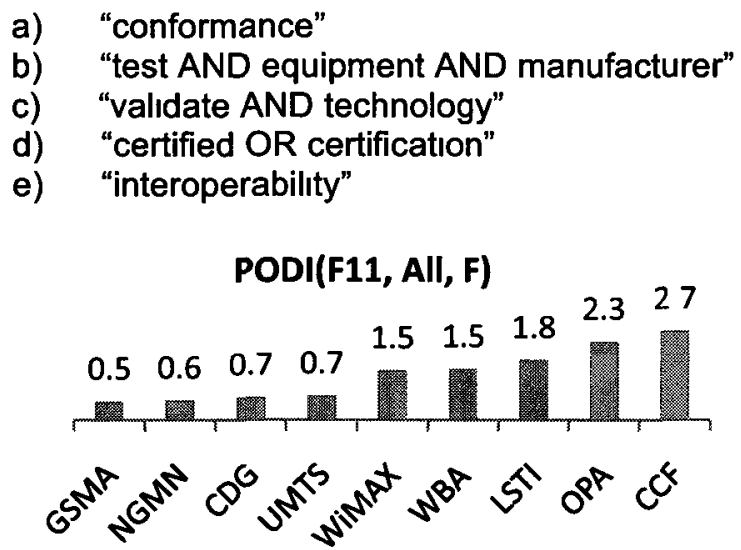 & 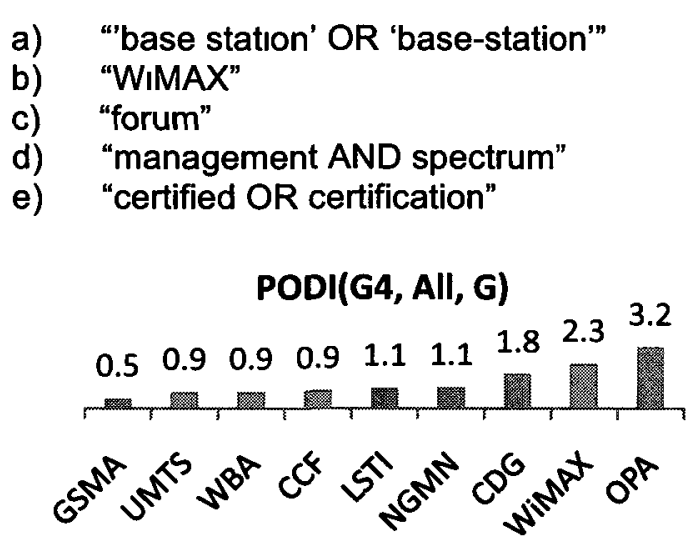 \\
\hline \multicolumn{2}{|c|}{ I3: Conformance and Certification (II) } \\
\hline $\begin{array}{l}\text { a) "Interoperability" } \\
\text { b) "conformance" } \\
\text { c) "certified OR certification" } \\
\text { d) "standards" }\end{array}$ & 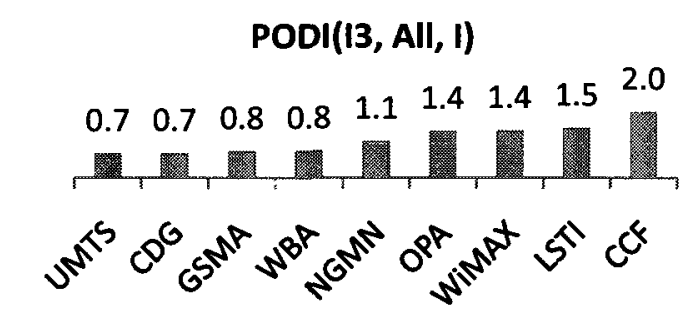 \\
\hline
\end{tabular}

Network operators use products from infrastructure providers and device manufacturers that passed the conformance and certification tests. The conformity to standards and specification is validated by the certification service providers. Besides safety, interference and performance, one of the reasons for certification is interoperability which ensures that similar products from different providers are inter-changeable and integrate seamlessly with other parts of the network. Table 30 presents the keywords that are representative for conformance and certification. The G4 factor defines one of the main 
characteristics of the WiMAX Forum - its focus on certification. A study of the WiMAX Forum confirms that the certification services for the base stations are widely used by its members.

\section{CDMA Technology and Standards}

Table 31: CDMA Technology and Standards

\begin{tabular}{|c|c|}
\hline 16: CDMA & ology and Standards \\
\hline $\begin{array}{l}\text { a) "CDMA OR “Code Division } \\
\text { Multiple Access" } \\
\text { b) "1XRTT" } \\
\text { c) "EV-DO OR EVDO" } \\
\text { d) "3GPP2" }\end{array}$ & 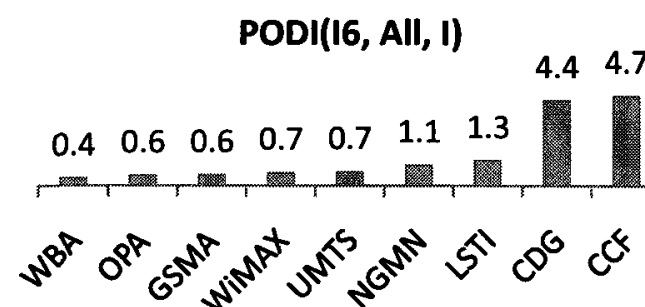 \\
\hline
\end{tabular}

The code division multiple access (CDMA) is a wireless technology used in the cdmaOne and CDMA2000 mobile phone family of standards (which are often referred to as simply CDMA). The $1 \times R T T$ and EV-DO are part of the CDMA2000 family of standards and were developed by the $3^{\text {rd }}$ Generation Partnership Project 2" (3GPP2). Therefore factor 16 is relevant for organizations with business models and offerings based on CDMA technologies and 3GPP2 standard. 


\section{Consortia Brand Names}

Table 32: Consortia Brand Names

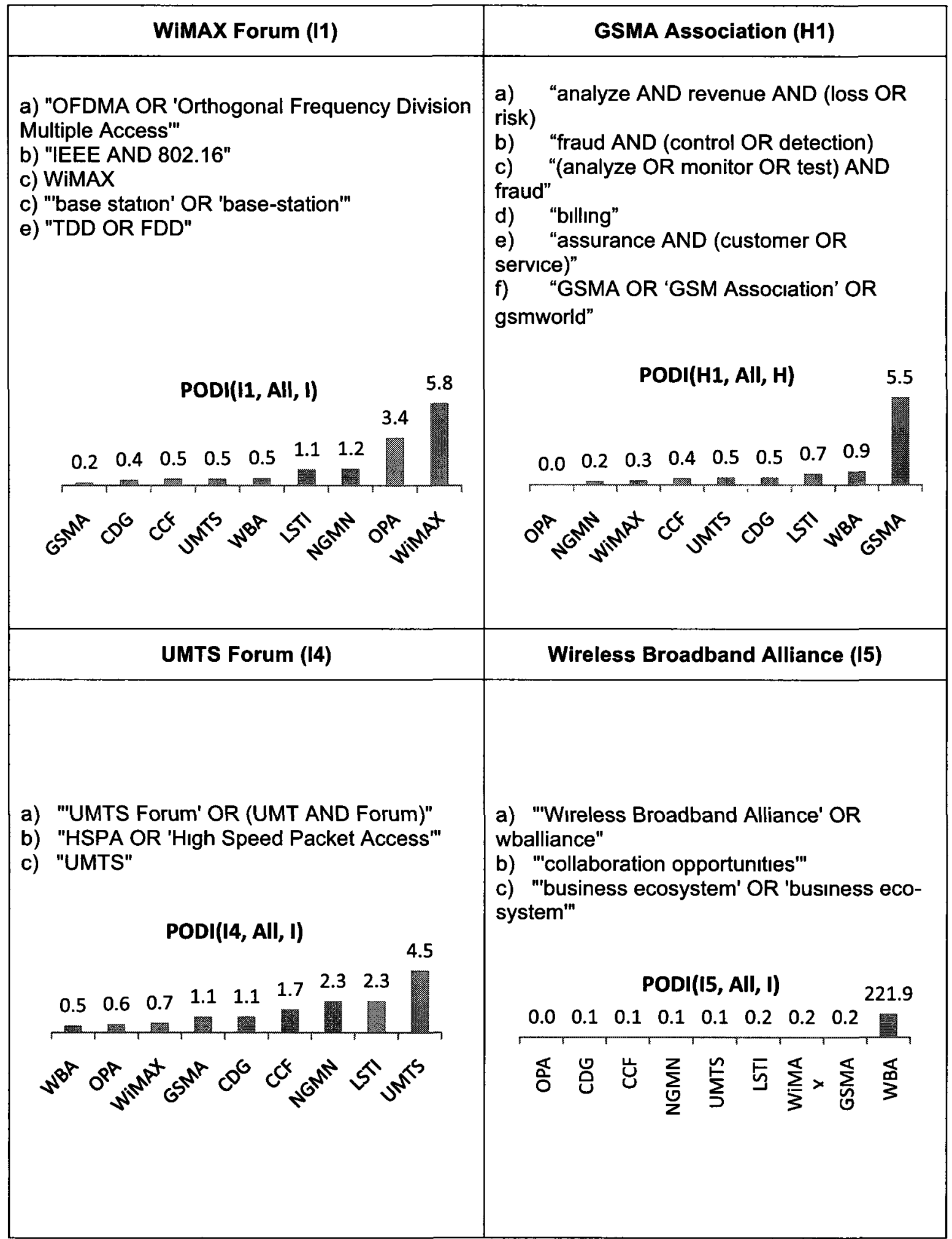




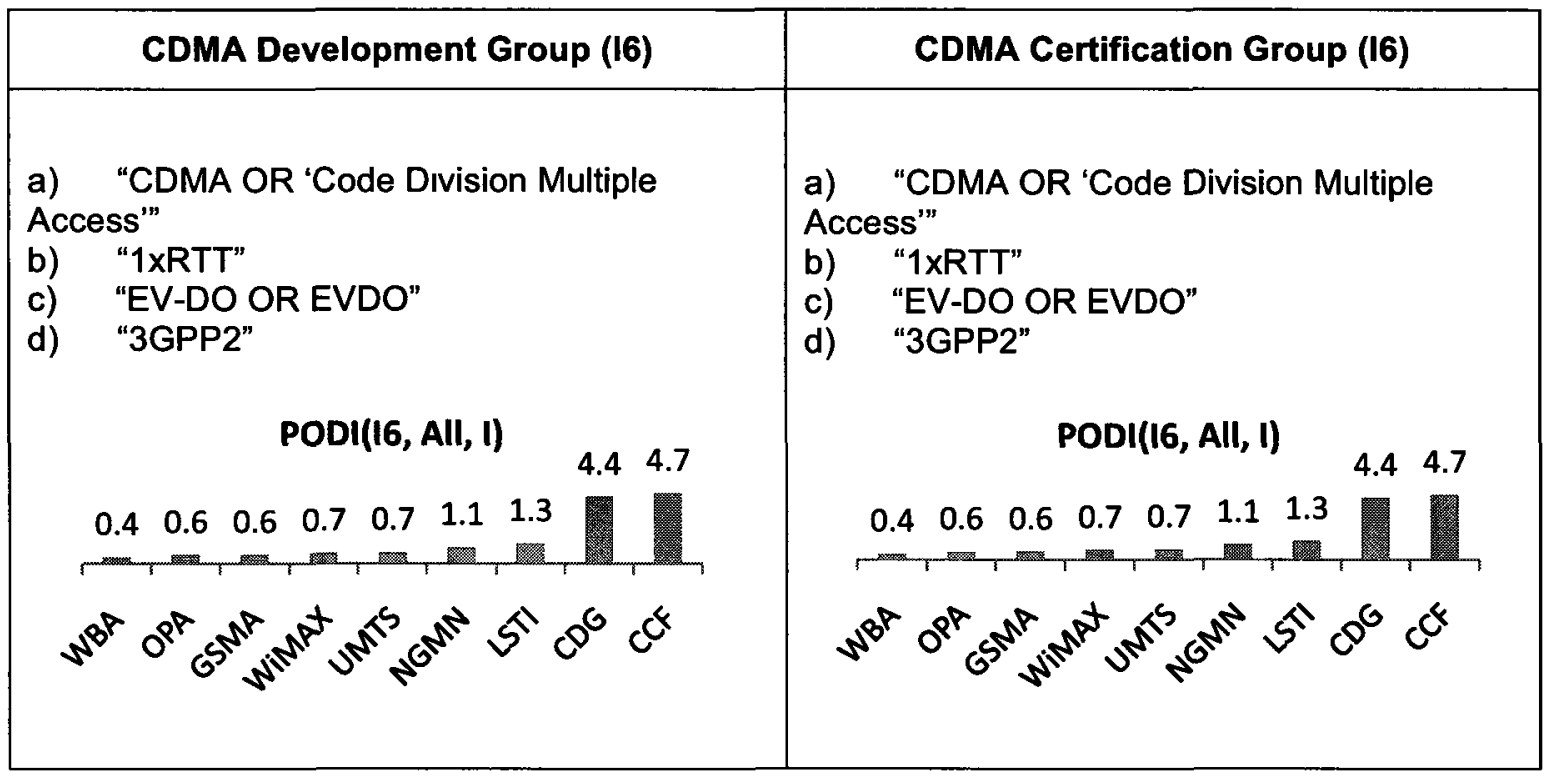

The majority of organizations' websites studied indicate the membership to industry consortia. The presence of a consortia' logo or name on an organization webpage is an indication of membership to the association. It also indicates an interest in the technologies, standards or the collaboration supported by the association. The factors and keywords identified in Table 32 show some of the consortia' names (WiMAX Forum, GSMA Association, UMTS Forum and Wireless Broadband Alliance) and some the constructs relevant to their members. GSMA is associated mostly with constructs of fraud control, UMTS Forum is associated mostly with its technology, Wireless Broadband Alliance members regard themselves as members of an ecosystem, and WiMAX Forum shows focus on the base stations. CDG and CCF show a strong focus on the CDMA standards and technologies. 


\subsection{Points of Difference for Consortia}

The points-of-difference (POD) for each consortium is defined by the groups of salient uncorrelated constructs identified from the Consortia PODI List. The Consortia PODI List provides a ranked list of POD Indexes for all the factors in each consortium. The POD Index (factor, consortium, sample) is used to indicate the numerical importance for each factor, consortium and sample as defined in Section 3.11 . 


\section{WiMAX Forum}

The PODI Indexes for the identified factors in each sample group are presented in Figure 10.

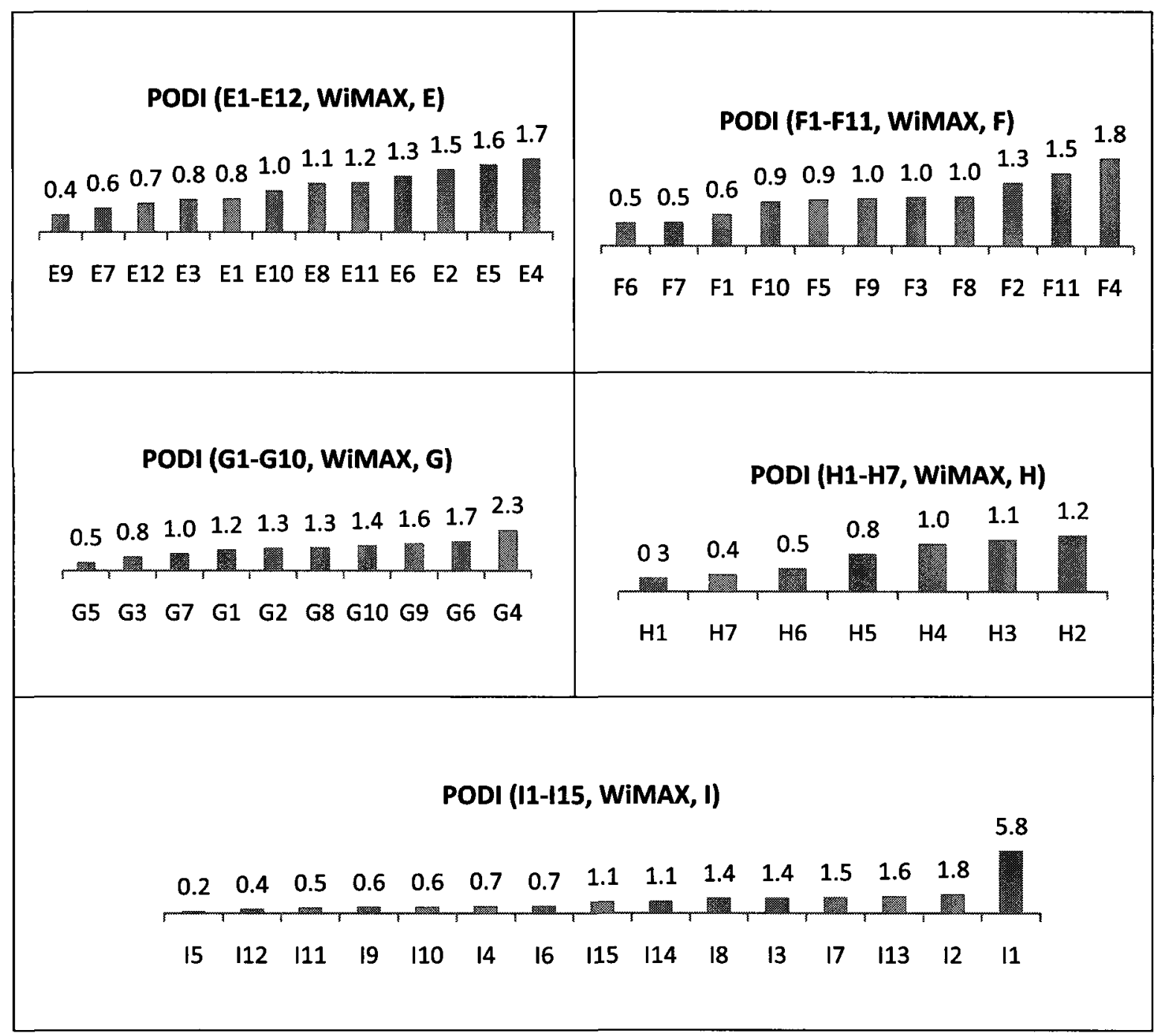

Figure 10: WiMAX Forum POD Index Chart

The WiMAX Forum salient constructs, with their comprising factors from each sample, and their POD Index are shown in Table 33. 
Table 33: WiMAX Forum Salient Constructs

\begin{tabular}{|l|l|l|}
\hline WiMAX Forum Salient Constructs & \multicolumn{1}{|c|}{ Factors } & \multicolumn{1}{c|}{ POD Index } \\
\hline WiMAX Technology and Standards & I1, E4 & $5.81,1.74$ \\
\hline Certificatıon & G4, F11 & $2.34,1.77$ \\
\hline Hardware & I2, G6, E5, F4 & $1.76,1.69,1.58,1.47$ \\
\hline Testıng Solutions & I13 & 1.60 \\
\hline
\end{tabular}

Grouping the salient constructs has to comply with the results from factor analysis in each sample group, in order to avoid any correlation between keywords. Based on the solutions indicated in Table 10, Table 11, Table 12, Table 13 and Table 14 the following salient construct groups, or POD, were identified for WiMAX Forum, and are shown in Table 34:

Table 34: WiMAX Forum POD

\begin{tabular}{|l|c|}
\hline \multicolumn{1}{|c|}{ WiMAX Forum POD } & POD Index \\
\hline WIMAX Technology and Standards (E4) & 1.74 \\
Hardware (E5) & 1.58 \\
\hline Certıfication (F11) & 1.77 \\
Hardware (F4) & 1.47 \\
\hline Certıfication (G4) & 2.34 \\
Hardware (G6) & 1.69 \\
\hline WIMAX Technology and Standards (I1) & 5.81 \\
Hardware (I2) & 1.76 \\
Testing Solutions (I13) & 1.60 \\
\hline
\end{tabular}




\section{GSM Association (GSMA)}

The POD Indexes for the identified factors in each sample group are presented for in Figure 11.

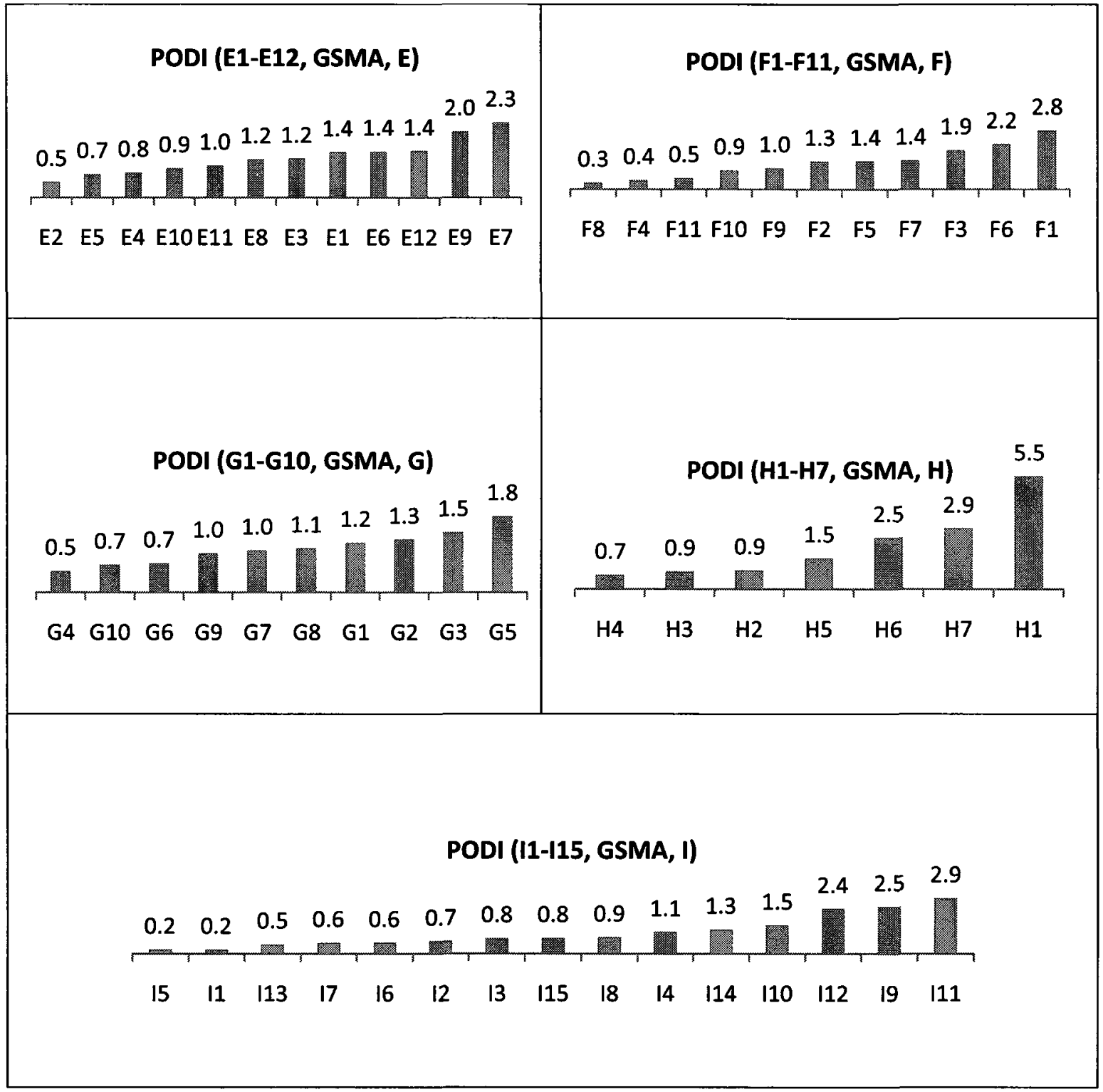

Figure 11: GSM Association POD Index Chart

The GSM Association salient constructs, with their comprising factors from each sample, and their POD Index are shown in Table 35. 
Table 35: GSMA Salient Constructs

\begin{tabular}{|l|l|l|}
\hline \multicolumn{1}{|c|}{ GSMA Salient Constructs } & \multicolumn{1}{c|}{ Factors } & \multicolumn{1}{c|}{ POD Index } \\
\hline Fraud Detection & H1, I11, F1 & $5.47,2.92,2.83$ \\
\hline Interoperability Solutions & H7, I12, F6, E9, G5 & $2.97,2.36,2.18,2.0,1.85$ \\
\hline Mobile Services & H6 & 2.49 \\
\hline Revenue Management Solutions & I9, E7, F3 & $2.47,2.27,1.88$ \\
\hline Fee Based Business Solutions & G3 & 1.46 \\
\hline
\end{tabular}

Grouping the salient constructs has to comply with the results from factor analysis in each sample group, in order to avoid any correlation between keywords. Based on the solutions indicated in Table 10, Table 11, Table 12, Table 13 and Table 14 the following salient construct groups, or POD, were identified for GSMA and are shown in Table 36.

Table 36: GSMA POD

\begin{tabular}{|l|c|}
\hline \multicolumn{1}{|c|}{ GSMA POD } & POD Index \\
\hline Revenue Management Solutions & 2.27 \\
(E7) & 2.00 \\
Interoperability Solutions (E9) & 2.83 \\
\hline Fraud Detection (F1) & 2.18 \\
Interoperability Solutions (F6) & 1.88 \\
Revenue Management Solutıons (F3) & 1.85 \\
\hline Interoperability Solutions (G5) & 1.46 \\
Fee Based Business Solutions (G3) & 5.47 \\
\hline Fraud Detection (H1) & 2.97 \\
Interoperability Solutions (H7) & 2.49 \\
Mobile Services (H6) & 2.92 \\
\hline Fraud Detection (I11) & 2.47 \\
Revenue Management Solutions (I9) & 2.36 \\
\hline Interoperability Solutions (I12) &
\end{tabular}




\section{CDMA Development Group (CDG)}

The POD Indexes for the identified factors in each sample group are presented in Figure 12.

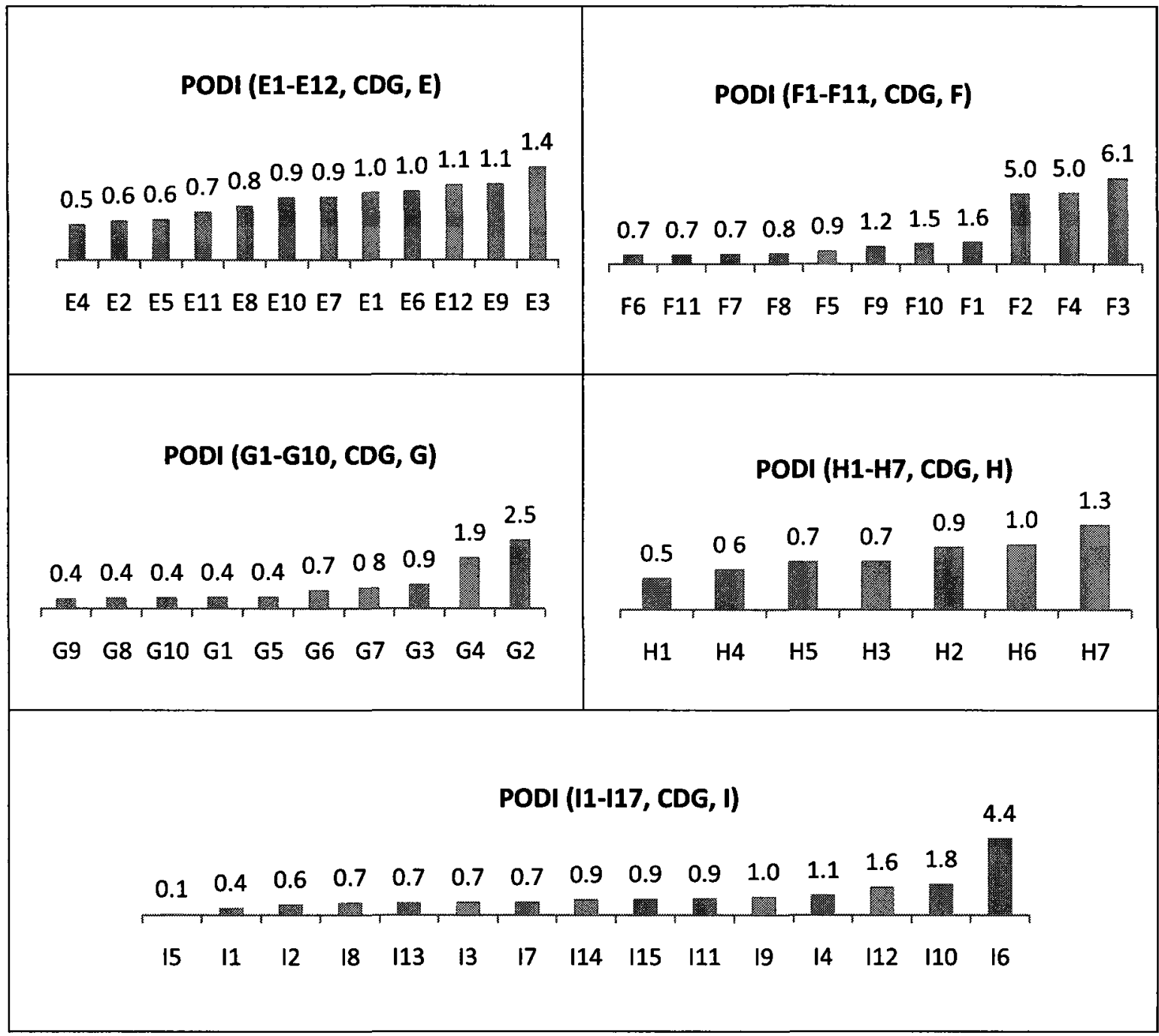

Figure 12: CDG POD Index Chart

The CDG salient constructs, with their comprising factors from each sample, and their POD Index are shown in Table 37. 


\section{Table 37: CDG Salient Constructs}

\begin{tabular}{|l|l|l|}
\hline \multicolumn{1}{|c|}{ CDG Salient Constructs } & Factors & POD Index \\
\hline Revenue Management Solutions & F3 & 6.10 \\
\hline Hardware & F4 & 5.05 \\
\hline Business Opportunity Solutions & F2, G2 & $4.99,3.53$ \\
\hline CDMA Technology and Standards & I6 & 4.43 \\
\hline Fee Based Busıness Solutions & I10 & 1.78 \\
\hline WiMAX Certification & G4 & 1.88 \\
\hline Interoperability Solutions & I12 & 1.60 \\
\hline
\end{tabular}

Grouping the salient constructs has to comply with the results from factor analysis in each sample group, in order to avoid any correlation between keywords. Based on the solutions indicated in Table 10, Table 11, Table 12, Table 13 and Table 14 the following salient construct groups, or POD, were identified for CDG and are shown in Table 38.

Table 38: CDG POD

\begin{tabular}{|l|c|}
\hline \multicolumn{1}{|c|}{ CDG POD } & POD Index \\
\hline Revenue Management Solutions (F3) & 6.10 \\
Hardware (F4) & 5.05 \\
Business Opportunity Solutions (F2) & 4.99 \\
\hline Busıness Opportunity Solutions (G2) & 3.53 \\
WIMAX Certification (G4) & 1.88 \\
\hline CDMA Technology and Standards (I6) & 4.43 \\
Fee Based Business Solutions (I10) & 1.78 \\
Interoperability Solutions (I12) & 1.60 \\
\hline
\end{tabular}




\section{Next Generation Mobile Networks Alliance (NGMN)}

The POD Indexes for the identified factors in each sample group are presented in

Figure 13.

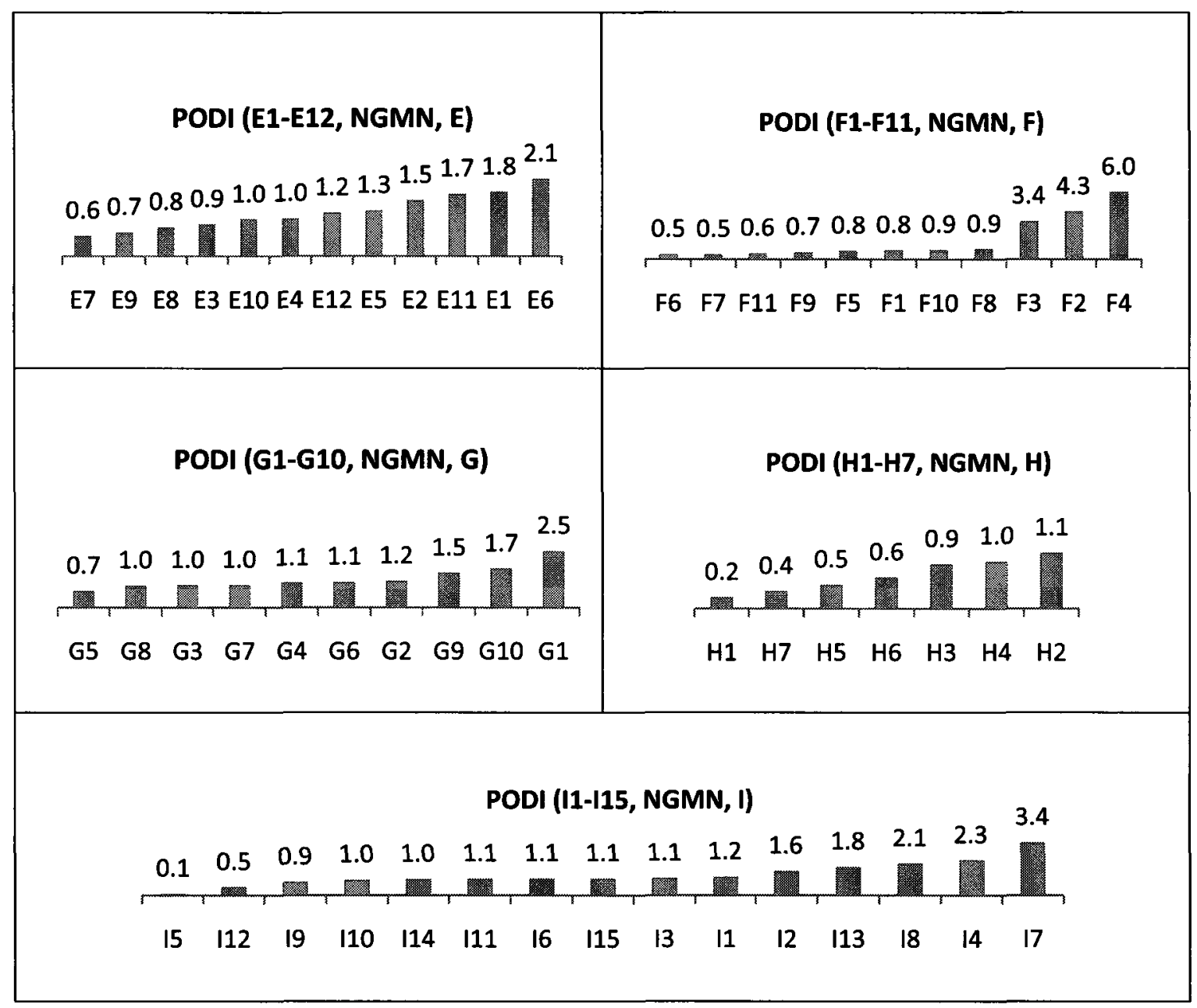

Figure 13: NGMN Alliance POD Index Chart

The NGMN Alliance salient constructs, with their comprising factors from each sample, and their POD Index are shown in Table 39. 
Table 39: NGMN Salient Constructs

\begin{tabular}{|l|l|l|}
\hline \multicolumn{1}{|c|}{ NGMN Salient Constructs } & \multicolumn{1}{c|}{ Factors } & \multicolumn{1}{c|}{ POD Index } \\
\hline Hardware & F4, I2 & $6.00,1,57$ \\
\hline Business Opportunity Solutions & F2 & 4.28 \\
\hline Revenue Management Solutions & F3 & 3.43 \\
\hline 3GPP Standards and LTE Technology & I7, E6 & $3.41,2.13$ \\
\hline Mobile Services & G1, E1 & $2.50,1.71$ \\
\hline UMTS & I4 & 2.27 \\
\hline Research & I8, E11, G9 & $2.06,1.71,1.54$ \\
\hline Testing Solutions & I13, G10, E2 & $1.83,1.73,1.54$ \\
\hline
\end{tabular}

Grouping the salient constructs has to comply with the results from factor analyses in each sample group, in order to avoid any correlation between keywords. Based on the solutions indicated in Table 10, Table 11, Table 12, Table 13 and Table 14 the following salient construct groups, or POD, were identified for NGMN and are shown in Table 40. 
Table 40: NGMN POD

\begin{tabular}{|l|c|}
\hline \multicolumn{1}{|c|}{ NGMN POD } & POD Index \\
\hline 3GPP Standards and LTE Technology (E6) & 2.13 \\
Mobile Services (E1) & 1.77 \\
Research (E11) & 1.71 \\
Testing Solutions (E2) & 1.54 \\
\hline Hardware (F4) & 6.00 \\
Business Opportunity Solutions (F2) & 4.28 \\
Revenue Management Solutions (F3) & 3.43 \\
\hline Mobile Services (G1) & 2.50 \\
Testing Solutions (G10) & 1.73 \\
Research (G9) & 1.54 \\
\hline 3GPP Standards and LTE Technology (I7) & 3.41 \\
UMTS (I4) & 2.27 \\
Research (I8) & 2.06 \\
Hardware (I2) & 1.57 \\
\hline
\end{tabular}




\section{CDMA Certification Forum (CCF)}

The POD Indexes for the identified factors in each sample group are presented in Figure 14.

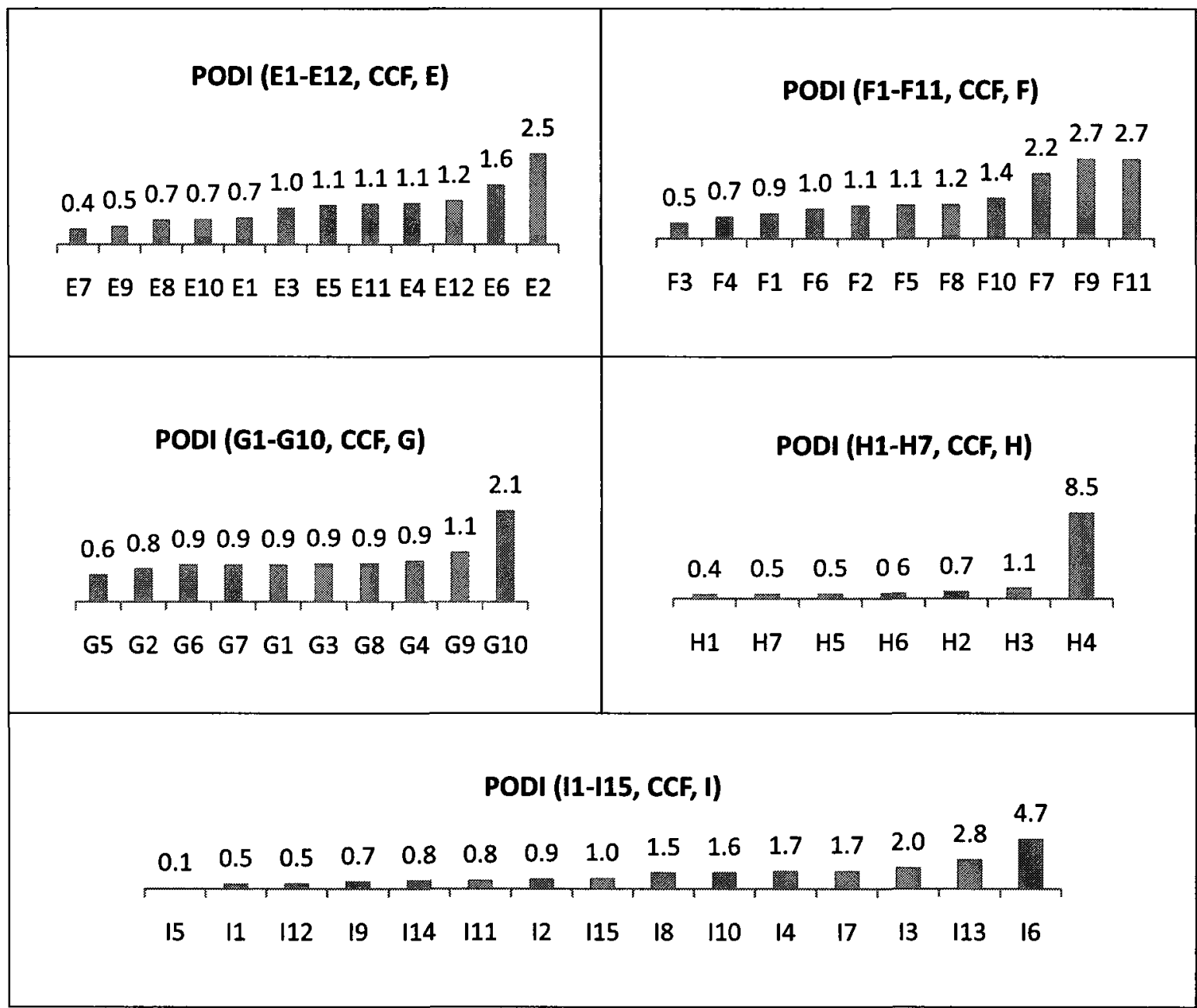

Figure 14: CCF POD Index Chart

The CCF salient constructs, with their comprising factors from each sample, and their POD Index are shown in Table 41. 
Table 41: CCF Salient Constructs

\begin{tabular}{|l|l|l|}
\hline \multicolumn{1}{|c|}{ CCF Salient Constructs } & \multicolumn{1}{c|}{ Factors } & \multicolumn{1}{c|}{ POD Index } \\
\hline Licenses and Regulation & $\mathrm{H} 4$ & 8.53 \\
\hline CDMA Standards and Technology & $\mathrm{I} 6$ & 4.66 \\
\hline Conformance and Certification & $\mathrm{F} 11, \mathrm{I} 3$ & $2.65,1.99$ \\
\hline Testing Solutions & $\mathrm{F} 9, \mathrm{E} 2, \mathrm{G} 10, \mathrm{I13}$ & $2.65,2.48,2.10,2.75$ \\
\hline Fee Based Business Solutions & $\mathrm{F} 7, \mathrm{I10}$ & $2.17,1.55$ \\
\hline 3GPP and LTE Technology & $\mathrm{I7,} \mathrm{E6}$ & $1,69,1.64$ \\
\hline UMTS & $\mathrm{I} 4$ & 1.67 \\
\hline Research & 18 & 1.52 \\
\hline
\end{tabular}

Grouping the salient constructs has to comply with the results from factor analysis in each sample group, in order to avoid any correlation between keywords. Based on the solutions indicated in Table 10, Table 11, Table 12, Table 13 and Table 14 the following salient construct groups, or POD, were identified for CCF and are shown in Table 42.

Table 42: CCF POD

\begin{tabular}{|l|c|}
\hline \multicolumn{1}{|c|}{ CCF POD } & POD Index \\
\hline Testing Solutions (E3) & 2.48 \\
3GPP and LTE Technology (E6) & 1.64 \\
\hline CDMA Standards and Technology I(6) & 4.66 \\
Conformance and Certıfication (I3) & 1.99 \\
3GPP and LTE Technology (I7) & 1.69 \\
UMTS (I4) & 1.67 \\
Fee Based Business Solutions (I10) & 1.55 \\
Research (I8) & 1.52 \\
\hline
\end{tabular}




\section{LSTI Forum}

The POD Indexes for the identified factors in each sample group are presented in Figure 15.

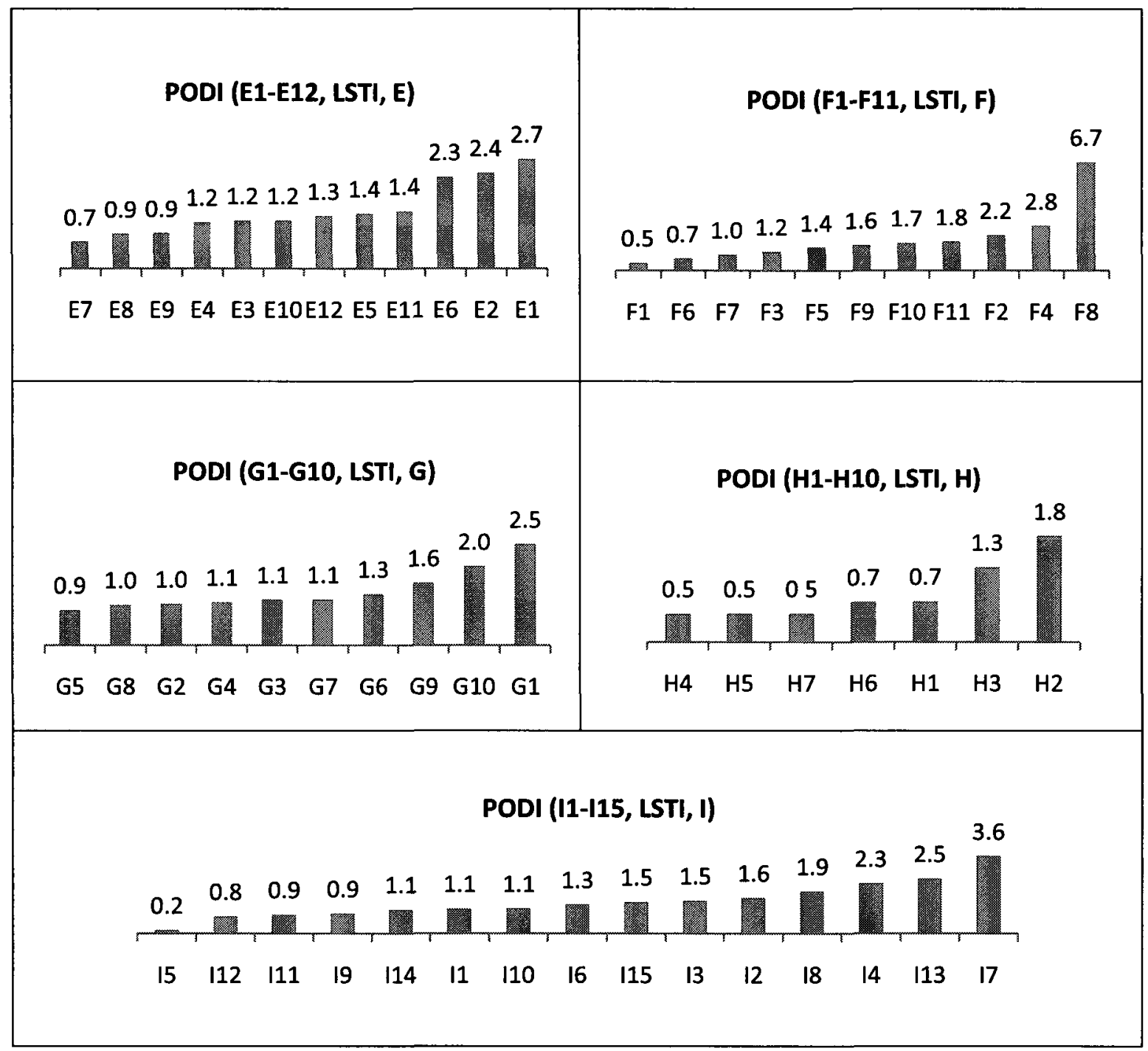

Figure 15: LSTI Forum POD Index Chart

The LSTI salient constructs, with their comprising factors from each sample, and their POD Index are shown in Table 43. 
Table 43: LSTI Forum Salient Constructs

\begin{tabular}{|l|l|l|}
\hline \multicolumn{1}{|c|}{ LSTI Salient Constructs } & \multicolumn{1}{c|}{ Factors } & \multicolumn{1}{c|}{ POD Index } \\
\hline 3GPP Standards and LTE Technology & F8, I7, E6, H2 & $6.72,3.57,2.27,1.84$ \\
\hline Hardware & F4, I2 & $2.74,1.63$ \\
\hline Mobile Services & E1, G1 & $2.72,2.52$ \\
\hline Testing & I13, E2, G10, F9 & $2.51,2.38,1.96,1.56$ \\
\hline UMTS & I4 & 2.29 \\
\hline Business Opportunity Solutions & F2 & 2.19 \\
\hline Research & I8, G9 & $1.94,1.55$ \\
\hline Conformance and Certification & F11, I3 & $1.79,1.50$ \\
\hline Licenses and Regulation & F10 & 1.70 \\
\hline
\end{tabular}

Grouping the salient constructs has to comply with the results from factor analysis in each sample group, in order to avoid any correlation between keywords. Based on the solutions indicated in Table 10, Table 11, Table 12, Table 13 and Table 14 the following salient construct groups, or POD, were identified for LSTI Forum and are shown in Table 44. 
Table 44: LSTI Forum POD

\begin{tabular}{|l|c|}
\hline \multicolumn{1}{|c|}{ LSTI POD } & POD Index \\
\hline 3GPP Standards and LTE Technology (F8) & 6.72 \\
Licenses and Regulation (F10) & 1.70 \\
\hline 3GPP Standards and LTE Technology (F8) & 6.72 \\
Testing (F9) & 1.56 \\
\hline 3GPP Standards and LTE Technology (I7) & 3.57 \\
UMTS (I4) & 2.29 \\
Research (I8) & 1.94 \\
Hardware (I2) & 1.63 \\
Conformance and Certification (I3) & 1.50 \\
\hline Busıness Opportunity Solutions (F2) & 2.19 \\
Licenses and Regulation (F10) & 1.70 \\
Testing (F9) & 1.56 \\
\hline Mobile Services (E1) & 2.72 \\
Testıng (E2) & 2.38 \\
3GPP Standards and LTE Technology (E6) & 2.27 \\
\hline Mobile Services (G1) & 2.52 \\
Testing (G10) & 1.96 \\
Research (G9) & 1.55 \\
\hline
\end{tabular}




\section{UMTS Forum}

The POD Indexes for the identified factors in each sample group are presented in Figure 16.

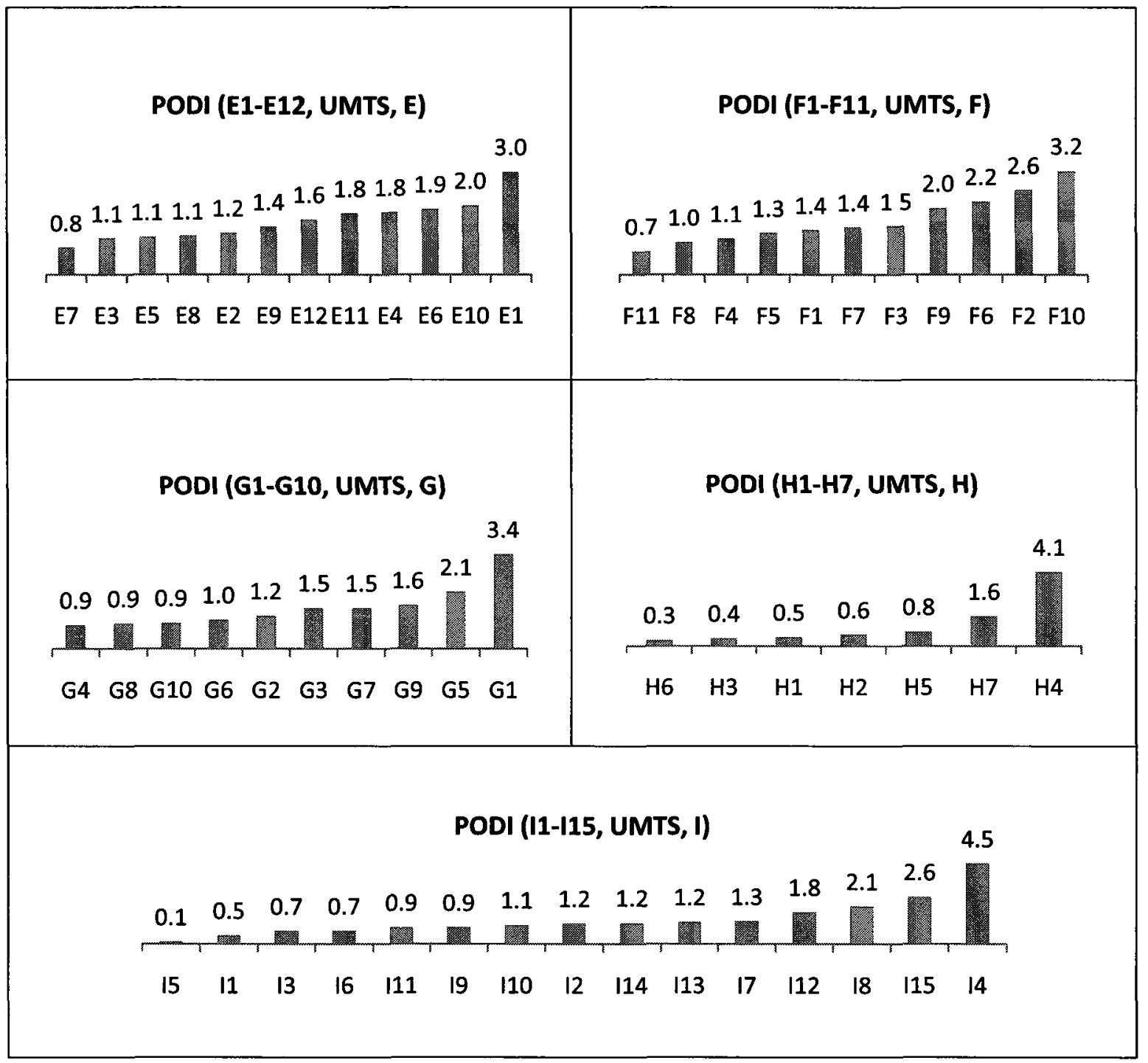

Figure 16: UMTS Forum POD Index Chart

The UMTS Forum salient constructs, with their comprising factors from each sample, and their POD Index are shown in Table 45. 
Table 45: UMTS Forum Salient Constructs

\begin{tabular}{|l|l|l|}
\hline \multicolumn{1}{|c|}{ UMTS Salient Constructs } & \multicolumn{1}{|c|}{ Factors } & \multicolumn{1}{c|}{ POD Index } \\
\hline UMTS & I4 & 4.50 \\
\hline Licenses and Regulation & H4, F10, I15 & $4.08,3.19,2.64$ \\
\hline Mobile Services & G1, E1 & $3.43,2.97$ \\
\hline Busıness Opportunity Solutions & F2 & 2.60 \\
\hline Interoperability Solutions & F6, G5, I12, H7 & $2.25,2.06,1.78,1.63$ \\
\hline Research & I8, E11, G9 & $2.10,1.77,1.58$ \\
\hline Monitoring Solutions & F9 & 2.04 \\
\hline Reputation & E10, G7 & $2.00,1.48$ \\
\hline 3GPP Standard and LTE Technology & E6 & 1.90 \\
\hline WIMAX Technology and Standard & E4 & 1.80 \\
\hline 3GPP Standard and 3G Technologies Evolution & E12 & 1.59 \\
\hline
\end{tabular}

Grouping the salient constructs has to comply with the results from factor analyses in each sample group, in order to avoid any correlation between keywords. Based on the solutions indicated in Table 10, Table 11, Table 12, Table 13 and Table 14 the following salient constructs groups, or POD, were identified for UMTS Forum and are shown in Table 46. 
Table 46: UMTS Forum POD

\begin{tabular}{|l|c|}
\hline \multicolumn{1}{|c|}{ UMTS POD } & POD Index \\
\hline Mobile Services (E1) & 2.97 \\
Reputation (E10) & 2.00 \\
3GPP Standard and LTE Technology (E6) & 1.90 \\
WiMAX Technology and Standard (E4) & 1.80 \\
Research (E11) & 1.77 \\
3GPP Standard and 3G Technologies Evolution (E12) & 1.59 \\
\hline Licenses and Regulatıon (F10) & 3.19 \\
Busıness Opportunity Solutions (F2) & 2.60 \\
Interoperability Solutions (F6) & 2.25 \\
Monitoring Solutions (F9) & 2.04 \\
\hline Mobile Services (G1) & 3.43 \\
Interoperability Solutions (G5) & 2.06 \\
Research (G9) & 1.58 \\
\hline Licenses and Regulatıon (H4) & 4.08 \\
Interoperabilty Solutions (H7) & 1.63 \\
\hline UMTS (I4) & 4.50 \\
Licenses and Regulation (I15) & 2.64 \\
Research (I8) & 2.10 \\
3GPP Standard and 3G Technologies Evolutıon (I12) & 1.59 \\
\hline
\end{tabular}




\section{Wireless Broadband Alliance (WBA)}

The POD Indexes for the identified factors in each sample group are presented in Figure 17.

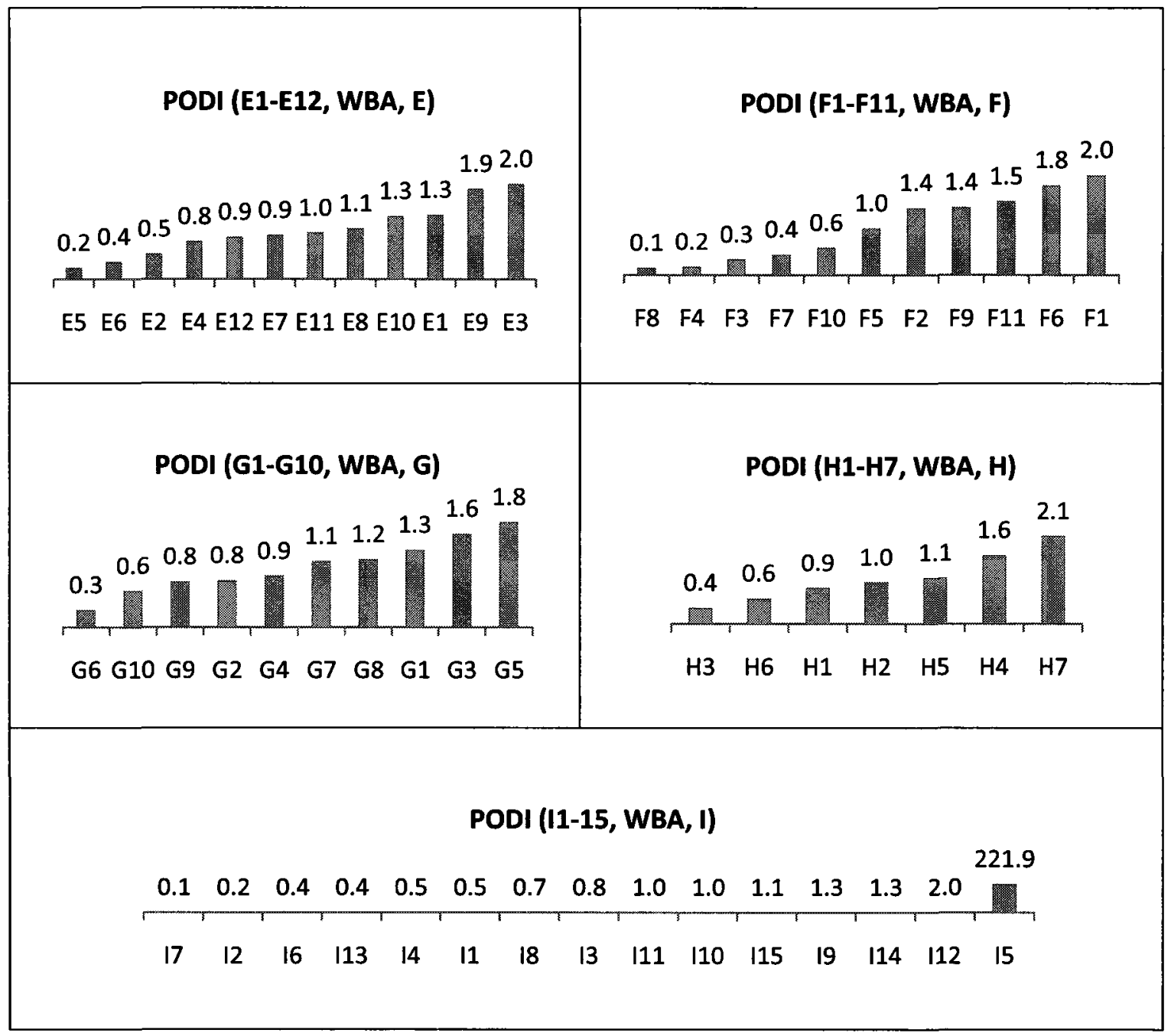

Figure 17: WBA POD Index Chart

The WBA salient constructs, with their comprising factors from each sample, and their POD Index are shown in Table 47. 
Table 47: WBA Salient Construct

\begin{tabular}{|l|l|l|}
\hline \multicolumn{1}{|c|}{ WBA Sallent Constructs } & \multicolumn{1}{c|}{ Factors } & \multicolumn{1}{c|}{ POD Index } \\
\hline Wireless Broadband Alliance & I5 & 221.9 \\
\hline Interoperability Solutions & H7, I12, E9, F6, G5 & $2.09,2.03,1.87,1.84,1.79$ \\
\hline Fraud Detection & F1 & 2.04 \\
\hline Fee Based Business Solutions & E3, G3 & $1.97,1.59$ \\
\hline Licenses and Regulation & H4 & 1.63 \\
\hline Conformance and Certification & F11 & 1.51 \\
\hline
\end{tabular}

Grouping the salient constructs has to comply with the results from factor analyses in each sample group, in order to avoid any correlation between keywords. Based on the solutions indicated in Table 10, Table 11, Table 12, Table 13 and Table 14 the following salient construct groups, or POD, were identified for WBA and are shown in Table 48. 
Table 48: WBA POD

\begin{tabular}{|l|c|}
\hline \multicolumn{1}{|c|}{ WBA POD } & POD Index \\
\hline Wireless Broadband Alliance (I5) & 221.9 \\
Interoperability Solutions (I12) & 2.03 \\
\hline Interoperability Solutıons (H7) & 2.09 \\
Licenses and Regulation (H4) & 1.63 \\
\hline Fraud Detection (F1) & 2.04 \\
Interoperability Solutions (F6) & 1.84 \\
\hline Fraud Detection (F1) & 2.04 \\
Conformance and Certification (F11) & 1.51 \\
\hline Fee Based Busıness Solutions (E3) & 1.97 \\
Interoperabılity Solutions (E9) & 1.87 \\
\hline Interoperability Solutions (G5) & 1.79 \\
Fee Based Busıness Solutions (G3) & 1.59 \\
\hline
\end{tabular}




\section{Open Patent Alliance (OPA)}

The POD Indexes for the identified factors in each sample group are presented in Figure 18.

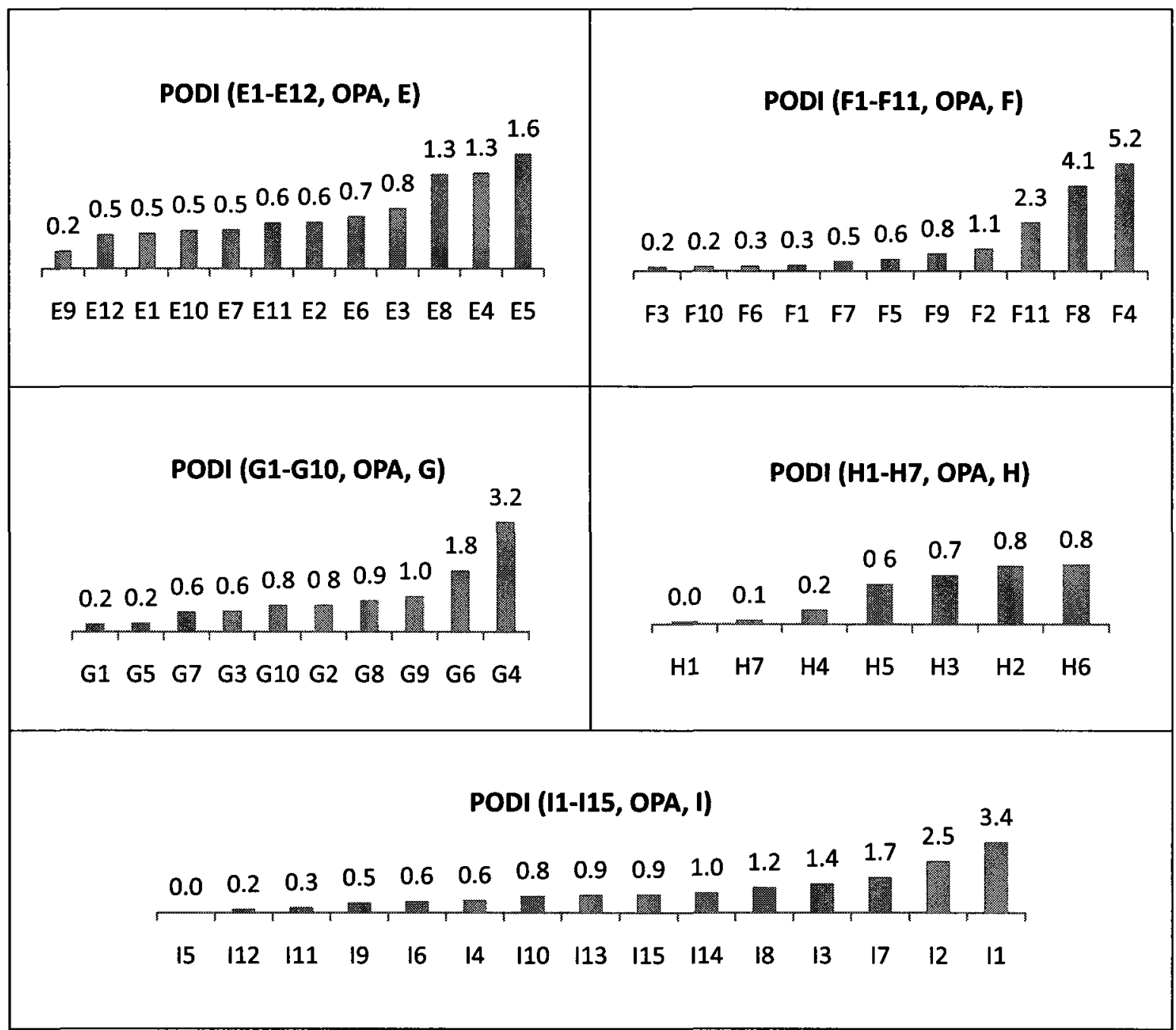

Figure 18: OPA POD Index Chart

The OPA salient constructs, with their comprising factors from each sample, and their POD Index are shown in Table 49. 
Table 49: OPA Salient Constructs

\begin{tabular}{|l|l|l|}
\hline \multicolumn{1}{|c|}{ OPA Salient Constructs } & \multicolumn{1}{c|}{ Factors } & \multicolumn{1}{c|}{ POD Index } \\
\hline Hardware & F4, 12, G6, E5 & $5.16,2.47,1.79,1.58$ \\
\hline 3GPP Standard and LTE Technology & F8, 17 & $4.09,1.70$ \\
\hline WiMAX Technology and Standard & I1 & 3.39 \\
\hline WiMAX Certification & G4 & 3.21 \\
\hline Conformance and Certification & F11 & 2.34 \\
\hline
\end{tabular}

Grouping the salient constructs has to comply with the results from factor analysis in each sample group, in order to avoid any correlation between keywords. Based on the solutions indicated in Table 10, Table 11, Table 12, Table 13 and Table 14 the following salient construct groups, or POD, were identified for OPA and are shown in Table 50.

Table 50: OPA POD

\begin{tabular}{|l|c|}
\hline \multicolumn{1}{|c|}{ OPA POD } & POD Index \\
\hline Hardware (F4) & 5.16 \\
Conformance and Certification (F11) & 2.34 \\
\hline WIMAX Technology and Standard (I1) & 3.39 \\
Hardware (I2) & 2.47 \\
3GPP Standard and LTE Technology & 1.70 \\
\hline WIMAX CertIfication (G4) & 3.21 \\
Hardware (G6) & 1.79 \\
\hline
\end{tabular}




\subsection{Multiple Memberships}

An analysis of single and multiple memberships for organizations in sample Group I using the technology factors could provide additional insights on the technology adoption. The POD Index ranking of organizations based on either the single or double membership was performed for the following factors:

- 16: CDMA Technology and 3GPP2 Standards

- I1: WiMAX Technology and IEEE 802.11 Standards

- 17: LTE Technology and 3GPP Standards

The PODI $(16, A l l, I)$ index for groups of organizations that are members of one or two consortia is shown in Figure 19.

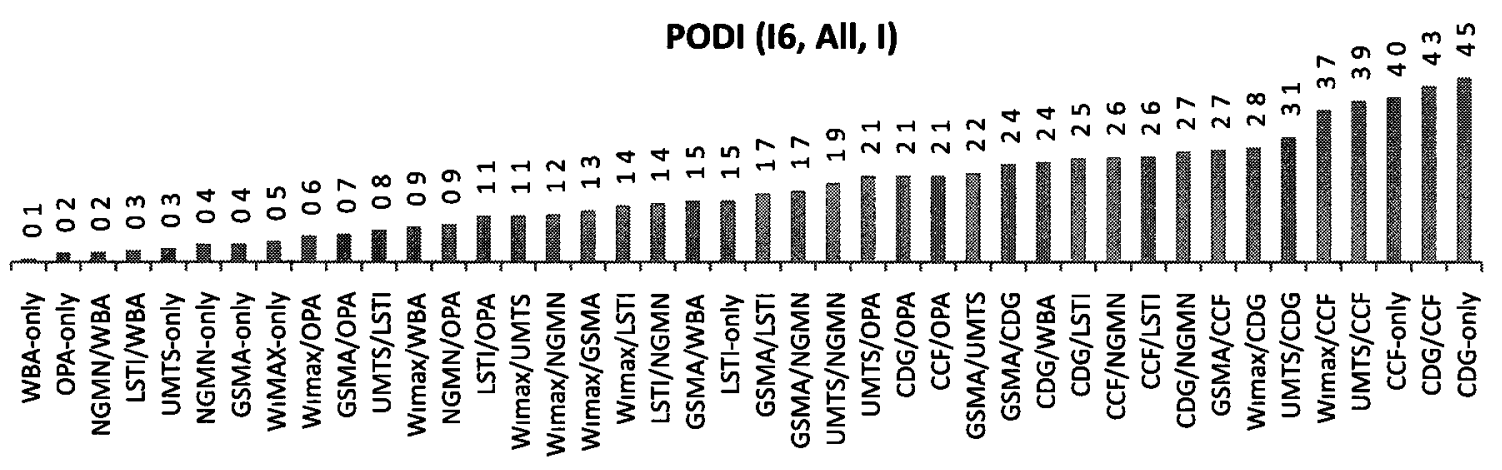

Figure 19: Distribution of CDMA Technology and Standards

The PODI $(11, A l l, l)$ index for groups of organizations that are members of one or two consortia is shown in Figure 20. 
PODI (I1, All, I)

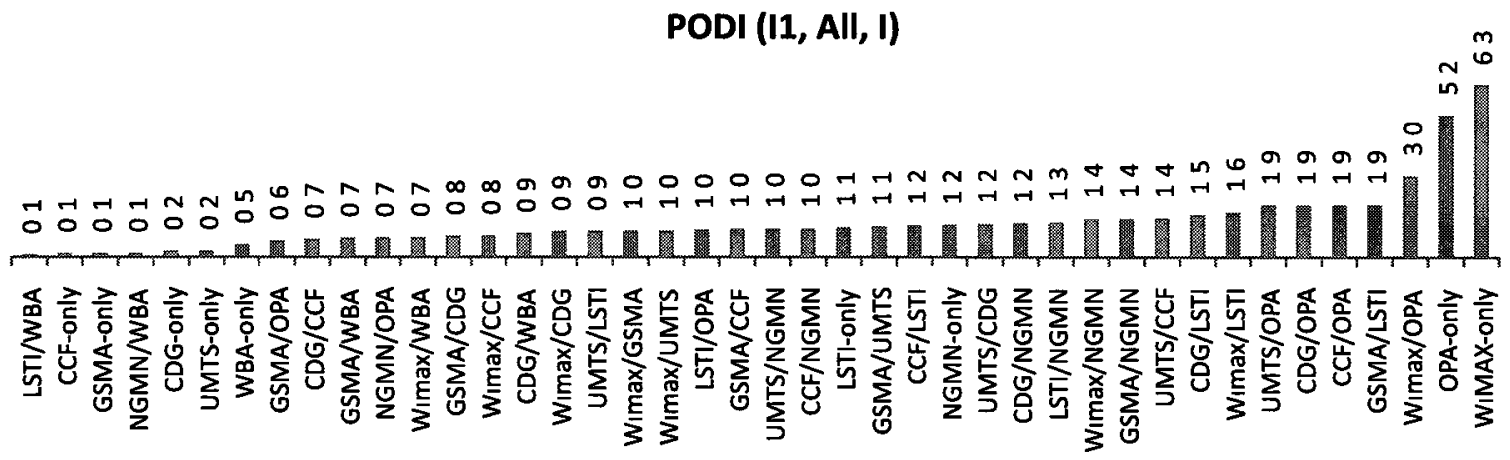

Figure 20: Distribution of WiMAX Technology and Standards

The PODI $(I 7, A l l, l)$ index for groups of organizations that are members of one or two consortia is shown in Figure 21.

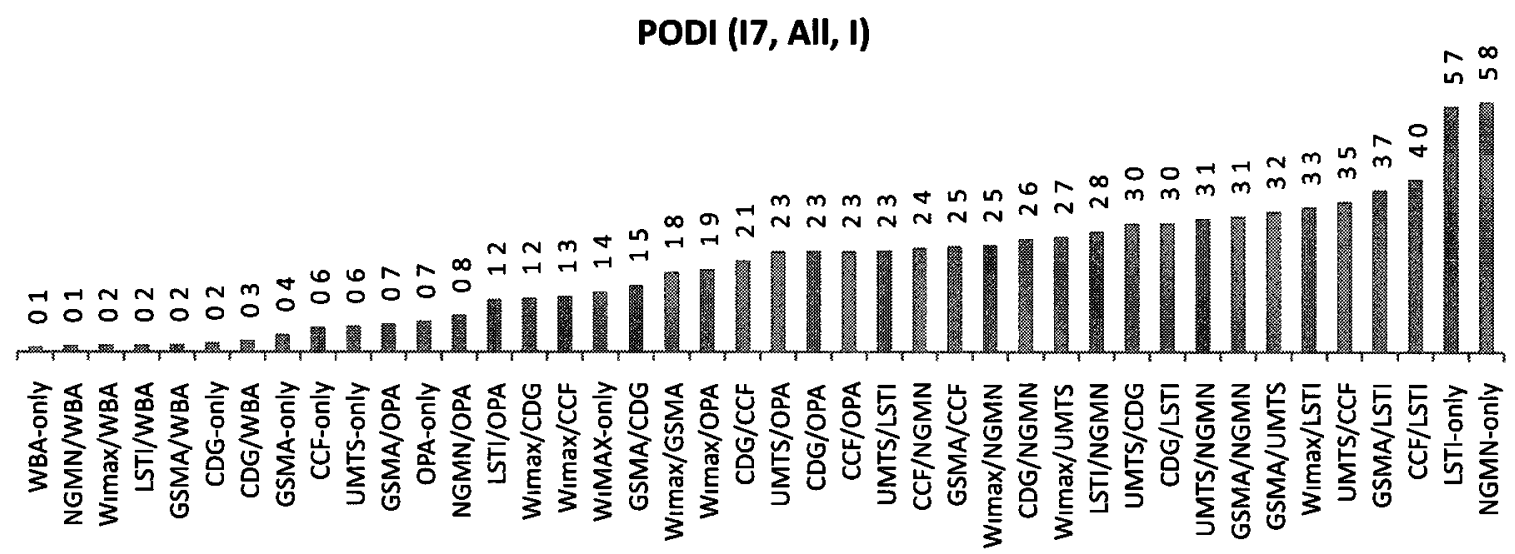

Figure 21: Distribution of LTE Technology and Standards

\subsection{Construct Groups Visualization}

A graphical representation of the construct groups identified for each consortium in each sample group is provided in Figure 22, Figure 23, Figure 24, Figure 25 and Figure 26. The visualization could help with the interpretation of constructs and the impact the shared membership have on these constructs by bringing 
together in one view, for each sample group, the construct groups identified for each association and their respective POD Index, the number of organizations in each association and the number of organizations shared between two consortia.

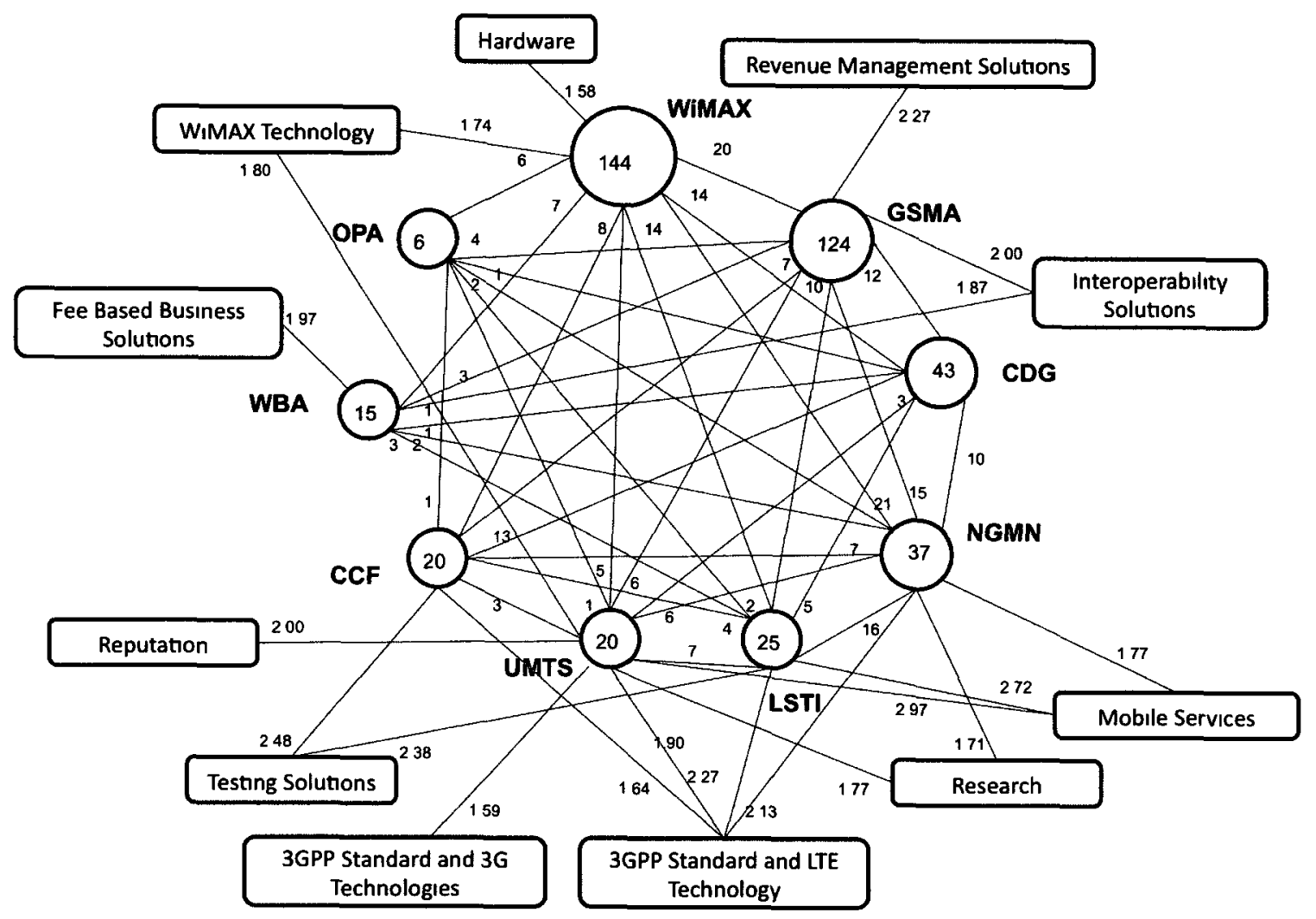

Figure 22: Sample Group E: Construct Groups Visualization 


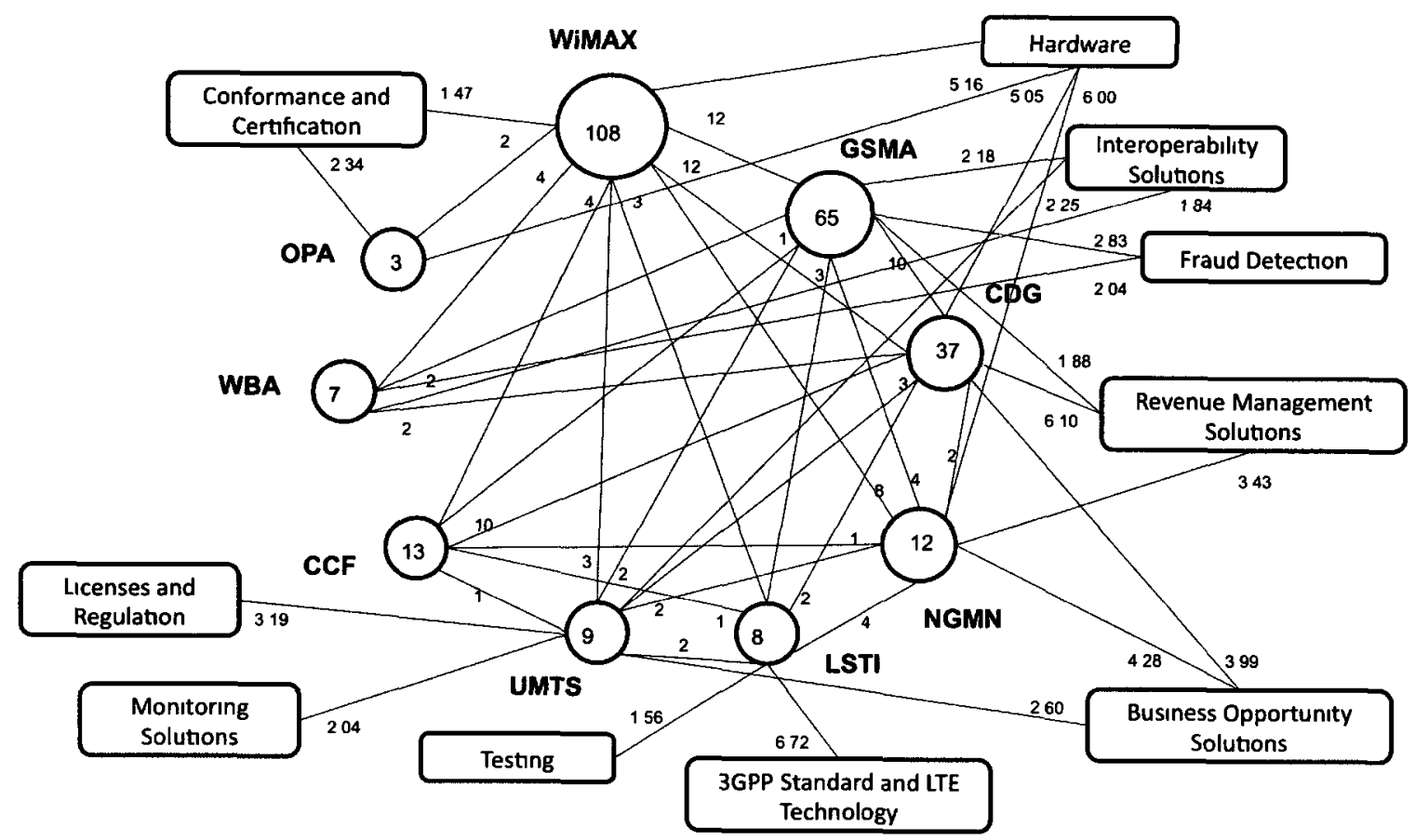

Figure 23: Sample Group F: Construct Groups Visualization

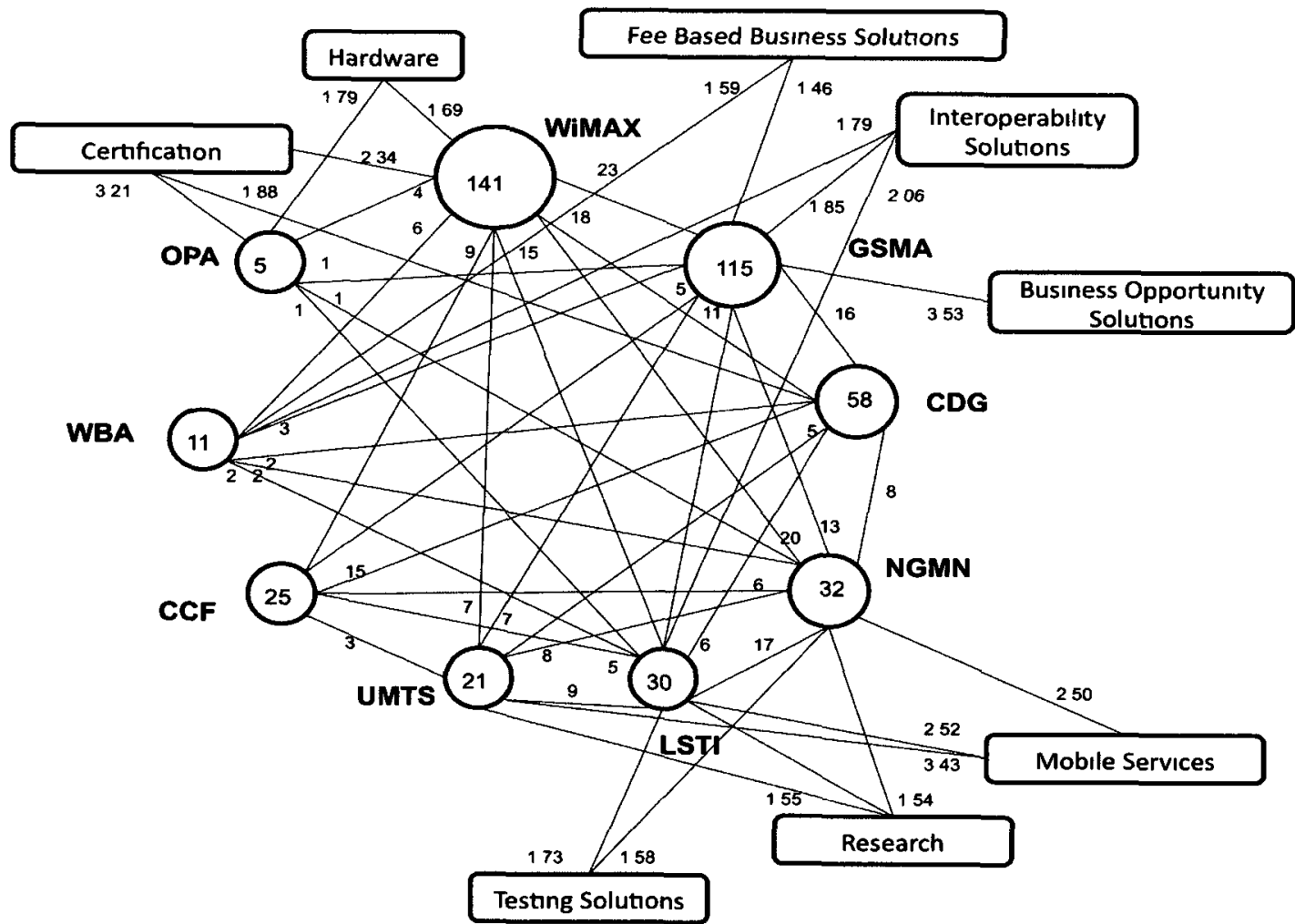

Figure 24: Sample Group G: Construct Groups Visualization 


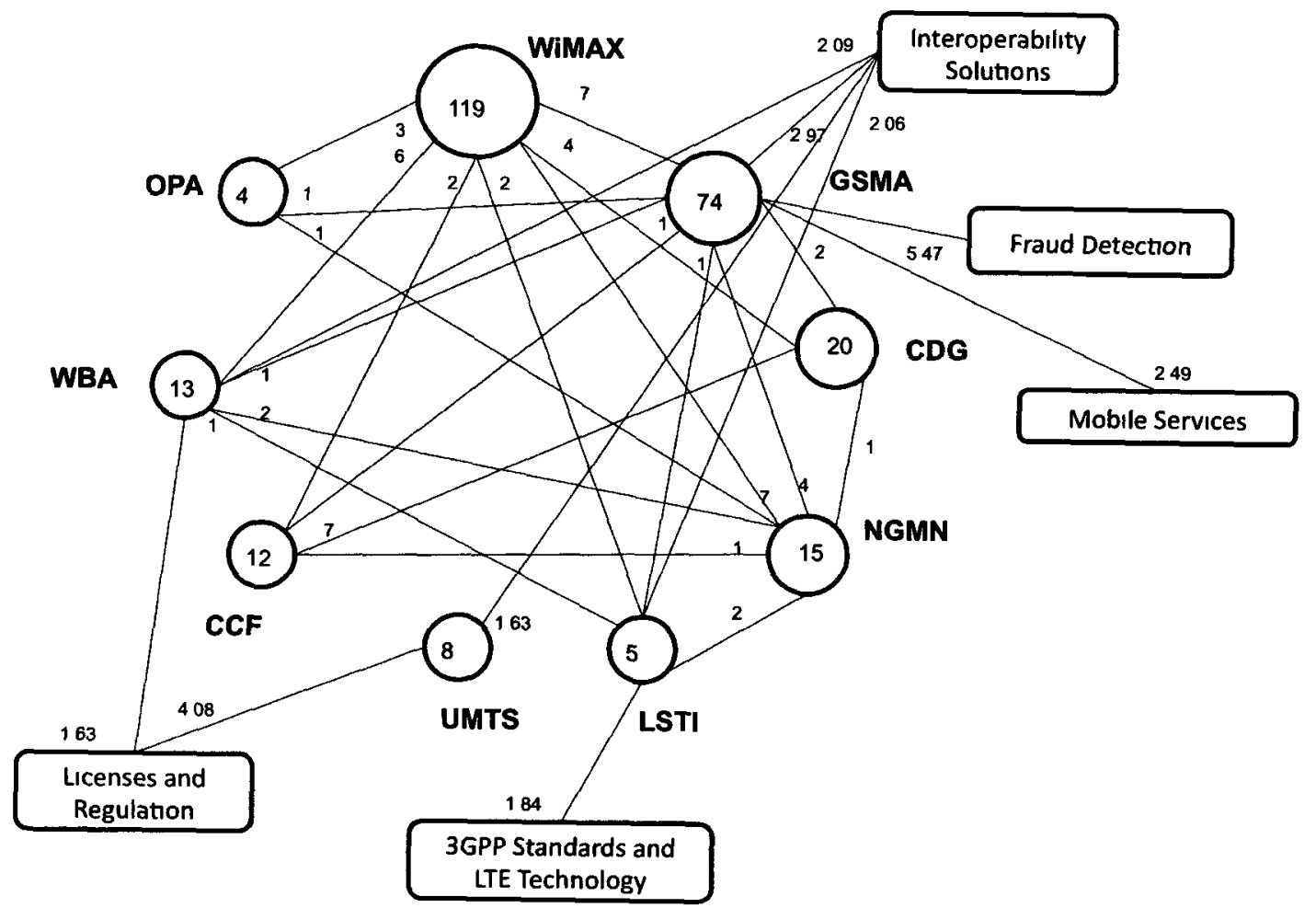

Figure 25: Sample Group H: Construct Groups Visualization

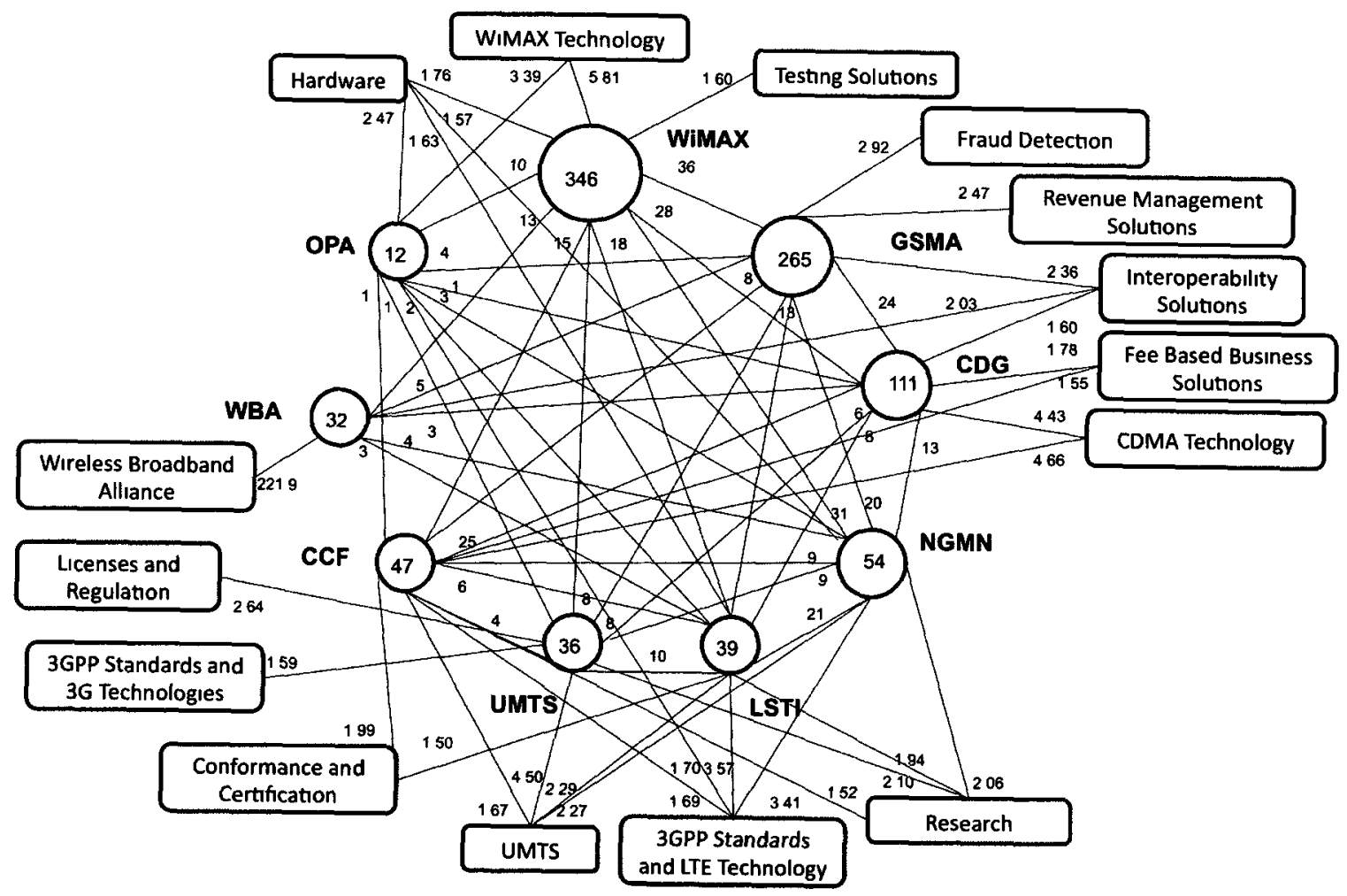

Figure 26: Sample Group I: Construct Groups Visualization 


\section{Discussion of Results}

This chapter discusses the results of the research. It is divided into eight sections. Section 5.1 provides a discussion on the points of difference in wireless industry consortia. Section 5.2 identifies membership motivation. Section 5.3 provides a view on the development phases of consortia. Section 5.4 identifies the characteristics of technological evolution. Section 5.5 provides evidence of technological adoption. Section 5.6 identifies the emerging role of backend systems. Section 5.7 discusses the insights acquired from the research results. Section 5.8 provides recommendations for organizations that operate as keystones.

\subsection{Points of Difference}

The points-of-difference (POD) for each consortia are defined by the groups of salient constructs identified in Section 4.6 Points of Difference.

This section provides a comparison between the POD identified in this research and the consortia's objectives obtained from the web pages of the associations, forums and alliances studied. 
WiMAX Forum

Table 51: Mapped Objectives for WiMAX Forum

\begin{tabular}{|l|l|}
\hline \multicolumn{1}{|c|}{ WiMAX Forum POD } & \multicolumn{1}{c|}{ WiMAX Forum Objectives } \\
\hline WiMAX Technology and Standards & $\begin{array}{l}\text { "The WiMAX Forum is the worldwide } \\
\text { consortium focused on global adoption } \\
\text { of WiMAX and chartered to establish } \\
\text { certification processes that achieve } \\
\text { interoperability, publish technical } \\
\text { specifications based on recognized } \\
\text { (see Table } 34 \text { for details) } \\
\text { standards, promote the technology } \\
\text { and pursue a favourable regulatory } \\
\text { environment"25 }\end{array}$ \\
$\begin{array}{l}\text { Discussion: } \\
\text { The certification of the hardware products for base stations are intended to } \\
\text { validate the cross-vendor interoperability at the lower layers of the } \\
\text { communication stack in the wireless network - the access network, and it is } \\
\text { based on the IEEE } 801.16 \text { standard and WiMAX technology. In summary, the } \\
\text { POD are an indication of: } \\
\text { Certification for standard compliance and interoperability at the access } \\
\text { level of the network }\end{array}$ \\
$\begin{array}{l}\text { Conclusion: } \\
\text { There is a good mapping between the points-of-difference identified and the } \\
\text { forum's objectives }\end{array}$
\end{tabular}

${ }^{25} \mathrm{http} . / / \mathrm{www}$. wimaxforum org/about/vision-and-mission, last checked July 14, 2010 


\section{GSM Association}

Table 52: Mapped Objectives for GSMA

\begin{tabular}{|c|c|}
\hline & GS \\
\hline $\begin{array}{l}\text { Interoperability Solutions } \\
\text { Fraud Detection } \\
\text { Revenue Management Solutions } \\
\text { Mobile Services } \\
\text { Fee Based Business Solutions } \\
\text { (See Table } 36 \text { for details) }\end{array}$ & $\begin{array}{l}\text { "The GSMA's mission is to create } \\
\text { value for operators and the mobile } \\
\text { industry in the provision of services for } \\
\text { the benefit of end users" } 26\end{array}$ \\
\hline $\begin{array}{l}\text { Discussion: } \\
\text { The majority of the GSM Associa } \\
\text { reflected on the focus on service } \\
\text { the POD show that: } \\
\text { - Interoperability is focuse } \\
\text { exchanged between the } \\
\text { between different networks } \\
\text { - There is a strong focus o } \\
\text { and services } \\
\text { Conclusion: } \\
\text { GSMA objectives are vague and } \\
\text { role, they provide suggestions fo } \\
\text { how the group brings value to its }\end{array}$ & $\begin{array}{l}\text { pplications for end-users. In summary, } \\
\text { he reliability of the user information } \\
\text { providers when mobile users roam } \\
\text { tional optimization, mobile applications } \\
\text { The identified POD have a definitional } \\
\text { oup's objectives meaning, and identify }\end{array}$ \\
\hline
\end{tabular}

\footnotetext{
${ }^{26}$ http.//www.gsmworld com/about-us/vision htm, last checked July 23, 2010
} 


\section{LSTI Forum}

Table 54: Mapped Objectives for LSTI Forum

\begin{tabular}{|c|c|}
\hline LS & ectives \\
\hline $\begin{array}{l}\text { 3GPP Standards and LTE Technology } \\
\text { UMTS } \\
\text { Research } \\
\text { Hardware } \\
\text { Conformance and Certification } \\
\text { (see Table } 44 \text { for more details) }\end{array}$ & $\begin{array}{l}\text { The LSTI Forum objective is to } \\
\text { "develop an open industry ecosystem } \\
\text { by involving all stakeholder } \\
\text { (manufacturers, regulators, operators, } \\
\text { research community, application } \\
\text { developers) in the process; early } \\
\text { cooperation to reduce risks; early proof } \\
\text { of concept and interoperability tests of } \\
\text { equipment between vendors; support } \\
\text { of 3GPP LTE/SAE standardization"28 }\end{array}$ \\
\hline $\begin{array}{l}\text { Discussion: } \\
\text { With no commercial deployment at thi } \\
\text { organizations are in standards, resear } \\
\text { D: Membership Distribution, the LSTI } \\
\text { consortia, more significantly with GS } \\
\text { mobile services components identifie } \\
\text { shared membership and it suggests } t \\
\text { are incumbents involved in other } \\
\text { summary, the POD show that: } \\
\text { - The involvement in the newest } \\
\text { its strongest constructs in stand } \\
\text { Conclusion: } \\
\text { LSTI Forum objectives are vague a } \\
\text { definitional role, they provide suggest } \\
\text { and identify how the forum brings value }\end{array}$ & $\begin{array}{l}\text { me }{ }^{29} \text { the area of focus for the member } \\
\text { and testing. As indicated in Appendix } \\
\text { rum membership is shared with other } \\
\text { Association and WiMAX Forum. The } \\
\text { in our results are a measure of the } \\
\text { a large proportion of the participants } \\
\text { bile communication technologies. In } \\
\text { obile communication technologies has } \\
\text { Is, research, development and testing } \\
\text { general. The identified POD have a } \\
\text { is for the forum's objectives meaning, } \\
\text { its members. }\end{array}$ \\
\hline
\end{tabular}

${ }^{28} \mathrm{http}$ ://www.Istiforum.org/about/intro.html, last accessed July 23, 2010

29 July 2010 


\section{CDMA Certification Forum}

Table 56: Mapped Objectives for CCF

\begin{tabular}{|l|l|}
\hline \multicolumn{1}{|c|}{ CCF POD } & \multicolumn{1}{|c|}{ CCF Objectives } \\
\hline CDMA Standards and Technology & "CDMA Certification Forum is a \\
Conformance and Certification & partnership between CDMA operators \\
3GPP and LTE Technology & and CDMA device vendors to establish \\
UMTS & and maintain a core global device \\
Fee Based Business Solutions & qualification process that helps improve \\
Research & interoperability conformance and \\
Testing Solutions & performance testing across the \\
(see Table 42 for more details) & globe." \\
\end{tabular}

\section{Discussion:}

The CDMA Certification Group was established in 2004, a decade later after the establishment of the CDMA Development Group, in order to establish a global CDMA certification process. The CCF shows strong support for the CDMA Standards and Technology construct and a relative medium support for the Conformance and Certification construct. The relative weak support for a wide range of other constructs, some of them specific to 3GPP technologies, is explained by the shared membership of operators and device manufacturers to other consortia, as shown in Appendix D: Membership Distribution. In summary, the POD show that:

- The main focus is on standards and certification

\section{Conclusion:}

There is a good mapping between the points-of-difference identified and the forum objectives.

\footnotetext{
${ }^{32}$ http.//www.globalccf.org/about us php, last accessed July 12, 2010
} 


\subsection{Legacy and Evolution}

The analysis of the members of the wireless industry consortia, as indicated in

Section 5.1 Points of Difference, shows that based on their establishment date and involvement with the respective technologies a map can be drawn that indicates the consortia's focus at different stages in the evolution of technologies.

Table 60: Legacy and Evolution Constructs

\begin{tabular}{|c|c|c|c|}
\hline Technology & Standards & $\begin{array}{c}\text { Consortia and year of } \\
\text { establishment }\end{array}$ & Constructs \\
\hline GSM & 3GPP & $\begin{array}{c}\text { GSM Association } \\
(1987)\end{array}$ & $\begin{array}{c}\text { Operational Optımızation } \\
\text { Interoperability Solutions } \\
\text { Mobile Services }\end{array}$ \\
\hline CDMA & $3 G P P 2$ & (see Table 36)
\end{tabular}


The identified constructs provide a trajectory from the legacy to newer technologies as indicated in Figure 27. This study shows that legacy technologies are characterized by a focus on optimization, services and cost reduction while the new and developing technologies are focused on standards, research, hardware, and testing. The outlier in this interpretation is the CDMA Certification Forum. The association was established ten years after the introduction of the CDMA technology. As a certification organization the focus on testing and certification at the access level of the network indicates that the access equipment is possibly still under development and has not become a commodity yet.

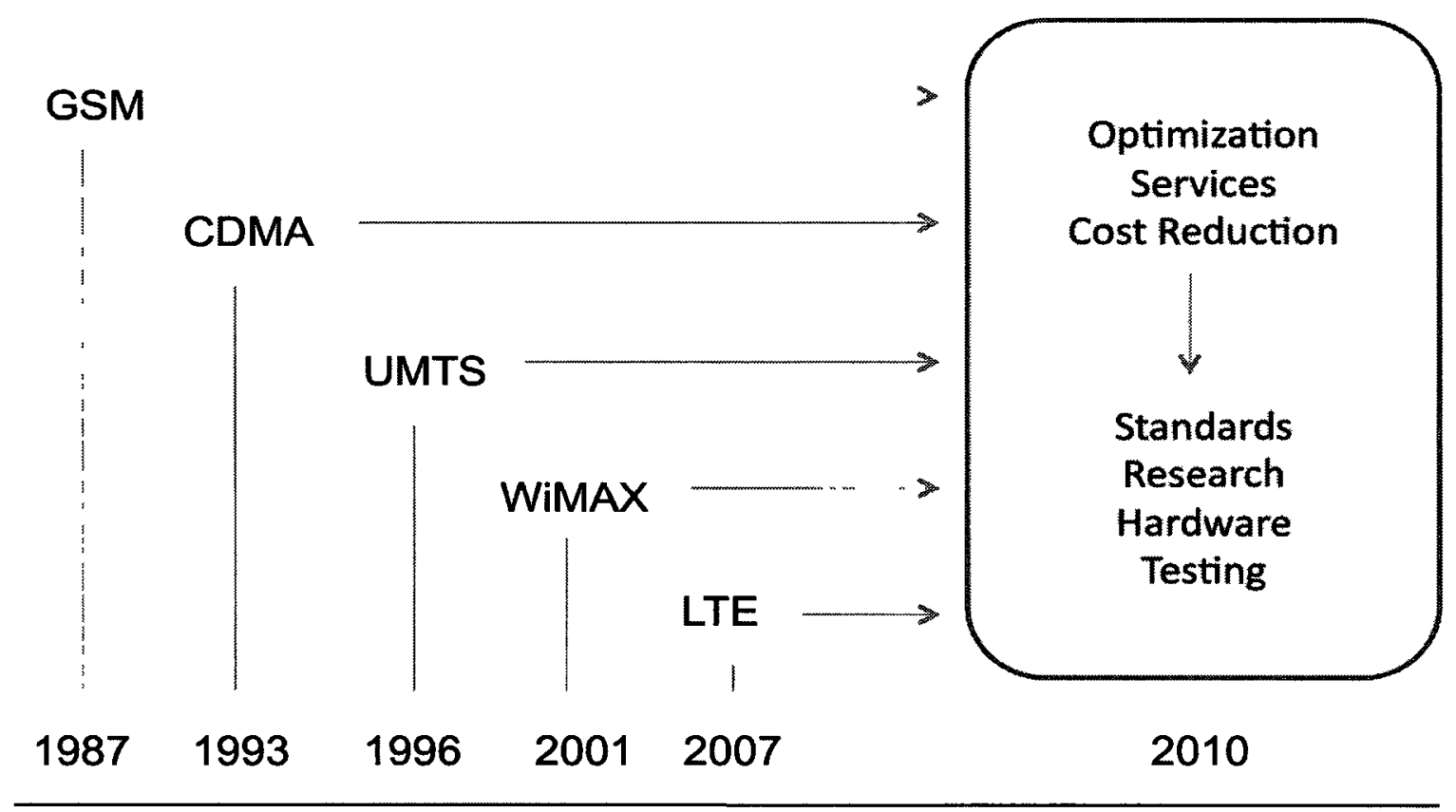

Figure 27: Legacy and Evolution 


\subsection{Technology Adoption}

The analysis of organizations with multiple memberships in the wireless industry consortia can provide insights into the technology adoption. A chronological view of the wireless industry consortia, technologies and standards is presented in Figure 28.

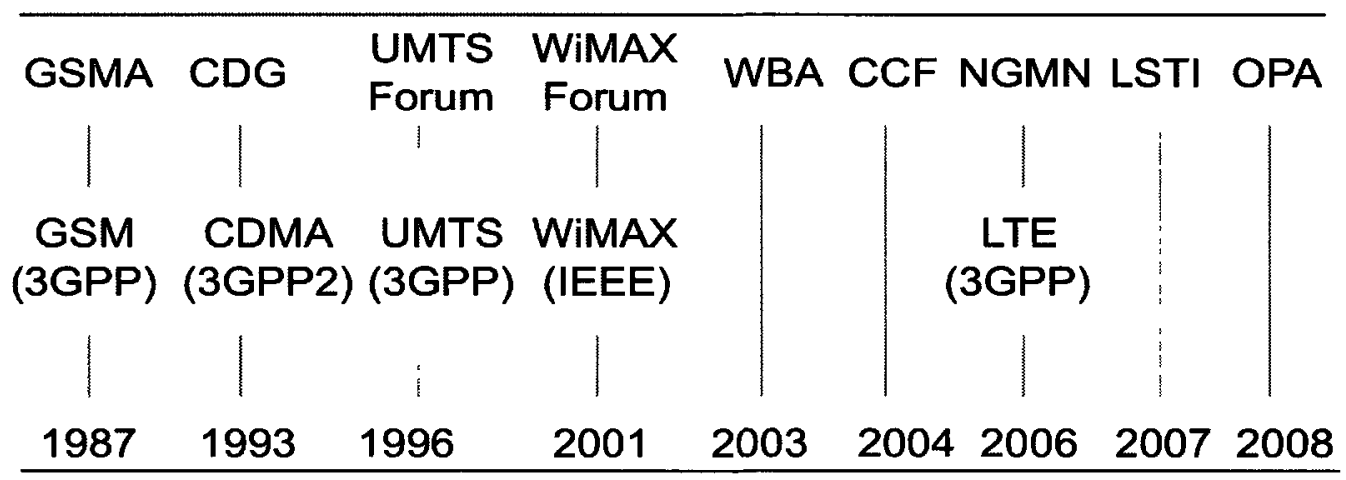

Figure 28: Chronological View

For organizations that are members of two consortia it can be inferred that the later chronological membership is an indication of adopting the technology that is supported by the later. The following factors were identified as representative for the technologies and standards and are used as proxies for detecting the technology adoption:

- 16: CDMA Technology and 3GPP2 Standards

- I1: WiMAX Technology and IEEE 802.11 Standards

- 17: LTE Technology and 3GPP Standards

The following consortia are used as proxy for the technology and standards they support: 
- GSMA: GSM Technology and 3GPP Standards

- CDG: CDMA Technology and 3GPP2 Standards

- UMTS Forum: UMTS Technology and 3GPP Standards

- WiMAX Forum: WiMAX Technology and IEEE 802.11 Standards

- LSTI and NGMN: LTE Technology and 3GPP Standards

The adoption map to CDMA and from CDMA to other technologies, based on $P O D I(16, A l l, I)$ Index identified in Figure 19, is presented in Figure 29:

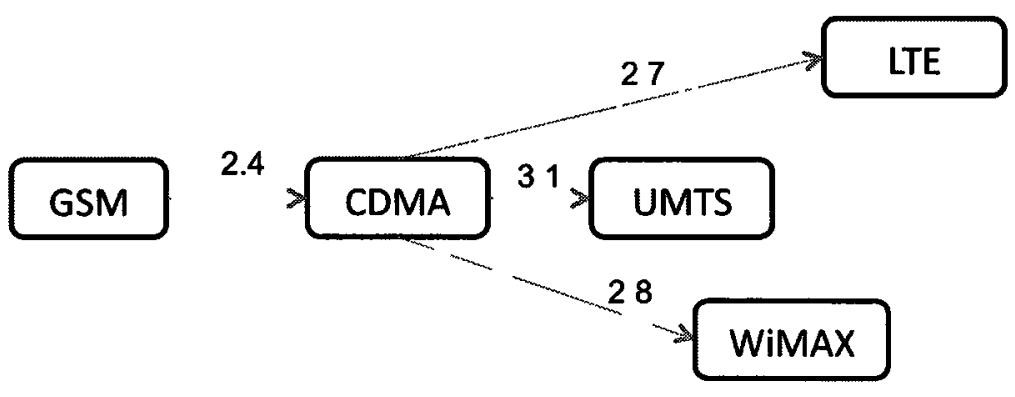

Figure 29: CDMA Adoption

The adoption map to WiMAX and from WiMAX to other technologies, based on $P O D I(I 1, A l l, I$,$) Index identified in Figure 20, is presented in Figure 30:$

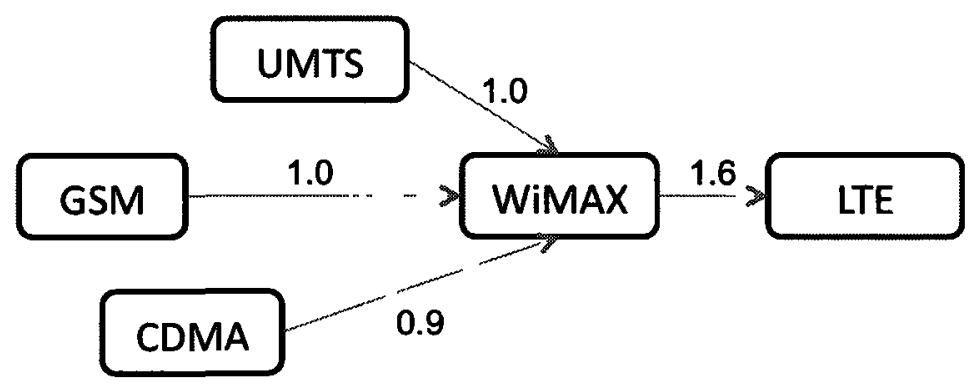

Figure 30: WiMAX Adoption

The adoption map to LTE, based on PODI (I1, All, I) Index identified in Figure 21, is presented in Figure 31: 


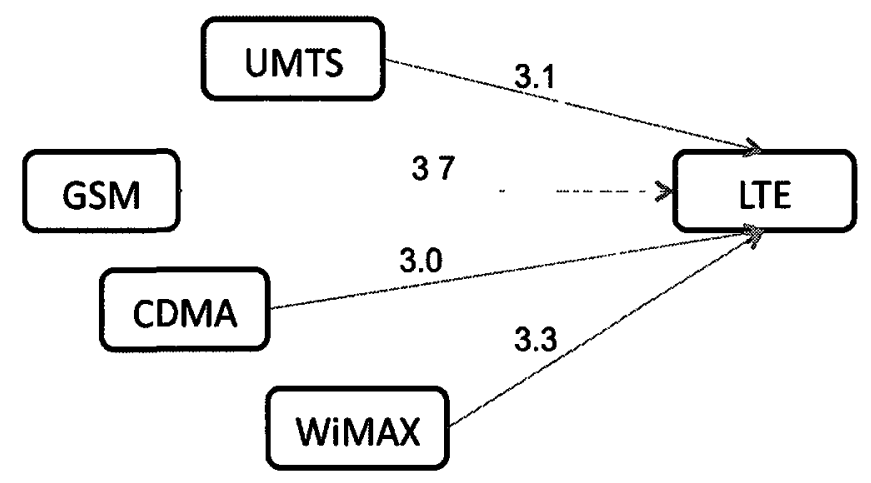

Figure 31: LTE Adoption

From the technologies and standards analyzed, CDMA/3GPP2, WiMAX/IEEE and LTE/3GPP, only WiMAX does not show a strong indication of adoption from the legacy standards. This could be an indication that the introduction of WiMAX allowed new comers to enter the market. By comparison, CDMA, even though it is specified by the 3GPP2 standards, indicates strong adoption from 3GPP legacy and to 3GPP evolution standards. This study also found that the evolution of 3GPP standards from legacy technologies, such as GSM and UMTS, to the evolution technology, LTE, is strongly supported.

\subsection{The Emerging Role of Backend Systems}

One observation is the strong showing of constructs related to service and billing:

- Revenue Management Solutions ( Table 21)

- Fee Based Business Solutions ( Table 17 )

- Mobile Services ( Table 15)

- Interoperability Solutions ( Table 23 )

- Fraud Detection ( Table 27 ) 
- Business Opportunity Solutions ( Table 28 )

- Security Solutions (Table 22)

In the study of the convergence of the mobile ecosystem Basole (2009) highlights the relative central network position of the service and billing providers. The service and billing providers provide software systems necessary for provisioning, billing, and customer service. Basole (2009) arguments that, as technologies, content and offerings converge, the ability to seamlessly provision and price new, bundled service becomes even more important as these backend systems enable network operators, service and content providers to monetize the products and services they offer.

These points explain in part the strength of the service and billing constructs identified in this study.

\subsection{Members Motivation for Participation}

The participation of the industry stakeholders in standards development activities, technology trials and equipment certification to validate the crossvendor interoperability of the radio access and core networks is often regarded as an effort to create or further the mobile ecosystem ${ }^{36}$. The niches created in the industry by associations, forums or alliances take shape under the leadership of these organizations which act as keystones and network hubs. lansiti and Levien (2004) defines them as active leaders, effective at both creating and sharing value across the system; they are the network hubs that sit

\footnotetext{
${ }^{36}$ http //www.Istiforum.org/medıa/press html?lıstNum=160, last accessed August 8, 2010
} 
at the core of the collaboration network. These associations, forums and alliances have attracted membership based on several manifest characteristics. A summary of these characteristics based on the results identified in Chapter 5 and the consortia "About Us" web pages is provided in Table 61.

Table 61: Members Motivation for Participation

\begin{tabular}{|c|c|}
\hline Con & Main Drivers for Participation \\
\hline orum & $\begin{array}{l}\text { The forum is an exclusive WiMAX certification provider: } \\
\text { - The certification for standard compliance and } \\
\text { interoperability at the access level of the network is one } \\
\text { of the main reasons for membership }\end{array}$ \\
\hline $\begin{array}{l}\text { GSM } \\
\text { Association }\end{array}$ & $\begin{array}{l}\text { The association is an interoperability enabler: } \\
\text { - In the absence of industry standards regulating the } \\
\text { roaming data exchange between network operators the } \\
\text { GSMA working groups have developed the NRTRDE - } \\
\text { a method to monitor customer's activities in the visited } \\
\text { networks and quickly detect roaming fraud }\end{array}$ \\
\hline $\begin{array}{l}\text { LSTI Forum } \\
\text { NGMN Alliance }\end{array}$ & $\begin{array}{l}\text { Members and the consortia are setting the LTE/SAE } \\
\text { standards: } \\
\text { - The 3GPP standard and the LTE technology represent } \\
\text { one of the strongest constructs found for the LSTI } \\
\text { Forum and NGMN Alliance members } \\
\text { Members participate in technology trials to test for } \\
\text { interoperability: } \\
\text { - The early stages of interoperability are defined by } \\
\text { research and testing as the technology is not mature } \\
\text { and stable enough }\end{array}$ \\
\hline
\end{tabular}




\begin{tabular}{|c|c|}
\hline $\begin{array}{l}\text { CDMA } \\
\text { Certification } \\
\text { Forum }\end{array}$ & $\begin{array}{l}\text { The forum is a certification provider: } \\
\text { - The certification testing for standard compliance allows } \\
\text { for cross-vendor interoperability } \\
\text { - By certifying its member's products, the association } \\
\text { brings value to its members by guaranteeing the } \\
\text { standards compliance and cross-vendor interoperability }\end{array}$ \\
\hline UMTS Forum & $\begin{array}{l}\text { The forum is a consultancy provider: } \\
\text { - There is large number of constructs identified for this } \\
\text { forum; this is explained in large part by its involvement } \\
\text { with both UMTS and LTE technologies; the forum } \\
\text { supports the interests of its members through studies } \\
\text { and reports on markets, applications, regulation, etc. }\end{array}$ \\
\hline $\begin{array}{l}\text { CDMA } \\
\text { Development } \\
\text { Group }\end{array}$ & $\begin{array}{l}\text { As the evolution path of } 3 G P P 2 \text { was dropped in favour of } \\
\text { 3GPP the group supports its members with the evolution from } \\
\text { CDMA to 4G/3GPP: } \\
\text { - The majority of its members are operators and this fact } \\
\text { is reflected in constructs specific to operators, such as } \\
\text { revenue management and business opportunity } \\
\text { solutions. } \\
\text { - The identification of the Hardware construct could be } \\
\text { explained by the new requirements for dual support } \\
\text { CDMA/LTE at the base station and user device level }\end{array}$ \\
\hline $\begin{array}{l}\text { Wireless } \\
\text { Broadband } \\
\text { Alliance }\end{array}$ & $\begin{array}{l}\text { The association is an interoperability enabler: } \\
\text { - In the absence of industry standards regulating the } \\
\text { roaming data exchange between Wi-Fi network } \\
\text { operators the WBA developed the WRIX - a roaming } \\
\text { specification for Wi-Fi }\end{array}$ \\
\hline
\end{tabular}


The alliance's goal is to create an IPR licensing structure for WiMAX

Open Patent

Alliance
- Most of the members are also members of WiMAX Forum

- The constructs identified in this study do not indicate a focus on the IPR licensing

\subsection{Phases of Development}

The characteristics identified in Table 61 suggest several phases in the development of consortia, as shown in Table 62.

Table 62: Consortia Phases of Development

\begin{tabular}{|c|c|l|}
\hline Phase & \multicolumn{1}{|c|}{ Phase Name } & \multicolumn{1}{|c|}{ Phase Description } \\
\hline 1 & $\begin{array}{c}\text { Provide a platform for } \\
\text { discussion among } \\
\text { interested parties }\end{array}$ & $\begin{array}{l}\text { The industry consortia enable the } \\
\text { communication among member organizations } \\
\text { on how to enter into an agreement to } \\
\text { accomplish a common purpose }\end{array}$ \\
\hline 2 & $\begin{array}{c}\text { Work with members } \\
\text { and standard bodies } \\
\text { in setting and } \\
\text { implementation of } \\
\text { standards }\end{array}$ & $\begin{array}{l}\text { CDMA Certification Forum works with its } \\
\text { members to ensure the compliance to 3GPP2 } \\
\text { standards. WiMAX Forum works with its } \\
\text { standard developed by IEEE. UMTS Forum, } \\
\text { LSTI Forum and NGMN Alliance work with } \\
\text { their members to ensure that their } \\
\text { recommendations are included in the } \\
\text { standards by the 3GPP organization }\end{array}$ \\
\hline
\end{tabular}




\begin{tabular}{|c|c|l|}
\hline 3 & $\begin{array}{c}\text { Enable the } \\
\text { interoperability of } \\
\text { members' products }\end{array}$ & $\begin{array}{l}\text { WiMAX Forum enables interoperability at the } \\
\text { lower layers of the communication stack (e.g. } \\
\text { technology trials for cross-vendor } \\
\text { interoperability or certification for industry } \\
\text { acceptance). GSM Association show a strong } \\
\text { focus on interoperability at higher layers of the } \\
\text { communication stack (e.g. methodologies for } \\
\text { inter-operator roaming user data exchange) }\end{array}$ \\
\hline
\end{tabular}

This study provided a cross-sectional analysis of consortia that were created at various points in time and suggests that these associations, forums and alliances evolve over time to adapt to the new technologies and business models of their members and cycle through phases 1,2 and 3 as shown in Figure 32.

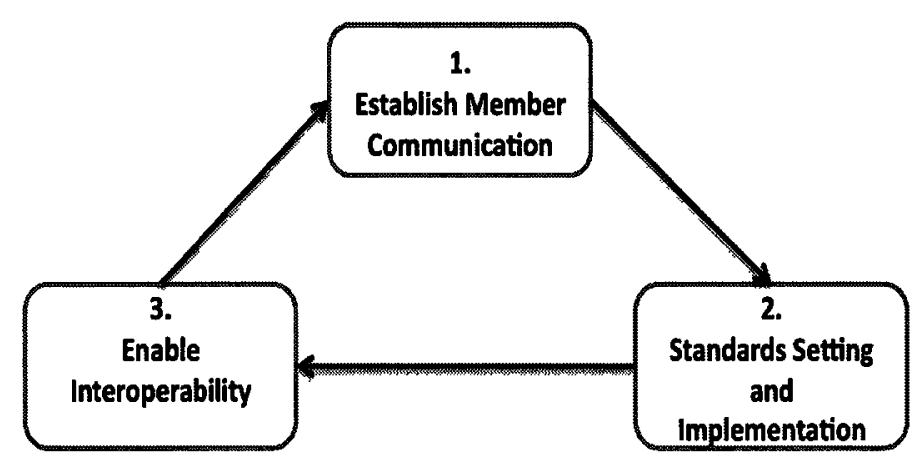

Figure 32: Consortia Evolution Cycle 


\subsection{Insights Gained From Research}

The following insights were gained from this research:

\section{I1: Product certification motivates organizations to join industry consortia}

There is an identifiable niche for certification for standard compliance at the access level of the network as indicated by the "Conformance and Certification" construct in Table 30. WiMAX Forum has become de facto the exclusive certification organization for base stations and user equipment for compliance to the WiMAX standard ${ }^{37}$. Members use "WiMAX Forum Certified" logo on their websites as a mark of compliance.

12: Interoperability of their products motivates organizations to join industry consortia

The conformance certification of products at the access level of the wireless network is based on the standards developed by 3GPP, 3GPP2 and IEEE standard organizations and represents a mandatory requirement for crossvendor interoperability. With the advance of global mobility the network operators have new requirements for roaming, user data exchange and fraud detection. These characteristics were identified by the "Interoperability Solutions" construct as shown in Table 23. In the absence of standards provided by the standard organizations, consortia such as GSM Association and

\footnotetext{
${ }^{37} \mathrm{http} . / \mathrm{www}$. wimaxforum org/certification/certıfication-overview, last accessed July 30, 2010
} 
Broadband Wireless Alliance have stepped in and provided platforms for interoperability such as NRTRDE ${ }^{38}$ or WRIX ${ }^{39}$.

13: As technology matures the new interoperability requirements move up in the network stack

If the layered model proposed by Fransman (2002) (see Section

2.1.3 The layered model) is used as a backdrop for mapping the salient constructs of interoperability identified by insights 11 and 12 , then it can be suggested that as the technology evolves and matures, the new requirements for product interoperability move up to the next layer in the wireless communication network stack.

14: Organizations involved in legacy technologies are characterized by a focus on optimization, services and cost reduction; organizations involved in the new and developing technologies are focused on standards, research, hardware, and testing

The most active organizations involved in the new and developing technologies are the infrastructure providers and the device manufacturers. In time, as the technology evolves, there is a drive for cost reduction for infrastructure equipment and devices as indicated by the identified constructs in Table 60 and Figure 27. As technologies, content, and offerings converge (Basole, 2009) the ability to provide new, bundled services becomes more important.

\footnotetext{
${ }^{38} \mathrm{http}: / \mathrm{www} . \mathrm{gsmw}$ orld com/newsroom/press-releases $/ 2069 \mathrm{htm}$, last accessed July 30, 2010

${ }^{39} \mathrm{http} / / \mathrm{www}$.wballiance.net/1ndex.html, last accessed July 30, 2010
} 
15: Service and billing providers form a critical segment in the wireless industry

Traditionally, the infrastructure providers, device manufacturers, network operators, application developers and content providers were regarded as the main players in the industry. Some of the salient constructs, identified and summarized in Section 5.4 The Emerging Role of Backend Systems, confirm the observations in Basole (2009) that the service and billing providers occupy a central position and play a critical role in the mobile ecosystem. These backend systems enable operators to provision and price new, bundled services and products.

16: The membership to wireless industry consortia provides an indication of technology adoption

Based on the chronological comparison between the consortia's establishment date and the technologies they support it can inferred that membership to more than one association, forum or alliance can be used as an indicator for the adoption of the technology supported by the later membership (see Section 5.3 Technology Adoption).

17: The hierarchical decomposition dissimilarity index is an indicator for factor analysis solutions

As indicated in Table 7, the initial exploratory sub-sampling resulted in eight sample groups ( $A, B, C, D, E, F, G$, and $H)$. The factor analysis results were retained only for groups $E, F, G$, and $H$, as these groups provided more relevant 
solutions. One observation is that the retained groups are characterized by small values of the dissimilarity index. Although the intent was to create subsamples with higher degrees of similarity this observation is no hard-set rule and more research is needed to validate this observation.

\section{8: Non random sampling is recommended for content analysis}

The results in this study show that the content analysis using factor reduction depends significantly on the sample. This reinforces the recommendations from Eisenhardt (1989, 2007) and Patton (1990) which highlight the inappropriateness of random sampling. This approach is particularly relevant in this study as its goal was to uncover as many and diverse constructs as possible and this was possible by creating sub-samples with higher similarity.

\section{Summary}

The results of this research identified the following points of difference for the associations, forums and alliances in the consortia studied:

- Supporters of legacy technologies are characterized by a focus on optimization, services and cost reduction. This is the case for GSM Association, CDMA Development Group and in part UMTS Forum.

- Supporters of newer technologies are characterized by a focus on standards, research, hardware, and testing. This is the case for WiMAX Forum, NGMN Alliance, LSTI Forum, and in part UMTS Forum.

- Member's motivation to participate is driven by two constructs: certification and interoperability. WiMAX Forum, CDMA Certification Forum and Open 
Patent Alliance are more active in certification. The interoperability is a focus area for GSM Association, CDMA Development Group, Wireless Broadband Alliance, and LSTI Forum.

- Multiple memberships combined with technology focus provide an indication of technology adoption:

- CDMA technology supporters also support GSM, UMTS, WiMAX and LTE technologies

- LTE technology supporters also support GSM, CDMA, UMTS and WiMAX technologies

- WiMAX technology supporters support LTE technology only, which suggests a large number of new market entrants

\subsection{Recommendations for Keystone Organizations}

Based on the research insights (see Section 5.7 Insights Gained From Research) and the identified constructs for the wireless industry consortia (see Section 4.5 Constructs) the following recommendations can be inferred for nonprofit organizations that play a keystone role:

Table 63: Recommendations for Keystone Organizations

\begin{tabular}{|c|l|l|}
\hline 1 & $\begin{array}{l}\text { Get involved in the } \\
\text { early stages of } \\
\text { technology }\end{array}$ & $\begin{array}{l}\text { Attract members by supporting their } \\
\text { recommendations to the standards bodies } \\
\text { Work with members and standards bodies in } \\
\text { setting and implementation of standards }\end{array}$ \\
\hline 2 & Act as an enabler of & \begin{tabular}{l} 
Provide a solutions for member's cross- \\
\hline
\end{tabular}
\end{tabular}




\begin{tabular}{|c|c|c|}
\hline & $\begin{array}{l}\text { interoperability for } \\
\text { members products } \\
\text { and services }\end{array}$ & $\begin{array}{l}\text { vendor interoperability needs such as } \\
\text { certification services (see Section } 5.7,11 \text { ) } \\
\text { Provide platforms of interoperability if no } \\
\text { standards are available (e.g. NRTRDE and } \\
\text { WRIX roaming platforms identified in Section } \\
5.7,12)\end{array}$ \\
\hline 3 & $\begin{array}{l}\text { Prepare to move up } \\
\text { the interoperability } \\
\text { stack as technology } \\
\text { matures }\end{array}$ & $\begin{array}{l}\text { As the technology matures a keystone should } \\
\text { prepare the ground for the next interoperability } \\
\text { needs (e.g. WiMAX Forum, which is focused } \\
\text { on certification, launched its roaming } \\
\text { guidelines and specifications under a new } \\
\text { brand name, WiMAX Roaming, and a new } \\
\text { website }{ }^{40} \text { ) }\end{array}$ \\
\hline 4 & $\begin{array}{l}\text { Identify the most } \\
\text { active members at } \\
\text { each stage in the } \\
\text { technology evolution } \\
\text { and support their } \\
\text { interests }\end{array}$ & $\begin{array}{l}\text { In the early stages of a technology the most } \\
\text { active members are the infrastructure } \\
\text { equipment providers and device } \\
\text { manufacturers. Later on, as the network } \\
\text { operators and service providers become the } \\
\text { most active members they depend more and } \\
\text { more on the service and billing providers (see } \\
\text { Section } 5.7,15 \text { ) }\end{array}$ \\
\hline
\end{tabular}

\footnotetext{
${ }^{40} \mathrm{http} / / \mathrm{www} . \mathrm{w}$ imaxroaming org/, last accessed August 12, 2010
} 


\section{Conclusions}

This chapter is organized into three sections. The first section provides the conclusions of this research. The second section provides the limitations of this research. The third section provides opportunities for future research.

\subsection{Conclusions}

The objective of this research was to examine the points of difference for members of associations, forums or alliances operating in the wireless industry. An organization' membership to an association, forum or alliance was used to classify the organization as a stakeholder in the standard and technologies supported by the consortium the organization is a member of. The introduction of the POD Index, as an instrument of comparison for consortia, allowed for the identification of differences amongst the associations, forums and alliances. This approach was validated by the fact that the relatively high value for the POD Index for standards and technologies constructs identified for a consortium matches the standard and technology openly supported by that consortium, as shown by Consortia Brand Names construct.

The points-of-difference (POD) - defined as groups of constructs - was used to create a mapping of consortia's objectives to constructs identified from consortia's members. The mapping of the 9 associations, forums and alliances resulted in three types of links between constructs and objectives: 
1. Strong support: there is a good mapping between the points-of-difference identified and the consortia's objective for WiMAX Forum, and CDMA Certification Forum.

2. Definitional role: the identified POD provide suggestions for what the consortia's objective means, and identify how the consortia brings value to its members. This is characteristic for consortia with vague and general objectives as shown in the case of: GSM Association, CDMA Development Group, UMTS Forum, LSTI Forum, NGMN Alliance, and Wireless Broadband Alliance.

3. Weak support: There is a poor mapping between the points-of-difference identified and the consortia's objective for Open Patent Alliance.

Another contribution made by this research was in identifying an opportunity on how to enhance the use of factor analysis from a technique of dimension reduction to a methodology of searching for construct diversity. In the research process the following methodology steps were identified:

1. A priori classification: the initial classification of organizations, based on the memberships to wireless industry consortia, helped identify which organizations support what standards and technologies. This a priori classification allows for constructs comparison between consortia.

2. Sub-sampling: using hierarchical decomposition, several homogenous sub-samples were identified. The non-probability sampling methodology created more similar samples on which factor analysis identified factors that would not be found otherwise in a random sample. 
3. Constructs identification: similar factors from the sub-samples are grouped together to define a construct.

4. Points of difference: the salient constructs indicate the relative importance of a construct for a consortium and are used for comparisons to other consortia.

The techniques for analyzing the industries and competitors proposed by Porter (2004) provide a view from an organization's level. By comparison, this research provides an analysis of an industry by comparing the differentiating points of its consortia.

To the best of my knowledge, this is the first study that uses this methodology. The use of sub-samples created using hierarchical decomposition and multiple factor analysis provides an approach that allows the identification of as many and diverse factors as possible. The non probability sampling approach is instrumental in the mapping of the wireless industry consortia.

A key finding made by this research was the identification of constructs that are specific to legacy or newer technologies. Based on consortia's establishment date and involvement with the respective technologies it was identified that:

1. Legacy technologies (GSM, CDMA): are characterized by constructs indicating a focus on optimization, services and cost reduction

2. Evolution technologies (WiMAX, LTE): are characterized by constructs indicating a focus on standards, research, hardware and testing 
The results from the analysis of the organizations with multiple membership to consortia helped in identifying the trajectories of technological adoption. From the technologies and standards analyzed, CDMA/3GPP2, WiMAX/IEEE and LTE/3GPP, only WiMAX does not show a strong indication of adoption from the legacy standards. This could be an indication that the introduction of WiMAX allowed more new comers to enter the market. By comparison, CDMA, even though it is specified by the 3GPP2 standards, indicates strong adoption to 3GPP evolution standards, and thus supports the idea of LTE as the convergence technology (Saini, 2009).

Another key finding is that membership to consortia is driven by two main goals: certification and interoperability. Consortia's keystone organizations step in to provide platforms for interoperability in the absence of standards.

\subsection{Limitations}

The research has at least three limitations:

- In general factor analysis requires that researchers have a good knowledge of the domain. A deep understanding of the wireless industry was required to conduct this research and as a result measuring the consistency is difficult.

- Factor analysis is a relatively subjective and especially so when used in conjunction with content analysis. The solutions identified in this research are based on my interpretation of the keywords and their meaning when grouped together and represent no hard-set rule for meaning. 
- The points-of-difference approach used in this research uses only those constructs that are significantly stronger, at the expense of the rest.

\subsection{Future Research}

This research identifies four opportunities for future research:

- Measure the competition between ecosystems by identifying and comparing their differentiating points using the methodology provided in this research.

- The results from this research can be enhanced by identifying each organization type (network operator, infrastructure provider, device manufacturer, application provider, content provider, service provider, etc.). This additional information could shed more light into to which organizations are the first technology adopters and whether the salient constructs identified are more prevalent to certain types of organizations.

- Identify which organizations have multiple memberships and what is their motivation. Are the multiple memberships specific to certain types of companies?

- Enhance to mapping methodology and possibly automate it. This would allow periodic evaluations of the industry over time and shed more light into technology adoption and how the identified constructs evolve. 


\section{References}

Allen, S. (2009). An empirical study of the components of value co-creation, Master Thesis, Technology Innovation Management, Carleton University, Ottawa, Ontario

Anderson, J.C., Narus, J.A., van Rossum, W. (2006). Customer value propositions in business markets, Harvard Business Review, March

Bailetti, A. and Callahan, J. (1995). Managing consistency between product development and public standards evolution, Research Policy, 24: 913-931

Balaji, T.S., Landers, B., Kates, J. and Moritz, B. (2005). A Carrier's Perspective on Creating a Mobile Multimedia Service, Communications of the ACM, 48(7): $49-53$

Baldwin, C. Y. (2007). Modularity, Transactions, and the Boundaries of Firms: A Synthesis, Paper presented at the Ross School of Business Strategy Seminar, University of Michigan, Ann Arbor, MI, September

Barney, J. D. and R. E. Hoskisson (1990). Strategic groups: Untested assertions and research proposals, Managerial and Decision Economics, 11: 187-198

Basole R.C. (2009). Visualization of inter-firm relations in a converging mobile ecosystem, Journal of Information Technology, 24: 144-159

Bauer J.M. (2010). Regulation, public policy, and investment in communications infrastructure, Telecommunication Policy, 34: 65-79

Becker, M. (2005). Unfolding of the Mobile Marketing Ecosystem: A growing strategic network, http://mmaglobal.com/?q=node/737

Bekkers, R. and Martinelli, A. (2010). The interplay between standardization and technological change: a study on wireless technologies, technological trajectories, and essential patent claims, Conference on Opening Up Innovation: Strategy, Organization and Technology, London, June 16 - 18

Blind K., Gauch S. and Hawkins R. (2010). How the stakeholders view the impacts of international ICT standards, Telecommunication Policy, 34: 162-174

Brusoni, S. and Prencipe, A. (2001). Unpacking the black box of modularity: technology, product, and organization, Industrial and Corporate Change, Vol. 21, No. 1

Caldarelli, G. (2007). Scale-free networks, Oxford University Press 
Chesbrough, H. (2003). Open Innovation: the new imperative for creating and profiting from innovation, Harvard Business Press

Chesbrough, H. and Prencipe, A. (2008). Networks of innovation and modularity: a dynamic perspective, International Journal of Technology Management, Vol. 42, No. 4, 414-425

Carlile, R. and Christensen, C.M. (2005). The cycles of theory building in management research, Research Paper, Version 6.0

Costello, A. B. and Osborne, J.W. (2005). Best practices in exploratory factor analysis: four recommendations for getting the most from your analysis, Practical Assessment Research and Evaluation, 10(7)

Coursaris, C., Hassanein, K. and Head, M. (2006). Mobile Technologies and the Value Chain: Participants, activities and value creation, International Conference on Mobile Business, Copenhagen, Denmark: IEEE, 8-18

Darlington, R. 2010. Factor Analysis. Last Accessed: July 2010. Available at: http://www.psych.cornell.edu/Darlington/factor.htm

Dargan, P. A. (2005). Open Systems and Standards for Software Product Development, Artech House Computing Library

de Nooy, W., Mrvar A. and Batagelj V. (2005). Exploratory Social Network Analysis with Pajek, Cambridge University Press

Deng, S. and Dart, J. (1994). Measuring market orientation: A multi-factor, multiitem approach, Journal of Marketing Management, Volume 10, Issue 8, 725742

Dittrich, K. and Duysters, G. (2007). Networking as a Means to Strategy Change: The case of open innovation in mobile telephony, Journal of Product Innovation Management, 24(6): 510-521

Eisenhardt, K. M. (1989). Building theories from Case study research, Academy of Management Review, Vol.14, No.4, 532-550

Eisenhardt, K.M., Graebner, M.E. (2007). Theory building from cases: opportunity and challenges, Academy of Management Journal, 50(1), 25-32

Farrell, Winslow (2000). How hits happen, Texere Publishing, London 
Ferrier, W. (2001). Navigating the Competitive Landscape: The Drivers and Consequences of Competitive Aggressiveness, Academy of Management Journal, 44(4): 858-877

Field, A. (2005). Discovering Statistics Using SPSS, Thousand Oaks, CA, Sage Publications

Fine, Charles H. (1998). Clock speed: Winning Industry Control in the Age of Temporary Advantage, Perseus Books

Fransman, Martin (2002). Mapping the evolving telecoms industry: the uses and shortcomings of the layer model, Telecommunications Policy, 26: 473-483

Fransman Martin (2007). The new ICT Ecosystem: Implications for Policy and Regulation, Cambridge University Press

Freeman, C. (1991). Networks of innovators: a synthesis of research issues, Research Policy, Vol. 20, No. 5, 499-514

Gemser G., Leenders M. and Wijnberg N. (1996). The Dynamics of Inter-firm Networks in the Course of the Industry Life Cycle: The Role of Appropriability, Technology Analysis and Strategic Management, Vol. 8, No. 4, 459-454

Gloor, P., Paasvaara, M., Schoder, D. and Willems, P. (2007). Finding Collaborative Innovation Networks Through Correlating Performance With Social Network Structure, Journal of Production Research, Taylor and Francis, April

Heldal, F., Sjovold, E., Heldal, A.F. (2004). Success on the Internet - optimizing relationships through the corporate site, International Journal of Information Management, Volume 24, Issue 2, April, 115-129

Hemphill Thomas (2009). Technology standards-setting in the US wireless telecommunications industry: A study of three generation of digital standards development, Telematics and Informatics, 26: 103-124

Hicks, D.M., Libaers, D.P., Porter, A.L., Schoeneck, D.J. (2007). Identification of the technology commercialization strategies of high-tech small firms, Small Business Research Summary, December. Available at http://www.sba.gov/advo/research/rs289tot.pdf

Hite, J.M. and Hesterly, W.S. (2001). The evolution of firm networks: from emergence to early growth of the firm, Strategic Management Journal, Vol. 22, No. 3, 275-286 
lansiti, M. and Levien, R. (2004a). The Keystone Advantage: What new dynamics of business ecosystems mean for strategy, innovation, and sustainability, Boston, MA, Harvard Business School Press

lansiti, M. and Levien, R. (2004b). Strategy as Ecology, Harvard Business Review 82(3): 68-78

Insch, A. (2008). Online communication of Corporate Environmental Citizenship: A study of New Zealand's electricity and gas retailers, Journal of Marketing Communications, 14(2):139-153

lyer B., Lee C. and Venkatraman N. (2006). Managing in a "Small World Ecosystem": Lessons from the Software Sector, California Management Review, 48(3): 28-47

Kazi, K. (2006). Optical Networking Standards: A Comprehensive Guide for Professionals

Keil T. (2002). De-facto standardization through alliances - lessons from Bluetooth, Telecommunication Policy, 26, Issues 3-4, 205-213

Ketchen, D. J. and Shook, C. L. (1996). The application of cluster analysis in strategic management research: an analysis and critique, Strategic Management Journal, Vol. 17, 441-458

Kim H. J., Weiss M.B.H., Morel B. (2009). Real options and technology management: Assessing technology migration in wireless industry, Telematics and Informatics, 26: 180-192

Kodama, Mitsuru (2002). Transforming an old economy company into a new economy success: the case of NTT DoCoMo, Leadership and Organization Development Journal, 23/1, 26-29

Kothandaraman, P. and Wilson, D. T. (2001). The Future of Competition: ValueCreating Networks, Industrial Marketing Management, 30: 379-389

Koza, M. P. and Lewin, A. Y. (1998). The Co-evolution of Strategic Alliances. Organization Science, Vol. 9, No. 3, May-June

Langlois, R. (2002). Modularity in technology and organization, Journal of Economic Behaviour and Organization, 49: 19-37

Langlois, R. and Robertson, P. (1992). Networks and innovation in a modular system: Lessons from the microcomputer and stereo component industries, Research Policy, 21: 297-313 
Leiponen, A. and Bar, T. (2008). Collaboration and networking in cooperative standard setting, Conference on Entrepreneurship and Innovation Organizations, Institutions, Systems and Regions. Copenhagen, Denmark, June $17-20$

Leiponen, A. (2008). Competing Through Cooperation: The Organization of Standard Setting in Wireless Telecommunications, Management Science, Vol. 54 , Issue 11, 1904-1919

Lombardi, S. (2009). Interactions between Eclipse Foundation Members and Eclipse Projects, Master Thesis, Technology Innovation Management, Carleton University, Ottawa, Ontario

Madey, G., Freeh, V., Tynan, R. (2002). The open source software development phenomenon: an analysis based on social network theory, AMCIS Proceedings, Paper 247

Maitland, Bauer and Westerveld (2002). The European market for mobile data: evolving value chains and industry structure, Telecommunications Policy, 26: 485-504

McGinnis, G. (2008). Competitive actions of companies whose revenue relies on open source software, Master's Thesis, Technology Innovation Management, Carleton University, Ottawa, Ontario

McMillan, S. (2000). The microscope and the moving target: The challenge of applying content analysis to the world wide web, Journalism and Mass Communication Quarterly, 77(1): 80-98

Meyer, A. D., Tsui, A. S. and Hinings, C. R. (1993). Configurational approaches to organizational analysis, Academy of Management Journal, 36: 1175-1195

Miller, D. and Mintzberg, H. (1983). The case for configuration, Sage, Beverly Hills, CA, 57-73

Moore, J. F. (1993). Predators and Prey: A New Ecology of Competition, Harvard Business Review, May-June

Moore, J.F. (1996). The Death of Competition: Leadership and strategy in the age of business ecosystems, HarperCollins, New York

Moore, J. F. (2006). Business ecosystem and the view from the firm, Antitrust Bulletin, Vol. 51, No. 1 
Neuman, W. L. (2003). Social Research Methods: Qualitative and Quantitative approaches, Allyn and Bacon, Boston, 5th Ed.

Newman, M.E.J. (2001). The structure of scientific collaboration networks, Proceedings of the National Academy of Science (USA), 98, 404-409

Oliver A., (2001). Strategic Alliances and the learning life-cycle of biotechnological firms, Organization Studies, 22/3, 467-489

Opoku, R. (2005). Communication of Brand Personality by Some Top Business Schools Online, Licentiate Thesis, Lulea University of Technology, ISSN: 14021757

Orsenigo L., Pammolli F. and Riccaboni M. (2001). Technological change and network dynamics - Lessons from the pharmaceutical industry, Research Policy, 30: 485-508

Pagani M. and Fine C.H. (2008). Value network dynamics in 3G-4G wireless communications: A systems thinking approach to strategic value assessment, Journal of Business Research, 61: 1102-1112

Patton, M. Q. (1990). Qualitative Evaluation and Research Methods, Sage, Newbury Park, CA, 2nd Ed.

Peltoniemi M. (2006). Preliminary theoretical framework for the study of business ecosystems, ECO, Vol. 8, No. 1, 10-19

Peppard, J. and Rylander, A. (2006). From Value Chain to Value Network: Insights for mobile operators, European Management Journal, 24(2-3): 128141

Perry, M. and Bodkin, C. (2000). Content analysis of 100 company Web sites. Corporate Communications: An International Journal, 5(2):87-97

Podolny, J. M. (2005). Status Signals: A Sociological Study of Market Competition, Princeton University Press

Pollach, I. (2005). Corporate self-presentation on the WWW: Strategies for enhancing usability, credibility and utility, Corporate Communications: An International Journal, 10(4): 285-301

Porter, Michael (1985). Competitive Advantage: Creating and Sustaining Superior Performance, New York: The Free Press 
Porter, Michael (2004). Competitive Strategy: Techniques for Analyzing Industries and Competitors, The Free Press

Porter, A., Schoeneck, D., Frey, P., Hicks, D. and Libaers, D. (2007). Mining the Internet for Competitive Technical Intelligence, Competitive Intelligence Magazine, 10(5): 24-28

Reinard, J. (2006). Communication Research Statistics, Thousand Oaks, CA, Sage Publications

Sabat H. K. (2002). The evolving mobile wireless value chain and market structure, Telecommunication Policy, 26: 505-535

Saini, G. (2009). Examining the $4 \mathrm{G}$ mobile standard convergence to the LTE standard, Master Thesis, Technology Innovation Management, Carleton University, Ottawa, Ontario

Sanchez, R. and Mahoney, J. (1996). Modularity, flexibility, and knowledge management in product and organization design, Strategic Management Journal, Vol. 17, Winter Special Issue, 63-76

Schilling, M., and Steensma, K. H. (2001). The use of modular organizational forms: An industry-level analysis, Academy of Management Journal, 44(6): 1149-1168

Steinbock D. (2003). Globalization of wireless value system: from geographic to strategic advantages, Telecommunication Policy, 27: 207-235

Stevens, J.P. (2009). Applied Multivariate Statistics for the Social Sciences, New York, NY, Routledge

Teo, S. (2002). Market entry strategies of wireless start-ups, Master Thesis, Lappeenranta University of Technology, Finland

Thomas, H. and Venkatraman, N. (1988). Research on strategic groups: Progress and Prognosis, Journal of Management Studies, 25: 537-555

Tilson, D. and Lyytinen, K. (2005). Making Broadband Wireless Services: An actor-network study of the US wireless industry standard adoption, Sprouts: Working Papers on Information Environments, Systems and Organizations, 5(3): 137-154

Tilson, D. and Lyytinen, K. (2006). The 3G Transition: Changes in the US wireless industry, Telecommunications Policy, 30(10-11): 569-586 
Vesa, J. (2003). The impact of industry structure, product architecture, and ecosystem on the success of mobile data services: a comparison between European and Japanese markets, Presented at ITS 14th European Regional Conference, Helsinki, Finland, August 23 - 24

Watts, D. (1999). Small Worlds, Princeton University Press, Princeton

Young D.L. (1980). Telecommunications as ecosystem: An Australian case study. Telecommunications Policy, Volume 4, Issue 3, September, 183-207

\subsection{Web Based Sources}

Keyword Search and Analysis Tool (KSAT): http://github.com/mwnorman/KSAT

SPSS Statistics: http://www.spss.com/

CDMA Certification Forum: http://www.globalccf.org

CDMA Development Group: http://www.cdg.org

GSM Association: http://www.gsmworld.com

LSTI Forum: http://www.Istiforum.org

Next Generation Mobile Networks Alliance: http://www.ngmn.org

Open Patent Alliance: http://openpatentalliance.com

Pajek: http://pajek.imfm.si/doku.php

UMTS Forum: http://www.umts-forum.org

WiMAX Forum: http://www.wimaxforum.org

Wireless Broadband Alliance: http://www.wballiance.net 


\section{Appendix}

\section{Appendix A: URLs, Samples and Membership}

\begin{tabular}{|c|c|c|c|}
\hline URL & $\mathbf{x}$ & $\mathbf{Y}$ & $\mathbf{A}$ \\
\hline http //accurıs-networks com/ & 1 & 1 & 1 \\
\hline http //authentec com/ & 1 & 2 & 1 \\
\hline http //www axxcelera com/ & 2 & 1 & 2 \\
\hline http //cellatsea com & 1 & 2 & 5 \\
\hline http //colibria com/ & 1 & 1 & 1 \\
\hline http //en bugroup com/ & 3 & 3 & 2 \\
\hline http //en enforta ru/ & 3 & 2 & 2 \\
\hline $\begin{array}{l}\text { http //global mitsubishielectric co } \\
\mathrm{m} /\end{array}$ & 1 & 1 & 2 \\
\hline hitp //mobilicity cal & 3 & 3 & 1 \\
\hline http //openpatentallance com/ & 3 & 2 & 9 \\
\hline http //panasonic net/ & 2 & 2 & 2 \\
\hline http //redknee com/ & 3 & 2 & 1 \\
\hline http //roamsys com & 2 & 3 & 1 \\
\hline http //tatacommunications com/ & 2 & 1 & 1 \\
\hline http //us fujitsu com/ & 1 & 1 & 2 \\
\hline http //us zyxel com/ & 1 & 1 & 2 \\
\hline http //w3 tue nl & 3 & 2 & 4 \\
\hline http //wateentel com/ & 3 & 4 & 2 \\
\hline http //ww2 cox com/ & 3 & 2 & 5 \\
\hline http //www 2degreesmobile co nz & 2 & 3 & 1 \\
\hline http //www 7layers com/ & 1 & 1 & 2 \\
\hline http / /www aa-tec com & 3 & 4 & 1 \\
\hline http //www accenture com/ & 1 & 1 & 2 \\
\hline $\begin{array}{l}\text { http //www accuris- } \\
\text { networks com/ }\end{array}$ & 1 & 1 & 52 \\
\hline http //www acer com/ & 1 & 2 & 92 \\
\hline http //www acision com/ & 3 & 2 & 1 \\
\hline http //www acmepacket com/ & 3 & 2 & 1 \\
\hline http //www actix com/ & 1 & 2 & 4 \\
\hline http / wwww adaptivemobile com/ & 1 & 3 & 1 \\
\hline http //www adecef com/ & 3 & 2 & 1 \\
\hline http / /www adt com tw/ & 2 & 2 & 2 \\
\hline http $/ / w w w$ advantest co $\mathrm{pp} /$ & 3 & 4 & 2 \\
\hline http //www aeroflex com/ & 3 & 1 & 62 \\
\hline http //www aeronix com/ & 2 & 2 & 2 \\
\hline http //www aervox com/ & 2 & 3 & 1 \\
\hline http / /www afdtech com/ & 2 & 3 & 1 \\
\hline http //www aglent com/ & 1 & 1 & 3 \\
\hline http //www agllisinternational co & 3 & 3 & 1 \\
\hline http //www ahciet net & 1 & 2 & 5 \\
\hline $\begin{array}{l}\text { http / wwww aheadcommunication } \\
\text { com }\end{array}$ & 3 & 3 & 2 \\
\hline
\end{tabular}

\begin{tabular}{|c|c|c|c|}
\hline URL & $\mathbf{x}$ & $\mathbf{Y}$ & $\mathbf{A}$ \\
\hline http //www alcent net/ & 2 & 1 & 52 \\
\hline http $/ / \mathrm{www}$ arrcell com/ & 1 & 1 & 5 \\
\hline $\begin{array}{l}\text { http //www alrcominternational co } \\
\mathrm{m} /\end{array}$ & 2 & 1 & 4 \\
\hline http //www arvana com / & 3 & 1 & 5 \\
\hline http //www airwalkcom com/ & 3 & 2 & 5 \\
\hline http //www arrwidesolutions com & 2 & 1 & 1 \\
\hline http / /www aksoran kz & 4 & 4 & 2 \\
\hline http //www alaska-wireless coml & 3 & 4 & 1 \\
\hline http //www albentia com/ & 3 & 3 & 2 \\
\hline http //www alcatel-lucent com & 2 & 1 & $\begin{array}{c}564 \\
23 \\
\end{array}$ \\
\hline hitp //www alegro com ec & 4 & 4 & 5 \\
\hline http //www alepo com/ & 2 & 1 & 2 \\
\hline http //www alıanza com/ & 2 & 3 & 2 \\
\hline http //www allround net & 2 & 2 & 1 \\
\hline hitp //www alltel com & 3 & 3 & 1 \\
\hline http //www altair-semı com/ & 3 & 2 & 2 \\
\hline http //www altobridge com & 3 & 3 & 1 \\
\hline http //www alvarion com/ & 3 & 3 & 92 \\
\hline hitp //www amdocs com/ & 1 & 1 & 2 \\
\hline http //www amdtelecom net/ & 3 & 3 & 1 \\
\hline http //www americanroamer com & 3 & 3 & 2 \\
\hline http //www amerilinkwireless com & 3 & 3 & 1 \\
\hline http //www anacom pt & 3 & 2 & 7 \\
\hline http /www anımatele com/ & 4 & 4 & 1 \\
\hline http //www anite com/ & 2 & 1 & 2 \\
\hline http //www anydata com / & 2 & 3 & 56 \\
\hline http //www apacewave com/ & 3 & 2 & 2 \\
\hline http / /www aptilo com/ & 1 & 3 & 2 \\
\hline http //www arabtel net/ & 4 & 4 & 2 \\
\hline http //www aradial com/ & 3 & 3 & 2 \\
\hline http //www arbinet com & 3 & 4 & 1 \\
\hline http / www arcadyan com/ & 4 & 4 & 2 \\
\hline http //www archclearıng com & 4 & 4 & 1 \\
\hline http / /www aristaenterprise com & 3 & 3 & 6 \\
\hline http //www arqiva com/ & 1 & 2 & 2 \\
\hline http //www arraycomm com/ & 2 & 1 & 2 \\
\hline http $/ / \mathrm{www}$ aselsan com $\mathrm{tr} /$ & 2 & 2 & 2 \\
\hline http //www astac net/ & 3 & 3 & 1 \\
\hline http //www astellia com/ & 2 & 3 & 1 \\
\hline http //www astri org/ & 2 & 2 & 2 \\
\hline http //www at4wireless com/ & 1 & 2 & 2 \\
\hline
\end{tabular}




\begin{tabular}{|c|c|c|c|}
\hline URL & $\mathbf{x}$ & $\mathbf{Y}$ & $\mathbf{A}$ \\
\hline http //www atdi com/ & 4 & 4 & 2 \\
\hline http //www atheeb com/ & 2 & 3 & 2 \\
\hline http //www att com/ & 2 & 2 & 42 \\
\hline http //www augereholdings com & 3 & 3 & 2 \\
\hline http //www avea com trl & 3 & 4 & 7 \\
\hline http //www awardsolutions com/ & 3 & 2 & 2 \\
\hline http //www awbnetworks com/ & 3 & 3 & 2 \\
\hline http //www axesstel com/ & 3 & 2 & 56 \\
\hline http / /www axisnt com/ & 3 & 2 & 2 \\
\hline http //www avlus com & 3 & 2 & 1 \\
\hline http / www azımuthsystems com/ & 3 & 2 & 3 \\
\hline http / www babilon-t t/ & 4 & 0 & 2 \\
\hline http //www bakrietelecom com/ & 3 & 4 & 5 \\
\hline http //www bassetlabs com & 3 & 3 & 1 \\
\hline http / $/$ www batelco com/ & 3 & 4 & 7 \\
\hline http / wwww bayan com ph/ & 3 & 4 & 5 \\
\hline http //www beceem com/ & 4 & 2 & 92 \\
\hline http //www belgacom-Ics com/ & 3 & 2 & 1 \\
\hline http //www belizetelemedia net/ & 2 & 3 & 5 \\
\hline http / /www bell ca & 2 & 2 & 421 \\
\hline http //www bellmobility ca & 2 & 1 & 5 \\
\hline http / www bendbroadband com & 1 & 2 & 1 \\
\hline http //www bhartı com/ & 2 & 3 & 2 \\
\hline http //www billing ru & 3 & 3 & 1 \\
\hline http //www bksv com/ & 2 & 1 & 6 \\
\hline $\begin{array}{l}\text { http //www bridgewatersystems C } \\
\text { om/ }\end{array}$ & 3 & 1 & 1 \\
\hline http //www broadcom com/ & 3 & 1 & 1 \\
\hline http //uww broadhop com/ & 2 & 2 & 2 \\
\hline http //www broadpointinc com & 3 & 3 & 1 \\
\hline http //www bsnl co inl & 2 & 2 & 2 \\
\hline http //www bt com & 3 & 2 & 2 \\
\hline http //www btc bwl & 2 & 2 & 2 \\
\hline http //www btopenzone com/ & 3 & 3 & 8 \\
\hline http //www cacl com & 3 & 3 & 2 \\
\hline http / www calcomp com tw & 4 & 4 & 6 \\
\hline http //www caprock-spur com I & 3 & 4 & 1 \\
\hline http //www cardboardfish com/ & 3 & 3 & 1 \\
\hline http //www catr cn & 3 & 1 & 6 \\
\hline http //www cbnl com/ & 3 & 2 & 4 \\
\hline http //www ccsemc com/ & 2 & 2 & 2 \\
\hline http //www cctwireless com/ & 3 & 3 & 5 \\
\hline http //www 5 orgl & 2 & 1 & 5 \\
\hline http //www cdot co in/ & 1 & 2 & 1 \\
\hline http //www cedicom ru/ & 1 & 1 & 2 \\
\hline http //www celestica com/ & 2 & 2 & 2 \\
\hline http //www cellc co za & 1 & 3 & 1 \\
\hline http //www cellcom com/ & 1 & 1 & 5 \\
\hline http //www celloneet com/ & 2 & 1 & 1 \\
\hline http //www cellonenation com/ & 2 & 1 & 1 \\
\hline
\end{tabular}

\begin{tabular}{|c|c|c|c|}
\hline URL & $\mathbf{x}$ & $\mathbf{Y}$ & $\mathbf{A}$ \\
\hline http / /www cellular1 net/ & 3 & 2 & 1 \\
\hline http //uww cellularone bm/ & 2 & 3 & 5 \\
\hline$\underline{L}$ & 2 & 3 & 1 \\
\hline http //www cellularone-slo com/ & 3 & 4 & 1 \\
\hline hitp //www celplan com/ & 1 & 2 & 2 \\
\hline http //www centennialpr com/ & 1 & 1 & 5 \\
\hline http //www cerlaku com & 4 & 4 & 5 \\
\hline http //www cerillion com/ & 1 & 1 & 1 \\
\hline http //www cetecomusa com/ & 2 & 2 & 2 \\
\hline http //www cewit org in & 1 & 2 & 2 \\
\hline http / wwww cgctw com & 4 & 3 & 6 \\
\hline http //www cherrypig com & 3 & 2 & 2 \\
\hline http //www chinamobile com/en/ & 1 & 1 & 43 \\
\hline http //www chinatelecom com cn/ & 4 & 4 & 52 \\
\hline http //www chınaunıcom com/ & 2 & 3 & 2 \\
\hline http //www chinawllc com & 4 & 4 & 6 \\
\hline http //www cht com tw/ & 1 & 2 & 2 \\
\hline http //www chuanwel com kh/ & 2 & 2 & 2 \\
\hline http //www cieluxielecom com/ & 3 & 4 & 2 \\
\hline http //www ciena com/ & 2 & 1 & 2 \\
\hline http //www cincinnatibell com/ & 2 & 1 & 1 \\
\hline http / www cinterion com & 3 & 2 & 1 \\
\hline http //www cIsco com/ & 1 & 1 & 923 \\
\hline http //www citic $1616 \mathrm{com}$ & 2 & 3 & 51 \\
\hline http //www citycell com/ & 2 & 3 & 5 \\
\hline http //www clearwire com/ & 1 & 1 & 92 \\
\hline http //www clickatell com/ & 2 & 1 & 1 \\
\hline http //www cloudmark com & 1 & 2 & 1 \\
\hline http //www cmotech com/ & 3 & 3 & 2 \\
\hline http //www coal com & 2 & 1 & 7 \\
\hline http //www comarch com/ & 1 & 1 & 1 \\
\hline http //www comarco com/ & 2 & 3 & 2 \\
\hline http / www comcast com & 1 & 1 & 2 \\
\hline http //www comfone com/ & 1 & 2 & 1 \\
\hline $\begin{array}{l}\mathrm{http} / / \mathrm{www} \text { commnetwireless co } \\
\mathrm{m} /\end{array}$ & 3 & 3 & 1 \\
\hline http / www communology com/ & 1 & 1 & 4 \\
\hline http //www comneon com/ & 3 & 1 & 1 \\
\hline http //www comprion com/ & 1 & 2 & 6 \\
\hline http //www comptel com/ & 1 & 1 & 1 \\
\hline http //www comreg lel & 1 & 2 & 7 \\
\hline http $/ / w w w$ comsourceinc net/ & 4 & 2 & 1 \\
\hline http //www comstar ru/ & 1 & 2 & 2 \\
\hline http //www comsysmoblle com/ & 1 & 1 & 2 \\
\hline $\begin{array}{l}\text { http //www comtec eecs unl- } \\
\text { kassel de/ }\end{array}$ & 1 & 2 & 4 \\
\hline http //www comunicazion! it & 3 & 3 & 7 \\
\hline http //www comverse coml & 1 & 1 & 7 \\
\hline http //www comviva com/ & 1 & 1 & 1 \\
\hline
\end{tabular}




\begin{tabular}{|c|c|c|c|}
\hline URL & $\mathbf{x}$ & $\mathbf{Y}$ & A \\
\hline http / www connectionservices co & 3 & 3 & 8 \\
\hline http //www convergys com/ & 1 & 1 & 1 \\
\hline http //www coresonic com/ & 1 & 2 & 23 \\
\hline http //www corrwireless com/ & 3 & 3 & 1 \\
\hline http //www cosmote gr & 1 & 1 & 7 \\
\hline http //www cpqd com brl & 2 & 1 & 2 \\
\hline http //www cradlepoint com & 1 & 1 & 2 \\
\hline http //www creospan com/ & 1 & 2 & 2 \\
\hline http //www crestel in/ & 1 & 1 & 2 \\
\hline http //www crosstel net/ & 3 & 4 & 1 \\
\hline $\mathrm{http} / \mathrm{www}$ ctc-g co $\mathrm{p} /$ & 1 & 2 & 2 \\
\hline http //www ctia org/ & 1 & 1 & 56 \\
\hline http //www cvalley com/ & 4 & 4 & 1 \\
\hline http //www cvallev net/ & 3 & 3 & 1 \\
\hline http //www cvidya com & 1 & 2 & 1 \\
\hline http //www cyberplat com/ & 2 & 2 & 1 \\
\hline http //www datang com/ & 1 & 2 & 1 \\
\hline http //www datangmobule $\mathrm{cn} /$ & 2 & 2 & 4 \\
\hline http / $/$ www dell com/ & 1 & 1 & 2 \\
\hline 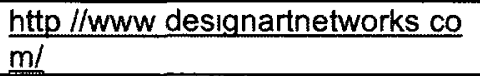 & 2 & 1 & 2 \\
\hline http //www deutschetelekom com & 1 & 2 & 82 \\
\hline http / wwww diffon com & 0 & 4 & 2 \\
\hline http //www digicelgroup com/ & 1 & 2 & 52 \\
\hline $\begin{array}{l}\text { http //www digitalbridgecommun! } \\
\text { cations com/ }\end{array}$ & 3 & 2 & 2 \\
\hline http //www dlınk com/ & 1 & 1 & 2 \\
\hline http //www dmts biz/ & 2 & 2 & 1 \\
\hline http //www docom 9 cific com/ & 2 & 1 & 5 \\
\hline http / /www dspr co jp/ & 3 & 2 & 2 \\
\hline http //www dtcwireless com/ & 2 & 3 & 1 \\
\hline http / /www du ae & 1 & 3 & 8 \\
\hline http / $/$ www eads com/ & 1 & 1 & 2 \\
\hline http //www eastcompeace com/ & 2 & 2 & 1 \\
\hline http //www ecitele com/ & 1 & 1 & 2 \\
\hline http //www ecrio com/ & 1 & 1 & 1 \\
\hline http //www edch coml & 3 & 3 & 1 \\
\hline http / $/$ www ee sgs com & 1 & 1 & 6 \\
\hline http / $/$ www einsteinwireless net/ & 2 & 3 & 1 \\
\hline http //www elonwireless com/ & 1 & 1 & 2 \\
\hline http //www eircom re/ & 1 & 2 & 2 \\
\hline http //www elektrobit com/ & 1 & 1 & 3 \\
\hline http //www elisa fi & 1 & 2 & 7 \\
\hline http //www elsagdatamat com/ & 2 & 1 & 1 \\
\hline http / /www eltekvalere com & 1 & 2 & 1 \\
\hline http //www emerytelcom com/ & 4 & 4 & 1 \\
\hline http //www emobile ip/en/ & 3 & 2 & 3 \\
\hline http //www epitiro com/ & 1 & 1 & 2 \\
\hline http //www epivalley com & 4 & 4 & 62 \\
\hline
\end{tabular}

\begin{tabular}{|c|c|c|c|}
\hline URL & $\mathbf{x}$ & $\mathbf{Y}$ & $\mathbf{A}$ \\
\hline http / $/$ www equinix com/ & 1 & 1 & 1 \\
\hline http //www ericsson com/ & 2 & 1 & 27 \\
\hline http //www eservglobal com/ & 1 & 1 & 1 \\
\hline http //www etisalat ae/ & 1 & 1 & 7 \\
\hline http //www etisalat com ng & 1 & 3 & 1 \\
\hline http //www etiworld com/ & 1 & 2 & 2 \\
\hline http //www etrı re kr/ & 1 & 2 & 2 \\
\hline http //www ets-lindgren com/ & 1 & 1 & 2 \\
\hline http $/ / w w w$ eu anritsu com $/$ & 1 & 1 & 42 \\
\hline http //www eurescom de/ & 2 & 1 & 7 \\
\hline http //www eutelsat com/ & 1 & 1 & 2 \\
\hline http //www eyelıne mobl/ & 1 & 1 & 1 \\
\hline http //www ezetop com/ & 2 & 2 & 1 \\
\hline http //www fbl gov & 1 & 2 & 2 \\
\hline http / /www ficora fi & 1 & 2 & 7 \\
\hline http //www fido cal & 2 & 2 & 1 \\
\hline http //www flextronıcs com/ & 1 & 1 & 1 \\
\hline http //www fon com & 2 & 2 & 8 \\
\hline http //www forsk com/ & 1 & 2 & 2 \\
\hline http / $/$ www francetelecom com $/$ & 1 & 1 & 7 \\
\hline http //www freedom 4 wifi com & 2 & 2 & 8 \\
\hline http //www freescale com/ & 1 & 1 & 3 \\
\hline $\begin{array}{l}\text { http } / / w w w \text { freewirebroadband co } \\
\mathrm{m} /\end{array}$ & 3 & 2 & 2 \\
\hline http //www fulkura co $\mathrm{p} /$ & 1 & 1 & 2 \\
\hline http //www fulitsu com & 1 & 1 & 43 \\
\hline http //www funaiworld com/ & 2 & 3 & 2 \\
\hline http //www futurecard ae/ & 4 & 4 & 1 \\
\hline http //www g3t net & 3 & 2 & 1 \\
\hline http //www qatewaycomms com/ & 1 & 1 & 1 \\
\hline http / / www gci com/ & 2 & 1 & 51 \\
\hline http //www gctsemi com/ & 2 & 1 & 92 \\
\hline http //www gds com lb/ & 2 & 3 & 2 \\
\hline http / /www gemalto com/ & 2 & 1 & 1 \\
\hline http //www gemtek-systems com/ & 4 & 2 & 2 \\
\hline http / www gencat cat/ & 2 & 4 & 2 \\
\hline http //www gfivemobile com & 3 & 1 & 1 \\
\hline http / /www gl-de com/ & 1 & 2 & 1 \\
\hline http / /www gigafone com/ & 3 & 3 & 1 \\
\hline http / www glgaset com/ & 2 & 2 & 2 \\
\hline http //www global6 org & 2 & 2 & 6 \\
\hline http //www qlobaldenso com/en/ & 2 & 2 & 2 \\
\hline http / /www globalservices bt com & 1 & 2 & 1 \\
\hline http / /www globitel com/ & 1 & 3 & 1 \\
\hline http //www gloworld com/ & 2 & 3 & 1 \\
\hline http //www gmsu ua/ & 3 & 1 & 1 \\
\hline http / www gni ch/ & 3 & 2 & 1 \\
\hline http / /www goldenwest com/ & 2 & 2 & 1 \\
\hline http //www google com/ & 3 & 2 & 2 \\
\hline http $/ / w w w$ gorilla com tw/ & 2 & 2 & 2 \\
\hline
\end{tabular}




\begin{tabular}{|c|c|c|c|}
\hline URL & $\mathbf{x}$ & $\mathbf{Y}$ & $\mathbf{A}$ \\
\hline http //www gotransverse com/ & 2 & 2 & 1 \\
\hline http //www gppm de & 2 & 3 & 7 \\
\hline http //www greenflyamerica com/ & 3 & 1 & 1 \\
\hline http //www greenpacket com & 1 & 2 & 2 \\
\hline http //www grid-net com/ & 3 & 1 & 2 \\
\hline http //www gtllimited com/ & 1 & 3 & 2 \\
\hline http //www guzik com/ & 3 & 4 & 2 \\
\hline http //www grsystem com & 4 & 4 & 2 \\
\hline http //www halertele com/ & 3 & 1 & 6 \\
\hline http //www harris coml & 2 & 1 & 2 \\
\hline http //www harrisstratex com/ & 2 & 2 & 2 \\
\hline http //www hclinfinet com/ & 2 & 3 & 2 \\
\hline http //www hfclconnect com/ & 1 & 1 & 2 \\
\hline http //www hitachı com/ & 1 & 3 & 42 \\
\hline http //www hitachl-cta com/ & 1 & 1 & 5 \\
\hline http / wwww hkcsl com & 1 & 3 & 8 \\
\hline http / www hotspot ne Ip & 3 & 2 & 8 \\
\hline http //www htc com & 2 & 1 & 52 \\
\hline http //www huawe I com/ & 1 & 3 & 567 \\
\hline http / www hutch co th & 3 & 2 & 5 \\
\hline http //www lac com tw/ & 1 & 1 & 2 \\
\hline http //www ibasis com/ & 1 & 1 & 1 \\
\hline http //www icerasemi com/ & 1 & 3 & 41 \\
\hline http //www icewireless cal & 3 & 2 & 1 \\
\hline http //www Idatech com/ & 2 & 1 & 1 \\
\hline http //www ideacellular com/ & 1 & 2 & 2 \\
\hline http //www idt net/ & 2 & 2 & 2 \\
\hline http //www III org tw/ & 2 & 1 & 2 \\
\hline http //www immix com/ & 3 & 1 & 1 \\
\hline http //www indosat com/ & 2 & 3 & 52 \\
\hline hitp / $/$ www indosatm2 com & 3 & 1 & 82 \\
\hline http / /www industrie gouv frl & 1 & 3 & 7 \\
\hline http //www infobip com & 3 & 3 & 51 \\
\hline hittp //www infobrain com/ & 3 & 2 & 1 \\
\hline hitto //www infodirections com/ & 1 & 4 & 1 \\
\hline http //www infomark co krl & 4 & 1 & 2 \\
\hline http / /www informatm com/ & 1 & 1 & 2 \\
\hline http / /www inn9th com/ & 2 & 3 & 21 \\
\hline http //www innowireless co kr/ & 4 & 2 & 2 \\
\hline http //www in-sprit com/ & 2 & 1 & 2 \\
\hline http //www intecbilling com/ & 1 & 1 & 1 \\
\hline hitte //www intel com 1 & 1 & 4 & 921 \\
\hline http //www interbro net/ & 0 & 1 & 2 \\
\hline http //www interdıgital com/ & 2 & 1 & 1 \\
\hline $\begin{array}{l}\text { http //www interoptechnologies c } \\
\text { om }\end{array}$ & 1 & 1 & 5 \\
\hline $\begin{array}{l}\text { http / /www interoptechnologies c } \\
\text { om/en/ }\end{array}$ & 1 & 2 & 1 \\
\hline http //www intertek-etlsemko com & 1 & 1 & 6 \\
\hline http / /www intracom-telecom com & 1 & 1 & 2 \\
\hline
\end{tabular}

\begin{tabular}{|c|c|c|c|}
\hline URL & $\mathbf{x}$ & $\mathbf{Y}$ & $\mathbf{A}$ \\
\hline http / /www jpass com & 2 & 1 & 82 \\
\hline http //www Ipaxiom com/ & 2 & 1 & 2 \\
\hline http /www ipcomsa com & 3 & 1 & 5 \\
\hline http //www ipfabrics com/ & 1 & 2 & 2 \\
\hline http //www IrIshbroadband ıe/ & 1 & 2 & 2 \\
\hline http //www iriswireless com/ & 2 & 2 & 1 \\
\hline http $/ /$ www isb co $/ p /$ & 1 & 1 & 2 \\
\hline http //www iskratel com/ & 1 & 4 & 2 \\
\hline http //www itısaluna com/ & 3 & 1 & 5 \\
\hline http / /www itrı org tw & 1 & 2 & 2 \\
\hline http / www its ws/ & 2 & 2 & 21 \\
\hline http //www Iwireless com/ & 2 & 1 & 1 \\
\hline http //www lasperwireless com/ & 1 & 1 & 1 \\
\hline http //www jdsu com & 1 & 1 & 1 \\
\hline http //www huapl edu/ & 1 & 1 & 2 \\
\hline http //www unnysoftware com/ & 1 & 2 & 1 \\
\hline hitp //www /rc co p/pengl & 2 & 2 & 2 \\
\hline http $/ /$ www juniglobal com/ & 2 & 2 & 2 \\
\hline http //www Juniper net & 2 & 1 & 42 \\
\hline http //www kabira com/ & 1 & 1 & 1 \\
\hline http //www kddl com/ & 1 & 4 & 524 \\
\hline http //www keithley com/ & 4 & 1 & 2 \\
\hline http $/ / w w w$ keynote-sigos com/ & 1 & 1 & 1 \\
\hline http //www kıneto com/ & 1 & 1 & 1 \\
\hline http //www kke co /p/ & 3 & 3 & 2 \\
\hline http / /www koc net & 2 & 1 & 2 \\
\hline http //www kpn com/ & 1 & 4 & 4 \\
\hline http //www kt com/ & 3 & 1 & 482 \\
\hline $\begin{array}{l}\text { http //www kyocera- } \\
\text { wireless com/ }\end{array}$ & 1 & 2 & 56 \\
\hline http //www l2one com & 3 & 4 & 1 \\
\hline http //www laotel com & 4 & 4 & 5 \\
\hline http //www laser |r/ & 4 & 1 & 2 \\
\hline http //www leapwireless com/ & 3 & 3 & 5 \\
\hline http //www lenovo com/us/en/ & 2 & 2 & 2 \\
\hline http / /www lge com & 1 & 4 & $\begin{array}{c}564 \\
21 \\
\end{array}$ \\
\hline http //www lgtelecom com/ & 4 & 3 & 53 \\
\hline http / /www /mt Iv & 3 & 1 & 7 \\
\hline http //www Intinfotech com/ & 1 & 2 & 2 \\
\hline http //www longlines com/ & 2 & 2 & 1 \\
\hline http / www look cal & 1 & 2 & 2 \\
\hline http //www 3 & 2 & 4 & 3 \\
\hline http $/ / \mathrm{www}$ m800400 com/ & 3 & 1 & 1 \\
\hline http //www mach com/ & 2 & 3 & $\begin{array}{c}582 \\
1 \\
\end{array}$ \\
\hline http //www mainstreetbb com & 1 & 1 & 2 \\
\hline http / www martin-group com/ & 1 & 1 & 1 \\
\hline http //www marvell com/ & 1 & 1 & 2 \\
\hline http //www maxis com my & 1 & 2 & 82 \\
\hline
\end{tabular}




\begin{tabular}{|c|c|c|c|}
\hline URL & $\mathbf{x}$ & $\mathbf{Y}$ & $\mathbf{A}$ \\
\hline http //www mblox com/ & 1 & 1 & 1 \\
\hline http //www mclel net/ & 2 & 2 & 1 \\
\hline http //www menatelecom com/ & 2 & 2 & 2 \\
\hline http //www metricowireless com/ & 2 & 3 & 6 \\
\hline $\begin{array}{l}\text { http //www meuccl- } \\
\text { solutions com/ }\end{array}$ & 3 & 3 & 1 \\
\hline http //www mfone com kh/ & 2 & 1 & 5 \\
\hline http //www mformation com/ & 1 & 1 & 1 \\
\hline http //www microsoft com & 1 & 4 & 1 \\
\hline http /www mid-texcellular com/ & 3 & 2 & 1 \\
\hline http //www mimoon de/ & 2 & 1 & 4 \\
\hline http //www mimos my/ & 1 & 1 & 2 \\
\hline http //www mindspeed com/ & 1 & 1 & 2 \\
\hline http //www mindtree com & 1 & 3 & 2 \\
\hline http / /www minowireless com & 3 & 4 & 1 \\
\hline http //www mitac-mtc com tw/ & 3 & 1 & 2 \\
\hline http //www mitre org/ & 1 & 3 & 2 \\
\hline http //www mitsum co $1 \mathrm{p} /$ & 3 & 3 & 2 \\
\hline http //www miltelecom com/ & 1 & 3 & 2 \\
\hline http //www mobile-8 com/ & 0 & 1 & 5 \\
\hline http //www mobileaccess com/ & 1 & 2 & 2 \\
\hline http //www mobilemark com/ & 2 & 2 & 2 \\
\hline hittp //www mobilemetrics net/ & 3 & 3 & 2 \\
\hline hittp //www mobilinkgsm com/ & 2 & 1 & 1 \\
\hline http //www moblkom at/ & 1 & 3 & 7 \\
\hline http //www mobitel si/ & 2 & 1 & 7 \\
\hline http //www mobitv com/ & 1 & 3 & 2 \\
\hline hitp //www modacom co kr/ & 3 & 2 & 2 \\
\hline hitp //www monitisegroup com/ & 1 & 2 & 1 \\
\hline http //www mosalctelecom com/ & 2 & 1 & 1 \\
\hline http / www motorola com & 1 & 2 & $\begin{array}{c}562 \\
41 \\
\end{array}$ \\
\hline http / /www movial com & 1 & 1 & 1 \\
\hline http //www moviuscorp com/ & 1 & 2 & 1 \\
\hline http / www mtasolutions com & 2 & 1 & 5 \\
\hline hittp $/ / \mathrm{www}$ mtI com twl & 1 & 2 & 2 \\
\hline http / /www mtiwe com/ & 2 & 3 & 2 \\
\hline http //www mtk com tw/ & 2 & 1 & 2 \\
\hline http / /www mtn co zal & 2 & 1 & 1 \\
\hline http //www mtnonline com/ & 1 & 1 & 1 \\
\hline hitp //www mts cal & 1 & 1 & 1 \\
\hline heto //www mts rul & 3 & 2 & 7 \\
\hline http //www mtsgsm com/ & 1 & 1 & 2 \\
\hline http //www mtsindia in/ & 1 & 1 & 5 \\
\hline http //www multilinks com/ & 2 & 3 & 5 \\
\hline http //www multinet net/ & 3 & 3 & 2 \\
\hline http //www murandi com / & 3 & 2 & 2 \\
\hline http / www murata com/ & 1 & 1 & 2 \\
\hline http //www mymotorola co kr/ & 3 & 4 & 3 \\
\hline http //www myungmin com & 3 & 4 & 2 \\
\hline
\end{tabular}

\begin{tabular}{|c|c|c|c|}
\hline URL & $\mathbf{x}$ & $\mathbf{Y}$ & $\mathbf{A}$ \\
\hline http //www nagra com/ & 1 & 2 & 2 \\
\hline http //www nawras om/ & 1 & 2 & 2 \\
\hline http //www nec com/ & 1 & 1 & 47 \\
\hline http //www neotel co za/ & 2 & 1 & 2 \\
\hline http //www nep net & 2 & 2 & 1 \\
\hline http //www netcommlimited com/ & 1 & 1 & 1 \\
\hline http //www nethawk fil & 1 & 1 & 2 \\
\hline http //www netındex co /p & 3 & 4 & 2 \\
\hline http //www netkrom com/ & 1 & 2 & 2 \\
\hline http $/ / w w w$ neuralt com/ & 2 & 3 & 1 \\
\hline http //www neustar biz/ & 1 & 1 & 1 \\
\hline http //www neustring com/ & 3 & 3 & 1 \\
\hline http //www newcorewireless net/ & 3 & 2 & 1 \\
\hline http //www newsiq-inc com/ & 4 & 2 & 6 \\
\hline http / www nex-techwireless com & 2 & 1 & 5 \\
\hline http / $/$ www 4 orgl & 1 & 1 & 4 \\
\hline hittp //www nokla com & 1 & 1 & $\begin{array}{c}562 \\
7\end{array}$ \\
\hline $\begin{array}{l}\text { hitp //www nokıasıemensnetwork } \\
\text { s com/ }\end{array}$ & 1 & 1 & 47 \\
\hline http //www nortel com/ & 2 & 1 & 7 \\
\hline http //www n-tele com/ & 3 & 3 & 1 \\
\hline http //www ntt com/ & 2 & 2 & 1 \\
\hline http //www nttdocomo com/ & 1 & 1 & 3 \\
\hline http //www nubilus eul & 3 & 3 & 2 \\
\hline http //www nu-z net/ & 3 & 2 & 1 \\
\hline http / / www okl com/ & 1 & 1 & 2 \\
\hline http //www olivetelecom in/ & 3 & 3 & 5 \\
\hline http //www onkyo com/ & 3 & 3 & 2 \\
\hline http /www on-waves com/ & 3 & 3 & 5 \\
\hline $\begin{array}{l}\text { http //www openmindnetworks co } \\
\mathrm{m} /\end{array}$ & 1 & 1 & 1 \\
\hline http //www openrangecomm com & 3 & 1 & 2 \\
\hline http //www openwave com & 1 & 1 & 1 \\
\hline http //www optel-Informatik de/ & 3 & 3 & 1 \\
\hline http //www option com/ & 1 & 1 & 1 \\
\hline http //www optus com au & 1 & 1 & 1 \\
\hline htip //www orange com & 1 & 1 & 1 \\
\hline http / www orange-wifi com & 3 & 3 & 8 \\
\hline http //www orga-systems com/ & 1 & 2 & 1 \\
\hline http //www otz net/ & 1 & 2 & 1 \\
\hline http //www palm com & 1 & 1 & 56 \\
\hline http //www panasonic net/ & 1 & 1 & 3 \\
\hline http //www payfone com/ & 3 & 3 & 1 \\
\hline http //www pcccinc com/ & 4 & 4 & 2 \\
\hline http //www pccw com & 1 & 1 & 582 \\
\hline http //www pctestlab com/ & 2 & 2 & 562 \\
\hline $\begin{array}{l}\text { http //www personalcommunicat! } \\
\text { onsdevices com/ }\end{array}$ & 2 & 1 & 5 \\
\hline http / www picochip com/ & 2 & 1 & 2 \\
\hline
\end{tabular}




\begin{tabular}{|c|c|c|c|}
\hline URL & $\mathbf{x}$ & $Y$ & $\mathbf{A}$ \\
\hline http //www pixip net & 3 & 2 & 1 \\
\hline http //www plateautel net/ & 4 & 4 & 1 \\
\hline http //www pmc-sierra com/ & 1 & 1 & 2 \\
\hline http //www pockel com/ & 2 & 1 & 5 \\
\hline http / /www pointredtech com & 3 & 1 & 2 \\
\hline http //www polystar com/ & 1 & 1 & 1 \\
\hline http / www posdata co kr/engl & 2 & 3 & 2 \\
\hline http //www powerwave com / & 2 & 1 & 42 \\
\hline http //www prisma-eng com/ & 1 & 1 & 1 \\
\hline http //www proxımetry com/ & 2 & 1 & 2 \\
\hline http / www proximitı com/ & 2 & 3 & 1 \\
\hline http / $/$ www pt com/ & 1 & 1 & 1 \\
\hline http //www pticom com/ & 1 & 1 & 5 \\
\hline http //www ptwifi pt & 3 & 3 & 8 \\
\hline http //www publicsafety gc ca & 2 & 2 & 2 \\
\hline http / www pwnets com/ & 1 & 2 & 2 \\
\hline http //www pyrogroup com & 2 & 1 & 1 \\
\hline http / /www gtel com qal & 1 & 3 & 2 \\
\hline http / www qualcomm co kr/ & 2 & 1 & 3 \\
\hline http / $/$ www qualcomm com/ & 1 & 1 & $\begin{array}{c}564 \\
7\end{array}$ \\
\hline http //www quantatw com/ & 3 & 3 & 2 \\
\hline http / www quiconnect com & 1 & 1 & 8 \\
\hline $\begin{array}{l}\text { http //www quintechelectronics c } \\
\text { om/ }\end{array}$ & 2 & 3 & 2 \\
\hline http / www racsa co crl & 1 & 3 & 2 \\
\hline http //www radius-ed com/ & 1 & 2 & 1 \\
\hline http //www radwin com/ & 2 & 2 & 2 \\
\hline http / /www rcom co in & 1 & 1 & 6 \\
\hline http / www reach com & 1 & 2 & 1 \\
\hline http //www realnetworks com/ & 1 & 1 & 1 \\
\hline $\begin{array}{l}\text { http //www redlinecommunication } \\
\text { s com/ }\end{array}$ & 2 & 1 & 2 \\
\hline http //www redpınesignals com/ & 2 & 1 & 2 \\
\hline http //www redplc com/ & 1 & 2 & 1 \\
\hline $\begin{array}{l}\text { http //www reliancecommunicatıo } \\
\text { ns co in/ }\end{array}$ & 1 & 1 & 2 \\
\hline http //www reverbnetworks com/ & 2 & 2 & 42 \\
\hline http //www rum com/ & 1 & 1 & $\begin{array}{c}425 \\
61 \\
\end{array}$ \\
\hline http //www rincon com/ & 3 & 3 & 2 \\
\hline http / $/$ www ring hr & 3 & 3 & 1 \\
\hline http //www rivada com & 1 & 1 & 5 \\
\hline http //www roamware com/ & 1 & 1 & 1 \\
\hline http //www rogers com & 2 & 2 & 1 \\
\hline http //www rohde-schwarz com/ & 1 & 1 & $\begin{array}{c}426 \\
3\end{array}$ \\
\hline http //www romtelecom rol & 1 & 1 & 5 \\
\hline http //www rsystems com/ & 1 & 2 & 2 \\
\hline http //www runcom com/ & 1 & 1 & 2 \\
\hline http //www sagem com/ & 1 & 2 & 2 \\
\hline
\end{tabular}

\begin{tabular}{|c|c|c|c|}
\hline URL & $\mathbf{x}$ & $\mathbf{Y}$ & $\mathbf{A}$ \\
\hline $\begin{array}{l}\text { http //www sagem- } \\
\text { communications com/ }\end{array}$ & 1 & 1 & 2 \\
\hline http //www sagemwireless com & 3 & 3 & 1 \\
\hline http //www saitechnology com/ & 2 & 2 & 2 \\
\hline http //www samsung com & 1 & 2 & $\begin{array}{c}429 \\
1\end{array}$ \\
\hline $\begin{array}{l}\mathrm{http} / / \mathrm{www} \text { samsungindiasoft co } \\
\mathrm{m} /\end{array}$ & 3 & 2 & 56 \\
\hline http //www samsungtelecom com & 2 & 1 & 3 \\
\hline http //www sandvine com/ & 1 & 1 & 2 \\
\hline http //www sanjole com/ & 3 & 2 & 2 \\
\hline http / wwww sasktel com/ & 1 & 1 & 1 \\
\hline http / /www satımo com/ & 3 & 3 & 2 \\
\hline http //www scarlet an/ & 2 & 3 & 2 \\
\hline http //www scarlet nl/ & 3 & 3 & 2 \\
\hline http / /www sel co /p/ & 3 & 2 & 2 \\
\hline http //www selex-comms com/ & 1 & 1 & 2 \\
\hline http //www seowonintech co kr/ & 3 & 3 & 2 \\
\hline http //www sequans com/ & 2 & 1 & 29 \\
\hline http //www setar aw/ & 3 & 3 & 5 \\
\hline http //www setcom eu/ & 3 & 1 & 63 \\
\hline http / /www sfone com vn & 3 & 3 & 5 \\
\hline http //www sfr com & 3 & 1 & 3 \\
\hline http / /www sharp co pl/ & 2 & 2 & 2 \\
\hline http //www sharp co uk/ & 2 & 2 & 7 \\
\hline http //www slaemic it/ & 2 & 2 & 2 \\
\hline http //www sicap com/ & 1 & 2 & 1 \\
\hline http //www sierrawireless com/ & 2 & 1 & 562 \\
\hline http //www sifycorp com/ & 1 & 1 & 2 \\
\hline http //www signalion com/ & 2 & 1 & 3 \\
\hline http //www sim com & 1 & 2 & 5 \\
\hline http //www simmetrypcs com/ & 1 & 1 & 1 \\
\hline http / wwww sirim-qas com my & 2 & 2 & 2 \\
\hline http //www sktelecom com/ & 1 & 1 & $\begin{array}{c}542 \\
3 \\
\end{array}$ \\
\hline http //www skycross com & 2 & 1 & 2 \\
\hline http //www skynetwork Ik/ & 3 & 2 & 2 \\
\hline http //www skype com/ & 2 & 2 & 2 \\
\hline http //www skytel mn/ & 4 & 4 & 5 \\
\hline http //www skyterra com/ & 1 & 1 & 5 \\
\hline http / $/$ www slb com/ & 1 & 1 & 2 \\
\hline http //www smart-bz com/ & 3 & 3 & 5 \\
\hline http //www smartcall us/ & 3 & 3 & 1 \\
\hline http //www smarttrust com/ & 1 & 2 & 1 \\
\hline http //www smilecoms com/ & 2 & 3 & 2 \\
\hline http / www smithmicro com & 1 & 1 & 21 \\
\hline http //www snet co kr & 4 & 4 & 2 \\
\hline http //www somanetworks com/ & 1 & 1 & 2 \\
\hline http //www sonusnet com/ & 1 & 1 & 1 \\
\hline http //www sony com/ & 3 & 2 & 52 \\
\hline
\end{tabular}




\begin{tabular}{|c|c|c|c|}
\hline URL & $\mathbf{x}$ & $\mathbf{Y}$ & $\mathbf{A}$ \\
\hline http //www sonvericsson com & 1 & 2 & 41 \\
\hline http //www spacetıme-eng com/ & 3 & 3 & 2 \\
\hline http //www sp-ausnet com au/ & 1 & 2 & 2 \\
\hline http / www spb com & 2 & 1 & 1 \\
\hline http //www spectec com tw/ & 2 & 3 & 2 \\
\hline http / www spiceglobal com & 2 & 1 & 51 \\
\hline http //www spidercloud com/ & 3 & 1 & 1 \\
\hline http //www spirent com/ & 2 & 1 & 56 \\
\hline http / wwww sprint com/ & 2 & 1 & 562 \\
\hline http //www st co krl & 1 & 1 & 2 \\
\hline http //www starcomms com/ & 3 & 3 & 5 \\
\hline http / www starentnetworks com & 1 & 1 & $\begin{array}{c}452 \\
3\end{array}$ \\
\hline http //www starhome com/ & 1 & 1 & 51 \\
\hline http //www starhub com & 1 & 1 & 8 \\
\hline http //www starsolutions com/ & 3 & 2 & 5 \\
\hline http //www stc com sa/ & 1 & 1 & 2 \\
\hline http //www stericsson com & 2 & 2 & 43 \\
\hline http //www subexworld com/ & 2 & 2 & 1 \\
\hline http //www suntecgroup com/ & 2 & 2 & 1 \\
\hline http //www swiftng com/ & 3 & 3 & 2 \\
\hline http / wwww swisscom ch & 2 & 2 & 8 \\
\hline $\begin{array}{l}\text { http } / \text { www sybase com/mobilese } \\
\text { rvices }\end{array}$ & 3 & 2 & 1 \\
\hline http //www sychıp com/ & 1 & 2 & 2 \\
\hline http //www symsoft com/ & 1 & 1 & 1 \\
\hline http //www syniverse com & 2 & 1 & $\begin{array}{c}582 \\
1\end{array}$ \\
\hline http / /www tht hr/enql & 1 & 2 & 7 \\
\hline http //www talsys coml & 3 & 2 & 1 \\
\hline $\begin{array}{l}\text { http //www tatacommunications C } \\
\text { om }\end{array}$ & 2 & 1 & 2 \\
\hline http / $/ w w w$ tataelxsi com/ & 1 & 1 & 2 \\
\hline http $/ / w w w$ tataindicom com/ & 2 & 1 & 56 \\
\hline http / www tatung com/ & 2 & 3 & 2 \\
\hline http / www tcs com/ & 1 & 1 & 2 \\
\hline http //www tdf frl & 1 & 1 & 2 \\
\hline http //www tec gov in & 1 & 1 & 2 \\
\hline http //www techmahindra com/ & 2 & 1 & 2 \\
\hline http //www tecnotree com & 1 & 1 & 1 \\
\hline http //www tecomproduct coml & 1 & 1 & 2 \\
\hline http / $/$ www tecore com/ & 3 & 1 & 1 \\
\hline http //www telath grl & 2 & 2 & 2 \\
\hline http / $/$ www tek com/ & 1 & 1 & 3 \\
\hline http //www tekelec com/ & 1 & 1 & 1 \\
\hline http / /www tektronix com/ & 3 & 4 & 2 \\
\hline http //www telcordia com/ & 3 & 1 & 421 \\
\hline http / www telec or ip/ & 3 & 2 & 2 \\
\hline http / www telecom co nz & 2 & 1 & 1 \\
\hline http / /www telecom nal & 1 & 3 & 5 \\
\hline http $/ \mathrm{wwww}$ telecom sitronics com & 1 & 1 & 1 \\
\hline
\end{tabular}

\begin{tabular}{|c|c|c|c|}
\hline URL & $\mathbf{x}$ & $\mathbf{Y}$ & $\mathbf{A}$ \\
\hline http //www telecomitalia com & 1 & 2 & 423 \\
\hline http //www telecomsys com/ & 1 & 1 & 521 \\
\hline http //www teleepoch com/ & 3 & 3 & 6 \\
\hline http //www telefonica com & 1 & 1 & 43 \\
\hline $\begin{array}{l}\text { http //www telefonica- } \\
\text { wholesale com/ }\end{array}$ & 1 & 1 & 1 \\
\hline http //www telekom com & 1 & 2 & 482 \\
\hline http //www telenor com & 1 & 1 & 1 \\
\hline http //www telenor com pk/ & 1 & 2 & 1 \\
\hline http //www telepin com/ & 1 & 1 & 1 \\
\hline http //www telespree com/ & 1 & 2 & 5 \\
\hline http //www telesur sr/ & 2 & 2 & 5 \\
\hline http //www teliasonera com/ & 1 & 1 & 4 \\
\hline http //www telit com/ & 1 & 1 & 1 \\
\hline http //www telkom co Id/ & 1 & 1 & 52 \\
\hline http / /www telkomsel com/ & 2 & 1 & 7 \\
\hline hitp //www tellabs com/ & 1 & 1 & 4 \\
\hline http //www telmex com & 1 & 2 & 8 \\
\hline http //www telnamobile com/ & 3 & 4 & 1 \\
\hline hittp //www telsasrl it/ & 3 & 3 & 2 \\
\hline http //www telsis com/ & 1 & 1 & 1 \\
\hline http / /www telstra com au & 1 & 1 & 1 \\
\hline http / /www teltronic es/ & 3 & 1 & 2 \\
\hline http $/ / w w w$ telus com/ & 1 & 1 & 421 \\
\hline http / www telusmobility com & 2 & 1 & 56 \\
\hline http //www terrestar com/ & 1 & 1 & 1 \\
\hline http //www testquest com/ & 1 & 2 & 6 \\
\hline http //www tfl com fij & 1 & 1 & 5 \\
\hline http / /www thecableshoppe com/ & 3 & 4 & 2 \\
\hline http / wwww three com aul & 2 & 3 & 1 \\
\hline http //www timewarnercable com/ & 2 & 2 & 2 \\
\hline http //www ti-sparkle t/ & 1 & 1 & 1 \\
\hline http / www tmng com/ & 1 & 2 & 1 \\
\hline http / /www t-mobile com/ & 1 & 1 & 3 \\
\hline http //www tno nl/ & 1 & 2 & 7 \\
\hline http / $/$ www tnsi com/ & 1 & 1 & 51 \\
\hline http //www tnzl com/ & 1 & 2 & 1 \\
\hline http //www tomizone com/ & 3 & 2 & 8 \\
\hline http //www torresnetworks com/ & 2 & 1 & 2 \\
\hline http //www toshiba com/ & 1 & 1 & 2 \\
\hline http //www towerstream com/ & 1 & 2 & 2 \\
\hline http //www tradevan com tw/ & 3 & 2 & 2 \\
\hline http //www trda-inc com $/$ & 2 & 2 & 2 \\
\hline http //www triatel Iv/ & 2 & 3 & 5 \\
\hline http //www triquint com/ & 1 & 1 & 2 \\
\hline http //www tropos com/ & 2 & 1 & 2 \\
\hline http / www truewifi net & 3 & 3 & 8 \\
\hline http / $/ \mathrm{www}$ trustvesta com/ & 1 & 2 & 1 \\
\hline http //www tstt co tt/ & 1 & 1 & 5 \\
\hline http //www tta or kr & 1 & 1 & 62 \\
\hline
\end{tabular}




\begin{tabular}{|c|c|c|c|}
\hline URL & $\mathbf{x}$ & $\mathbf{Y}$ & $\mathbf{A}$ \\
\hline http $/ /$ www ttc org tw/ & 3 & 1 & 2 \\
\hline http //www turboconcept com/ & 3 & 2 & 2 \\
\hline http / /www turkcell com tr/ & 1 & 1 & 3 \\
\hline http //www turktelekom com trl & 1 & 2 & 2 \\
\hline http / wwww turner com/ & 2 & 4 & 2 \\
\hline http / www tycoelectronics com/ & 3 & 2 & 2 \\
\hline http //www tyntec com/ & 1 & 1 & 1 \\
\hline http / /www ubeeinteractive com/ & 2 & 1 & 2 \\
\hline http //www ubidyne com/ & 1 & 1 & 4 \\
\hline http //www ubıquam com/ & 3 & 4 & 62 \\
\hline http //www ubiquisys com/ & 1 & 2 & 1 \\
\hline http //www ufone com/ & 2 & 3 & 1 \\
\hline http / $/$ www uk sgs com/ & 1 & 2 & 2 \\
\hline http //www umic rwth-aachen de/ & 1 & 2 & 4 \\
\hline http / /www 7 & 1 & 1 & 7 \\
\hline http //www unicel com/ & 2 & 2 & 1 \\
\hline http //www unionwireless com/ & 3 & 3 & 1 \\
\hline http //www unistars $|v|$ & 4 & 3 & 2 \\
\hline http //www unwired com au/ & 3 & 3 & 8 \\
\hline $\begin{array}{l}\text { http //www unwiredaustralla com } \\
\text { aul }\end{array}$ & 1 & 2 & 2 \\
\hline http //www uq2 jp/ & 2 & 1 & 9 \\
\hline http //www us anritsu com & 1 & 1 & 56 \\
\hline http //www uscellular com & 2 & 1 & 56 \\
\hline http //www utimaco coml & 1 & 1 & 2 \\
\hline http //www utu fil & 2 & 2 & 2 \\
\hline http //www vanso com/ & 3 & 4 & 1 \\
\hline http //www vanu com/ & 2 & 1 & 1 \\
\hline http //www vee com tw/ & 3 & 4 & 2 \\
\hline http $/ /$ www veltı com/ & 1 & 1 & 1 \\
\hline http //www veraznetworks com/ & 1 & 1 & 1 \\
\hline http //www vensign com/ & 1 & 1 & 281 \\
\hline http //www verizonwireless com & 2 & 2 & 56 \\
\hline http //www vermontel com/ & 2 & 4 & 1 \\
\hline http //www viaero com/ & 1 & 1 & 1 \\
\hline http //www via-telecom com/ & 1 & 2 & 56 \\
\hline http //www vibo com tw/ & 2 & 2 & 2 \\
\hline http / /www videotron com & 1 & 1 & 1 \\
\hline http //www vimpelcom com/ & 1 & 1 & 7 \\
\hline http / /www visafone com ng/ & 3 & 3 & 5 \\
\hline http //www vivotech com/ & 1 & 2 & 1 \\
\hline http //www vnl in/ & 1 & 1 & 1 \\
\hline http //www vodacom co zal & 2 & 3 & 1 \\
\hline http //www vodafone co nzl & 1 & 2 & 1 \\
\hline http / /www vodafone com au & 1 & 1 & 1 \\
\hline http //www vodafone com/ & 1 & 1 & 3 \\
\hline http //www vodafone nl & 1 & 1 & 5 \\
\hline http //www voxbone com/ & 1 & 3 & 1 \\
\hline http //www vtt fil & 1 & 1 & 2 \\
\hline http //www w2bl com/ & 1 & 1 & 56 \\
\hline
\end{tabular}

\begin{tabular}{|c|c|c|c|}
\hline URL & $\mathbf{x}$ & $\mathbf{Y}$ & $\mathbf{A}$ \\
\hline http //www waridtel co ug/ & 2 & 3 & 2 \\
\hline http //www warıdtel com/ & 2 & 3 & 1 \\
\hline http //www wasko pl/ & 2 & 2 & 2 \\
\hline http /www watchdata com/ & 1 & 2 & 1 \\
\hline http //www wavesat com/ & 2 & 1 & 2 \\
\hline http //www slliance net & 1 & 1 & 8 \\
\hline $\begin{array}{l}\mathrm{http} / / \mathrm{www} \text { wedotechnologies co } \\
\mathrm{m}\end{array}$ & 1 & 2 & 1 \\
\hline http //www westcentral com/ & 3 & 3 & 1 \\
\hline http //www westlinkcom com/ & 3 & 2 & 1 \\
\hline http / www wichorus com & 2 & 1 & 423 \\
\hline http / $/ w w w 2 ~ b g /$ & 2 & 3 & 2 \\
\hline http $/ / \mathrm{www} 22020 \mathrm{com} /$ & 3 & 1 & 2 \\
\hline http //www 2forum orgl & 1 & 1 & 2 \\
\hline http //www wimoss com/ & 4 & 3 & 2 \\
\hline http //www windmobile ca/ & 2 & 2 & 1 \\
\hline http //www windriver com/ & 1 & 1 & 2 \\
\hline http //www wirelesslogix com/ & 3 & 2 & 2 \\
\hline http //www wisperhighspeed com & 3 & 2 & 2 \\
\hline http //www witech it/ & 1 & 2 & 2 \\
\hline http //www wl-tribe com/ & 2 & 3 & 2 \\
\hline http //www workssys com/ & 3 & 2 & 2 \\
\hline http //www worldmax nl/ & 1 & 2 & 2 \\
\hline http //www xintec com/ & 1 & 3 & 1 \\
\hline http //www xırkachıpset com/ & 4 & 3 & 2 \\
\hline http //www xit net/ & 2 & 1 & 1 \\
\hline http //www yemenmobile com ye/ & 4 & 3 & 5 \\
\hline http //www yota ru/en/ & 1 & 2 & 2 \\
\hline http //www ytlcomms my & 2 & 2 & 2 \\
\hline http / $/ w w w$ ytlesolutions com/ & 2 & 2 & 28 \\
\hline http / /www zain com & 1 & 1 & 1 \\
\hline http //www zong com pk/ & 3 & 3 & 1 \\
\hline http //www zscaler com & 2 & 2 & 1 \\
\hline http / /www zte com cn & 1 & 1 & $\begin{array}{c}564 \\
23 \\
\end{array}$ \\
\hline http //www1 globe com ph/ & 1 & 1 & 2 \\
\hline http //www2 btcbahamas com/ & 1 & 2 & 5 \\
\hline htto //www2 ctcak net/ & 3 & 4 & 1 \\
\hline https //www nethawk fil & 1 & 1 & 3 \\
\hline httos //www wireless att com & 1 & 1 & 1 \\
\hline
\end{tabular}

\begin{tabular}{|cc|}
\hline \multicolumn{2}{|c|}{ Legend } \\
\hline & 1 GSMA \\
X-1 Group E & 2 WIMAX \\
X-2 Group F & 3 LSTI \\
Y-1 Group G & 4 NGMN \\
Y-2 Group H & 5 CDG \\
X \& Y Group I & 6 CCF \\
A Consortia & 7 UMTS \\
& 8 WBA \\
& 9 OPA \\
\hline
\end{tabular}




\section{Appendix B: Hierarchical Decomposition}

As indicated in de Nooy (2005), in social network analysis a position in the network is indicated by a particular pattern of ties. Actors with similar patterns of ties are said to be relationally equivalent, to constitute an equivalence class or occupy equivalent positions in a network. Two vertices are structurally equivalent if they have identical ties with themselves, each other and all other vertices.

Structural equivalence could be calculated based on the dissimilarity of two vertices and is expressed by an index that ranges from zero (completely similar) to one (completely different). The hierarchical clustering is a statıstical technique which allows the clustering of vertices based on the structural equivalency. The clustering process can be visualized by a dendrogram, which can be used as a reference when creating a partition with classes of companies belonging to the same cluster. It is up to the researcher to decide the number of classes. For this study we aimed at having clusters with a sufficient number that offers a sample large enough for subsequent factor analysis.

The Pajek ${ }^{41}$ hierarchical clustering is based on dissimilarity " $\mathrm{d} 1$ " which represents the number of neighbours the 2 vertices don't share. The hierarchical decomposition for the initial sample groups Q1, Q2, Q3 and Q4 is presented next:

\begin{tabular}{|c|c|}
\hline Initial Sample Group Q1 & Initıal Sample Group Q2 \\
\hline 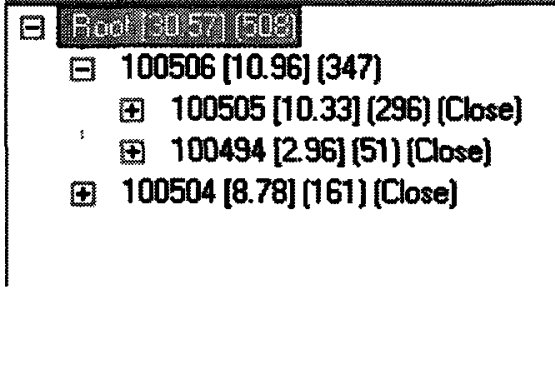 & 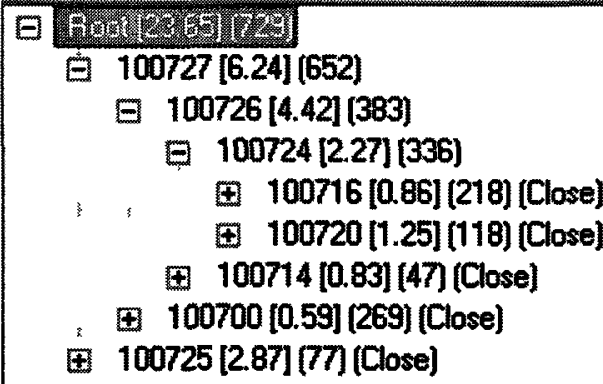 \\
\hline Initial Sample Group Q3 & Initial Sample Group Q4 \\
\hline 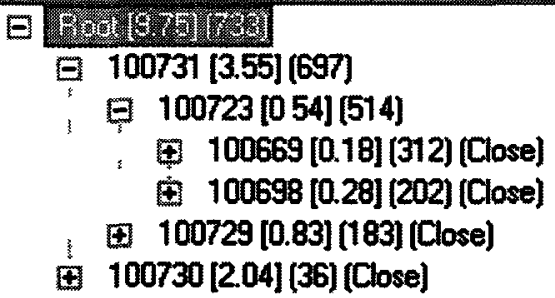 & 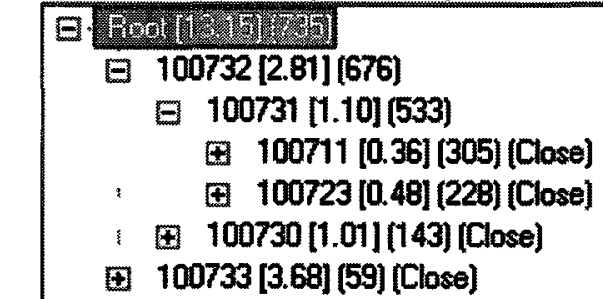 \\
\hline
\end{tabular}

${ }^{41} \mathrm{http}: / /$ pajek $1 \mathrm{mfm} . \mathrm{s} 1 /$ doku.php 


\section{Appendix C: Factor Analysis Results}

\begin{tabular}{|l|c|c|}
\hline \multicolumn{2}{|c|}{ E1 Mobile Services (I) } & \multicolumn{2}{c|}{ Loadıng } \\
\cline { 2 - 3 } & E S1 & E S11 \\
\hline a) "mobıle AND content AND delıvery" & 902 & 89 \\
\hline b) "mobıle AND services AND (commerce OR billıng)" & 896 & 912 \\
\hline c) “(consulting OR engıneerıng) AND services" & 870 & 845 \\
\hline d) "mobıle AND messagıng AND services" & 778 & 817 \\
\hline e) "customızatıon OR customıze OR customized OR personalıze OR Indıvidualıze" & 719 & 715 \\
\hline Average Loading & 833 & 83 \\
\hline Varıance after Rotation (\%) & 1497 & 1390 \\
\hline
\end{tabular}

\begin{tabular}{|l|r|r|r|r|r|r|r|r|r|}
\hline \multirow{2}{*}{ E2 Testing Solutions (I) } & \multicolumn{9}{|c|}{ Loading } \\
\cline { 2 - 11 } & E S1 & E S2 & E S3 & E S4 & E S5 & E S6 & E S7 & E S8 & E S9 \\
\hline a) "measurement" & 878 & 883 & 877 & 875 & 878 & 878 & 877 & 875 & 881 \\
\hline $\begin{array}{l}\text { b) "Instrumentation OR } \\
\text { Instrument" }\end{array}$ & 861 & 869 & 862 & 862 & 867 & 851 & 848 & 856 & 849 \\
\hline $\begin{array}{l}\text { c) "(performance OR } \\
\text { optımızation) AND (analysıs } \\
\text { OR audit)" }\end{array}$ & 808 & 791 & 792 & 796 & 794 & 814 & 804 & 813 & 798 \\
\hline $\begin{array}{l}\text { d) "test AND evaluation AND } \\
\text { equipment" }\end{array}$ & 798 & 800 & 828 & 828 & 821 & 811 & 805 & 818 & 807 \\
\hline $\begin{array}{l}\text { e) "test AND equipment AND } \\
\text { manufacturer" }\end{array}$ & 689 & 676 & 691 & 695 & 685 & 703 & 712 & 696 & 710 \\
\hline Average Loading & 807 & 804 & 818 & 811 & 809 & 811 & 809 & 812 & 809 \\
\hline Varıance after Rotation (\%) & 1441 & 1439 & 1388 & 1436 & 1425 & 1479 & 1548 & 1482 & 1622 \\
\hline
\end{tabular}

\begin{tabular}{|l|c|c|c|c|c|c|c|c|}
\hline \multirow{2}{*}{ E3 Fee Based Busıness Solutions (I) } & \multicolumn{7}{|c|}{ Loading } \\
\cline { 2 - 9 } & E S1 & E S2 & E S3 & E S4 & E S5 & E S6 & E S7 & E S8 \\
\hline a) "(data OR voice) AND plans" & 801 & 801 & 815 & 820 & 812 & 813 & 818 & 817 \\
\hline $\begin{array}{l}\text { b) "unlımıted AND (callıng OR text } \\
\text { OR distance)" }\end{array}$ & 784 & 783 & 786 & 797 & 801 & 805 & 798 & 798 \\
\hline $\begin{array}{l}\text { c) "("Moblle Termınal Supplier" OR } \\
\text { "Mobıle Terminal" OR manufacturer) } \\
\text { AND mobile AND phone" }\end{array}$ & 761 & 761 & 749 & 752 & 764 & 752 & 754 & 752 \\
\hline d) "Internet AND mobıle" & 671 & 682 & 675 & 662 & 643 & 633 & 641 & 639 \\
\hline $\begin{array}{l}\text { e) "customer AND (options OR } \\
\text { choice OR choose)" }\end{array}$ & 645 & 654 & 642 & 617 & 624 & 620 & 632 & 631 \\
\hline Average Loadıng & 732 & 736 & 733 & 730 & 729 & 725 & 729 & 727 \\
\hline Varıance after Rotation (\%) & 1204 & 1152 & 1141 & 1187 & 1192 & 1276 & 1309 & 1259 \\
\hline
\end{tabular}




\begin{tabular}{|l|r|r|r|r|c|}
\hline \multirow{2}{*}{ E4 WIMAX Technology and Standard (I) } & \multicolumn{5}{|c|}{ Loading } \\
\cline { 2 - 6 } & E S1 & E S2 & E S3 & E S9 & E S11 \\
\hline a) "WImax" & 735 & 740 & 742 & 741 & 739 \\
\hline b) "TDD OR FDD" & 712 & 724 & 717 & 701 & 711 \\
\hline c) "IEEE AND 802 16" & 712 & 758 & 752 & 695 & 753 \\
\hline d) "ecosystem AND mobile AND broadband" & 707 & 646 & 650 & 708 & 658 \\
\hline e) "forum" & 665 & 555 & 573 & 681 & 58 \\
\hline Average Loadıng & 706 & 685 & 687 & 705 & 688 \\
\hline Variance after Rotation (\%) & 1059 & 1068 & 1022 & 1223 & 1000 \\
\hline
\end{tabular}

\begin{tabular}{|l|c|c|}
\hline \multicolumn{1}{|c|}{ E5 Hardware (I) } & \multicolumn{2}{c|}{ Loading } \\
\cline { 2 - 3 } & E S1 & E S2 \\
\hline a) "mıcroprocessor OR processor OR microcontroller OR DSP OR 'RF subsystem' OR \\
'power management' OR chips OR chipsets OR sensor" & 800 & 807 \\
\hline b) "semıconductor" & 799 & 799 \\
\hline c) "design" & 724 & 723 \\
\hline d) "packagıng" & 702 & 699 \\
\hline Average Loading & 756 & 757 \\
\hline Variance after Rotation (\%) & 1030 & 1032 \\
\hline
\end{tabular}

\begin{tabular}{|l|c|c|c|c|c|}
\hline \multicolumn{2}{|c|}{ E6 3GPP Standard and 4G Technologies (I) } & \multicolumn{5}{|c|}{ Loadıng } \\
\cline { 2 - 6 } & E S2 & E S3 & E S4 & E S5 & E S11 \\
\hline a) 'Radıo Access' & 746 & 750 & 790 & 794 & 683 \\
\hline b) "LTE OR 'Long Term Evolution' OR eUTRAN" & 738 & 741 & 779 & 787 & 684 \\
\hline c) "3GPP" & 727 & 726 & 740 & 744 & 654 \\
\hline d) “IMS OR 'IP Multımedıa Subsystem"' & 717 & 703 & 673 & 653 & 776 \\
\hline $\begin{array}{l}\text { e) “(product OR process OR service) AND (evolution OR } \\
\text { evolve)" }\end{array}$ & 692 & 683 & 679 & 671 & 665 \\
\hline Average Loading & 724 & 720 & 0,732 & 730 & 69 \\
\hline Variance after Rotation (\%) & 1220 & 1187 & 1185 & 1233 & 1101 \\
\hline
\end{tabular}

\begin{tabular}{|l|c|c|c|c|c|c|}
\hline \multirow{2}{*}{ E7 Revenue Management Solutions (I) } & \multicolumn{5}{|c|}{ Loadıng } \\
\cline { 2 - 8 } & E S3 & E S4 & E S5 & E S6 & E S7 & E S8 \\
\hline $\begin{array}{l}\text { a) "solution AND (OSS OR 'Operation Support } \\
\text { System')" }\end{array}$ & 871 & 864 & 882 & 892 & 888 & 888 \\
\hline b) "BSS OR 'Business Support System"” & 829 & 826 & 848 & 851 & 849 & 849 \\
\hline c) "solution AND (outsourcing OR delivery)" & 713 & 727 & 700 & 701 & 710 & 710 \\
\hline d) "billing" & 706 & 703 & 689 & 683 & 685 & 685 \\
\hline e) "provisioning" & 671 & 669 & 659 & 663 & 662 & 662 \\
\hline Average Loadıng & 730 & 758 & 756 & 758 & 759 & 759 \\
\hline Variance after Rotation (\%) & 1250 & 1300 & 1301 & 1334 & 1398 & 1342 \\
\hline
\end{tabular}




\begin{tabular}{|l|c|}
\hline \multicolumn{1}{|c|}{ E8 Security Solutions (I) } & Loading \\
\cline { 2 - 2 } & E S4 \\
\hline a) "(protect OR protecting OR promote) AND (consumers OR users)" & 842 \\
\hline b) "(security OR 'customer protection' OR protection) AND (virus OR malware OR & 775 \\
'Inappropriate content' OR spam OR phishing)" & 724 \\
\hline c) "authentıcatıon OR security OR signature" & 529 \\
\hline d) "authority" & 718 \\
\hline Average Loading & 969 \\
\hline Variance after Rotation (\%) & \\
\hline
\end{tabular}

\begin{tabular}{|l|c|c|c|c|c|}
\hline \multirow{2}{*}{ E9 Interoperability Solutions (I) } & \multicolumn{5}{|c|}{ Loading } \\
\cline { 2 - 6 } & E S5 & E S6 & E S7 & E S8 & E S9 \\
\hline a) “(SMS OR MMS) AND services" & 799 & 788 & 783 & 784 & 765 \\
\hline b) “VAS OR Value Added Services"” & 701 & 685 & 681 & 691 & 697 \\
\hline c) “roaming OR NRTRDE" & 693 & 697 & 701 & 704 & 722 \\
\hline d) "network AND operator" & 654 & 699 & 699 & 635 & 731 \\
\hline Average Loadıng & 712 & 717 & 716 & 704 & 729 \\
\hline Varlance after Rotation (\%) & 990 & 1030 & 1074 & 1072 & 1050 \\
\hline
\end{tabular}

\begin{tabular}{|l|c|c|c|}
\hline \multirow{2}{*}{ E10 Reputation (I) } & \multicolumn{3}{|c|}{ Loading } \\
\cline { 2 - 4 } & E S6 & E S9 & E S11 \\
\hline a) "reputation OR competence" & 758 & 741 & 746 \\
\hline b) "agreement" & 699 & 706 & 690 \\
\hline c) "governance OR govern" & 692 & 672 & 662 \\
\hline d) "regulator OR regulate OR supervise OR regulation OR regulatory" & 647 & 644 & 655 \\
\hline Average Loading & 699 & 691 & 688 \\
\hline Variance after Rotation (\%) & 895 & 1020 & 866 \\
\hline
\end{tabular}

\begin{tabular}{|l|c|c|c|}
\hline \multicolumn{2}{|c|}{ E11 Research (I) } & \multicolumn{3}{|c|}{ Loading } \\
\cline { 2 - 4 } & E S7 & E S9 & E S11 \\
\hline a) "(university OR universities) AND research" & 843 & 846 & 85 \\
\hline b) "research OR Innovatıon OR 'research and development"' & 817 & 777 & 725 \\
\hline c) "science AND technology" & 688 & 712 & 75 \\
\hline Average Loadıng & 783 & 778 & 775 \\
\hline Varıance after Rotation (\%) & 885 & 931 & 756 \\
\hline
\end{tabular}

\begin{tabular}{|l|c|c|}
\hline \multirow{2}{*}{ E12 3GPP Standard and 3G Technologies Evolution } & \multicolumn{2}{|c|}{ Loading } \\
\cline { 2 - 3 } & E S8 & E S11 \\
\hline a) "GPRS" & 768 & 846 \\
\hline b) "UMTS" & 762 & 629 \\
\hline c) "GSM" & 724 & 771 \\
\hline d) "WCDMA" & 656 & 559 \\
\hline Average Loading & 727 & 701 \\
\hline Variance after Rotation (\%) & 1007 & 929 \\
\hline
\end{tabular}




\begin{tabular}{|l|r|r|r|r|c|c|c|c|c|}
\hline \multirow{2}{*}{ F1 Fraud Detection (I) } & \multicolumn{10}{|c|}{ Loading } \\
\cline { 2 - 11 } & F S1 & F S2 & F S3 & F S4 & F S5 & F S6 & F S7 & F S8 & F S9 \\
\hline $\begin{array}{l}\text { a) “(analyze OR monitor OR } \\
\text { test) AND fraud" }\end{array}$ & 945 & 943 & 944 & 944 & 947 & 949 & 946 & 947 & 947 \\
\hline $\begin{array}{l}\text { b) "fraud AND (control OR } \\
\text { detection) }\end{array}$ & 920 & 913 & 907 & 915 & 919 & 925 & 922 & 924 & 920 \\
\hline $\begin{array}{l}\text { c) "analyse AND revenue } \\
\text { AND (loss OR risk) }\end{array}$ & 876 & 905 & 897 & 902 & 903 & 877 & 894 & 894 & 906 \\
\hline $\begin{array}{l}\text { d) “assurance AND } \\
\text { (customer OR service)" }\end{array}$ & 821 & 825 & 825 & 825 & 824 & 810 & 819 & 815 & 818 \\
\hline Average Loading & 891 & 897 & 893 & 897 & 898 & 890 & 895 & 895 & 898 \\
\hline Variance after Rotation (\%) & 1956 & 2089 & 1981 & 1970 & 1948 & 2101 & 2080 & 1957 & 1944 \\
\hline
\end{tabular}

\begin{tabular}{|l|c|c|}
\hline \multicolumn{2}{|c|}{ F2 Busıness Opportunity Solutions (I) } & \multicolumn{2}{|c|}{ Loading } \\
\cline { 2 - 3 } & F S1 & F S10 \\
\hline a) "new AND (market OR Industry)" & 817 & 793 \\
\hline b) "solution AND (outsourcing OR delivery)" & 784 & 681 \\
\hline c) "strategy AND development" & 779 & 762 \\
\hline d) "network AND operator" & 700 & 574 \\
\hline e) "end-to-end AND communıcation AND solutions" & 681 & 708 \\
\hline Average Loadıng & 752 & 704 \\
\hline Variance after Rotation (\%) & 1905 & 1427 \\
\hline
\end{tabular}

\begin{tabular}{|l|c|c|c|c|c|c|c|c|c|c|}
\hline \multicolumn{1}{|c|}{$\begin{array}{c}\text { F3 Revenue } \\
\text { Management } \\
\text { Solutions (II) }\end{array}$} & F S1 & F S2 & F S3 & F S4 & F S5 & F S6 & F S7 & F S8 & F S9 & F S10 \\
\cline { 2 - 10 } \\
\hline $\begin{array}{l}\text { a) "BSS OR } \\
\text { 'Busıness Support } \\
\text { System"” }\end{array}$ & 904 & 882 & 881 & 880 & 878 & 888 & 881 & 880 & 880 & 920 \\
\hline $\begin{array}{l}\text { b) "solution AND } \\
\text { (OSS OR 'Operatıon } \\
\text { Support System')" }\end{array}$ & 890 & 917 & 917 & 915 & 914 & 909 & 914 & 914 & 915 & 883 \\
\hline $\begin{array}{l}\text { c) "activation AND } \\
\text { mediatıon AND } \\
\text { service" }\end{array}$ & 869 & 880 & 878 & 880 & 880 & 882 & 881 & 879 & 879 & 865 \\
\hline $\begin{array}{l}\text { d) "'cost of } \\
\text { ownership' OR } \\
\text { 'optımıse } \\
\text { infrastructure' OR } \\
\text { 'optımize } \\
\text { infrastructure" }\end{array}$ & 720 & 761 & 760 & 763 & 766 & 756 & 760 & 764 & 767 & 695 \\
\hline Average Loadıng & 846 & 860 & 859 & 859 & 860 & 859 & 859 & 859 & 860 & 841 \\
\hline $\begin{array}{l}\text { Variance after } \\
\text { Rotation (\%) }\end{array}$ & 1847 & 1895 & 1780 & 1794 & 1795 & 1902 & 1909 & 1794 & 1782 & 1432 \\
\hline
\end{tabular}




\begin{tabular}{|l|r|r|r|}
\hline \multicolumn{1}{|c|}{ F4 Hardware (II) } & \multicolumn{3}{|c|}{ Loadıng } \\
\cline { 2 - 4 } & F S1 & F S2 & F S9 \\
\hline a) "signal AND processing" & 853 & 836 & 840 \\
\hline $\begin{array}{l}\text { b) "microprocessor OR processor OR mıcrocontroller OR DSP OR 'RF } \\
\text { subsystem' OR 'power management' OR chips OR chipsets OR sensor" }\end{array}$ & 749 & 716 & 730 \\
\hline c) "multt-standard" & 748 & 803 & 778 \\
\hline d) "'base station' OR 'base-station"' & 681 & 712 & 664 \\
\hline Average Loading & 758 & 767 & 753 \\
\hline Varıance after Rotation (\%) & 1418 & 1527 & 1437 \\
\hline
\end{tabular}

\begin{tabular}{|l|c|c|c|}
\hline \multicolumn{1}{|c|}{ F5 Security Solutions (II) } & \multicolumn{3}{|c|}{ Loadıng } \\
\cline { 2 - 4 } & F S2 & F S3 & F S4 \\
\hline a) “(protect OR protecting OR promote) AND (consumers OR users)" & 928 & 926 & 921 \\
\hline b) “reputation OR competence" & 903 & 899 & 903 \\
\hline c) "(security OR 'customer protection' OR protection) AND (virus OR malware & 837 & 840 & 831 \\
OR 'inappropriate content' OR spam OR phishing)" & & & \\
\hline d) “conformity OR compliance" & 595 & 597 & 606 \\
\hline Average Loading & 816 & 816 & 815 \\
\hline Variance after Rotation (\%) & 1754 & 1650 & 1654 \\
\hline
\end{tabular}

\begin{tabular}{|l|c|c|}
\hline \multirow{2}{*}{ F6 Interoperability Solutions (II) } & \multicolumn{2}{|c|}{ Loadıng } \\
\cline { 2 - 3 } & F S3 & F S10 \\
\hline a) “(SMS OR MMS) AND services" & 890 & 878 \\
\hline b) “roaming OR NRTRDE" & 840 & 840 \\
\hline c) "mobıle AND messaging AND services" & 738 & 703 \\
\hline d) "VAS OR 'Value Added Services"” & 723 & 719 \\
\hline e) “GSM" & 505 & 527 \\
\hline Average Loading & 739 & 733 \\
\hline Varlance after Rotation (\%) & 1705 & 1489 \\
\hline
\end{tabular}

\begin{tabular}{|l|c|c|}
\hline \multirow{2}{*}{ F7 Fee Based Business Solutions (II) } & \multicolumn{2}{|c|}{ Loading } \\
\cline { 2 - 3 } & $\mathrm{F} \mathrm{S4}$ & $\mathrm{F} \mathrm{S5}$ \\
\hline a) "phones OR smartphones OR PDA OR accessories OR cards" & 778 & 775 \\
\hline b) "customer AND (options OR choice OR choose) & 770 & 772 \\
\hline c) “(data OR voice) AND plans" & 761 & 758 \\
\hline d) "unlımited AND (calling OR text OR distance) & 707 & 703 \\
\hline e) "choose AND different AND plans" & 693 & 700 \\
\hline Average Loading & 742 & 742 \\
\hline Varıance after Rotation (\%) & 1658 & 1637 \\
\hline
\end{tabular}




\begin{tabular}{|l|c|c|c|}
\hline \multirow{2}{*}{ F8 3GPP Standard and LTE Technology (II) } & \multicolumn{3}{|c|}{ Loadıng } \\
\cline { 2 - 4 } & F S5 & F S6 & F S7 \\
\hline a) "3GPP" & 883 & 888 & 884 \\
\hline b) "MIMO OR 'smart antenna"' & 883 & 883 & 887 \\
\hline c) “LTE OR 'Long Term Evolution' OR eUTRAN" & 865 & 857 & 868 \\
\hline d) "TDD OR FDD" & 666 & 670 & 665 \\
\hline Average Loadıng & 824 & 824 & 826 \\
\hline Variance after Rotation (\%) & 1632 & 1736 & 1734 \\
\hline
\end{tabular}

\begin{tabular}{|l|c|c|}
\hline \multicolumn{1}{|c|}{ F9 Monitoring Solutions } & \multicolumn{2}{c|}{ Loadıng } \\
\cline { 2 - 3 } & F S6 & F S10 \\
\hline a) "solutions AND network AND monitorıng AND analysıs" & 889 & 816 \\
\hline b) "(performance OR optımızatıon) AND (analysıs OR audit)" & 790 & 732 \\
\hline c) "solutions AND (telematıcs OR metering OR trackıng OR alarms OR monitoring)" & 660 & 585 \\
\hline d) "automatıon" & 623 & 738 \\
\hline Average Loadıng & 741 & 718 \\
\hline Varıance after Rotation (\%) & 1527 & 1072 \\
\hline
\end{tabular}

\begin{tabular}{|l|c|c|c|}
\hline \multicolumn{2}{|c|}{ F10 Licenses and Regulation (I) } & \multicolumn{3}{c|}{ Loadıng } \\
\cline { 2 - 4 } & F S7 & F S8 & F S10 \\
\hline a) “(ISsue OR adminıster) AND (licence OR licensıng)" & 790 & 796 & 794 \\
\hline b) "market AND (regulation OR oversıght)" & 778 & 782 & 716 \\
\hline c) "(enable OR enabling OR promote OR promoting) AND competition" & 728 & 734 & 717 \\
\hline d) "authority" & 683 & 662 & 665 \\
\hline Average Loadıng & 745 & 744 & 723 \\
\hline Varıance after Rotation (\%) & 1432 & 1347 & 1069 \\
\hline
\end{tabular}

\begin{tabular}{|l|c|c|}
\hline \multirow{2}{*}{ F11 Conformance and Certification (I) } & \multicolumn{2}{|c|}{ Loadıng } \\
\cline { 2 - 3 } & F S8 & F S9 \\
\hline a) "conformance" & 889 & 912 \\
\hline b) "test AND equipment AND manufacturer" & 822 & 822 \\
\hline c) "valıdate AND technology" & 793 & 787 \\
\hline d) "certıfied OR certificatıon" & 690 & 657 \\
\hline e) "Interoperabılity" & 528 & 495 \\
\hline Average Loadıng & 745 & 735 \\
\hline Varıance after Rotation (\%) & 1714 & 1722 \\
\hline
\end{tabular}

\begin{tabular}{|l|r|c|c|c|c|c|}
\hline \multicolumn{2}{|c|}{ G1 Mobile Services (II) } & \multicolumn{5}{c|}{ Loading } \\
\cline { 2 - 8 } & G S1 & G S3 & G S4 & G S5 & G S6 & G S7 \\
\hline a) “(consulting OR engineering) AND services" & 873 & 865 & 848 & 862 & 848 & 872 \\
\hline b) "mobıle AND content AND delıvery" & 867 & 887 & 892 & 890 & 897 & 867 \\
\hline c) "database AND services" & 866 & 872 & 866 & 869 & 871 & 856 \\
\hline d) "mobıle AND services AND (commerce OR billing)" & 851 & 862 & 871 & 866 & 883 & 847 \\
\hline Average Loadıng & 865 & 873 & 869 & 872 & 875 & 861 \\
\hline Varlance after Rotation (\%) & 1474 & 1274 & 1876 & 1873 & 1861 & 2013 \\
\hline
\end{tabular}




\begin{tabular}{|l|c|c|c|c|c|}
\hline \multirow{2}{*}{ G2 Business Opportunity Solutions (II) } & \multicolumn{4}{|c|}{ Loading } \\
\cline { 2 - 6 } & G S1 & G S2 & G S3 & G S4 & G S5 \\
\hline a) "solution AND provider" & 835 & 849 & 843 & 843 & 843 \\
\hline b) "'end-to-end' AND communication AND solutions" & 763 & 750 & 741 & 760 & 767 \\
\hline c) "solution AND (outsourcing OR delivery) & 739 & 779 & 756 & 723 & 716 \\
\hline d) "new AND (market OR Industry)" & 689 & 667 & 661 & 693 & 698 \\
\hline e) "cost AND (reduce OR reduction OR saving OR effective) & 661 & 628 & 665 & 701 & 708 \\
\hline Average Loading & 737 & 735 & 733 & 744 & 746 \\
\hline Variance after Rotation (\%) & 1437 & 1765 & 1239 & 1846 & 1849 \\
\hline
\end{tabular}

\begin{tabular}{|l|c|c|c|c|c|c|}
\hline \multicolumn{2}{|c|}{ G3 Fee Based Business Solutions (III) } & \multicolumn{5}{|c|}{ Loading } \\
\cline { 2 - 7 } & G S1 & G S2 & G S3 & G S4 & G S5 & G S7 \\
\hline a) "subscription OR activation OR contract" & 810 & 802 & 788 & 819 & 817 & 826 \\
\hline $\begin{array}{l}\text { b) "ringtones OR games OR songs OR wallpaper OR } \\
\text { screensavers OR tones OR IM" }\end{array}$ & 750 & 752 & 776 & 765 & 777 & 743 \\
\hline $\begin{array}{l}\text { c) "service AND mobile AND (banking OR payment } \\
\text { OR money OR financial)" }\end{array}$ & 735 & 758 & 764 & 770 & 770 & 743 \\
\hline d) "new AND (contract OR collaboration OR partner)" & 715 & 746 & 688 & 713 & 694 & 725 \\
\hline Average Loading & 752 & 765 & 754 & 767 & 765 & 759 \\
\hline Variance after Rotation (\%) & 1201 & 1373 & 1011 & 1469 & 1469 & 1638 \\
\hline
\end{tabular}

\begin{tabular}{|l|c|c|c|c|}
\hline \multirow{2}{*}{ G4 WIMAX Certification } & \multicolumn{4}{|c|}{ Loading } \\
\cline { 2 - 5 } & G S1 & G S2 & G S3 & G S6 \\
\hline a) “'base station' OR 'base-station"” & 789 & 761 & 780 & 767 \\
\hline b) "wImax" & 766 & 777 & 763 & 801 \\
\hline c) "forum" & 716 & 734 & 726 & 723 \\
\hline d) “management AND spectrum" & 593 & 618 & 607 & 589 \\
\hline e) "certified OR certification" & 549 & 465 & 527 & 557 \\
\hline Average Loading & 683 & 671 & 681 & 687 \\
\hline Varıance after Rotation (\%) & 1180 & 1402 & 1028 & 1486 \\
\hline
\end{tabular}

\begin{tabular}{|l|c|c|}
\hline \multicolumn{2}{|c|}{ G5 Interoperability Solutions (III) } & \multicolumn{2}{|c|}{ Loading } \\
\cline { 2 - 3 } & G S1 & G S7 \\
\hline a) “roamıng OR NRTRDE" & 797 & 797 \\
\hline b) “solutions AND (roamıng OR VAS OR 'Customer Care')" & 790 & 801 \\
\hline c) "network AND operator" & 694 & 717 \\
\hline d) “(SMS OR MMS) AND services" & 686 & 668 \\
\hline Average Loading & 742 & 746 \\
\hline Varıance after Rotation (\%) & 1126 & 1512 \\
\hline
\end{tabular}




\begin{tabular}{|l|c|}
\hline \multicolumn{1}{|c|}{ G6 Hardware (III) } & Loading \\
\cline { 2 - 2 } $\begin{array}{l}\text { a) "microprocessor OR processor OR mıcrocontroller OR DSP OR 'RF subsystem' OR 'power } \\
\text { management' OR chıps OR chipsets OR sensor" }\end{array}$ & G S2 \\
\hline b) "desıgn" & 786 \\
\hline c) "(product OR process) AND (modularity OR modular OR module)" & 710 \\
\hline d) "system AND integration" & 669 \\
\hline Average Loading & 742 \\
\hline Varıance after Rotation (\%) & 1389 \\
\hline
\end{tabular}

\begin{tabular}{|l|c|}
\hline \multicolumn{1}{|c|}{ G7 Reputation (II) } & Loading \\
\cline { 2 - 2 } & G S3 \\
\hline a) "reputation OR competence" & 792 \\
\hline b) "governance OR govern" & 691 \\
\hline c) "agreement" & 669 \\
\hline d) "regulator OR regulate OR supervise OR regulation OR regulatory" & 560 \\
\hline Average Loading & 678 \\
\hline Variance after Rotation (\%) & 839 \\
\hline
\end{tabular}

\begin{tabular}{|l|c|}
\hline \multicolumn{1}{|c|}{ G8 Security Solutions (III) } & Loading \\
\cline { 2 - 2 } & G S3 \\
\hline a) “(protect OR protecting OR promote) AND (consumers OR users) & 715 \\
\hline b) "conformity OR compliance" & 691 \\
\hline c) "authentıcation OR security OR signature & 636 \\
\hline Average Loadıng & 681 \\
\hline Varıance after Rotation (\%) & 730 \\
\hline
\end{tabular}

\begin{tabular}{|l|c|c|c|}
\hline \multirow{2}{*}{ G9 Research (II) } & \multicolumn{3}{|c|}{ Loadıng } \\
\cline { 2 - 4 } & G S4 & G S6 & G S7 \\
\hline a) “(university OR universitıes) AND research" & 802 & 794 & 785 \\
\hline b) "research OR Innovation OR 'research and development"' & 710 & 720 & 717 \\
\hline c) "science AND technology" & 694 & 698 & 693 \\
\hline d) "technology AND development" & 683 & 626 & 701 \\
\hline Average Loading & 722 & 710 & 724 \\
\hline Varıance after Rotation (\%) & 1341 & 1403 & 1417 \\
\hline
\end{tabular}

\begin{tabular}{|l|c|c|}
\hline \multicolumn{2}{|c|}{ G10 Testıng Solutions (II) } & \multicolumn{2}{|c|}{ Loadıng } \\
\cline { 2 - 3 } & G S5 & G S6 \\
\hline a) “(performance OR optımızatıon) AND (analysıs OR audit)" & 805 & 783 \\
\hline b) “measurement" & 696 & 712 \\
\hline c) "test AND coverage" & 695 & 725 \\
\hline d) "research AND testıng" & 660 & 536 \\
\hline Average Loadıng & 714 & 689 \\
\hline Varıance after Rotation (\%) & 1245 & 1216 \\
\hline
\end{tabular}




\begin{tabular}{|l|r|c|c|}
\hline \multirow{2}{*}{ H1 Fraud Detection (II) } & \multicolumn{3}{|c|}{ Loading } \\
\cline { 2 - 4 } & H S1 & H S2 & H S5 \\
\hline a) "analyse AND revenue AND (loss OR risk) & 901 & 900 & 871 \\
\hline b) "fraud AND (control OR detection) & 890 & 892 & 902 \\
\hline c) “(analyze OR monitor OR test) AND fraud" & 877 & 883 & 801 \\
\hline d) "billing" & 705 & 703 & 618 \\
\hline e) "assurance AND (customer OR service)" & 685 & 681 & 755 \\
\hline f) "GSMA OR 'GSM Association' OR gsmworld" & 606 & 609 & 597 \\
\hline Average Loading & 777 & 778 & 757 \\
\hline Varıance after Rotation (\%) & 1811 & 1813 & 1749 \\
\hline
\end{tabular}

\begin{tabular}{|l|c|c|c|c|}
\hline \multicolumn{2}{|c|}{ H2 3GPP Standard and LTE Technology (III) } & \multicolumn{3}{|c|}{ Loading } \\
\cline { 2 - 5 } & H S1 & H S2 & H S3 & H S5 \\
\hline a) “(product OR process OR service) AND (evolution OR evolve)" & 828 & 825 & 821 & 827 \\
\hline b) "(product OR process) AND (modularity OR modular OR module)" & 804 & 805 & 801 & 806 \\
\hline c) "(performance OR optımızation) AND (analysıs OR audit)" & 803 & 797 & 791 & 801 \\
\hline d) "convergence" & 779 & 781 & 787 & 78 \\
\hline e) “"cost effective' OR migratıon OR evolution OR path" & 683 & 691 & 690 & 684 \\
\hline f) “LTE OR 'Long Term Evolution' OR eUTRAN" & 557 & 559 & 553 & 557 \\
\hline Average Loadıng & 742 & 743 & 741 & 742 \\
\hline Varlance after Rotation (\%) & 1616 & 1618 & 1526 & 1615 \\
\hline
\end{tabular}

\begin{tabular}{|l|c|}
\hline \multicolumn{1}{|c|}{ H3 Testıng Solutions (III) } & Loading \\
\cline { 2 - 2 } & H S1 \\
\hline a) "test AND coverage" & 862 \\
\hline $\begin{array}{l}\text { b) "solutions AND (VoIP OR 'Voice over IP' OR RCS OR 'Rıch Communication Suite' OR } \\
\text { VCC OR 'Voice Call Contınuity')" }\end{array}$ & 818 \\
\hline c) "system AND solution" & 785 \\
\hline d) "multi-standard" & 739 \\
\hline e) "automation" & 607 \\
\hline Average Loading & 762 \\
\hline Varlance after Rotation (\%) & 1439 \\
\hline
\end{tabular}

\begin{tabular}{|l|r|r|r|}
\hline \multicolumn{2}{|c|}{ H4 Licenses and Regulation (II) } & \multicolumn{3}{|c|}{ Loadıng } \\
\cline { 2 - 4 } & H S1 & H S2 & H S5 \\
\hline a) "regulator OR regulate OR supervise OR regulation OR regulatory" & 844 & 861 & 847 \\
\hline b) "market AND (regulation OR oversight)" & 824 & 803 & 816 \\
\hline c) "guidelınes OR rules OR regulation" & 812 & 792 & 815 \\
\hline d) "(Issue OR administer) AND (IIcence OR licensıng)" & 693 & 694 & 698 \\
\hline Average Loadıng & 793 & 787 & 794 \\
\hline Varıance after Rotation (\%) & 1250 & 1309 & 1518 \\
\hline
\end{tabular}




\begin{tabular}{|l|r|c|}
\hline \multicolumn{1}{|c|}{ H5 Security Solutions (IV) } & \multicolumn{2}{|c|}{ Loading } \\
\cline { 2 - 3 } & H S2 & H S3 \\
\hline a) "(protect OR protecting OR promote) AND (consumers OR users)" & 929 & 929 \\
\hline b) "reputation OR competence" & 854 & 858 \\
\hline $\begin{array}{l}\text { c) "(security OR 'customer protection' OR protection) AND (virus OR malware OR } \\
\text { 'inappropriate content' OR spam OR phishing)" }\end{array}$ & 745 & 736 \\
\hline d) "router OR gateway" & 716 & 707 \\
\hline e) "conformity OR compliance" & 486 & 512 \\
\hline Average Loading & 746 & 748 \\
\hline Varıance after Rotation (\%) & 1392 & 1283 \\
\hline
\end{tabular}

\begin{tabular}{|c|c|}
\hline \multirow{2}{*}{ H6 Mobile Services (III) } & Loading \\
\hline & H S3 \\
\hline a) "mobıle AND applıcatıons" & 793 \\
\hline b) "mobıle AND messaging AND services" & 781 \\
\hline c) "device AND management" & 776 \\
\hline d) "mobıle AND services AND (commerce OR billing)" & 732 \\
\hline e) "mobıle AND (advertısing OR marketıng)" & 720 \\
\hline f) "(data OR voIce) AND plans" & 702 \\
\hline g) "(consulting OR engineering) AND services" & 651 \\
\hline Average Loadıng & 736 \\
\hline Varıance after Rotation (\%) & 1676 \\
\hline
\end{tabular}

\begin{tabular}{|l|c|c|}
\hline \multicolumn{2}{|c|}{ H7 Interoperability Solutions (IV) } & \multicolumn{2}{c|}{ Loading } \\
\cline { 2 - 3 } & H S3 & H S5 \\
\hline a) "(SMS OR MMS) AND services" & 816 & 807 \\
\hline b) "solutions AND ('SIM card' OR 'smart card')" & 766 & 777 \\
\hline c) "solutions AND (roamıng OR VAS OR 'Customer Care')" & 743 & 724 \\
\hline d) "service AND mobile AND (banking OR payment OR money OR financial)" & 704 & 705 \\
\hline e) "roamıng OR NRTRDE" & 643 & 633 \\
\hline Average Loading & 734 & 729 \\
\hline Varıance after Rotation (\%) & 1353 & 1250 \\
\hline
\end{tabular}

\begin{tabular}{|l|c|c|c|c|}
\hline \multicolumn{2}{|c|}{ I1 WIMAX Technology and Standard (II) } & \multicolumn{4}{|c|}{ Loading } \\
\cline { 2 - 6 } & IS1 & I S3 & I S4 & I S5 \\
\hline a) "OFDMA OR 'Orthogonal Frequency DIvIsıon Multıple Access'" & 762 & 764 & 756 & 755 \\
\hline b) "IEEE AND 802 16" & 743 & 745 & 744 & 754 \\
\hline c) WIMAX & 649 & 664 & 651 & 671 \\
\hline c) "'base station' OR 'base-station"' & 630 & 628 & 63 & 64 \\
\hline e) "TDD OR FDD" & 608 & 651 & 6 & 67 \\
\hline Average Loadıng & 679 & 691 & 676 & 698 \\
\hline Variance after Rotation (\%) & 961 & 785 & 896 & 826 \\
\hline
\end{tabular}




\begin{tabular}{|l|c|c|c|c|}
\hline \multicolumn{1}{|c|}{ 12 Hardware (IV) } & \multicolumn{3}{|c|}{ Loading } \\
\cline { 2 - 5 } & IS1 & IS3 & I S4 & I S5 \\
\hline $\begin{array}{l}\text { a) "mıcroprocessor OR processor OR microcontroller OR DSP OR 'RF } \\
\text { subsystem' OR 'power management' OR chips OR chipsets OR sensor" }\end{array}$ & 77 & 78 & 78 & 79 \\
\hline b) "semıconductor" & 74 & 74 & 74 & 75 \\
\hline c) "desıgn" & 74 & 72 & 73 & 74 \\
\hline c) "signal AND processıng" & 60 & 60 & 59 & 60 \\
\hline Average Loadıng & 71 & 71 & 71 & 72 \\
\hline Varlance after Rotation (\%) & 815 & 738 & 772 & 734 \\
\hline
\end{tabular}

\begin{tabular}{|l|r|r|r|}
\hline \multirow{2}{*}{ I3 Conformance and Certification (II) } & \multicolumn{3}{|c|}{ Loading } \\
\cline { 2 - 4 } & IS1 & I S3 & I S4 \\
\hline a) "Interoperability" & 738 & 714 & 742 \\
\hline b) "conformance" & 650 & 728 & 638 \\
\hline c) "certified OR certification" & 634 & 649 & 632 \\
\hline d) "standards" & 558 & 537 & 565 \\
\hline Average Loadıng & 645 & 657 & 644 \\
\hline Variance after Rotatıon (\%) & 742 & 683 & 700 \\
\hline
\end{tabular}

\begin{tabular}{|l|r|r|r|r|}
\hline \multirow{2}{*}{14 UMTS } & \multicolumn{4}{|c|}{ Loadıng } \\
\cline { 2 - 5 } \multicolumn{2}{|c|}{ I S1 } & I S3 & I S4 & I S5 \\
\hline a) "'UMTS Forum' OR (umts AND forum)" & 912 & 908 & 909 & 909 \\
\hline b) "HSPA OR 'High Speed Packet Access'"' & 803 & 806 & 801 & 806 \\
\hline c) "UMTS" & 738 & 752 & 739 & 754 \\
\hline Average Loading & 818 & 822 & 816 & 823 \\
\hline Varıance after Rotation (\%) & 734 & 659 & 691 & 698 \\
\hline
\end{tabular}

\begin{tabular}{|l|r|r|}
\hline \multirow{2}{*}{15 Wireless Broadband Allıance } & \multicolumn{2}{|c|}{ Loading } \\
\cline { 2 - 3 } & I S1 & I S5 \\
\hline a) "'Wireless Broadband Allıance' OR wballıance" & 942 & 942 \\
\hline b) "'collaboratıon opportunitıes"' & 935 & 934 \\
\hline c) "'busıness ecosystem' OR 'busıness eco-system'" & 644 & 641 \\
\hline Average Loading & 840 & 839 \\
\hline Varıance after Rotation (\%) & 730 & 710 \\
\hline
\end{tabular}

\begin{tabular}{|l|r|r|r|r|}
\hline \multirow{2}{*}{ I6 CDMA Technology and Standards } & \multicolumn{4}{|c|}{ Loadıng } \\
\cline { 2 - 6 } & IS1 & I S3 & I S4 & I S5 \\
\hline a) "CDMA OR 'code divisıon multiple access"' & 767 & 772 & 771 & 787 \\
\hline b) "1xRTT" & 713 & 688 & 696 & 702 \\
\hline c) "EV-DO OR EVDO" & 679 & 671 & 668 & 603 \\
\hline d) "3GPP2" & 595 & 612 & 608 & 713 \\
\hline Average Loadıng & 689 & 686 & 685 & 701 \\
\hline Varıance after Rotation (\%) & 688 & 627 & 653 & 683 \\
\hline
\end{tabular}




\begin{tabular}{|l|r|c|}
\hline \multirow{2}{*}{17 3GPP Standard and LTE Technology (IV) } & \multicolumn{2}{|c|}{ Loadıng } \\
\cline { 2 - 4 } & IS1 & I S4 \\
\hline a) "LTE OR 'Long Term Evolution' OR eUTRAN" & 761 & 752 \\
\hline b) "3GPP" & 730 & 723 \\
\hline c) "MIMO OR 'smart antenna"' & 587 & 6 \\
\hline Average Loadıng & 690 & 69 \\
\hline Varıance after Rotation (\%) & 658 & 623 \\
\hline
\end{tabular}

\begin{tabular}{|l|r|r|r|r|}
\hline \multicolumn{2}{|c|}{ 18 Research (III) } & \multicolumn{4}{|c|}{ Loading } \\
\cline { 2 - 5 } & I S1 & I S3 & I S4 & I S5 \\
\hline a) "research OR Innovation OR 'research and development"' & 754 & 747 & 746 & 757 \\
\hline b) "(university OR universities) AND research' & 740 & 743 & 743 & 714 \\
\hline c) "science AND technology" & 630 & 642 & 631 & 622 \\
\hline d) "research AND testing" & 591 & 573 & 59 & 638 \\
\hline Average Loadıng & 679 & 676 & 675 & 682 \\
\hline Varıance after Rotation (\%) & 658 & 601 & 621 & 644 \\
\hline
\end{tabular}

\begin{tabular}{|l|c|}
\hline \multicolumn{1}{|c|}{ I9 Revenue Management Solutions (III) } & Loading \\
\cline { 2 - 2 } & I S2 \\
\hline a) "solution AND (OSS OR 'Operatıon Support System')' & 871 \\
\hline b) "BSS OR 'Busıness Support System"' & 846 \\
\hline c) "solution AND (outsourcıng OR delıvery)" & 636 \\
\hline d) “'cost of ownership' OR 'optımıse infrastructure' OR 'optımıze infrastructure"' & 581 \\
\hline e) "billing" & 561 \\
\hline Average Loadıng & 699 \\
\hline Varıance after Rotation (\%) & 924 \\
\hline
\end{tabular}

\begin{tabular}{|l|c|c|c|}
\hline \multicolumn{2}{|c|}{ I10 Fee Based Business Solutions (IV) } & \multicolumn{3}{|c|}{ Loadıng } \\
\cline { 2 - 4 } & I S2 & I S3 & I S4 \\
\hline a) "(data OR volce) AND plans" & 798 & 793 & 744 \\
\hline b) "unlımited AND (calling OR text OR distance)" & 739 & 734 & 723 \\
\hline c) "phones OR smartphones OR PDA OR accessories OR cards" & 685 & 734 & 683 \\
\hline d) "customer AND (optıons OR cholce OR choose)" & 665 & 703 & 714 \\
\hline $\begin{array}{l}\text { e) “("Mobile Terminal Supplier" OR "Mobile Terminal" OR manufacturer) AND } \\
\text { mobile AND phone" }\end{array}$ & 584 & 593 & 589 \\
\hline Average Loadıng & 694 & 711 & 69 \\
\hline Varıance after Rotation (\%) & 856 & 783 & 805 \\
\hline
\end{tabular}

\begin{tabular}{|l|c|}
\hline \multicolumn{1}{|c|}{111 Fraud Detection (III) } & Loadıng \\
\cline { 2 - 2 } & I S2 \\
\hline a) "fraud AND (control OR detection)" & 892 \\
\hline b) "(analyze OR monitor OR test) AND fraud" & 855 \\
\hline c) "analyse AND revenue AND (loss OR risk)" & 679 \\
\hline d) "assurance AND (customer OR service)" & 588 \\
\hline Average Loading & 754 \\
\hline Variance after Rotation (\%) & 834 \\
\hline
\end{tabular}




\begin{tabular}{|l|r|r|r|}
\hline \multirow{2}{*}{112 Interoperability Solutions (V) } & \multicolumn{3}{|c|}{ Loading } \\
\cline { 2 - 5 } & IS2 & I S3 & I S5 \\
\hline a) "(SMS OR MMS) AND services" & 786 & 763 & 768 \\
\hline b) "VAS OR 'Value Added Services"' & 765 & 736 & 735 \\
\hline c) "roaming OR NRTRDE" & 755 & 780 & 797 \\
\hline d) "solutions AND (roamıng OR VAS OR 'Customer Care"' & 745 & 788 & 794 \\
\hline Average Loading & 763 & 767 & 773 \\
\hline Variance after Rotation (\%) & $\mathbf{8 2 1}$ & 768 & 804 \\
\hline
\end{tabular}

\begin{tabular}{|c|c|}
\hline \multirow{2}{*}{ I13 Testıng Solutions (IV) } & Loadıng \\
\hline & 152 \\
\hline a) "measurement" & 749 \\
\hline b) "test AND equipment AND manufacturer" & 683 \\
\hline c) "test AND evaluation AND equipment" & 643 \\
\hline d) "(performance OR optımızation) AND (analysıs OR audit)" & 622 \\
\hline e) "Instrumentation OR instrument" & 606 \\
\hline Average Loading & 660 \\
\hline Varıance after Rotation (\%) & 784 \\
\hline
\end{tabular}

\begin{tabular}{|l|c|}
\hline \multicolumn{1}{|c|}{ I14 Security Solutions (V) } & Loadıng \\
\cline { 2 - 2 } & I S2 \\
\hline a) "(protect OR protecting OR promote) AND (consumers OR users)" & 853 \\
\hline $\begin{array}{l}\text { b) "(security OR 'customer protection' OR protection) AND (virus OR malware OR } \\
\text { 'inappropriate content' OR spam OR phıshıng)" }\end{array}$ & 776 \\
\hline c) "authentıcatıon OR security OR sıgnature" & 629 \\
\hline d) "reputation OR competence" & 626 \\
\hline Average Loading & 721 \\
\hline Varıance after Rotation (\%) & 769 \\
\hline
\end{tabular}

\begin{tabular}{|l|r|r|}
\hline \multicolumn{2}{|c|}{ I15 Licenses and Regulation (III) } & \multicolumn{2}{|c|}{ Loadıng } \\
\cline { 2 - 3 } & I S2 & I S5 \\
\hline a) "guidelınes OR rules OR regulation" & 744 & 752 \\
\hline b) "regulator OR regulate OR supervise OR regulation OR regulatory" & 723 & 756 \\
\hline c) "(ISsue OR admınıster) AND (IIcence OR licensıng)" & 680 & 646 \\
\hline d) "authorıty" & 618 & 692 \\
\hline Average Loading & 691 & 711 \\
\hline Varıance after Rotation (\%) & 694 & 677 \\
\hline
\end{tabular}




\section{Appendix D: Membership Distribution}

\begin{tabular}{|l|c|c|c|c|c|c|c|c|c|c|}
\hline Group E & 312 & WIMAX & GSMA & CDG & NGMN & LSTI & UMTS & CCF & WBA & OPA \\
\hline WIMAX & 144 & 144 & 20 & 14 & 21 & 14 & 5 & 8 & 7 & 6 \\
\hline GSMA & 124 & 20 & 124 & 12 & 15 & 10 & 6 & 7 & 3 & 4 \\
\hline CDG & 43 & 14 & 12 & 43 & 10 & 5 & 3 & 13 & 1 & 1 \\
\hline NGMN & 37 & 21 & 15 & 10 & 37 & 16 & 6 & 7 & 2 & 2 \\
\hline LSTI & 25 & 14 & 10 & 5 & 16 & 25 & 7 & 4 & 3 & 2 \\
\hline UMTS & 20 & 5 & 6 & 3 & 6 & 7 & 20 & 3 & 0 & 1 \\
\hline CCF & 20 & 8 & 7 & 13 & 7 & 4 & 3 & 20 & 0 & 1 \\
\hline WBA & 15 & 7 & 3 & 1 & 2 & 3 & 0 & 0 & 17 & 0 \\
\hline OPA & 6 & 6 & 4 & 1 & 2 & 2 & 1 & 1 & 0 & 6 \\
\hline
\end{tabular}

Group E distribution

\begin{tabular}{|l|c|c|c|c|c|c|c|c|c|}
\hline Consortium & WIMAX & GSMA & CDG & NGMN & LSTI & UMTS & CCF & WBA & OPA \\
\hline Members & 144 & 124 & 43 & 37 & 25 & 20 & 20 & 15 & 6 \\
\hline Percentage [\%] & 4615 & 3974 & 1378 & 1186 & 801 & 641 & 641 & 481 & 192 \\
\hline
\end{tabular}

\begin{tabular}{|l|c|c|c|c|c|c|c|c|c|c|}
\hline Group F & 202 & WIMAX & GSMA & CDG & NGMN & LSTI & UMTS & CCF & WBA & OPA \\
\hline WIMAX & 108 & 108 & 12 & 12 & 8 & 3 & 3 & 4 & 4 & 2 \\
\hline GSMA & 65 & 12 & 65 & 10 & 4 & 3 & 2 & 1 & 2 & 0 \\
\hline CDG & 37 & 12 & 10 & 37 & 2 & 2 & 3 & 10 & 2 & 0 \\
\hline NGMN & 12 & 8 & 4 & 2 & 12 & 4 & 2 & 1 & 0 & 0 \\
\hline LSTI & 8 & 2 & 3 & 2 & 4 & 8 & 2 & 1 & 0 & 0 \\
\hline UMTS & 9 & 3 & 2 & 3 & 2 & 2 & 9 & 1 & 0 & 0 \\
\hline CCF & 13 & 4 & 1 & 10 & 1 & 1 & 1 & 13 & 0 & 0 \\
\hline WBA & 7 & 4 & 2 & 2 & 0 & 0 & 0 & 0 & 7 & 0 \\
\hline OPA & 3 & 2 & 0 & 0 & 0 & 0 & 0 & 0 & 0 & 3 \\
\hline
\end{tabular}

Group F distribution

\begin{tabular}{|l|c|c|c|c|c|c|c|c|c|}
\hline Consortium & WiMAX & GSMA & CDG & NGMN & LSTI & UMTS & CCF & WBA & OPA \\
\hline Members & 108 & 65 & 37 & 12 & 8 & 9 & 13 & 7 & 3 \\
\hline Percentage [\%] & 53.47 & 32.18 & 18.32 & 5.94 & 3.96 & 4.46 & 6.44 & 3.47 & 1.49 \\
\hline
\end{tabular}




\begin{tabular}{|l|c|c|c|c|c|c|c|c|c|c|}
\hline Group G & 305 & WIMAX & GSMA & CDG & NGMN & LSTI & UMTS & CCF & WBA & OPA \\
\hline WIMAX & 141 & 141 & 23 & 18 & 20 & 15 & 7 & 9 & 6 & 4 \\
\hline GSMA & 115 & 23 & 115 & 16 & 13 & 11 & 7 & 5 & 3 & 1 \\
\hline CDG & 58 & 18 & 16 & 58 & 8 & 6 & 5 & 15 & 2 & 0 \\
\hline NGMN & 32 & 20 & 13 & 8 & 32 & 17 & 8 & 6 & 2 & 1 \\
\hline LSTI & 30 & 15 & 11 & 6 & 17 & 30 & 9 & 5 & 2 & 1 \\
\hline UMTS & 21 & 7 & 7 & 5 & 8 & 9 & 21 & 3 & 0 & 0 \\
\hline CCF & 25 & 9 & 5 & 15 & 6 & 5 & 3 & 25 & 0 & 0 \\
\hline WBA & 11 & 6 & 3 & 2 & 2 & 2 & 0 & 0 & 11 & 0 \\
\hline OPA & 5 & 4 & 1 & 0 & 1 & 1 & 0 & 0 & 0 & 5 \\
\hline
\end{tabular}

Group G distribution

Group G distribution
\begin{tabular}{|l|c|c|c|c|c|c|c|c|c|}
\hline Consortium & WiMAX & GSMA & CDG & NGMN & LSTI & UMTS & CCF & WBA & OPA \\
\hline Members & 141 & 115 & 58 & 32 & 30 & 21 & 25 & 11 & 5 \\
\hline Percentage [\%] & 46.23 & 37.70 & 19.02 & 10.49 & 9.84 & 6.89 & 8.20 & 3.61 & 1.64 \\
\hline
\end{tabular}

\begin{tabular}{|l|c|c|c|c|c|c|c|c|c|c|}
\hline Group H & 228 & WIMAX & GSMA & CDG & NGMN & LSTI & UMTS & CCF & WBA & OPA \\
\hline WIMAX & 119 & 119 & 7 & 4 & 7 & 2 & 0 & 2 & 6 & 3 \\
\hline GSMA & 74 & 7 & 74 & 2 & 4 & 1 & 0 & 1 & 1 & 1 \\
\hline CDG & 20 & 4 & 2 & 20 & 1 & 0 & 0 & 7 & 0 & 0 \\
\hline NGMN & 15 & 7 & 4 & 1 & 15 & 2 & 0 & 1 & 2 & 1 \\
\hline LSTI & 5 & 2 & 1 & 0 & 2 & 5 & 0 & 0 & 1 & 0 \\
\hline UMTS & 8 & 0 & 0 & 0 & 0 & 0 & 8 & 0 & 0 & 0 \\
\hline CCF & 12 & 2 & 1 & 7 & 1 & 0 & 0 & 12 & 0 & 0 \\
\hline WBA & 13 & 6 & 1 & 0 & 2 & 1 & 0 & 0 & 13 & 0 \\
\hline OPA & 4 & 3 & 1 & 0 & 1 & 0 & 0 & 0 & 0 & 4 \\
\hline
\end{tabular}

Group H distribution

\begin{tabular}{|l|c|c|c|c|c|c|c|c|c|}
\hline Consortium & WiMAX & GSMA & CDG & NGMN & LSTI & UMTS & CCF & WBA & OPA \\
\hline Members & 119 & 74 & 20 & 15 & 5 & 8 & 12 & 13 & 4 \\
\hline Percentage [\%] & 52.19 & 32.46 & 8.77 & 6.58 & 2.19 & 3.51 & 5.26 & 5.70 & 1.75 \\
\hline
\end{tabular}




\begin{tabular}{|l|c|c|c|c|c|c|c|c|c|c|}
\hline Group 1 & 736 & WIMAX & GSMA & CDG & NGMN & LSTI & UMTS & CCF & WBA & OPA \\
\hline WIMAX & 346 & 346 & 36 & 28 & 31 & 18 & 8 & 15 & 13 & 10 \\
\hline GSMA & 265 & 36 & 265 & 24 & 20 & 13 & 8 & 8 & 5 & 4 \\
\hline CDG & 111 & 28 & 24 & 111 & 13 & 8 & 6 & 25 & 3 & 1 \\
\hline NGMN & 54 & 31 & 20 & 13 & 54 & 21 & 9 & 9 & 4 & 3 \\
\hline LSTI & 39 & 18 & 13 & 8 & 21 & 39 & 10 & 6 & 3 & 2 \\
\hline UMTS & 36 & 8 & 8 & 6 & 9 & 10 & 36 & 4 & 0 & 1 \\
\hline CCF & 47 & 15 & 8 & 25 & 9 & 6 & 4 & 47 & 0 & 1 \\
\hline WBA & 32 & 13 & 5 & 3 & 4 & 3 & 0 & 0 & 32 & 0 \\
\hline OPA & 12 & 10 & 4 & 1 & 3 & 2 & 1 & 1 & 0 & 12 \\
\hline
\end{tabular}

Group I distribution

\begin{tabular}{|l|c|c|c|c|c|c|c|c|c|}
\hline Consortium & WIMAX & GSMA & CDG & NGMN & CCF & LSTI & UMTS & WBA & OPA \\
\hline Members & 346 & 265 & 111 & 54 & 47 & 39 & 36 & 32 & 12 \\
\hline Percentage [\%] & 4701 & 3601 & 1508 & 734 & 639 & 530 & 489 & 435 & 163 \\
\hline
\end{tabular}

